\title{
Epidural anaesthesia during labour
}

Citation for published version (APA):

de Boer, R. (1984). Epidural anaesthesia during labour. [Doctoral Thesis, Maastricht University]. Rijksuniversiteit Limburg. https://doi.org/10.26481/dis.19840831rb

Document status and date:

Published: 01/01/1984

DOI:

10.26481/dis.19840831rb

Document Version:

Publisher's PDF, also known as Version of record

\section{Please check the document version of this publication:}

- A submitted manuscript is the version of the article upon submission and before peer-review. There can be important differences between the submitted version and the official published version of record.

People interested in the research are advised to contact the author for the final version of the publication, or visit the DOI to the publisher's website.

- The final author version and the galley proof are versions of the publication after peer review.

- The final published version features the final layout of the paper including the volume, issue and page numbers.

Link to publication

\footnotetext{
General rights rights.

- You may freely distribute the URL identifying the publication in the public portal. please follow below link for the End User Agreement:

www.umlib.nl/taverne-license

Take down policy

If you believe that this document breaches copyright please contact us at:

repository@maastrichtuniversity.nl

providing details and we will investigate your claim.
}

Copyright and moral rights for the publications made accessible in the public portal are retained by the authors and/or other copyright owners and it is a condition of accessing publications that users recognise and abide by the legal requirements associated with these

- Users may download and print one copy of any publication from the public portal for the purpose of private study or research.

- You may not further distribute the material or use it for any profit-making activity or commercial gain

If the publication is distributed under the terms of Article $25 \mathrm{fa}$ of the Dutch Copyright Act, indicated by the "Taverne" license above, 


\section{EPIDURAL ANAESTHESIA DURING LABOUR}


Cover design: Marijke de Boer, 1983

Druk: Drukkerij Rokema, Ammerzoden.

Lay-out en zetwerk: Zetterij de Matrijs, Tiel. 


\title{
EPIDURAL ANAESTHESIA DURING LABOUR
}

\author{
Proefschrift
}

Ter verkrijging van de graad van Doctor in de Geneeskunde aan de Rijksuniversiteit Limburg

te Maastricht, op gezag van de Rector Magnificus

Prof. Dr. H. C. Hemker, volgens besluit

van het College van Dekanen in het openbaar te verdedigen in de Aula van de Universiteit op

vrijdag 31 augustus 1984

des namiddags te vier uur

door

Rinze de Boer

geboren te Appelscha 


\section{Promotor:}

Prof. dr. J. de Haan,

Rijksuniversiteit Limburg, Maastricht.

\section{Copromotor:}

Dr. H.W. Jongsma, Katholieke Universiteit, Nijmegen.

\section{Referenten:}

Dr. L.A. Schellekens, De Weverziekenhuis, Heerlen

Dr. M.A. Allessie, Rijksuniversiteit Limburg, Maastricht

Prof. dr. T.K.A.B. Eskes, Katholieke Universiteit, Nijmegen. 
Aan:

Marijke

Getske, Hanneke, Nienke, Lenneke en Marije 



\section{Voorwoord}

Het in dit proefschrift beschreven onderzoek werd verricht op de afdeling Obstetrie en Gynaecologie van het De Weverziekenhuis te Heerlen (Dr. L.A. Schellekens; Dr. Th.J. van Sante; Dr. J.M.H.Ubachs; Dr. J.E.G.M. Stoot). Het onderzoek werd uitgevoerd onder supervisie en begeleiding van Prof. dr. J. de Haan, Dr. L.A. Schellekens en Dr. H.W. Jongsma.

Gaarne wil ik mijn dank betuigen aan de velen zonder wier hulp dit proefschrift niet tot stand gekomen zou zijn.

Hooggeleerde de Haan, zeer gewaardeerde promotor, $U$ ben ik zeer erkentelijk voor Uw intensieve en kritische begeleiding. Dit gebeurde immer in een ontspannen en plezierige sfeer. Uw inzicht in de onderhavige problematiek is mij tot grote steun geweest.

Zeergeleerde Jongsma, zeer gewaardeerde copromotor, Uw kennis van automatiseringsprocessen en $\mathrm{Uw}$ inzicht in de foetale fysiologie hebben grote indruk op mij gemaakt. Voor de vele tijd die $\mathrm{U}$ besteed hebt aan het bediscussiëren en het interpreteren van de resultaten ben ik $U$ buitengewoon dankbaar.

Zeergeleerde Schellekens, $\mathrm{U}$ ben ik zeer erkentelijk voor de mogelijkheid welke U mij geboden hebt om het hier beschreven onderzoek te verrichten. Met name Uw immer aanwezige intresse en $U w$ vast vertrouwen in de voltooiing van deze studie, waren voor mij een grote stimulans.

Veel dank ben ik verschuldigd aan de heer J. Schep (Afdeling Electrotechnische Dienst, De Weverziekenhuis te Heerlen) voor de technische assistentie. U was zowel overdag als 's-nachts bereid om hulp te bieden, ook wanneer het niet Uw vakgebied betrof. Zonder $\mathrm{U}$ had dit onderzoek niet gerealiseerd kunnen worden.

De computerverwerking van het foetale en moederlijke ECG en van de weeënactiviteit vond plaats op de afdeling Bio-informatica (hoofd: Dr. H.W. Jongsma) van het instituut voor Obstetrie en Gynaecologie (hoofden: Prof. dr. T.K.A.B. Eskes en Prof. dr. R. Rolland) van het St. Radboudziekenhuis, katholieke Universiteit, Nijmegen.

Zowel de bloedgasanalyses als de bepalingen van de bupivacaine concentraties vonden plaats in het Klinisch Chemisch Laboratorium van het De Weverziekenhuis te Heerlen (hoofd: Prof. dr. P.J. Brombacher). De methodiek voor de bepaling van de bupivacaine concentratie werd ontwikkeld door de heer P. Verheesen en Drs. H.M.C. Cremers, waarna alle bepalingen steeds persoonlijk door de heer $\mathrm{P}$. Verheesen werden verricht.

De Statistische verwerking vond plaats op de Mathematisch-Statistische Adviesafdeling (hoofd: Drs. Ph. v. Elteren) van de Katholieke Universiteit te Nijmegen. Weledelge- 
leerde van Elteren, het was steeds een genoegen om met $U$ over dit onderzoek wan gedachten te wisselen. Met Uw logische denkwijze en uw didactische gaven bracht $U$ de voor mij moeilijke statistische problemen tot begrijpelijke proporties terug. Ook ben ik veel dank verschuldigd aan de heer $J$. Mulder voor zijn bijdragen aan de statistische bewerking.

Het verloskamerpersoneel van het De Weverziekenhuis te Heerlen (hoofd: mevrouw E.J. van Til, later mevrouw M.B.H. van Hasselt-Broerze) heeft in grote mate bijgedragen tot de realisering van dit onderzoek.

De collegae Broeders, Horbach en Corbey, met wie ik thans in associatief verband samenwerk in het Groot Ziekengasthuis te 's-Hertogenbosch ben ik zeer erkentelijk voor de plezierige wijze waarop zij mij in staat stelden dit proefschrift te voltooien.

De secretaresses van de afdeling Obstetrie en Gynaecologie van het Groot Ziekengasthuis te 's-Hertogenbosch waren steeds bereid administratieve hulp te verlenen. Met name ben ik mevrouw D. van Rumpt en mevrouw H.M. Horsten-van de Goor veel dank verschuldigd voor het vele typewerk dat zij hebben verricht.

Mejuffrouw B.M. Maas (Afdeling Obstetrie en Gynaecologie van het St. Radboudziekenhuis te Nijmegen) typte de definitieve versie van het manuscript op de tekstverwerker. De heer W.P.J. Maas droeg op zeer accurate wijze zorg voor de tekeningen en de figuren.

De firma Astra Farmaceutica B.V. heeft niet alleen op financiële wijze bijgedragen aan het tot stand komen van dit proefschrift, maar heeft ook vele praktische hulp en adviezen geboden. Met name ben ik veel dank verschuldigd aan Dr. P. Brasem en de heer J.H. Ruiter.

Tevens wil ik de firma Organon Nederland B.V. dank zeggen voor hun financiële ondersteuning.

De basale rust die ik altijd in mijn gezin heb kunnen vinden heeft in hoge mate bijgedragen aan de gemoedstoestand waarin ik dit proefschrift heb kunnen voltooien. Hiervoor gaat mijn oprechte dank wit naar mijn echtgenote Marijke en mijn dochters Getske, Hanneke, Nienke, Lenneke en Maartje. 


\section{CONTENTS}

\section{CHAPTER 1 INTRODUCTION}

CHAPTER 2 DELIVERY PAIN AND NERVE PATHWAYS

The innervaton of the uterus

The efferent sympathetic innervation of the uterus anaesthesia is given

The effect of epidural anaesthesia on the foetal heart rate pattern flow

The development of maternal hypotension during epidural anaesthesia

The development of overly strong uterine activity during epidural anaesthesia

Possible vasoconstrictor action of the local anaesthetic agent on the uterine vascular bed 

the foetall heart acid-base balance

The effect of epidural anaesthesia on the maternal acid-base balance

The first stage of labour

The second stage of labour of the foetus

The pharmacological aspects of the local anaesthetic agents

Maternal and foetal concentrations of local anaesthetic agents in the blood

\section{OF EPIDURAL ANAESTHESIA} cardiovascular system cardiovascular system 


\section{CHAPTER 7 PATIENTS AND METHODS}

Comparison of the control group with the epidural group

Dosage of the local anaesthetic agent

The level of the epidural hypalgesia

The parameters calculated from the foetal heart rate

Calculation of the contraction parameters $\quad 85$

7.4

Method for determining the concentration of bupivacaine in $\quad 90$ the maternal blood plasma and in blood plasma from $\quad 90$

Materials and methods

Calculation

Methods concerning maternal blood pressure and

maternal heart rate 

period after administration of the epidural anaesthesia

Study of the foetal heart rate parameters during the last ninety minutes of the first stage

8.4.1 The mean of the foetal heart rate parameters during the last ninety minites of the first stage

The trend of the foetal heart rate parameters during the last ninety minutes of the first stage foetal heart rate parameters in the 120 minute period following administration of epidural anaesihesia

8.6 The relationship between the maternal plasma bupivacaine concentration and the foetal heart rate parameters in the 120-minute observation period following administration of epidural anaesthesia

The effect of a top-up dose on the foetal heart rate parameters

\section{CHAPTER 9 RESULTS REFERRING TO THE CONTRACTION} PARAMETERS the two groups administration of epidural anaesthesia epidural anaesthesia 
9.4.1 The mean of the contraction parameters during the last ninety minutes of the first stage

9.4.2 The trend of the contraction parameters during the last ninety minutes of the frst stage contraction parameters in the 120 minute period following administration of the epidural anaesthesia

\section{8}

Discussion

CHAPTER 10 RESULTS CONCERNING THE EFFECT OF EPIDURAL ANAESTHESIA ON THE MATERNAL AND FOETAL ACID-BASE BALANCE of labour

10.1.5 The changes of the maternal acid-base balance during the second stage of labour

The change of the foetal acid-base balance during the second stage of llabour of labour 
11.3 Bupivacaine concentrations in umbilical cord plasma 159

$\begin{array}{lll}11.4 & \text { Discussion } & 160\end{array}$

CHAPTER 12 THE EFFECT OF EPIDURAL ANAESTHESIA

ON MATERNAL BLOOD PRESSURE AND MATERNAL HEART RATE

The effect of epidural anaesthesia on maternal blood pressure The maternal blood pressure before and after administration of the epidural anaesthesia.

The maternal blood pressure following administration of the epidural anaesthesia versus the maternal blood pressure in the control group

12.1.4 The maternal blood pressure in the control group and in the epidural group during the last ninety minutes of the first stage administration of epidural anaesthesia The maternal RR interval length during the last ninety minutes of 


\section{List of Abbreviations}

$\begin{array}{ll}\text { a } & \text { artery } \\ \mathrm{BE} & \text { base excess } \\ \mathrm{cm} & \text { centimetre } \\ \mathrm{EA} & \text { cardiotocogram } \\ \mathrm{ECG} & \text { epidural anaesthesia } \\ \mathrm{fig} & \text { electrocardiogram } \\ \mathrm{FD} & \text { figure } \\ \mathrm{FDD} & \text { full dilatation } \\ \mathrm{g} & \text { interval between last dose and delivery } \\ \mathrm{Hz} & \text { gramme } \\ \mathrm{ID} & \text { Herz } \\ \mathrm{kg} & \text { interval difference } \\ \mathrm{kPa} & \text { kilogramme } \\ \mathrm{l} & \text { kilo Pascal } \\ \mathrm{L}_{\mathrm{n}} & \text { litre } \\ \mathrm{LDD} & \mathrm{n} \text { th lumbar spinal segment } \\ \mathrm{ln} & \text { interval between last dose and delivery } \\ \mathrm{LOA} & \text { natural logarithm } \\ \mathrm{LOP} & \text { left occiput anterior position } \\ \mathrm{LOT} & \text { left occiput posterior position } \\ \mathrm{log} & \text { left occiput transverse position } \\ \mathrm{LTI} & \text { logarithm } \\ \mu \mathrm{g} & \text { long term irregularity } \\ \mu \mathrm{ml} & \text { microgramme } \\ \mathrm{mEq} & \text { microlitre } \\ \mathrm{mg} & \text { milliequivalent } \\ \mathrm{min} & \text { milligramme } \\ \mathrm{ml} & \text { minute } \\ \mathrm{mm} & \text { millilitre } \\ \mathrm{mmol} & \text { millimetre of mercury } \\ & \text { millimol } \\ \text { millisecond } \\ \text { number }\end{array}$




$\begin{array}{ll}\mathrm{ng} & \text { nanogramme } \\ \mathrm{OA} & \text { occiput anterior position } \\ \mathrm{OP} & \text { occiput posterior position } \\ \mathrm{p} & \text { tail probability } \\ \mathrm{pCO}_{2} & \text { partial carbon dioxide pressure } \\ \mathrm{pH} & \text { degree of acidity: } \\ & \text { negative logarithm of hydrogen ion concentration in equivalent per } \\ & \text { litre } \\ \mathrm{pKa} & \text { dissociation constant } \\ \mathrm{pO}_{2} & \text { partial oxygen pressure } \\ \mathrm{psi} & \text { pounds per square inch } \\ \mathrm{ROA} & \text { right occiput anterior position } \\ \mathrm{ROP} & \text { right occiput posterior position } \\ \mathrm{ROT} & \text { right occiput transverse position } \\ \mathrm{SD} & \text { standard deviation } \\ \mathrm{s} & \text { second } \\ \mathrm{S} & \text { start of the investigation } \\ \mathrm{SEM} & \text { standard error of the mean } \\ \mathrm{S} & \mathrm{n}_{\mathrm{n}}^{\text {th }} \text { sacral spinal segment } \\ \mathrm{T}_{\mathrm{n}} & \mathrm{n}^{\text {th }} \text { thoracic spinal segment } \\ \mathrm{UA} & \text { umbilical artery } \\ \mathrm{UV} & \text { umbilical vein } \\ \text { VC } & \text { variation coefficient } \\ \mathrm{Xe} & \text { Xenon }\end{array}$




\section{Introduction}

In The Netherlands, little interest has been shown in anaesthesia with drugs during childbirth because, true to tradition, delivery took place at home and parity was high which meant that only a small number of primigravid women were involved. Moreover, in The Netherlands childbirth is looked upon as a physiological event for which anaesthesia is not necessary. In our country, pharmacological anaesthesia is to a great extent totally in the hands of the obstetrician who usually commands a small arsenal of methods.

The ideal anaesthesia for childbirth would conform to the following criteria:

1. The method must reduce the pain to a considerable extent.

2. The method must not exercise any unfavourable effect on labour or expulsion force.

3. The method must not be harmful to the child.

4. The method must not be disadvantageous for the mother and must not have an unfavourable effect on delivery or lactation.

5. Should a surgical intervention become necessary during delivery, this should not be negatively affected by the prior administration of obstetric anaesthesia.

6. There should be no question of any greater tendency towards bleeding due to insufficient retraction and contraction of the myometrium.

7. The method should be capable of being carried out by any physician, including in general practice, and of individual tailoring.

It is obvious that an anaesthetic method which meets all of the above-mentioned criteria probably does not exist. Equally, it is clear that the degree to which pain is experienced during childbirth - and therefore the need to treat this pain - is greatly dependent on the attitude of the medical and nursing staff towards the necessity of anaesthesia during childbirth.

Apart from pharmacological methods of anaesthesia, obstetrics also makes use of psychological methods. Dick-Read $(1933,1959)$ in his books 'Natural childbirth' and 'Childbirth without fear' puts the emphasis on informing the patient, re-education, autosuggestion and relaxation techniques.

In The Netherlands, this has led, amongst other things, to courses in pregnancy gymnastics for expectant parents. Russian obstetricians have developed a system for psychoprophylaxis during childbirth, which is especially based on the theories of Pavlov. The autosuggestive character clearly occupies a place in the foreground (Velvoski et al., 1950). Lamaze (1954) and Lamaze and Vellay (1952) obtained good results with such a method. 
The pharmacological methods of anaesthesia can be subdivided as follows:

1. Inhalation anaesthesia.

2. Oral, rectal or parenteral administration of analgesics and/or spasmolytic agents.

3. Regionall anaesthesia.

Both in anaesthesiology as in obstetrics, more and more interest is being shown in regional anaesthesia. In obstetrics, the following possibilities for regional anaesthesia are available:

1. Local infiltration of the perineum.

2. Pudendal anaesthesia.

3. Paracervical anaesthesia.

4. Parawertebral anaesthesia.

5. Epidural anaesthesia.

6. Subarachnoid anaesthesia.

All these different types of regional anaesthesia block the sensory innervation of the uterus at different levels.

Local infiltration of the perineum and pudendal anaesthesia are only usable during the second stage of labour. Paracervical and paravertebral anaesthesia block the pain, which originates during the first stage, but give no pain relief during the second stage. Epidural and subarachnoid anaesthesia block the pain during the first stage as well as during the second stage of labour.

Studying the literature data, it appeared that there were controversial opinions in certain areas. It will be tried in chapter five to point out possible causes, which could be responsible for the conflicting literature data. The study to be described is an attempt to determine the influence of epidural anaesthesia on some maternal and foetal physiological parameters, which are frequently used in foetal and maternal monitoring.

It involved a prospective, non-randomised study into the effects of epidural anaesthesia during labour on:

1. The foetal heart rate and the short term and long term irregularity in the foetal heart rate pattern.

2. The uterine contractions.

3. The maternal and foetal acid-base balance.

4. The concentration of the local anaesthetic in the maternal plasma and in the plasma of the umbilical cord.

5. The maternal blood pressure and the maternal heart rate.

It is not the object of this study to make a comparison between the various methods of pharmacological anaesthesia. 


\section{Delivery pain and nerve pathways}

\subsection{Delivery pain}

The object of epidural anaesthesia during labour is to block conduction at the point where the afferent nerves from the uterus and the birth canal enter the epidural space. Most probably, the pain during the dilatation phase is for the most part caused by stretching of the uterine cervix. The following considerations seem to support this theory:

1. Stretching of smooth muscle tissue is an adequate stimulus for visceral pain.

2. The uterus contractions following administration of oxytocin are usually relatively painless until the uterine cervix starts to dilate.

3. Pregnant women undergoing Caesarean section under local anaesthesia have an as yet unaesthetised myometrium which is insensitive to incision and palpation whereas stretching and manipulation of the uterine cervix is extremely painful. The nature and localisation of this pain is comparable with the pain of childbirth.

4. Stretching of the uterine cervix in a gynaecological or obstetric patient produces pain which is similar to that of childbirth.

5. Braxton-Hicks contractions are only slightly painful, here the uterine cervix is of course not yet dilated.

However, it is very likely that contractions of the uterus muscle contribute to the development of the delivery pain. Rysanek and Cavanagh (1958) are of the opinion that the pain arises due to pressure on the nerve endings in the myometrium during contractions. Moir (1939) and Dick-Read (1959) have suggested an ischemic change in the myometrium during the contraction and that this is responsible for the pain. Dick-Read (1959) has also raised the possibility that inflammatory changes in the myometrium during parturition contribute to childbirth pain. In addition, traction forces on the ligaments, the adnexa and the peritoneum probably also give rise to pain sensations, as do pressure on- and traction of the rectum, bladder and urethra.

Pain experienced during the second stage of labour is of a different origin to that experienced during the dilatation phase. During the second stage of labour the pain is in particular localised in the vulva, vagina and perineum and probably arises as a result of stretching of these tissues. The pregnant woman generally experiences this pain as less taxing than that of the first stage of labour because the woman in this phase can actively participate in the birth of her child, this is in contrast to the first stage during which she finds herself in an anticipatory and mainly passive situation.

\subsection{The innervation of the uterus}

Henry Head (1893) was the first to consider the innervation of the uterus. On the basis of clinical observation he reached the conclusion that pain sensations from the corpus uteri 
were conducted to the eleventh and twelfth thoracic spinal segments whereas, in contrast, pain sensations arising in the uterine cervix were conducted to the second third and fourth sacral segments via the parasympathetic nervous system.

It was not untill 1933 when Cleland's now classical study of the innervation of the birth canal saw the light of day. Apart from a few small details, his theory is still generally accepted, even today. The innervation of the uterus belongs to the autonomic nervous system. The autonomic nervous system consists of two anatomically and functionally distinct parts, namely the parasympathetic and (ortho)sympathetic components.

The autonomic nervous system consists of a central and a peripheral part. The central autonomic centres lie in the hypothalamus, the brain stem and the spinal cord. Autonomic functions are integrated in the hypothalamus and come under the influence of impulses from the cerebral cortex.

\subsubsection{The efferent sympathetic innervation of the uterus}

The majority of the data presented in this chapter have been taken from Bonica (1972) and Abouleish (1977). The first sympathetic neuron in this system lies in the hypothalamus. The cell bodies of the peripheral sympathetic nerves which innervate the uterus lie in the lateral horns of the fifth thoracic upto and including the second lumbar spinal segment (second neuron). The axons from these neurons leave the spinal cord via the ventral root, together with non-autonomic axons. However, they soon leave the ventral root via the white ramus communicans, coursing towards the sympathetic chain. The preganglionic fibre in this ramus can make synaptic contact with the third neuron in different ways. The most frequent of which in the efferent innervation of the uterus are probably the following:

1. The axon of the second neuron traverse through the paravertebral ganglion without synapsing so that it can then synapse in one of the prevertebral ganglia. The most important of these prevertebral ganglia are: the celiac ganglion, the superior mesenteric ganglion, the inferior mesenteric ganglion and the inferior hypogastric ganglion.

2. The axons of the second neuron run through the sympathetic trunk towards the level of the sacral spinal cord where they synapse. The axons of the third neuron then run via the inferior hypogastric plexus towards the uterus.

Our knowledge of the efferent sympathetic innervation of the uterus is at the moment still incomplete. For instance the exact role of the efferent sympathetic nervous system during childbirth with regard to uterine contractions and the blood supply of the uterus is not precisely known.

\subsubsection{The afferent innervation}

The afferent innervation of the uterus, adnexa and ligaments reaches the tenth thoracic to and including the first lumbar spinal segment. The first neuron lies in the spinal ganglion of the dorsal nerve root. The second neuron lies in the posterior horn of the spinal cord. The third neuron is situated in the thalamus. The pain sensation is conducted 
from the spinal cord level to the hypothalamus via the lateral spinothalamic tract where the nerve fibres cross the median line. The afferent nerves from the uterus run through the inferior hypogastric plexus towards the superior hypogastric plexus and then go to the sympathetic trunk either directly or via the celiac ganglion. These fibres course towards the spinal ganglion via the white ramus communicans. What is involved in childbirth pain is the so-called 'referred pain', that is, pain that is experienced in a site which is different from the one in which it arises. A plausible explanation for the referred pain is that the uterus and some somatic structures share the same 'neuron pool'. The impulses from the uterus reach their own neurons and also those that, for instance belong to the abdominal wall innervation. If the pain stimuli from the uterine cervix are strong enough then they also stimulate the neurons belonging to the abdominal wall. The cerebral cortex interprets this as if the pain stimuli were genuinely arising in the abdominal wall. Referred pain involved in uterine contractions localises in the lower abdomen, the trochantor major, the iliac crest and low down in the back. This reflects the sensory innervation of the uterus. (From the tenth thoracic up to and including the first lumbar spinal segment.)

\subsubsection{The parasympathetic nervous system}

The cell bodies of the preganglionic neurons lie in the lateral horns of the second, third, fourth and fifth sacral spinal segments. The axons traverse the ventral root, the white ramus communicans and the paravertebral ganglion (without synapsing) to form the pelvic nerve and then either run through the inferior hypogastric plexus or form juxta-uterine synapses. This synapse may also be intramural. The role of this nervous system during childbirth is not clear. If the Ferguson reflex does exist in hurnans then this nervous system may well be involved.

\subsubsection{Pain pathways during the first and second stage of labour}

As has been said, the pain which is experienced during the dilatation phase probably arises as a result of dilatation of the uterine cervix. It emerges from heading 2.2.2. that the pain stimuli during the dilatation phase are conducted to the tenth thoracic up to and including the first lumbar spinal segments.

However, the pain that is experienced during the second stage of labour is conducted via the pudendal nerves to the second, third and fourth sacral spinal segments.

It is clear from this that the pain stimuli which arise during the first stage reach the central nervous system at a totally different level than do those that arise during the second stage. In fig. 2.1. there is a schematic representation of this. 


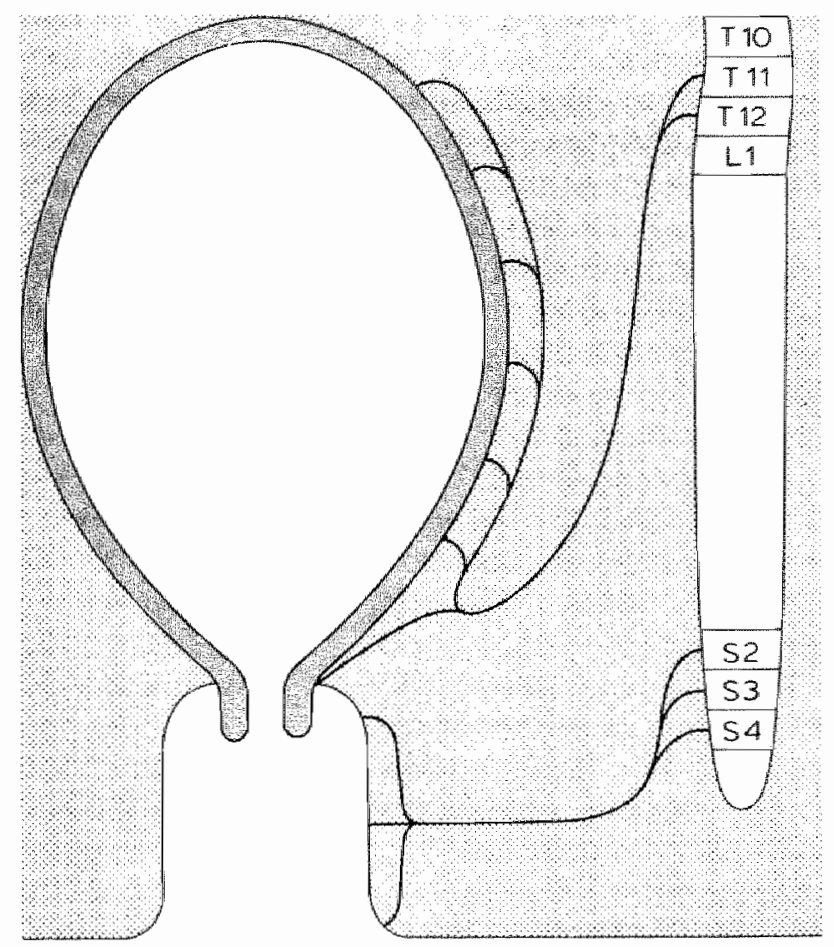

Figure 2. ISchematic representation of the pain pathways during the first and second stage of labour. 
CHAPTER 3

\section{Anatomy}

\subsection{Anatomy of the epidural space}

The epidural space is the space inside the spinal column which envellopes the dura mater. The dura mater is the most external of the meninges (see fig. 3.1).

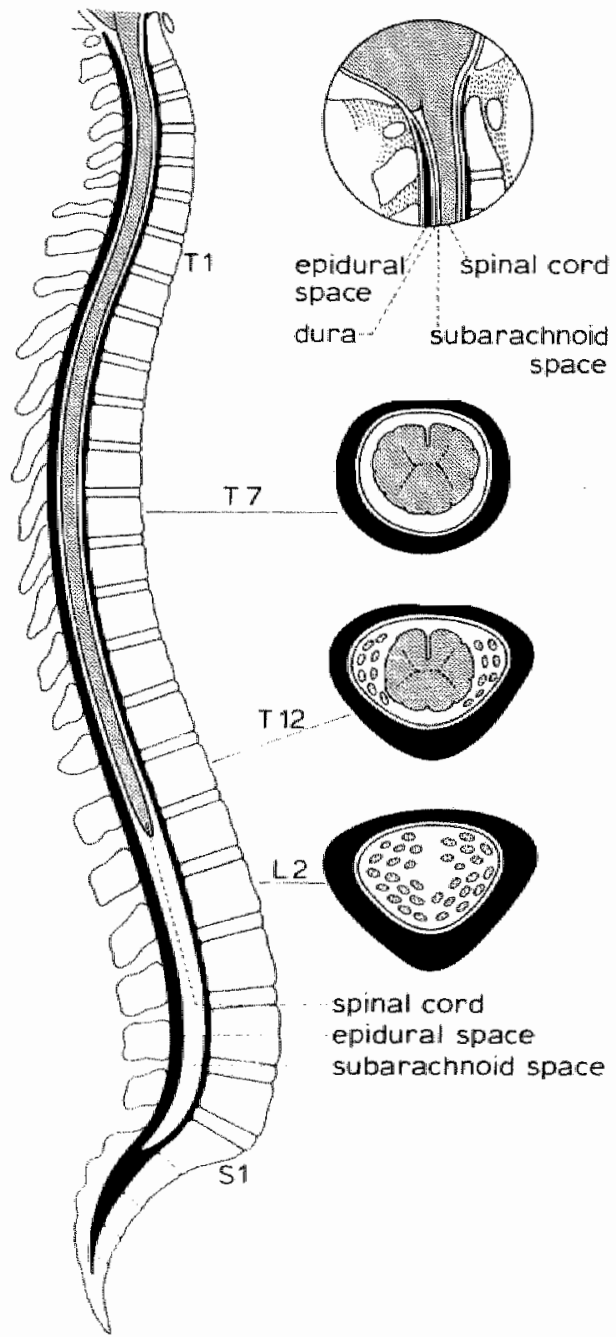

Figure 3. A Anatomy of the epidural space and the spinal column. (According to Bionica, 1972) 
Cranially, the epidural space extends as far forwards as the foramen magnum. The intracranial dura mater divides in the foramen magnum to form a periosteal layer which clads the vertebrae and the dura mater which envelopes the spinal cord. Thus, there is no open connection between the epidural space in the spinal canal and the intracranial epidural space.

In the caudal direction, the epidural space stretches out to the sacral hiatus which is closed by the sacrococcigeal ligament.

The ventral limit of the epidural space is formed by the posterior longitudinal ligament which clads the corpus of the vertebrae and the intervertebral discs.

On both lateral sides, the limits are formed by the vertebral arches, interrupted by the intervertebral foramina. Thus there is an open connection between the epidural and paravertebral space.

On the dorsal side, the limit to the epidural space is formed by the flaval ligament. This stiff ligament which has a thickness which varies between 3 and $5 \mathrm{~mm}$ is of great importance in determining the position of the epidural space during puncture. This point will be returned to when the technique of epidural puncture is discussed.

\subsection{The measurements of the epidural space}

The size of the epidural space varies according to the different spinal levels. The size of the ventral component of the epidural space is more or less constant at $\pm 1 \mathrm{~mm}$. The posterolateral component is usually bigger and varies between $1.5 \mathrm{~mm}$ (cervical) and 3 to $5 \mathrm{~mm}$ (thoracic) or 4 to $6 \mathrm{~mm}$ (lumbar). At the point of the lumbosacral transition the posterolateral compartment is $\pm 2 \mathrm{~mm}$ in cross-section. From these proportions it appears that there is less chance of perforation the dura mater during puncture at the lumbar level than would be the case at a higher level.

\subsection{The content of the epidural space}

The epidural space is filled with loose connective tissue, fat tissue and an extensive venous plexus and lymph vessels (see fig. 3.2).

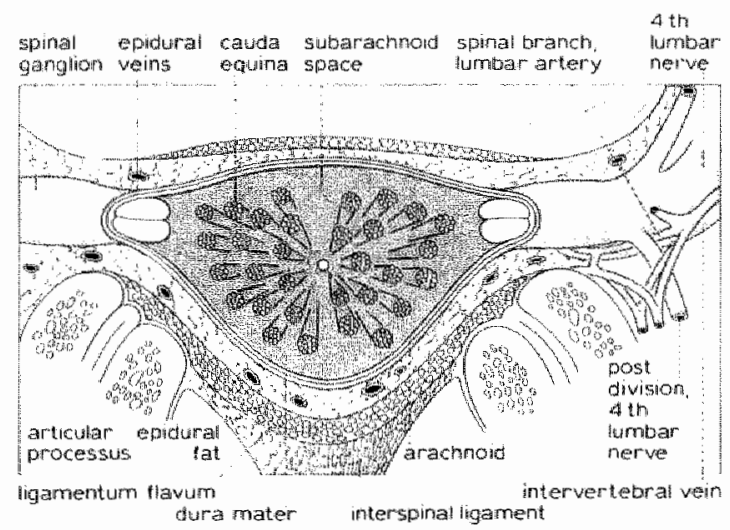

Figure 3.2 Cross section of the spinal canal at the level of the intervertebral disk between the third and fourh lumbar vertebrae. (According to Bonica, 1972) 
The anterior and posterior roots of the spiral nerves run through the epidural space. The epidural space continues further caudally than does the spinal cord (see fig. 3.1).

Usually the spinal cord only goes as far as the first lumbar vertebra where it ends in the conus medullaris. The spinal cord is encircled by three meninges:

1. The pia mater which lies immediately on the spinal cord.

2. The arachnoid. Between the arachnoid and the pia mater there is a network of mesothelial cells. This space is called the subarachnoid space. It is here that the cerebrospinal fluid circulates.

3. The dura mater. This is the strongest of the enveloping meninges. Between the dura mater and the aracnoidea there is a potential space, the subdural space.

The dural sac runs caudally further than does the spinal cord, namely as far as the second sacral vertebra. From the first lumbar vertebra - the point at which the spinal cord stops -the dural sac still contains cerebrospinal fluid and the cauda equina. At the caudal end the dural sac becomes a thin connective tissue string called the 'fillum durae matris spinalis', which is fixed to the bone at the sacral hiatus.

\subsection{Spinal nerves}

Thirty one pairs of dorsal and thirty one pairs of ventral roots arise from the spinal cord. These unite to form thirty one pairs of spinal nerves. In the dorsal root there is an oval shaped thickening which is called the spinal ganglion. The cell bodies of the peripheral sensory neurons lie in this ganglion.

At the cervical level, the spinal ganglion lies in the intervertebral foramen. Caudally, the spinal ganglion adopts a more and more median position. The course of the nerve roots in the cranial part of the spinal canal is horizontal. In the caudal direction the root course is more and more vertically orientated. This is probably due to the embryological development of the spinal canal and its contents. Up to the third month of foetal life, the spinal canal is completely filled by the spinal cord. After that point in time there is a difference in growth rates which leaves the spinal cord somewhat behind that of the spinal canal. This difference could also explain the way in which the epidural space originates.

The membranous covering of the ventral and dorsal roots is pretty much identical to that of the spinal cord. As one approaches the spinal ganglion the thickness of the dura mater becomes reduced. From the spinal ganglion onwards, the enclosing consists only of dura mater which then becomes the perineurium of the spinal nerve in the paravertebral space.

\subsection{Topographical anatomy}

Dorsally to the epidural space there are the following anatomical structures, wich are of importance during puncture of the epidural space: skin, subcutis, supraspinal ligament, interspinal ligament and flaval ligament (see fig. 3.3). 

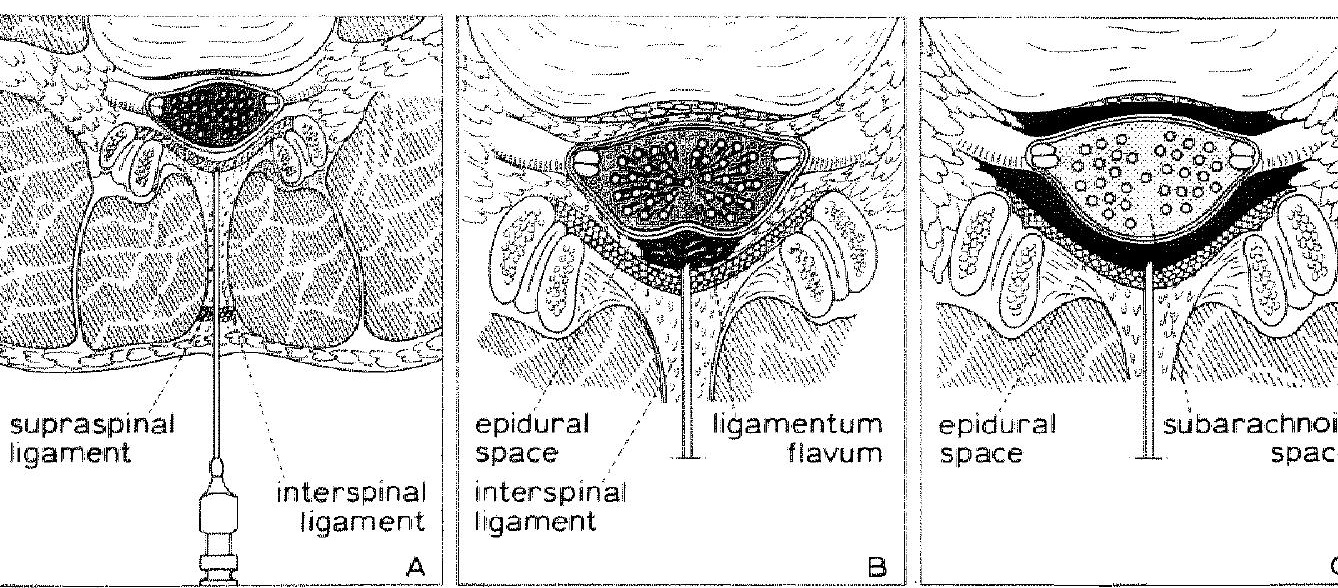

Figure 3.3Cross section of the spinal canal with the point of the needle in the epidural space. Nore in $B$ and $C$ the spread of the local anaesthetic. (According to Bomica, 1972)

The average distance between the skin and the epidural space is between four and six centimetres. However, one must remember that there can be great differences from one patient to another. In obesity, a distance of eight centimetres or more is no rarity.

In the lumbar area the spinal crests are short and are more or less vertically orientated with respect to the axis of the spinal column, thus the access to the epidural space also lies vertical to the axis of the spinal column.

As one goes along the spinal column, the orientation of the access route gradually changes under the influence of the physiological curvature of the spinal colum: as one progresses cranially the access route slopes upwards and thus becomes longer. When the spine is flexed, the space between the spinal crests increases and this makes puncture more simple. Another advantage of flexion is that the spinal cord is displaced more ventrally in the epidural space, thus increasing the posterolateral measurement. 


\section{Puncture of the epidural space}

There are different methods of puncturing the epidural space. A few of these methods make use of the subatmospheric pressure which usually pertains in the epidural space. In the present investigation the 'loss of resistance' method has always been employed.

\subsection{Epidural puncture according to the loss of resistance method}

At the time of puncture the pregnant woman lies on her left side with her spinal column in maximum flexion and her back along the edge of the bed. The flexion is desirable because the interspinous space increases as flexion increases, thus the access route becomes larger and puncture proceeds more easily. Another advantage is that in flexion the dural sac is displaced towards the most anterior part of the epidural space thus making the posterolateral part of the epidural space bigger and this reduces the likelihood of dural perforation. The back of the woman is desinfected. Caudally the back is iodinated up to the start of the gluteal cleavage, cranially this is done up to the points of the scapulae and laterally as far as the iliac crests. The desinfected area is covered with sterile drapes. In this investigation the third lumbar intervertebral space was always used for the puncture.

Intradermal and subcutaneous anaesthesia is carried out using 0.25 per cent bupivacaine with adrenaline added at a concentration of $1: 200,000$. This anaesthetic agent is used for the whole of the procedure. A scalpel blade is used to make a small incision in the median line skin. This is done for two reasons:

1. Insertion of the epidural needle proceeds more easily.

2. The risk that a punched-out piece of skin with the desinfectant on it will come into the epidural space is in this way avoided. In this way one avoids the possibility of the formation of an inclusion cyst and of irritation of the nerve roots due to the desinfectant.

Using a 16 gauge Tuohy needle the subcutis and the supraspinall ligament is penetrated so that the tip of the needle lies in the interspinal ligament. One of the most frequent reasons for unsuccessful puncture is that the needle is not introduced precisely in the mid line. The supraspinal ligament can be felt as a round edge between the spinal proccesses. Controlled but considerable pressure is needed to bore through this ligament without allowing the needle to wander off to the left or right (see fig. 3.3).

Once the needle has gone through the supraspinal ligament the stylet is removed and a 2 $\mathrm{ml}$ syringe filled with isotonic saline solution is carefully adapted to the needle. Prior to fitting, the plunger and the insides of the syringe are thoroughly wetted so that the plunger meets more or less no resistance in the syringe tube. This is of essential importance in determining the position of the epidural space as will soon be seen. 
The needle is fixed between the thumb and index finger of the left hand and the other digits are stretched against the woman's back. Using the right hand, the needle is pushed forwards in phases with repeated examination of the degree of resistance on the plunger while trying to inject the liquid into the tissue. If the tip of the needle is in the interspinal ligament there will be moderate resistance. However, if the needle tip is in the stiff flaval ligament then the resistance will be quite severe. From this point onwards the needle is pushed in, milimetre by milimetre while every time the resistance on the plunger is assessed. As soon as needle tip enters the epidural space, the resistance on the plunger falls and the liquid can be injected into the epidural space with almost no resistance. This sensation is known as the 'loss of resistance'. It may be that a few drops leak back out of the needle but this usually stops spontaneously after thirty to sixty seconds.

If the dura mater is perforated then generally a copious quantity of fluid flows out. It is possible to differentiate between cerebrospinal fluid and isotonic saline that has leaked back by allowing a droplet to fall on the forearm - if the liquid is at body temperature then one may take it that this is cerebrospinal fluid. If the liquid is cooler then one can take it that it is injection fluid that has leaked back. However, if there is still any doubt then one can use a bed-side glucose determination to detect for the presence of glucose in the liquid.

If there is a bloody tap than probably one of the veins in the extensive venous plexus in the epidural space has been punctured. In such a case the stylet is returned to the needle for one minute, if the bleeding persists then the puncture procedure is repeated in the fourth lumbar intervertebral space.

A vinyl plastic catheter is now introduced via the needle and using graduations on the catheter, it is pushed cranially three centimetres beyond the end of the needle. The further that the catheter is pushed in, the greater is the chance that the venous plexus will be perforated. If the epidural catheter is pushed far in there is equally a chance that the catheter will go through an intervertebral foramen, leave the epidural space and enter the paravertebral space.

Once the catheter is in place, the needle is withdrawn over the catheter, taking care that the catheter remains in position. Then an aspiration test is done to exclude that the end of the catheter is in a blood vessel or in the subarachnoid space. If there is a positive aspiration test - with regard to blood - then the catheter is drawn back a little. If the aspiration test remains positive then an attempt is made to realize the epidural anaesthesia in the fourth lumbar intervertebral space.

The port of entry of the catheter in the skin is carefully covered with sterile gauze. Then the catheter is fixed against the skin with a long plaster on the patient's back. The catheter is taken over the patient 3 s shoulder and fixed on her breast. Before giving a therapeutic dose of local anaesthetic, a test dose is always given. 


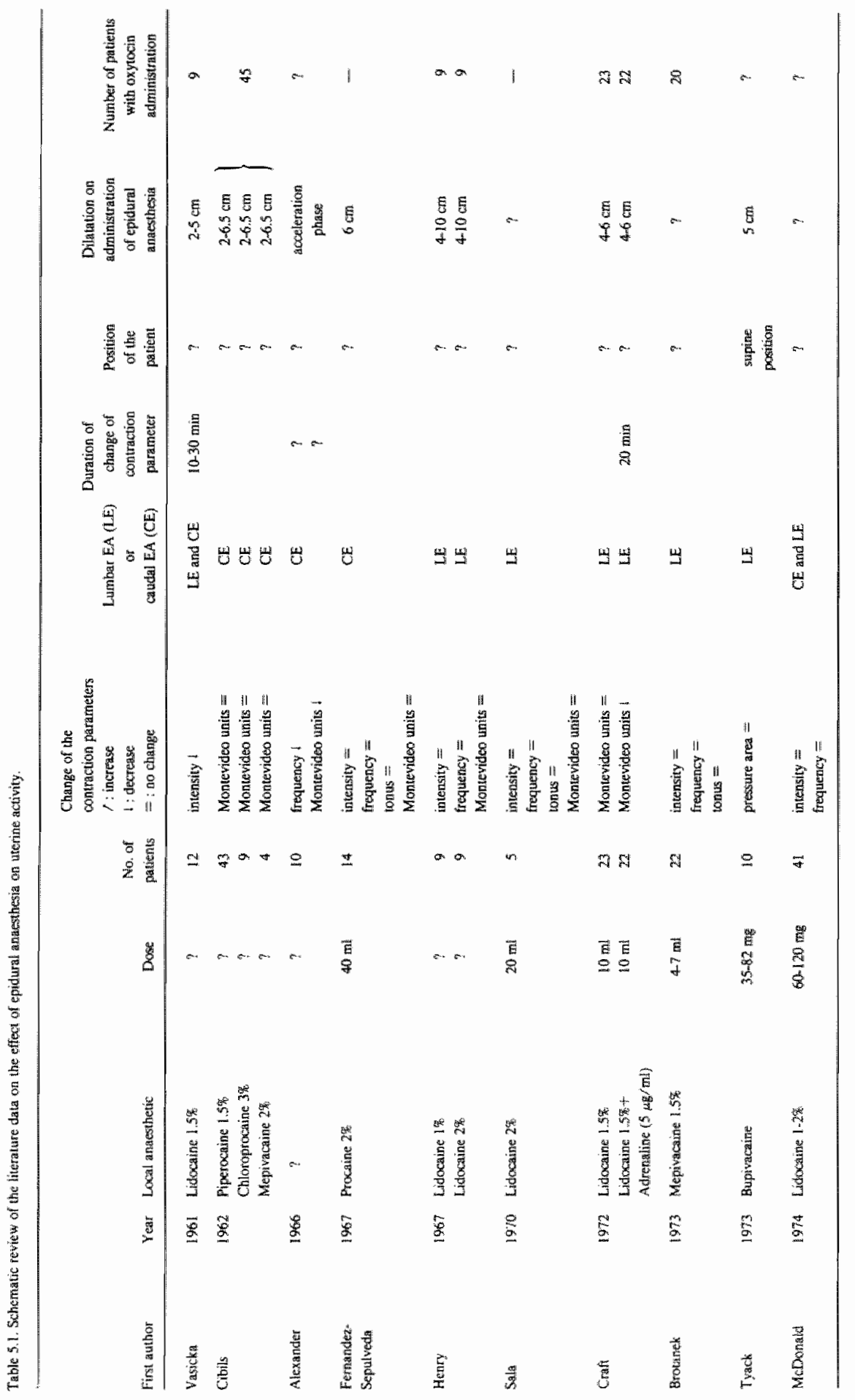




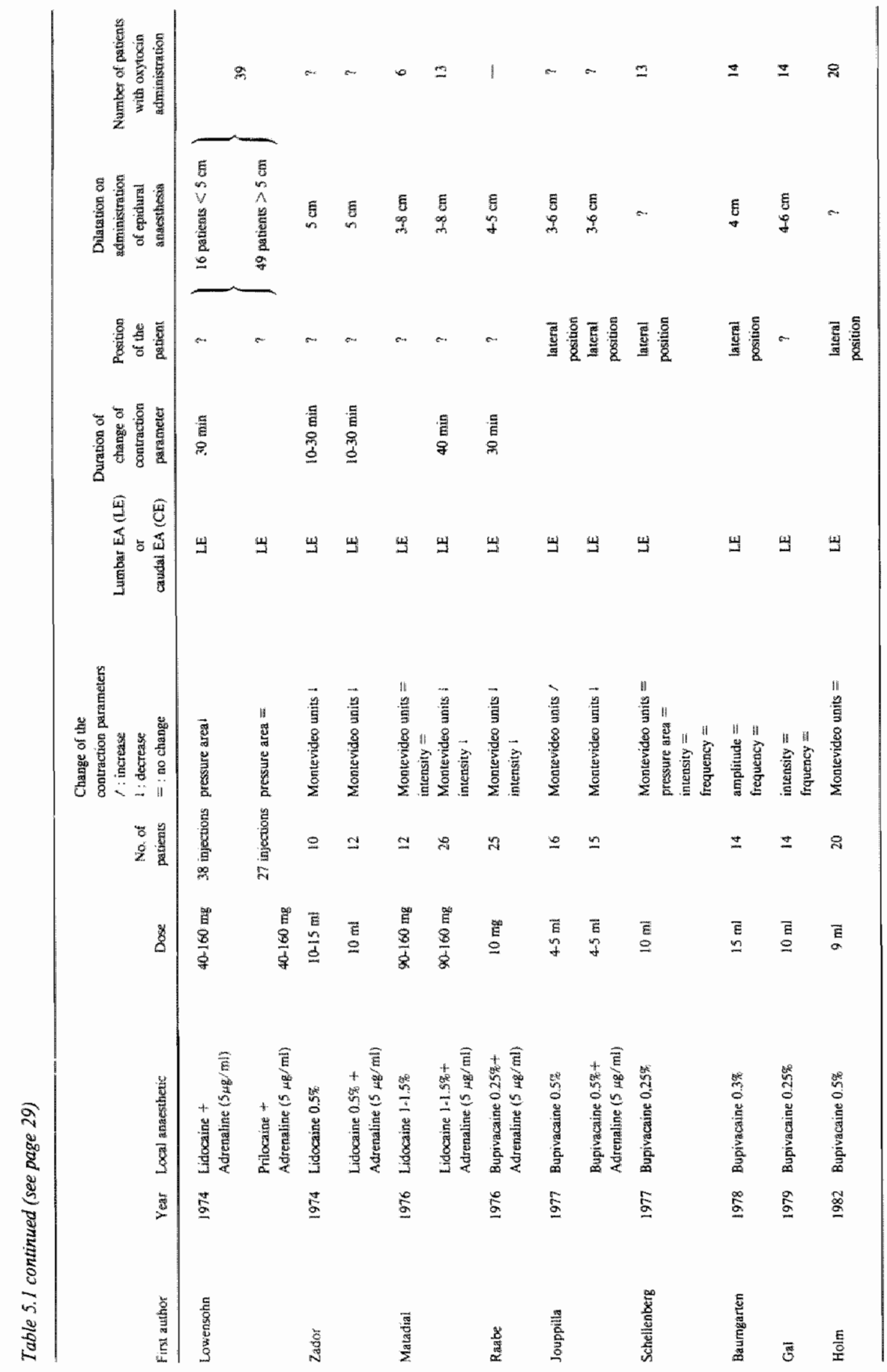




\section{Literature data}

In this chapter attention will be given to the most important data concerning the influence of epidural anaesthesia on the mother and her child.

In this connection, the following factors are important:

1. The effect of epidural anaesthesia on the uterine activity.

2. The effect of epidural anaesthesia on the foetal heart rate pattern.

3. The effect of epidural anaesthesia on the maternal and foetal acid-base balance.

4. Pharmacological aspects of local anaesthetic agents.

\subsection{The effect of epidural anaesthesia on uterine activity}

The results of different researchers on the effect on uterine activity vary.

The effect of anaesthesiological denervation of the uterus is complex and dependent on neurogenous, humoral and hemodynamic factors. In the case of epidural anaesthesia this is somewhat extra complicated because some of the local anaesthetic enters the blood stream and on the way could have an effect on the uterine activity and the cardiovascular system. Also, the adrenaline which is added to the local anaesthetic can have an effect on the uterine activity and the cardiovascular system.

Table 5.1 summarises the most important resullis of the various researchers. Vasicka and Kretchmer (1961), Alexander and Franklin (1966), Craft et al., (1972), Zador and Nilsson (1974), Lowensohn et al. (1974), Matadial and Cibils (1976) and Raabe and Belfrage (1976) found a temporary reduction in uterine activity following administration of epidural anaesthesia. Usually, this fall occurred in the first hour after administration of epidural analgesia and in most studies only lasted for fifteen to thirty minutes. Vasicka and Kretchmer (1961), Zador and Nilsson (1974), Matadial and Cibils (1976) and Raabe and Belfrage (1976) ascribed the reduction in uterine activity to a falling intensity of contractions. Alexander and Franklin (1966) however, were of the opinion that a reduction in contraction frequency was the main cause of decreasing uterine activity.

Other investigators were unable to find any effect of epidural anaesthesia on uterine activity (Cibils and Spackman, 1972; Henry et all 1967; Fernandez-Sepulveda and Gomez-Rogers, 1967; Sala et al., 1970; Brotanek et al., 1973; Tyack et al., 1973; McDonald et al., 1974; Schellenberg, 1977; Jouppila et al., 1977; Baumgarten et al., 1978; Gal et al., 1979 and Holm, 1982).

In a retrospective investigation of 1000 patients to whom epidural anaesthesia was administered and of 1000 patients to whom it was not, Crawford (1972-b) came to the conclusion that this form of analgesia had no effect on the duration of the first stage in multiparous women. In his study the first stage of labour in nulliparous women was 
indeed, even shorter. However most of the women in the non-epidural group were given other forms of pharmacological analgesia during labour.

Nielsen et al., (1962) were of the opinion that epidural anaesthesia had no effect on the duration of the first stage of labour. Phillips et all, (1977) obtained no abnormal labour curves in 598 patients who were given epidural anaesthesia (bupivacaine 0.125 per cent + adrenaline 1:200,000). Studd et al., (1980) also came to the conclusion that epidural anaesthesia had no effect on the duration of the first stage.

Raabe and Belfrage (1976) made mention of the fact that epidural anaesthesia could produce a favourable effect in patients whose uterus activity was uncoordinated. Such a favourable effect could be the result of blockade of the autonomic innervation of the uterus. The removal of fear and pain could possible also play a part.

In studying the literature, a number of factors emerge which could possibly partly explain the above-mentioned discrepancies. These factors are:

1. The development of hypotension during the epidural anaesthesia.

2. The addition of adrenaline to the local anaesthetic agent.

3. The effect of the individual properties and dosages of the local anaesthetic agents.

4. The effect of the moment in time during the childbirth process when the epidural anaesthesia is carried out.

5. The effect of the level of the epidural blockade.

6. A few other factors which could have an effect upon uterine activity.

\subsubsection{The development of hypotension}

Vasicka and Kretchmer (1961) and Vasicka et al., (1964) observed that the intensity of the uterus contractions generally fell by 10 to $20 \mathrm{mmHg}$ following administration of epidural anaesthesia. This effect lasted for 10 to 30 minutes and was almost always accompained by a reduction in blood pressure. However, in this study, if the blood pressure remained normal, then there was no change or hardly any change in contraction intensity. The study by Vasicka and colleagues demonstrates that hypotension during epidural anaesthesia may be a cause of reduced uterine activity.

Lowensohn et al., (1974) were unable to find any correlation between short-term reduction of uterine activity and blood pressure following epidural anaesthesia. The only factor in this investigation which correlated with the reduction in uterine activity was the nature of the local anaesthetic agent. Lidocaine caused a clear reduction in uterine activity whereas with propitocaine this was very much less the case.

The causes for the reduction in blood pressure during epidural anaesthesia have been thoroughly described by many authors (Bonica, 1972; Weaver et al., 1975; Moir, 1976; Abouleish, 1977; Bromage, 1978; Crawford, 1978).

Epidural anaesthesia bllocks not only the sensory nerve fibres but also the sympathetic nerve fibres. Switching off a part of the sympathetic nervous system leads to peripheral vasodilatation in the area concerned, as result of which blood 'pools" in the area and venous return to the heart is reduced. This can induce reduced cardiac output and hypotension.

All authors are of the opinion that a woman who has received epidural anaesthesia must 
avoid the supine position because this seriously increases the frequency and degree of hypotension. Even a pregnant woman who has received no form of anaesthesia will have reduced uteroplacental perfusion and a predisposition to hypotension if she is in the supine position.

Two pathohysiological mechanisms are responsible for this:

1. Reduction of the venous return as a result of pressure of the gravid uterus on the inferior vena cava.

2. Reduction of blood flow in the aorta as a result of pressure of the gravid uterus. This effect occurs in particular during contractions and the phenomenon is known as the 'Poseiro effect' (Poseiro, 1967).

A large proportion of pregnant women can maintain a normal blood pressure in the supine position by peripheral vasoconstriction. In a woman who has been given an epidural anaesthesia, part of this compensation mechanism is removed because in the lower half of the body there is peripheral vasodilatation due to blockade of the sympathetic system at the epidural level.

The frequency of occurrence of hypotension is given greatly varying values in the literature (see section 5.2.1.1). This large variation is, in the first instance, due to the diversity of definitions which the various authors attach to the concept of hypotension. Furthermore, it is of course important to know whether or not the usual precautionary measures have been taken such as good intravenous filling of the vascular system and positioning of the woman on her side. Of course, hypotension and the associated reduction in uterine activity may be the direct result of the epidural anaesthesia but it is just as likely that the cause lies in failure to observe the necessary precautions. If adrenaline is added to the local anaesthetic agent then the frequency and degree of hypotension increases (see section 6.1.3). It seems from the above-mentioned data from the literature that a fall in blood pressure of the woman may cause a reduction in uterine activity.

\subsubsection{Addition of adrenaline to the local anaesthetic agent}

From a theoretical point of view one would predict that because of its vasoconstrictive property, adrenaline will increase the duration of effect of the local anaesthetic agent and reduce its toxicity. The toxicity would be reduced because a smaller amount of the local anaesthetic agent is taken up into the blood.

The reduced local perfusion of the tissues in the epidural space - due to the vasoconstrictive action of adrenaline -also causes an acidosis. This effect occurs after the local anaesthetic agent has penetrated the nervous tissue. The reduced $\mathrm{pH}$ results in a relatively large proportion of the local anaesthetic agent being found in the unionised state. The local anaesthetic agent in unionised form has hydrophilic and lipophobic properties, as a result of which, membrane penetration is reduced thus bringing about a concomittant reduction in diffusion of the anaesthetic out of the cell. The local anaesthetic is, as it were, locked in intracellularly and thus can exercise its effect for longer (Abouleish, 1977). 
Using bupivacaine and other long-working local anaesthetic agents, the duration of the epidural anaesthesia seems not to be affected by the addition of adrenaline (section 5.4.3.2). The effect of the addition of adrenaline to bupivacaine on the blood level of the latter is wariably reported in the literature (section 5.4.3.2).

It is not only the local anaesthetic agent which is resorbed from the epidural space but also a proportion of the adrenaline. Adrenaline has both alpha- and beta sympathicomimetic properties. In low concentrations (for example such as following resorption into the blood stream from the epidural space) adrenaline has a predominant beta sympathicomimetic effect (Bonica et al., 1971).

These beta adrenergic properties of adrenaline could have an inhibitory effect on uterine activity (Hendricks et al., 1961; Zuspan et al., 1962; Shnider and Levinson, 1979). Rucker (1925) noted that childbirth was protracted if during caudal epidural anaesthesia $330 \mu \mathrm{g}$ adrenaline at a concentration of 1:200,000 was added to the local anaesthetic agent However, in this study, labour proceeded normally if the adrenaline was left out. Harris (1950) demonstrated that the uterine activity was reduced if between 200 and 500 ug adrenaline was administered intramuscularly. This was also the case if the adrenaline was administered intravenously at a dose of 2.5 to $5 \mu \mathrm{g} / \mathrm{min}$. Lederman et al., (1978) found a significant negative correlation between the concentration of adrenaline in the maternal blood and the uterine activity. If the concentration of adrenaline is no higher than $1: 200,000(5 \mu \mathrm{g} / \mathrm{ml})$ and the volume of the anaesthetic solution is limited to between 4 and $6 \mathrm{ml}$, then the quantity of adrenaline is only one tenth the dose used by Rucker in 1925. It seems improbable that this dosage can affect the uterine activity to any significant extent (Bromage, 1978).

Craft et al., (1972), Zador and Nilsson (1974), Matadial and Cibils (1976) found a significant fall in uterine activity following epidural anaesthesia if adrenaline had been added to the local anaesthetic (at a concentration of $5 \mu \mathrm{g} / \mathrm{ml}$ ). In these studies this effect either did not occur at all or occurred to a much smaller extent if the same local anaesthetic was given without the adrenaline. Jouppila et al., (1977) found a significant difference in uterine activity (Montevideo Units) between a group of women receiving bupivacaine 0.5 per cent during the epidural anaesthesia and a group who were given 0.5 per cent bupivacaine with adrenaline added at a concentration of $5 \mu \mathrm{g} / \mathrm{ml}$.

Lowensohn et al., (1974) found no difference in the effect of epidural anaesthesia on falling uterine activity, irrespective of whether adrenaline had been added to the local anaesthetic or not.

Bonica et al., (1971), Matadial and Cibils (1976) and Moir (1976) observed that the frequency of hypotension occurrence increased if during epidural anaesthesia a local anaesthetic agent was used to which adrenaline had been added. Bonica's group in particular have ascribed this effect to the beta sympathicomimetic effect of adrenaline on the heart and circulatory system. The peripheral vasodilatation occurring as a result of this sympathicomimetic effect is said to exceed the stimulatory effect of adrenaline on the heart such that the net result is a reduction in blood pressure. Bromage (1978), however, has another explanation for the increase in frequency and seriousness of the blood pressure reduction when adrenaline is added to the local anaesthetic agent. According to Bromage, the quality of the epidural anaesthesia increases if adrenaline is 
added to local anaesthetic agent. It is not only the loss of sensitivity that would increase but also the sympathetic blockade would become more intense so in the area concerned, vasodilatation would also increase. Because of this, the chance of hypotension would also increase. Section 5.1.1 has already considered the relationship between hypotension and uterine activity.

In view of the above-mentioned data from the literature, the conclusion that adrenaline has an inhibitory effect on uterine activity would seem to be justified. Whether or not the influence of adrenaline in the local anaesthetic solution on the course of labour is clinically significant is still open to question.

\subsubsection{The lacal anaesthetic used and its dosage}

Lowensohn et al., (1974) compared lidocaine with propitocaine in epidural anaesthesia and found that there was a significant reduction in uterine activity only with lidocaine. This reduction did not occur with propitocaine. They found no relationship between the dose of the local anaesthetic and the effect on uterine activity.

Tyack et al., (1973) found no relationship between plasma levels of the local anaesthetic agent (bupivacaine) and the effect on uterine activity.

Vroman et al., (1977) found that after administration of epidural anaesthesia (bupivacaine 0.25 per cent) 7 of 24 nulliparous women had an uterine hypertonia. In these 24 women childbirth had been induced by amniotomy but no labour-stimulating agents had been used. Greiss et al., (1976) demonstrated in an experiment with sheep that local anaesthetics can greatly increase uterine activity in the sense of hypertonia and at the same time may reduce uteroplacental blood flow. This reduced blood flow should partly be the result of increased uterine activity and partly be due to a direct action of the local anaesthetic on the vessel wall, i.e. vasoconstriction. This effect remained unchanged after blocking alpha receptors with phenoxybenzamine. These results are in agreement with the in vitro studies done by Cibils (1976-b). This author found that uterine arteries obtained during early pregnancy and at full term would contract in a solution of lidocaine and mepivacaine. The concentrations varied between 50 and $800 \mu \mathrm{g} / \mathrm{ml}$. The effect of the local anaesthetics on the walls of the uterine arteries was dose-dependent. Alpha blockers had no effect on these contractions. Greiss et al., (1976) have also measured the threshold concentrations above which a reduction in uterine blood flow occurs in non-pregnant sheep. For bupivacaine this value was $1.0 \mu \mathrm{g} / \mathrm{ml}$. For lidocaine, procaine and mepivacaine the values were between 3 and $4 \mu \mathrm{g} / \mathrm{ml}$. McCaughey et al., (1962) found in in-vitro studies an 8 per cent increase in myometrial contractility if lidocaine was added at a concentration of $2 \mu \mathrm{g} / \mathrm{ml}$.

Thus, there are a number of studies which lead one to suspect that local anaesthetics have a stimulating effect on the myometrium. However, this has not been confirmed by clinical investigation in which the effect of epidural anaesthesia on uterine contractions is studied. There are a number of animal experiments and in vitro studies which validate the proposition that local anaesthetics can produce a vasoconstriction of the uterine arteries (see also section 5.2.1.3) and perhaps by this means exercise an effect on uterinc activity. 
5.1.4The moment during the process of childbirth when epidural anaesthesia is given Alexander and Franklin (1966) suggested that inhibition of a possibly present Ferguson reflex might represent an explanation for the reduced uterine activity which they found following adminmistration of an epidural anaesthesia. This Ferguson reflex would mainly occur in the acceleration phase of the first stage. Epidural anaesthesia early in childbirth would then have no effect on uterine activity whereas during the acceleration phase of the first stage it would. Sala et al., (1970) noted that the increase in uterine activity that occurred during artificial dilatation of the uterine cervix (Fisch et al., 1964) did not occur in women who had received epidural anaesthesia. Apart from that, they found no change in uterine activity following administration of epidural anaesthesia. Raabe and Belfrage (1976) found a significant inhibitory effect if the epidural anaesthesia was given early in the first stage. Henry et al., (1967) and Lowensohn et al., (1974) were not able in their studies to find any relation between the effect of epidural anaesthesia on uterine activity and the point in the first stage when it was given.

Abouleish (1977) was of the opinion that blockade of the sympathetic nerves that innervate the uterus and which arise from the fifth thoracic up to and including the second lumbar segment could produce a reduction of uterine activity. According to him, this would only be the case in the early first stage. In the acceleration phase of the first stage this innervation would either be of no importance or very much less importance as far as uterine activity is concerned.

Zador and Nilsson (1974) noticed that the first injection of local anaesthetic into the epidural space produced a greater reduction in uterine activity than successive injections during the course of labour. The development of an 'uterine tachyphylaxis' for lidocaine could be a possible explanation. Another hypothesis has already been mentioned above (Abouleish, 1977).

It is not clear from the literature data whether the point in time during the childbirth process when the epidural anaesthesia is carried out has an accessory effect on uterine activity.

\subsubsection{The level of the epidural anaesthesia}

On theoretical grounds one could argue that the chance and severity of blood pressure reduction increases if the epidural anaesthesia reaches a high anatomic level. Naturally, with high epidural anaesthesia, many spinal segments are blocked and this means that to a great extent the sympathetic nervous system is switched out. As a result there would be vasodilatation in a relatively large part of the body, as a consequence of which there would be increased chance of hypotension. The relationship between hypotension and uterine activity has already been discussed in section 5.1.1. Bonica et al., (1970) demonstrated in tests on non-pregnant volunteers that the degree of cardiovascular changes was dependent on the number of spinal segments blocked. Abouleish (1977) was of the opinion that blockade of the sympathetic nerves which innervate the uterus can have a direct inhibitory effect on uterine activity, particularly in the beginning of the first stage (see section 5.1.4). Vasicka and Kretchmer (1961) and Vasicka et al., (1964), however, could demonstrate no inhibitory effect of epidural anaesthesia on uterine 


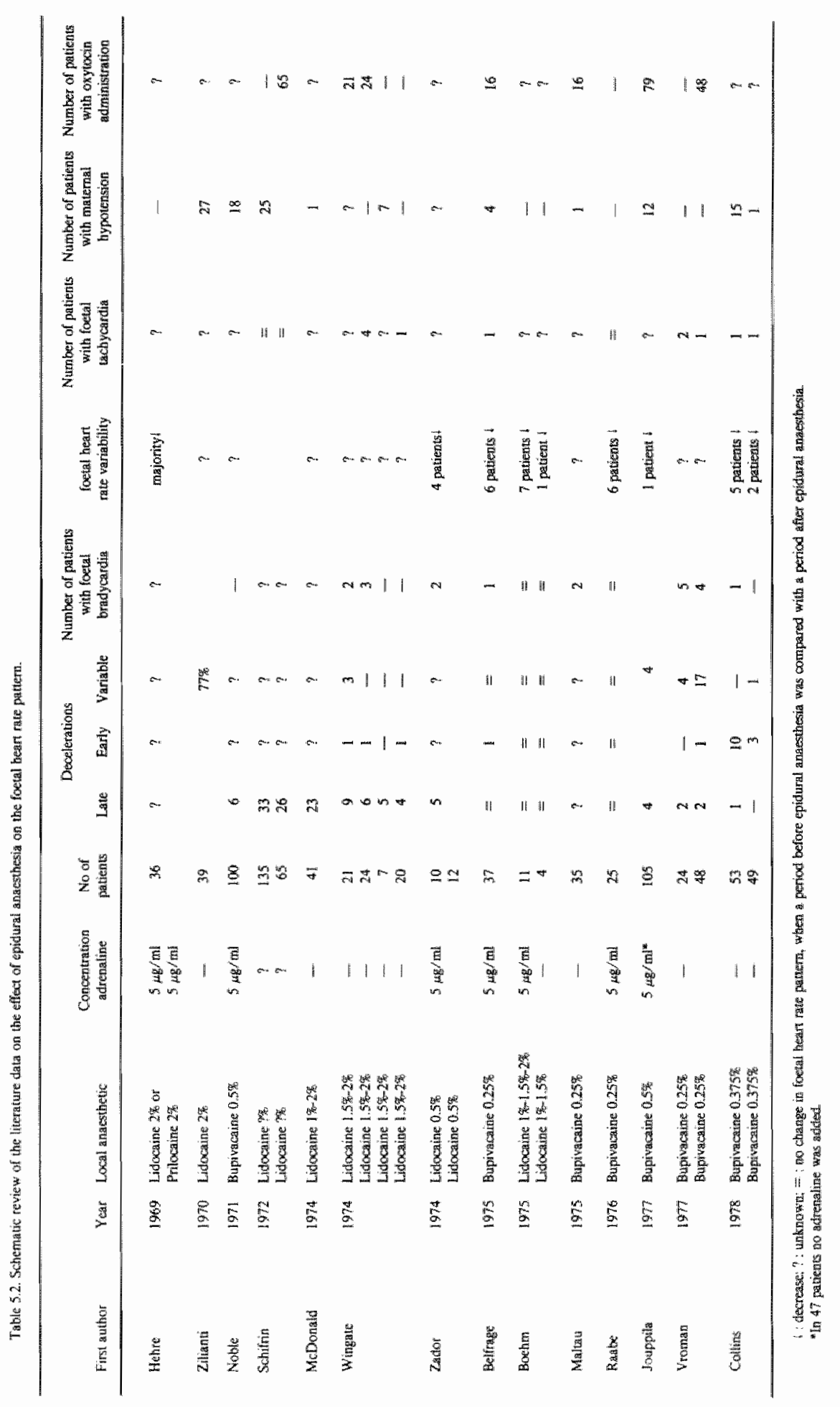


activity in anaesthesia carried out up to the level of the sizth thoracic segment provided that blood pressure remained within normal limits.

\subsubsection{Other factors}

Apart from the above-mentioned reasons, there are a number of other factors which make it difficult to get a good insight into the relationship between epidural anaesthesia and uterine activity.

\section{a. The woman's position:}

Not all authors have standardised the patient's position in their studies of the effect of epidural anaesthesia on uterine activity. However, it is known that uterine activity is dependent on the position of the women (Caldeyro-Barcia et al., 1960; Mendez-Bauer et al., 1976) so standardisation is necessary for proper interpretation of the results. Also, the supine position in patients with epidural anaesthesia often causes hypotension (section 5.1.1) and a possible reduction of uterine activity as a result. Crawford (1972-) and Schellenberg (1977) emphasised that epidural anaesthesia had no effect on uterine activity if the patient was prevented from lying on her back.

\section{b. The natural trend in uterine activity:}

Normally, uterine activity probably increases during the course of childbirth (Miller et al., 1976; Steer et al., 1984). Therefore in a study it is not sufficient to make measurements only before and after administration of the epidural anaesthesia.

\section{c. The use of other drugs that may influence uterine activity:}

In some studies the patients received analgesics andolor sedatives prior to transition to epidural anaesthesia. In other studies the patients who were serving as controls were given sedatives andor analgesics or nitrous oxide. This represents the introduction of one or more variables that could have a potential effect on uterine activity and in turn complicates interpretation of the results.

\section{d. Lumbar or caudal epidural anaesthesia:}

Both are forms of epidural anaesthesia. In lumbar epidural anaesthesia the local anaesthetic is injected via one of the lumber intervertebral spaces. In caudal epidural anaesthesia, the sacral hiatus is used to gain access to the epidural space. If one wants to take away the pain of the childbirth during the first stage, then the tenth, eleventh and twelfth thoracic spinal segments must be blocked by the local anaesthetic agent. In view of the anatomy of the epidural space, much more local anaesthetic has to be used in caudal epidural anaesthesia in order to achieve the objective than is the case with lumbar epidural anaestesia. Thus, usually the dose administered in caudal epidural anaesthesia is larger than that used in lumbar epidural anaesthesia.

\subsection{The effect of epidural anaesthesia on the foetal heart rate pattern}

There are various researchers who have observed changes in the foetal heart rate pattern following administration of an epidural anaesthesia during childbirth. However, there 
are also authors who found no changes in the foetal theart rate pattern after epidural anaesthesia.

This chapter will attempt to provide an overview of the literature data. Also, a description will be given of the routes by which epidural anaesthesia could exercise an effect on foetal heart rate.

In assessing the data from the literature concerning the effect of epidural anaesthesia on the foetal heart rate pattern, the following parameters were in the main considered:

1. Foetall heart rate

2. Variability in the foetal heart rate pattern (short term and/or long term variability)

3. Periodic changes such as accelerations and decelerations.

Table 5.2 presents the most important findings of the different authors, schematically summarised.

Wingate et $\mathrm{al}_{\text {., }}$ (1974) found that the frequency of pathological heart rate patterns increased following epidural anaesthesia. They compared 72 women who received epidural anaesthesia during labour (lidocaine 1.5 or 2 per cent) with 100 women who received either no analgesia or a different form of analgesia. In the epidural group, decelerations were found in 40 per cent of the patients. In instances where the epidural anaesthesia was accompanied by hypotension, more than 70 per cent of the patients demonstrated decelerations in the foetal heart rate pattern. Nothing was said about the basal foetal heart rate nor about the variability of the foetal heart rate pattern. In the control group 9 per cent of the patients developed a decelerative heart rate pattern. In this study the foetal heart rate pattern was recorded using an ultrasound transducer. The two groups were not good comparable since the obstetric pathology was not equally divided between the two of them. Thirty of the patients in the epidural group had already received another form of analgesia before the decision was made to employ epidural anaesthesia.

Schifrin (1972) studied the foetal heart rate pattern in 135 pregnant women who underwent epidural anaesthesia but who did not receive any oxytocin. In 24 per cent of the patients late decelerations were present in the foetal heart rate pattern. Another group of patients from this investigation ( 65 patients) received epidural anaesthesia and also labour stimulation with oxytocin. In 40 per cent of these patients late decelerations occurred. In the control group of 119 women, the author found late decelerations in 17 per cent. About 20 minutes after administration of the epidural anaesthesia, the variability in the foetal heart rate pattern fell. The concept of 'variability" was not further defined. There were no changes in the basal foetal heart rate. This author is of the opinion that correction of hypotension by intravenous filling of the circulatory system and putting the patient on her side would cause the pathological characteristics of the foetal heart rate pattern to disappear in a great number of the patients. The foetal heart rate pattern was obtained via a scalp electrode. No distinction in this study was made between lumbar and caudal epidural anaesthesia and lidocaine was used as the local anaesthetic agent. The concentration and dosage was not standardised. In an unknown number of patients adrenaline was added to the local anaesthetic. 
Zilianti et all, (1970) found abnormal foetal heart rate patterns in 77 per cent of patients during epidural anaesthesia (bradycardia or decelerations). The concept of bradycardia was defined as a reduction of the basal foetal heart rate to below 100 beats per minute. A deceleration was defined as a reduction in the foetal heart rate to below 100 beats per minute occurring during a contraction. Fifteen per cent of the patients had already exhibited a pathological heart rate pattern prior to the administration of the epidural anaesthesia. Ninety per cent of the patients exhibited a reduction in blood pressure following the epidural anaesthesia (the definition of hypotension that the authors applied is given in table 5.3). In an unknown number of patients, the foetall heart rate was determined by auscultation. For the rest of the patients, the foetal heart rate was determined from the foetal ECG (scalp electrode). In this study lidocaine 2 per cent was used. The dosage which was used during the whole of labour varied between 120 and $360 \mathrm{mg}$.

McDonald et al., (1974) compared a thirty minute period prior to epidural anaesthesia in a group of 41 patients with a period of thirty minutes after epidural anaesthesia. They calculated the number of late decelerations as a percentage of the contractions (for example, 5 late decelerations in 10 contractions is 50 per cent). They found that in 23 of the 41 women there was an increase in the percentage of late decelerations - these were women who had received oxytocin. However, no alterations in the foetal acid-base balance occurred. The blood gas analyses were done on blood taken from the foetal scalp. The lidocaine dosage varied between 60 and $200 \mathrm{mg}$. In this study there was no correlation between the extent of occurrence of late decelerations and the lidocaine dosage.

Jouppila et al., (1977) found late decelerations in 4 per cent of the patients in the first 30 minutes following the epidural anaesthesia. Also, 4 per cent of the foetal heart rate patterns were characterised by variable decelartions and/or bradycardia. In 1 per cent there was a clear reduction in the variability. This variability was visually assessed. The foetal heart rate pattern was determined using a scalp electrode. In this study bupivacaine 0.5 per cent was used and the dosage varied between 10 and $25 \mathrm{mg}$. The considerably low number of pathological heart rate patterns (in comparison with the studies mentioned earlier) was ascribed by the authors to the low dosage of local anaesthetic and preventing the women from lying on their backs. Huovinen et al., (1976) demonstrated that the percentage of pathological heart rate patterns observed following administration of epidural anaesthesia fell from 56 per cent to 10 per cent if the patients were prevented from lying on their backs.

Belfrage et $\mathrm{I}_{\mathrm{l}}$, (1975-a) investigated foetal heart rate patterns in 37 patients to whom epidural anaesthesia was administered. A period of between 15 and 30 minutes prior to administration of epidural anaesthesia was compared with a 100 minute period after carrying out the epidural anaesthesia. Bupivacaine 0.25 per cent was used and adrenaline had been added to it at a concentration of 1:200,000. In six patients a reduction of base line irregularity was observed in the foetal heart rate pattern during ten to twenty minutes. The variability was classified using Hammacher's criteria (1969). This reduction occurred as soon as within the first half hour following administration of the epidural anaesthesia. The maternal blood pressure always remained normal. The 
reduction in the variability of the foetal heart rate pattern was not followed by changes in the foetal acid-base balance. Neither was the loss of variability associated with high foetal blood levels of bupivacaine during the first stage, the blood samples were taken at set time intervals from the foetal scalp. Apart from this, Belfrage et al., (1975-a) found no increase in the number of decelerations or bradycardial episodes following administration of epidural anaesthesia. Hehre et al., (1969) concluded from their investigation that the beat-to-beat variability was reduced following epidural anaesthesia. This effect occurred a few minutes after administration of the epidural anaesthesia and was only maintained for a few minutes. The researchers were of the opinion that this was the result of a direct inhibiting effect of the local anaesthetic on the foetal myocardium. The foetal ECG was obtained by means of an electrode on the foetal scalp. The interval between two successive heart beats was continuously determined.

Boehm et al., (1975) also found a reduction in the foetal heart rate variability immediately after administration of the epidural anaesthesia. This phenomenon was observed in eight out of fifteen patients and lasted only ten minutes. It occurred inside five minutes following administration of the epidural anaesthesia. The foetal heart rate pattern was obtained using a scalp electrode. The heart rate variability was visually assessed according to the criteria elaborated by Boehm and Growdon (1974). In this study they used lidocaine and the dosage varied between 90 and $200 \mathrm{mg}$. No correlation could be established between the lidocaine dosage and the reduction in heart rate variability. No pathological changes could be found in the foetal heart rate pattern in 25 patients by Raabe and Belfrage (1976) following administration of epidural anaesthesia using 25 $\mathrm{mg}$ bupivacaine 0.25 per cent to which adrenaline had been added at a concentration of $1: 200,000$. A period of thirty minutes prior to epidural anaesthesia was compared with a period of forty minutes after epidural anaesthesia. They did find a temporary reduction in the beat-to-beat variability in six patients. This study does not say how the variability in the foetal heart rate pattern was assessed or quantified. Maltau (1975) concluded that epidural anaesthesia with bupivacaine 0.25 per cent caused no increase in the number of foetal bradycardial episodes during the first stage. The author employs the criteria of O'Gureck et al., (1972) to define the concept of bradycardia. These authors define bradycardia as a foetal heart rate of less than 90 beats per minute maintained for two complete contraction cycles or for a period of more than five minutes. In two patients bradycardia occurred. Once during a period when the mother became hypotensive (in the supine position!) and once as a result of 'over stimulation' with oxytocin. Noble et a1., (1971) found no difference with respect to foetall heart rate pattern between a patient group (of 100 members) who received epidural anaesthesia and a patient group of 102 members who were given other forms of analgesia. In this study bupivacaine 0.25 per cent was used and adrenaline had been added to it at a concentration of 1:200,000. The maximum dose in the investigation amounted to $31 \mathrm{mg}$.

Matadial and Cibils (1976) were unable to find any change in the foetal heart rate pattern following administration of epidural anaesthesia provided that maternal hypotension was avoided. In this study lidocaine was used at a maximal dose of $160 \mathrm{mg}$. In 26 out of 38 patients adrenaline was added at a concentration of 1:200,000 to the local anaesthetic agent. 
In 24 nulliparae receiving epidural anaesthesia with 0.25 per cent bupivacaine, Vroman et al., (1977) encountered bradycardia five times. On three occasions the bradycardia was associated with uterine hypertonus. No labour-stimulating drugs had been administered. In two patients late decelerations occurred, once in connection with tachycardia and once simultaneously with bradycardia. In 19 multiparae no abnormal foetal heart rate patterns were observed, apart from one instance of foetal arrythmia for a short period. The foetal heart rate patterns were assessed on the basis of Hon's criteria (1968). The concept of bradycardia was defined as follows: A reduction in foetal heart rate between two contractions to less than 100 beats per minute with this situation pertaining for at least 10 minutes. In 48 nulliparae who received both epidural anaesthesia and oxytocin, Vroman et al., (1977) found bradycardia four times. In all four cases, the bradycardia was associated with uterine hypertonus. In two patients late decelerations were found. In 35 patients who came under epidural anaesthesia and who received labour induction with oxytocin, bradycardia in combination with hypertonus occurred only in one patient. In this patient there were no late decelerations. The abovementioned findings of Vroman et al., 1977 were obtained during the first stage of labour. Zador and Nilsson (1974) investigated the effect of epidural anaesthesia on the foetal heart rate pattern in 22 patients without obstetric problems. Lidocaine 0.5 per cent was used as the local anaesthetic. For 12 of the women adrenaline was added at a concentration of 1:200,000. Bradycardia occurred in two patients (foetal heart rate less than 100 beats per minute for more than two minutes). In five patients late decelerations developed for a short period. In four patients the 'irregularity' of the heart rate pattern decreased. It is not stated how this 'irregularity' was assessed or quantified.

Collins et al, (1978) investigated the foetal heart rate pattern in 102 women who received epidural anaesthesia during labour. Forty nine of the women received a one litre intravenous infusion of Hartmann's solution prior to the epidural anaesthesia. The other patients received no preloading. In those women who received the preloading, an abnormal foetal heart rate pattern occurred five times (three times early decelerations, once variable decelerations and twice loss of beat-to-beat variability). However, in the women who received no infusion, there were eighteen occurrences of abnormal foetal heart rate pattern (early decelerations 10 times, late decelerations once, loss of beat to beat variability five times, bradycardia once and tachycardia once). In eight patients the abnormal foetal heart rate pattern was accompanied by a fall in the maternal blood pressure. The foetal heart rate pattern was assessed according to the criteria of Beard et al., (1971). It is not clear whether the foetal heart rate pattern was obtained using a scalp electrode or with an external transducer.

Lavin et al., (1981) found a significant increase in foetal heart rate variability (beat-tobeat variability) after epidural block, using $12 \mathrm{ml}$ bupivacaine $0.25 \%$ without adrenaline. No significant changes were noted in baseline foetal heart rate. The authors are of the opinion that bupivacaine may have caused minimal stress because of either a direct myocardial effect or a diminished utero-placental blood flow. No maternal hypotension occured in this investigation.

On theoretical grounds, epidural anaesthesia would be able to influence the foetal heart rate pattern in the following ways at least: 
1. By a reduction in uteroplacental perfusion.

2. By a direct action of the local anaesthetic agent on the foetal myocardium and foetal nervous system.

These factors will be further discussed in sections 5.2.1 and 5.2.2.

\subsubsection{The effect of epidural anaesthesia on the uteroplacental blood flow}

From a theoretical point of view and taking into account data from the literature, there are four potentialities for alteration of uteroplacental perfusion due to epidural anaesthesia.

1. The development of a fall in maternal blood pressure during the epidural anaesthesia.

2. The development of overly strong uterine activity during epidural anaesthesia (uterine hypertonus).

3. A possible vasocinstrictor action of the local anaesthetic on the uterine vascular bed.

4. A possible action of adrenaline on the uterine vascular bed.

\subsection{I.I The development of maternal hypotension during epidural anaesthesia}

Epidural anaesthesia may lead to a fall in the maternal blood pressure (see sections s.1.1 and 6.1). A fall in the maternal blood pressure can cause changes in the foetal heart rate pattern. Hon et al., (1960) analysed the foetal heart rate patterns in some women who underwent periods of hypotension caused by conduction anaesthesia (including epidural anaesthesia). A few minutes after maternal hypotension occurred, foetal bradycardia could be observed in the foetal heart rate pattern. This bradycardia rectified itself a few minutes after the maternal blood pressure returned to normal again. If epidural anaesthesia is accompanied by a reduction of blood pressure in the mother then in about 70 per cent of the cases a pathological heart rate pattern will develop (Zilianti et al., 1970; Schifrin, 1972; Wingate et al., 1974). If the development of maternal hypotension is as far as possible prevented by intravenous filling and having the patient in the lateral position then practically no pathological heart rate patterns occur (Belfrage et al., 1975-a; Maltau, 1975; Matadial and Cibils, 1976; Raabe and Belfrage, 1976; Jouppila et al., 1977).

Among the various authors there is considerable variation in the definition of the concept of hypotension. This is one of the reasons why the frequency of hypotension is so variably quoted in the literature. Furthermore, application of prophylactic measures such as intravenous filling and positioning the patient on her side will have an effect on the frequency with which hypotension occurs. It is not always clear from the publications whether the patients were allowed to lie on their backs nor for how long and how often blood pressure was measured after each dose of the local anaesthetic. In most investigations this was done every five minutes for half an hour. Table 5.3 presents the most important findings from the literature in schematic form.

Wingate et al., (1974) noticed that the percentage of abnormall foetal heart rate patterns fell from 71 per cent to 40 per cent if maternal hypotension was avoided. In Maltau's vestigation (1975) two patients got a bradycardia. In the case of one of the wo- 


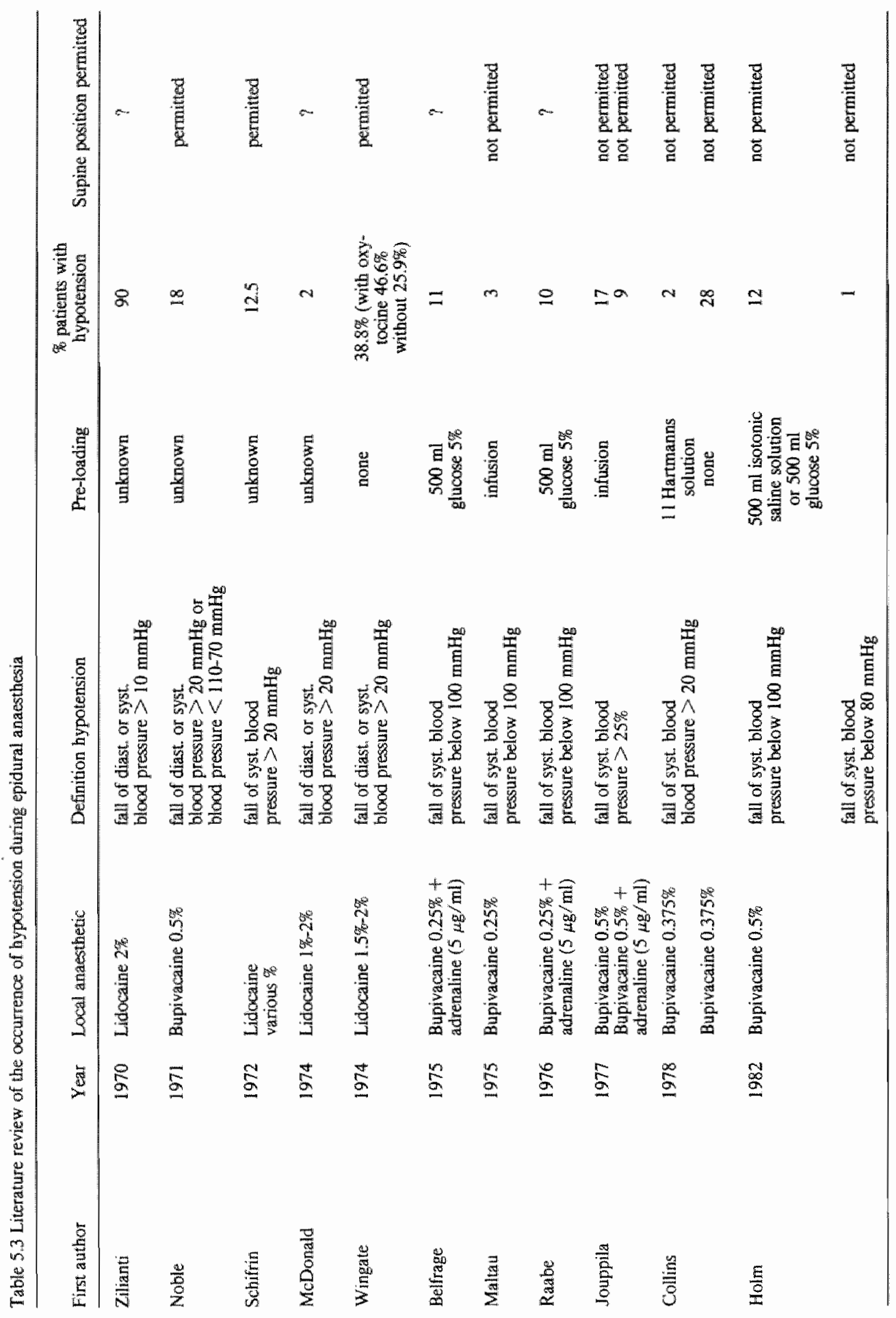


men this was due to hyperstimulation with oxytocin and in the other, maternal hypotension was the cause. In the investigation by Zador and Nilsson (1974), late decelerations occurred in five patients. In four of the five patients, the cause was a fall in the maternal blood pressure. Collins et al., (1978) recorded the foetal heart rate pattern and the maternal blood pressure in 102 women who underwent epidural anaesthesia. Fifty one of the patients were administered one litre of Hartmann's solution intravenously just prior to the epidrual anaesthesia. The other women got no preload infusion. Due to this intravenous infusion the percentage of abnormal foetal heart rate patterns fell from 34 to 12 per cent whilst the frequency of maternal hypotension fell from 28 per cent to 2 per cent. Brotanek et al., (1973) used a semiquantitative method to measure uterine perfusion, the so-called 'heated thermistor' technique. Following epidural anaesthesia with 1.5 per cent mepivacaine, 4 to $5 \mathrm{ml}$, no changes were found in uterine blood flow. At a dose of $7 \mathrm{ml} \mathrm{mepivacaine} 1.5$ per cent, a temporary reduction in uterine blood flow occurred but in all cases this happened simultaneously with a fall in maternal blood pressure. This supported the hypothesis that the reduced perfusion of the uterus could be caused by a fall in maternal blood pressure.

\subsubsection{The development of overly strong uterine activity during epidural anaesthesia.}

A reduction in the uteroplacental blood flow may equally develop as a result of too strong uterine activity. Vroman et al., (1977) found during the epidural anaesthesia using 0.25 per cent bupivacaine of 24 nulliparae who had not been induced with oxytocin, that there were seven occurrences ( 29 per cent) of uterine hypertonus. Foetal bradycardia developed in three of these seven patients. In 48 nulliparae whose labour was induced with oxytocin and who were also given epidural anaesthesia, there were 10 occurrences ( 21 per cent) of uterine hypertonus. Bradycardia arose in four out of these ten patients. The conclusion of the authors was that epidural anaesthesia employing bupivacaine may lead to uterine hypertonus. It emerged from the research results of McDonald et al., (1974) and of Schifrin (1972) that the combination of oxytocin administration with epidural anaesthesia led to a greater incidence of decelerations and bradycardia in comparison to epidural anaesthesia without oxytocin. It is possible that patients to whom epidural anaesthesia has been given are more sensitive to oxytocin. McCaughey et al., (1962) in in-vitro studies on human myometrial tissue found that there was an increase of eight per cent in contractility if lidocaine was added to the tissue bath at a concentration of $2 \mu \mathrm{g} / \mathrm{ml}$. Greiss et al., (1976) demonstrated in an experiment on sheep that the uterine activity increased when lidocaine, procaine, mepivacaine or bupivacaine was administered intra-arterially. Episodes of marked increase in uterine contractility have also been observed following inadvertent injections of local anaesthetics intravascularly during epidural block (Miller et al., 1978),

It appears from the in vitro experiments and from the animal experiments that local anaesthestics can stimulate contractions of the myometrium. However, during epidural anaesthesia, hemodynamic, humoral and neurogenic changes occur and each of these can exercise an effect on uterine activity. Thus, the direct effect of local anaesthetic agents on the myometrium cannot separately be quantified in clinical studies using epidural anaesthesia. 


\subsubsection{Possible vasoconstrictor action of the local anaesthetic agent on the uterine vascular bed}

It appears from the in vitro studies done by Cibils (1976-b) that local anaesthetic agents have a vasoconstrictor effect on human uterine arteries (section 5.1.1.2). In their in vitro studies, Gibbs and Noel (1977) came to the same conclusion. Greiss et al., (1976) demonstrated in a sheep experiment that different types of local anaesthetic agents which were administered intravascularly could cause a reduction in blood flow of the placental and non-placental vascular bed of the gravid sheep uterus. This effect was partly caused by increasing intra uterine pressure (section 5.2.1.2) but was partly dependent on active vasoconstriction of not only the placental but also of the nonplacental circulation of the uterus. This vasoconstriction was a direct result of the local anaesthetic and the effect was not affected by blocking of the alpha adrenergic system. The threshold concentrations above which reduction of uterine perfusion occurred in these experiments was $1.0 \mu \mathrm{g} / \mathrm{ml}$ for bupivacaine and between 3 and $4 \mu \mathrm{g} / \mathrm{ml}$ for lidocaine, mepivacaine and procaine. The concentrations necessary for a 25 per cent reduction in uterine perfusion were also calculated. This was respectively $2.5,12,15$ and $40 \mu \mathrm{g} / \mathrm{ml}$ for bupivacaine, mepivacaine, procaine and lidocaine.

Husemeyer and Crawely (1979) determined the interwillous blood flow before and after epidural anaesthesia by means of a $133 \mathrm{Xe}$ inhalation technique. In this investigation, the dose of bupivacaine amounted to $37.5 \mathrm{mg}$. No statistically significant reduction in intervillous blood flow was observed following administration of the epidural anaesthesia despite the fact that there was a significant reduction in the mean arterial pressure. There was no significant correlation between the reduction of the mean arterial pressure and the extent of the changes in the intervillous blood flow. Rekonen et al., (1976) described a method by means of which the intervillous blood flow and the myometrial blood flow could be measured. This method is based on the clearance of intravenously administered 133Xe. Using this method Jouppila et al., (1978-a) studied the intervillous blood flow in women who underwent a Caesarean section under epidural anaesthesia. Sixteen to twenty ml of lidocaine to which adrenaline had been added at a concentration of $5 \mu \mathrm{g} / \mathrm{ml}$ was used. A reduction in intervillous blood flow was observed in seven of the nine patients. The mean value of 13 per cent for the reduction as compared to the control value turned out not to be significant. The reduction in intervillous blood flow was the clearest in two patients whose blood pressure fell. In another study, Jouppila et al., (1978b) studied the effect of epidural anaesthesia on intervillous blood flow in normal childbirth. A small dose $(20 \mathrm{mg})$ of 0.5 per cent bupivacaine solution was used. In a number of patients $20 \mu \mathrm{g}$ adrenaline was added. No significant changes in the intervillous lous blood flow were observed in the first twenty minutes following the administration of the epidural anaesthesia.

Hollmén et al., (1982) also used the 133Xe clearance technique to study intervillous blood flow. An increase in intervillous blood flow was observed in twenty healthy women, ten of whom received epidural anaesthesia with $10 \mathrm{ml}$ bupivacaine 0.25 per cent and ten of whom received epidural anaesthesia with $10 \mathrm{ml}$ chloroprocaine 2 per cent. The increased placental blood flow was ascribed to a reduction in vascular 
resistance in the uteroplacental vascular bed as a result of sympathetic blockade. Blood pressure, uterine activity and the basal tone of the uterus did not change during the investigation period. Jouppila et al., (1979) used the 133Xe clearance technique to measure the placental blood flow before and after epidural anaesthesia in women who had hypertension. Eleven patients had pre-eclampsia and six had essential hypertension. Bupivacaine 0.5 per cent was used at a dose of $20 \mathrm{mg}$. Following epidural anaesthesia a slight but non-significant increase in placental blood flow was observed. In two patients in whom a slight uteroplacental blood flow was observed, the foetal heart rate pattern was characterised by a reduction in the base-line variability.

Jouppila et al., (1982) have repeated the above-mentioned investigation on nine patients with serious pre-eclampsia. Bupivacaine 0.25 per cent at a dose of $10 \mathrm{ml}$ was used. After the epidural anaesthesia the placental blood flow increased significantly. In their study of 1979 no significant increase in placental blood flow was found in pre-eclamptic patients by the authors whereas their publication of 1982 shows that they did. However, in the latter study a greater volume of the local anaesthetic agent was used so that the sympathetic blockade was more extensive. The researchers are of the opinion that this explains the difference in results between the two studies. Brotanek et al., (1973) used a semiquantitative method, the so-called heated thermistor technique, to measure uterine blood flow. The authors found no changes in uterine blood flow provided that the maternal blood pressure remained normal..

It appears that the last seven studies do not support the in vitro studies by Cibils (1976-b), Gibbs and Noel (1975) nor the animal experiment by Greiss et al., (1976). It seems valid to suppose that local anaesthetic agents can cause vasoconstriction in the vascular system of the uterus. Possibly, this effect only occurs at blood concentrations that are not normally achieved during epidural anaesthesia. Furthermore, the effect of anaesthesiological denervation of the uterus at the epidural level is very complicated and dependent on neurogenic, humoral and hemodynamic factors whereas the intravascular administration of local anaesthetics only enlightens one facet of epidural anaesthesia.

\subsubsection{Possible effect of adrenaline on the uterine vascular bed}

Since it was not clear from the above-mentioned studies whether the changes occurring in the uteroplacental blood flow after epidural anaesthesia were to be attributed to the local anaesthetic agent or to the added adrenaline, the effect of adrenaline on uteroplacental perfusion has also been investigated. In sheep experiments, Greiss (1963) demonstrated that intravenous infusion of adrenaline in doses of $0.1,0.25,0.50$ and $1.00 \mu \mathrm{gg} / \mathrm{kg}$ per minute produced a reduction in uterine blood flow that was more or less dosedependent. The reduced blood flow was due to vasoconstriction in the uterine vascular bed and not to a change in intra-uterine pressure. The results of Rosenfeld et al. (1976) correlated with those of Greiss (1963) and they concluded that adrenaline administered intravenously at doses of between 0.2 and $4 \mu \mathrm{g} / \mathrm{kg}$ per minute caused a significant reduction in uterine blood flow in pregnant sheep whereas blood pressure remained normal. At lower doses, uterine blood flow changed either not at all or only slightly. Wallis et al., (1976) studied the effect of epidural anaesthesia on uterine blood flow, foetal cardiovascular condition and foetal acid-base balance in pregnant sheep. Chlo- 
roprococaine 1.5 percent was used in that investigation. Between 60 and $80 \mu \mathrm{g}$ adrenaline was added for some of the experimental animals. The total blood flow through the uterus remained unchanged with chloroprocaine 1.5 per cent but where 60 to $80 \mu \mathrm{g}$ adrenaline had been added, the uterine blood flow fell by approximately 14 per cent. This effect was maintained for about 15 minutes. Foetal blood pressure remained stable but the foetal heart rate had tendency to rise if adrenaline had been added to the local anaesthetic agent. However, if the adrenaline had been left out there was a slight reduction in foetal blood pressure and foetal heart rate. The foetal acid-base balance did not change after epidural anaesthesia, not even when adrenaline had been added to the local anaesthetic agent.

Electrical stimulation of the sympathetic nerve fibres which innervate the sheep uterus causes an increase in vascular resistance of about 65 per cent whereas anxiety and tension causes a reduction of uterine blood flow between 25 and 33 per cent (Greiss et al., 1967). It can be concluded on the basis of the study by Jouppilla et al., (1978-b) that epidural anaesthesia, even when adrenaline has been added to the local anaesthetic, has no effect on blood flow in the intervillous space. Albright et al., (1981) studied intervillous blood flow in 12 healthy pregnant women prior to and after epidural anaesthesia. The intervillous blood flow was measured using the $133 \mathrm{Xe}$ clearance technique. This technique has been described in detail by Rekonen et al, (1976). Chloroprocaine 1.5 per cent was used in this investigation. $10 \mathrm{ml}$ of the local anaesthetic agent was administered to which $50 \mu \mathrm{g}$ adrenaline had been added. Despite a significant fall in blood pressure, the intervillous blood flow remained constant.

In assessing the effect of epidural anaesthesia on uterine blood flow, two mechanisms play a role: the concentration of catecholamines achieved in the circulation as a result of the addition of adrenaline to the local anaesthetic agent and secondly, the effect of pain anxiety and tension on the part of the woman on the spontaneously present catecholamines in the circulation. It is probable that the adrenaline concentrations (attributed to added adrenaline in the anaesthetic) during epidural anaesthesia do not achieve the critical level necessary to cause reduced uteroplacental blood flow. Furthermore, it cannot be excluded that in some cases anxiety, pain and tension during labour can produce catecholamine levels which reach such a magnitude that they reduce the intervillous blood flow. These factors, anxiety, pain and tension are not present during epidural anaesthesid, or are present in much reduced form, so the endogenous production will be much lower than in women who have not received any analgesia (Lederman et all., 1977; Shnider et al, 1983).

From the above mentioned data it seems that stimulation of the sympathetic system - by whatever means - causes a reduction in uteroplacental blood flow. It is possible that sympathetic denervation of the uterus by epidural anaesthesia partly protects the uterine blood flow against vasoconstriction (Bromage, 1978). Switching off part of the sympathetic nervous system, which leads to the above-mentioned favourable effect, however, also has repercussions on the cardiovascular system of the mother in the sense that a predisposition arises for the development of hypotension with its concommitant reduced uteroplacental perfusion. Furthermore, sympathetic denervation of the uterus by epidural anaesthesia can have no protective effect with respect to a potential wasocon- 
striction due to the local anaesthetic agent. On the basis of literature data it may be concluded that this direct pharmacological effect of the local anaesthetic probably does not arise via the sympathetic system. The net effect depends on the balance between the favourable and unfavourable effects of the epidural anaesthesia on uterine blood flow.

\subsubsection{The cardiodepressive effect of the local anaesthetic agent on the foetal heart}

Much research into the effect of local anaesthetic agents on the cardiovascular system has been done in adults. In particular there is a lot of information about lidocaine because this agent has clinical applications in the treatment of cardiac ventricular arrhythmias.

Covino and Vassallo (1976) have summarised the effects of local anaesthetics on the circulatory system as follows below.

The first change which arises as a result of local anaesthetics is an increase in peripheral vascular resistance due to a direct effect of the local anaesthetic agent on smooth muscle tissue in the vessel walls. In addition, cardiac output increases as a result of an indirect effect of the local anaesthetic agent mediated by the central nervous system. With higher doses of local anaesthetic, hypotension develops due to generalised vasodilatation and a decreased myocardial contractility. Sinus bradycardia and asystole can occur at lethal doses of the anaesthetic. These effects may arise due to a direct influence of the anaesthetic on the myocardium but probably are further potentiated by the effect of the local anaesthetic on the vasomotor centre in the medulla oblongata.

Page et al., (1961) and Nyirjesy et al., (1963) felt that local anaesthetic agents have a negative chronotropic and negative inotropic effect on the foetal myocardium. It emerges from in vitro research by Andersson et al., (1970) that mepivacaine prolongs atrioventricular and intraventricular conduction time in the isolated human foetal heart. Only a moderate reduction ( 12 per cent) of the spontaneous contraction rate was seen even at the highest concentration used $(20 \mu \mathrm{g} / \mathrm{ml})$.

Holm (1982) found a reduction in basal foetal heart rate following administration of epidural anaesthesia with bupivacaine 0.5 per cent to which no adrenaline had been added. Hehre et al, (1969) discovered that there was a short lived reduction in the variability of the foetal heart rate pattern after epidural anaesthesia. According to the author this is a consequence of a direct effect of the local anaesthetic agent on the foetal myocardium. The authors have proposed that at higher blood levels of the anaesthetic agent, the foetal myocardial contractility falls and leads to hypotension. As a result of this, perfusion in the foetal side of the placenta decreases and this produces foetal hypoxia and acidosis. Similarly, McDonald et al., (1974) and Wingate et al., (1974) suggested the possibility of a cardiodepressive effect of the local anaesthetic on the foetal myocardium as an explanation of the increased number of decelerations after epidural anaesthesia. However, Zilianti et al., (1970) observed pathological foetal heart rate patterns prior to the attainment of peak levels of the local anaesthetic agent in the blood. The authors considered it to be improbable that the pathological foetal heart rate patterns had been caused by a direct effect of the local anaesthetic on the foetal myocardium.

This conclusion was subscribed to by Belfrage et al., (1975-a) and by Maltau (1975). In 
a number of patients Belfrage et al., (1975-a) saw a short lived reduction in the variability of the foetal heart rate pattern and this did not correlate with the plasma levels of the local anaesthetic agent (bupivacaine). Boehm et al., (1975) observed a reduction in the foetal heart rate variability immediately after administration of the epidural anaesthesia. In this study no correlation could be found between the lidocaine dosage and the reduction in heart rate variability.

In view of the literature data, it would seem justified to suppose that local anaesthetic agents when administered in non-toxic doses in adults produce an increase in blood pressure as a result of an increase not only of peripheral vascular resistance but also of cardiac output. At toxic doses hypotension and bradycardia arise. It seems very likely that local anaesthetics have the same effect on the foetal cardiovascular system. The concentration of the local anaesthetic agent at which negative effects are produced in the foetal cardiovascular system is not known. However, the effect on the foetal heart rate pattern does not always have to be mediated by a direct pharmacological effect on the cardiovascular system, it can also be caused by the effect of the local anaesthetic agent on the uteroplacental blood flow or on the foetal central nervous system.

\subsection{The effect of epidural anaesthesia on the maternal and foetal acid-base balance}

In the last 15 years there has been a great deal of research into the physical and biochemical changes that occur in the mother and child during childbirth. The effects of various forms of anaesthesia, including epidural anaesthesia, have been studied. In certain areas the litterature data are controversial. Few studies have been precisely standardised and the patients who served as controls often received a wide range of analgesic agents. Furthermore, there are a number of variables that have nothing to do with epidural anaesthesia that may affect the acid-base balance of the mother and her child, for example, supine position of the mother (Humphrey et al., 1973; Humphrey et al., 1974), or (over)dosage of oxytocin and the degree of hydration and calory provision to the mother during labour. In many studies no attention or insufficient attention has been paid to these factors.

\subsubsection{The effect of epidural anaesthesia on the maternal acid-base balance}

In the literature differences are described between the first stage and the second stage of labour. For this reason attention is given to both periods separately.

\subsubsection{The first stage of labour}

Pearson and Davies (1973-a) demonstrated that the base excess fell in the maternal arterial blood and the lactate concentration increased during labour. However, the patients here received pethidine, sometimes in combination with promazine. These effects were present to a much lesser extent if pain was treated with epidural anaesthesia. These researchers found lower $\mathrm{pCO}_{2}$ values in the control group than in the patients who were given epidural anaesthesia. In neither of the two groups could $\mathrm{pH}$ changes be observed. According to the authors, the lower $\mathrm{pCO}_{2}$ values in the control group were caused by hyperventilation because of pain and fear. The authors stated that the metabolic acidosis in the control group was probably largely compensatory in nature. 
The shift of the maternal acid-base balance in the direction of acidosis (increasing lactate concentration and falling base excess) prevents any increment in $\mathrm{pH}$ that might be expected as a result of hyperventilation. With good analgesia, such as epidural anaesthesia the hyperventilation response would not be present. The cessation of hyperventilation following effective epidural block was confirmed by pneumotachographic studies. Thalme et al. (1974-a,b) came to the same conclusion as Pearson and Davies (1973-a). The patients in the control group of Thalme et al., (1974-a) were given pethidine in combination with chlorpromazine.During the last part of the first stage, these patients received inhalation anaesthesia in the form of nitrous oxide and oxygen. The determinations of the acid-base balance were performed in venous blood.

Zador and Nilsson (1974) in a control group also found a fall in base excess during the first stage. In the group of patients who were given epidural anaesthesia the base excess remained constant. The $\mathrm{pCO}_{2}$ values remained constant for both the control group and the epidural group. There was no significant difference between the two groups from the point of view of $\mathrm{pCO}_{2}$. A slight reduction in $\mathrm{pH}$ was observed in both the control group and the epidural group. From studying the figures in this study it would seem that the reduction of the $\mathrm{pH}$ was not significant in the control group nor in the epidural group. At the start of labour the patients in the control group received pethidine or diazepam whereas during the last part of the first stage they were given inhalation anaesthesia using a nitrous oxide-oxygen mixture. Capillary blood was used for the determination of the acid-base balance. No changes in the maternal acid-base status were found during epidural anaesthesia by Jouppila and Hollmen (1976). There was a non-significant increase in the base deficit. However, lactate concentration did increase significantly. A significant reduction in $\mathrm{pCO}_{2}$ and a significant elevation of $\mathrm{pH}$ was seen in the patients in the control group. According to the authors, this was due to hyperventilation. In the control group, the lactate concentration was higher than in the epidural group. In both groups the $\mathrm{pO}_{2}$ was constant during delivery. In this study, five of the fourteen patients in the control group had been given pethidine. The tests were done on arterial blood. Holm (1982) examined the maternal venous acid-base balance in three groups of women. One group of women received epidural anaesthesia, another received pethidine and a third group received absolutely no analgesic drugs. Labour was induced with oxytocin in all three groups. Both nulliparae and multiparae were studied. For the nulliparae the findings were as follows: In the epidural group the $\mathrm{pH}$ remained pretty constant. There was a slight $\mathrm{pH}$ reduction in the pethidine group and a slight increase in $\mathrm{pH}$ in the control group. In the epidural group the base excess fell much less markedly than it did in the control and pethidine groups. The fall in $\mathrm{pCO}_{2}$ was the most noticeable in the control group and was present to a lesser extent in the other two groups. The $\mathrm{pO}_{2}$ rose in the control group and remained constant in the pethidine group whereas in the epidural group a reduction was observed. This study does not indicate whether the differences were significantly different from zero. Study of the figures involved indicates that the changes of $\mathrm{pO}_{2}$ in the pethidine and control groups were not significant. There probably was a significant reduction of the $\mathrm{pO}_{2}$ in the epidural group. It appears from this study that there was a shift in blood gas values and $\mathrm{pH}$ in correspondence with hyperventilation. This occurred to a lesser extent in the pethidine and epidural groups. The changes in 
base excess in the various groups justifies the conclusion of the author that the shift of the acid-base balance towards metabolic acidosis in the epidural group was much less than in the pethidine and control groups. According to Crawford (1978) it is possible that pain may induce changes in peripheral blood flow leading to inadequate tissue perfusion, and that the metabolic acidosis may in part reflect chronic tissue hypoxia. Probably, patients who received epidural anaesthesia have a lesser tendency towards metabolic acidosis. Furthermore, the blood gas changes accompanying hyperventilation should be absent in patients who are given epidural anaesthesia.

\subsubsection{The second stage of labour}

No increase in lactate concentration was found by Pearson and Davies (1973-b) in a number of patients who had no bearing-down reflex because of epidural anaesthesia and who were not encouraged to push. The presenting head was allowed to advance by unassisted uterine contractions with delivery by a low outlet forceps extraction. In the control group where pethidine had been used as the analgesic, there was a considerable increase in lactate concentration whereas, in a number of patients from the epidural group who were encouraged to assist in bearing down there was a slight increase in lactate concentration. On the basis of these results, Pearson and Davies (1973-b), like' Dijkhuizen (1979), came to the conclusion that uterine activity does not contribute to the lactate concentration in the maternal blood or does so only marginally.

The $\mathrm{pH}$ and the base excess fell in the control group but remained constant in the epidural group. Zador and Nilsson (1974) found a reduction in $\mathrm{pH}$ and base excess in both the epidural group and the control group. However in the control group, pethidine, diazepam, nitrous oxide-oxygen was administered. The $\mathrm{pH}$ changes were less in the epidural group than in the control group. The $\mathrm{pCO}_{2}$ had a tendency in the control group to rise but in the epidural group it fell slightly. Study of the figures concerned indicate that the changes in $\mathrm{pCO}_{2}$ were not significant. Similariy, Thalme et al., (1974-a) found in the control group a shift of the maternal acid-base balance towards a metabolic acidosis. This shift was markedly less in patients who received epidural anaesthesia. The $\mathrm{pCO}_{2}$ rose somewhat in both the control group and the epidural group. In both the control group and the epidural group Jouppila and Hollmen (1976) observed the development of metabolic acidosis during the second stage of labour. However, in this study a segmental epidural anaesthesia was administered in which only the lower thoracic spinal segments were blocked - thus the second stage of labour was not free of pain and the bearing down reflex remained normal. As a result of her research, Holm (1982) came to the conclusion that epidural anaesthesia partly protects the mother against the metabolic acidosis that develops during the second stage of labour. Similarly, Vroman et al., (1977) came to the conclusion that in the epidural group, there was a much reduced occurrence of metabolic acidosis in comparison with the control group. In this study the immediate post partum $\mathrm{pCO}_{2}$ was the same in both groups.

In view of the literature data, it would seem justifiable to conclude that epidural anaesthesia wholly or partly prevents a shift of the maternal acid-base balance towards metabolic acidosis. With respect to epidural anaesthesia, the literature refers to the 
following three factors which could influence the maternal acid-base balance:

1. Hyperventilation

2. Maternal muscular activity

3. Catecholamine concentrations in the maternal blood.

These three points will be briefly considered.

\subsubsection{Hyperventilation}

Hyperventilation often arises during the first stage of labour if there is no analgesia or if analgesia is inadequate (Reids, 1966; Fisher and Prys-Roberts, 1968; Sangoul et al, 1975; Marx, 1981). The hyperventilation is said to be a consequence of the pain and fear which the woman experiences during labour. Furthermore, hyperventilation is also a consequence of the breathing technique which the woman would have learned in antenatal classes. As a result of hyperventilation, the maternal acid-base balance suffers a fall in $\mathrm{pCO}_{2}$ and an increase in $\mathrm{pH}$. For the woman, hyperventilation means increased oxygen consumption (Sangoul et al., 1975; Marx, 1981). Sangoul et al., (1975) found a 14 per cent decrease in oxygen consumption consequent to institution of regional anaesthesia. In extreme situations, hyperventilation could bring about such an alkalosis that the hemoglobin dissociation curve would shift to the left over a wide range. This could mean reduced oxygenation of the foetus (Lumley et al., 1969; Lumley and Wood, 1973; Levinson et al., 1974; Miller et al., 1974). Lumley and Wood $(1969,1973)$ have reviewed and summarised this problem and came to the conclusion that hyperventilation during childbirth has no effect on the foetus. However, during general anaesthesia for Caesarean section, hyperventilation can have a negative effect on foetal oxygenation. After studying the literature and as a result of his own research, Dijkhuizen (1979) reached the same conclusion.

Low et al., (1974) proposed that increased lactate could be found during labour as the result of hyperventilation. In hyperventilation tests, usually it was only in animal experiments that a lactate increase was found. It has not been convincingly demonstrated that there is a lactate increase during hyperventilation in humans., Eldridge and Salzer (1967), however, found an increase in the lactate concentration in adults who hyperventilated without general anaesthesia.

Lumley et al., (1969) and Macrae and Bechit (1978) found that there was no reduction of the buffering bases in hyperventilating pregnant women or women undergoing childbirth. Dijkhuizen (1979) let pregnant and non-pregnant test subjects hyperventilate and breath superficially. The respiratory changes led to neither an increase in lactate concentration nor to a fall in the buffering bases in the blood. The $\mathrm{pH}$ rose significantly and the $\mathrm{pCO}_{2}$ fell significantly.

If childbirth proceeds painlessly under epidural anaesthesia, pain induced hyperventilation will be absent and therefore the effect of hyperventilation on the acid-base balance will accordingly be absent. 


\subsubsection{Maternal muscular activity}

As indicated in section 5.3.1.1, most authors are of the opinion that the lactate concentration rises during childbirth and the buffering bases in the blood diminish. Various reasons for this are to be found in the literature. The relationship between hyperventilation and lactate increase has already been considered in section 5.3.1.3. Another process that could explain the increase in lactate found during childbirth is the increase in catecholamines in maternal blood (section 5.3.1.5). According to the literature, there is almost unanimous agreement that the most important component in the reduction of buffering bases in the mother during childbirth is the increased lactate concentration. Dijkhuizen (1979) had non-pregnant test subjects bear down in imitation of second stage of labour. The lactate concentrations rose to levels that were comparable with those usually found in the second stage of labour. According to the author's conclusion, muscular activity, other than that of the contracting uterus, can explain the increased lactate found during childbirth. Elimination of pain by administration of epidural anaesthesia will reduce random muscular activity (motor unrest) in the mother; (Jouppila and Hollmén, 1976), and therefore with epidural anaesthesia, metabolic acidosis will develop much less rapidly during childbirth. Pearson and Davies (1973-b) found that in a number of patients who could not assist in bearing down because of an absent bearing down reflex due to epidural anaesthesia that there was no increase in lactate concentration during the second stage of labour. Pearson and Davies (1973-b), like Dijkhuizen (1979), came to the conclusion that the increase in lactate is the result of muscular activity by the mother and is not caused by uterine contractions. With epidural anaesthesia, motor unrest in the woman will be reduced. Furthermore, the bearing down reflex is partially or totally inhibited as a result of the epidural anaesthesia so the women can usually bear down less well during uterine contractions. This results in less muscular activity on the part of the woman and therefore less lactate formation.

\subsubsection{Catecholamine concentration in the maternal blood}

It seems from human experimental research that administration of adrenaline causes an increase in the concentration of lactate in the blood (Greene, 1961; Oliva, 1970). In animal experiments too, administration of adrenaline results in increased lactate concentration (Comline and Silver, 1972; Kusaka and Ui, 1977). If catecholamine concentrations were to increase during childbirth then this could equally be an explanation for the increased lactate concentration found in the maternal blood during childbirth. Falconer and Powless (1982) determined plasma adrenaline levels in women during labour where epidural anaesthesia had been administered and in women who received some other form of analgesia. This study gives the impression that epidural anaesthesia reduces the rise in adrenaline levels which occur during the beginning of the second stage of labour.

Irestedt et al., (1982) compared the maternal adrenaline and noradrenaline concentrations at birth. In twenty women an elective Caesarean section was carried out under epidural anaesthesia. In another twenty women Caesarean section was done under general anaesthesia. Similarly, in ten women who delivered vaginally, the catechola- 
mine concentrations were determined at the time of the birth of the child. The highest catechollamine levels were found in the last-mentioned group, the lowest were found in the epidural group. Shnider et al.s (1983) found that after administration of epidural anaesthesia in fifteen women there was a significant fall in maternal adrenaline concentration. It seems reasonable to accept that the stress and pain which is present during childbirth in many patients leads to an increase in the catecholamine concentrations but this is not the case with epidural anaesthesia (Lederman et al., 1977; Shnider et al., 1983). The adrenal gland is innervated by sympathetic nerves which arise from the fifth thoracic upto and including the first lumbar spinal sement. During epidural anaesthesia these segments can be partly or completely blocked. This, equally could be the cause of reduced catecholamine release from the adrenal gland. In this connection Celander's experiments in cats are important for he deminstrated that stimulation of the sympathetic nervous system can produce a twenty-fold increase in the catecholamine release (Celander, 1954). Physical tension and repeated Valsalva maneuvres have been mentioned as other possible causes for the increased catecholamine level during the second stage of labour (Falconer and Powless, 1982; Robertson et al., 1979).

In view of the literature data it seems reasonable to accept that the stress and pain, that many patients experience during childbirth, causes an increase in the catechoiamine concentrations and this is not the case during epidural anaesthesia, or at least to a lesser extent.

\subsubsection{The effect of epidural anaesthesia on the acid-base balance of the foetus}

The foetal acid-base balance is probably jointly determined by the concentration differences between the mother and the foetus, the integrity of the uteroplacental unit and the buffering system of the foetus. A number of studies mention that an artificially induced acidosis or alkalosis in the mother produces a shift of the foetal acid-base balance in the same direction (Goodlin and Kaiser, 1957; Newman et al., 1967-a +b). A number of other researchers found a positive correlation between the foetal and the maternal blood with respect to the $\mathrm{pCO}_{2}$ and bicarbonate concentrations (Kubli, 1968; Newman et al., 1967-a+b; Chang and Wood, 1976). Several authors have in the physiological domain also found a positive correlation between the maternal and foetal pH (Jacobson and Rooth, 1971; Pearson and Davies, 1974-a; Thalme et al., 1974-a; Belfrage et al., 1975-a). The relationship and interactions between the maternal and foetal acid-base balance are very complex and partly still unclarified. It is clear from the literature data that epidural anaesthesia wholly or partly prevents the shift of the mother $3 \mathrm{~s}$ acid-base balance towards metabolic acidosis. If there is a positive correlation between the maternal and foetal acid-base status, and if the uteroplacental perfusion is not disadvantageously affected by epidural anaesthesia then on the basis of the abovementioned data one may accept that epidural anaesthesia has no negative effects on the acid-base balance of the fetus.

Pearson and Davies (1974-a) and Thalme et al., (1974-a) found no difference between epidural and control groups during the dilatation phase in delta $\mathrm{pH}$, delta base excess and delta $\mathrm{pCO}_{2}$ (these are the foetomaternal differences) and they were able to demonstrate that, with full dilatation, the foetuses from the epidural group were less 
inclined towards acidosis than those from the control group. In the fetuses from the epidural group there was a significantly higher $\mathrm{pH}$ and a significantly higher base excess. There is a very close correlation between the changes that occur in the fetus and those that occur in the acid-base balance of the mother during labour. The authors are of the opinion that the differences which were found with respect to foetal acid balance can be explained on the basis of the changes in the maternal acid-base balance.

No differences between the epidural and control groups were found by Thalme et al., (1974-a) with respect to base excess and $\mathrm{pH}$ at full dilatation. Zador and Nilsson (1974) found that during the dilatation period there was a slight increase in delta $\mathrm{pH}$ in the control group and a slight reduction of the delta pH in the epidural group. It is not clear from this study whether these changes differed significantly from zero. These researchers too found that at full dilatation there was a higher base excess and higher $\mathrm{pH}$ in fetuses from the epidural group as compared with those from the control group. In both groups the $\mathrm{pCO}_{2}$ increased somewhat during the first stage of labour. Study of the figures seems to show that these changes were not significantly different from zero. Jouppila and Hollmen, (1976) found no significant differences in the foetal acid-base balance between the control group and the epidural group. In these studies the patients in the control groups were given analgesics and/or nitrous oxide-oxygen mixture, thus the results must be assessed with some reservation. Belfrage et al., (1975-a) carried out foetal blood sampling from the foetal scalp at $10,20,30,60$ and 100 minutes immediately after epidural anaesthesia in order to determine the foetal acid-base balance. No significant changes were observed. The delta $\mathrm{pH}$ (foetomaternal difference) was always \pm 0.11 units. There was a significant positive correlation between the maternal and foetal $\mathrm{pH}$.

Pearson and Davies (1974-b) observed an increasing maternal metabolic acidosis during the second stage of labour in patients from the control group. The foetal $\mathrm{pH}$ fell in the same manner as did the mother $3 \mathrm{~s}$ so the delta $\mathrm{pH}$ did not increase during the second stage. In absolute terms, the fall of $\mathrm{pH}$ in the epidural group was less than that in the control group. The delta $\mathrm{pH}$ did not change in the control group during childbirth whereas the delta $\mathrm{pH}$ in the epidural group increased. In both of the two groups there was a clear correlation between the magnitude of the fall of foetal $\mathrm{pH}$ and the duration of the second stage. Thalme et al., (1974-a) were able to demonstrate that the children who had been born under epidural anaesthesia had a higher base excess than those from the control group. No significant differences between the two groups were found in terms of $\mathrm{pH}$, nor delta $\mathrm{pH}$. In both groups the $\mathrm{pCO}_{2}$ fell during the second stage. However, at birth there were no significant differences between the two groups. Zador and Nilsson (1974) were unable to find any significant differences between the epidural group and the control group with regard to base excess and $\mathrm{pH}$ of blood from the umbilical artery. What did emerge, however, was that the base excess progressively, fell if the second stage took longer than 60 minutes. This effect was much more pronounced in the control group than in the epidural group. Thus, with regard to base excess, significant differences were found if the second stage lasted longer than 60 minutes. The $\mathrm{pCO}_{2}$ changed neither in the epidural group nor in the control group.

Thalme et. al., (1974-b) found a higher lactate concentration in the control group than in 
the epidural group. Vroman et al.,(1977) found that the children who were born under epidural anaesthesia had a lower umbilical arterial pH than had children from the control group where the mothers were nulliparae but not where they were multiparae. The control group was not further described, all that is said is that there were 'suitable controls'. Apart from this, significant differences were found in terms of delta $\mathrm{pH}$, delta base excess and delta $\mathrm{pCO}_{2}$ favouring the control group. Thierry et al., (1974) were unable to demonstrate differences between an epidural and a control group in terms of $\mathrm{pH}$ or base excess. The controls in this study received no analgesic drugs.

Noble et al., (1971) found a significantly higher $\mathrm{pH}$ in the epidural group than in the control group. The patients in the control group had been administered various types of opiates during labour.

Interpretation of the literature data concerning the effect of epidural anaesthesia on the foetal acid-base balance is difficult because in most studies, the women in the control group were given other forms of analgesia during childbirth. However, it seems probable that with epidural anaesthesia the foetus is 'protected' against metabolic acidosis because the mother is less likely to experience metabolic acidosis (section 5.3.1).

\subsection{The pharmacological aspecis of the local anaesthetic agents}

Most of the local anaesthetics are tertiary amines $(\mathbf{N H})$, where each hydrogen ion is replaced by an organic group. They possess the following structure: aromatic part

Table 5.4 Structural formulae of a number of local anaesthetics of the amide-linked group and of the esther-linked group

Amide-linked group

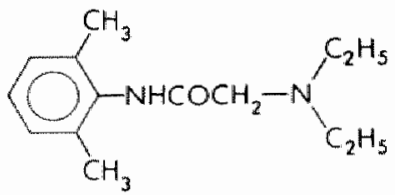

Lidocaine

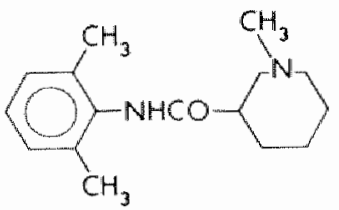

Mepivacaine

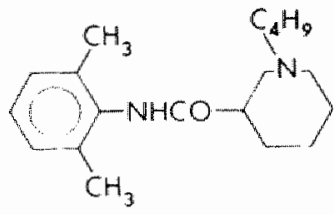

Buplvacaine
Ester-linked group<smiles>CCN(CC)CCOC(=O)c1cc[nH+]cc1</smiles>

Procaine<smiles>CCN(CC)CCOC(=O)c1ccc(N)cc1Cl</smiles>

Chloroprocaine<smiles>CN(C)CCOC(=O)c1ccc(N(C)C)cc1</smiles>

Tettracaine 
-intramediate chain - amine portion. Alterations in any part of this chemical scheme will modify the anaesthetic properties of the compound. The aromatic part of the molecule determines the lipid solubility, the intermediate chain decides the metabolic pathway, and the amine part controls the water solubility. The chain linking the aromatic and amine part of the molecule can be either an ester - or amide - type. If it is an ester-type (for example, procaine, chloroprocaine, tetracaine), the local anaesthetic is said to belong to the ester-linked group and is hydrolyzed by the plasma cholinesterase. If the intermediate chain is an amide-type, the local anaesthetic is said to belong to the amide-linked group (for eample, lidocaine, mepivacaine, bupivacaine, etidocaine). Table 5.4 presents an overview of the structural formulae of a number of local anaesthetic agents.

Most local anaesthetic agents are weak bases. The commonly used salts of local anaesthetics are the chlorides. This is the salt of a weak base and a strong acid and the pH usually lies between four and five. The dissociation constant (pKa) of most local anaesthetic agents lies between seven and ten. Both the ionised and the unionised forms of the local anaesthetic are present in a solution. Numerically the quantities of the two forms present is dependent on the dissociation constant and the hydrogen ion concentration. The following equation applies:

$$
\mathrm{A}+\mathrm{H}^{+} \leftrightharpoons \mathrm{AH}^{+}
$$

$\mathrm{A}$ is the unionised from of the local anaesthetic agent. Electrically, it is a neutral molecule which dissolves in water oniy with difficulty or not at all and is easily soluble in lipids. In view of its lipophilic character, this form of the local anaesthetic is capable of penetrating the cell membranes consisting of lipoproteins.

$\mathrm{AH}+$ is the ionised form of the local anaesthetic. It is a positively charged cation, easily soluble in water and insoluble in lipids. The hydrophilic, lipophobic character explains the poor penetrative capacity into cell membranes.

The relative concentration of each form is dependent on the $\mathrm{pKa}$ of the drug and the $\mathrm{pH}$ of the medium. With bupivacaine the dissociation constant is 8.05 and this means that with a pH of $8.05,50$ per cent of the local anaesthetic is in the ionised form and 50 per cent is in the unionised form. The relationship between these different factors can be expressed as follows:

$$
\mathrm{pH}=\mathrm{pKa}-\log \left(\mathrm{AH}^{+}-\mathrm{A}\right)
$$

As the $\mathrm{pH}$ of the solvent in which the local anaesthetic is to be found falls below the $\mathrm{pKa}$, so a larger and larger proportion of the local anaesthetic becomes ionised. Thus in acidosis, the water solubility of the local anaesthetic will increase and the lipid solubility (membrane penetration) will fall.

The anaesthetic which is currently most used in obstetrics is bupivacaine. Bupivacaine is usually used in the following concentrations: 0.125 per cent, 0.25 per cent and 0.5 per 
cent. The structural formula of bupiwacaine is given in table 5.4 This local anaesthetic was created at $A B$ Bofors by Ekenstam et al., (1957). The molecular weight is 324 and the dissociation constant ( $\mathrm{pKa}$ ) is 8.05 . Chemically, bupivacaine is related to mepivacaine. In bupivacaine, the methyl group of mepivacaine is replaced by a butyl group (table 5.4). Two other local anaesthetics that are used quite often are lidocaine and etidocaine. Lidocaine, however, is an anaesthetic with shorter duration of action than bupivacaine. With lidocaine, fairly higher serum levels are found in the foetal blood (Shnider and Levinson, 1979). Etidocaine is also a long-acting local anaesthetic but has a more intensive motor blockade and this is a disadvantage in obstetrics (Shnider and Levinson, 1979; Bromage, 1978). Bupivacaine has a high plasma protein binding capacity and is easily soluble in lipids. Ninety to ninety five per cent of bupivacaine is bound to the maternal plasma proteins. The foetus, however, has less ability than the adult to bind the local anaesthetic to protein, 50 per cent to 60 per cent that of the adult (Tucker et al., 1970-b; Mather et al., 1971). Bupivacaine gives good sensory blockade but produces little motor blockade (Shnider and Levinson, 1979; Bromage, 1978). The bupivacaine is metabolised in the liver and both it and its much less toxic metabolite, pipecolylxylidine (PPX) are slowly excreted via the kidneys (Reynolds, 1971-a). Löfström et al., (1966) were unable to demonstrate any neurotoxic effect of bupivacaine. Bupivacaine did not affect the haematopoietic system or the liver function (Nordqvist and Dhunér, 1966).

In many investigations bupivacaine (Marcaine) was used to which adrenaline had been added at a concentration of $5 \mu \mathrm{g} / \mathrm{ml}$. To this $0,5 \mathrm{mg} / \mathrm{ml}$ sodium metabisulphite was added to prevent oxidation of the adrenaline. The result of this is that the $\mathrm{pH}$ of this solution lies between three and four. On theoretical grounds this would seem to be a relative disadvantage because a large proportion of the local anaesthetic is then in the ionised state. This means that the lipid solubility and therefore the nerve cell membrane penetration is reduced. Therefore it would be better to add fresh adrenaline at a concentration of $5 \mu \mathrm{g} / \mathrm{ml}$ just prior to using the local anaesthetic.

\subsubsection{Mechanism of action}

The analgesic effect of the local anaesthetics probably depends on stabilisation of the nerve axon membrane due to blocking sodium and potassium transport across the cell membrane.

At a physiological pH, the local anaesthetic is present partly in the ionised form of a positively charged cation and partly in the form of an electrically neutral molecule. The cation is capable of forming an electrostatic bond with the external surface of the nerve memebrane and thereby block the nerve. Biotoxins such as tetrodotoxin and saxitoxin exercise their effects in this manner. However, the usual local anaesthetic have another mode of action (Covino and Vassallo, 1976; Abouleish, 1977). The research results of Ritchie (1975), Ritchie et al., (1965-a, 1965-b), Narahashi et al., (1970), Armstrong et al., (1973) and Strichartz (1973) suggest that the unionised, lipophilic part reaches the intracellular space across the membrane. Part of the local anaesthetic is then ionised as a result of the ambient intracellular $\mathrm{pH}$. These positively charged cations form an electrostatic bond with the inside of the nerve membrane and in this way blockade of the 
nerve will arise. Covino and Vassallo (1976) are of the opinion that the local anaesthetics owe part of their effect to another mechanism. Namely to 'membrane expansion'. If the electrically neutral form of the local anaesthetic should be located in the cell membrane then changes would occur in the cell membrane which would then reduce the transport capacity of ions across the membrane. This would result in inhibition of neural excitation.

\subsubsection{Transplacental transport of bupivacaine}

Thomas et al., (1975) measured a maternal plasma bupivacaine concentration during epidural anaesthesia which was four times higher than the foetal bupivacaine concentration in the plasma from the umbilical vein. However, when they measured only the free fraction, i.e. that part of the bupivacaine that was not proteinbound, they found that the maternal and foetal concentrations were the same. Like Belfrage et al., (1975-b) and Covino (1977) they are of the opinion that placental transport of bupivacaine occurs as passive diffusion of the unbound fraction.

The foetus has considerably less capacity to bind the bupivacaine to protein, than the adult (Tucker et. al., 1970-b; Mather et al., 1971). Bupivacaine is bound in maternal plasma for 88 per cent, compared with only 51 per cent in umbilical plasnia at the 5 $\mu \mathrm{g} / \mathrm{ml}$ level. Corresponding figures at the $1 \mu \mathrm{g} / \mathrm{ml}$ level were 95 per cent and 66 per cent (Tucker et al., 1970-b). This is probably the reason for the foetomaternal differences found in the plasma bupivacaine concentrations. Figure 5.1 gives a schematic representation of the placental passage of bupivacaine.

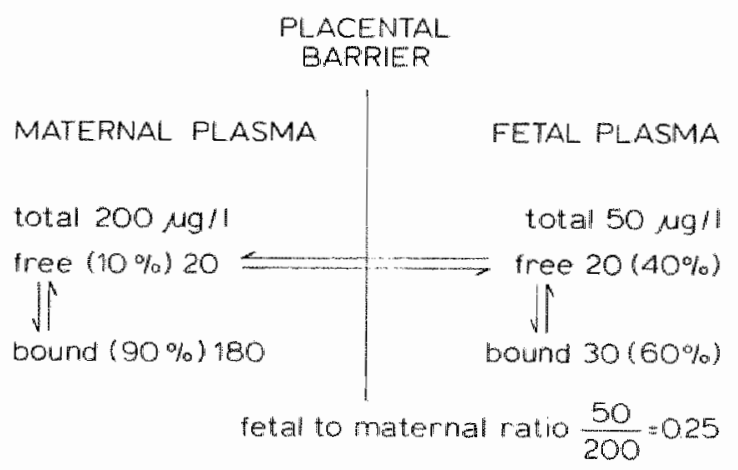

Fig. 5. I Model of placental passage of bupivacaine (according to Abouleish, 1977)

As is shown in figure 5.1, the total concentration of bupivacaine in the foetus is lower than it is in the mother. Despite this lower concentration, the concentration of unbound bupivacaine in the foetus is the same as it is in the mother. The pharmacological and toxic activity of a drug depends on the free fraction and not the fraction bound to plasma protein. The concentration of bupivacaine in the umbilical artery is about 20 per cent lower than that in the umbilical vein (Tucker et al., 1970-b).

In an experiment with sheep, Kennedy et. al., (1979) showed that $\mathrm{pH}$ also seems to be an important factor that co-determinates the foetal bupivacaine concentration: as the 


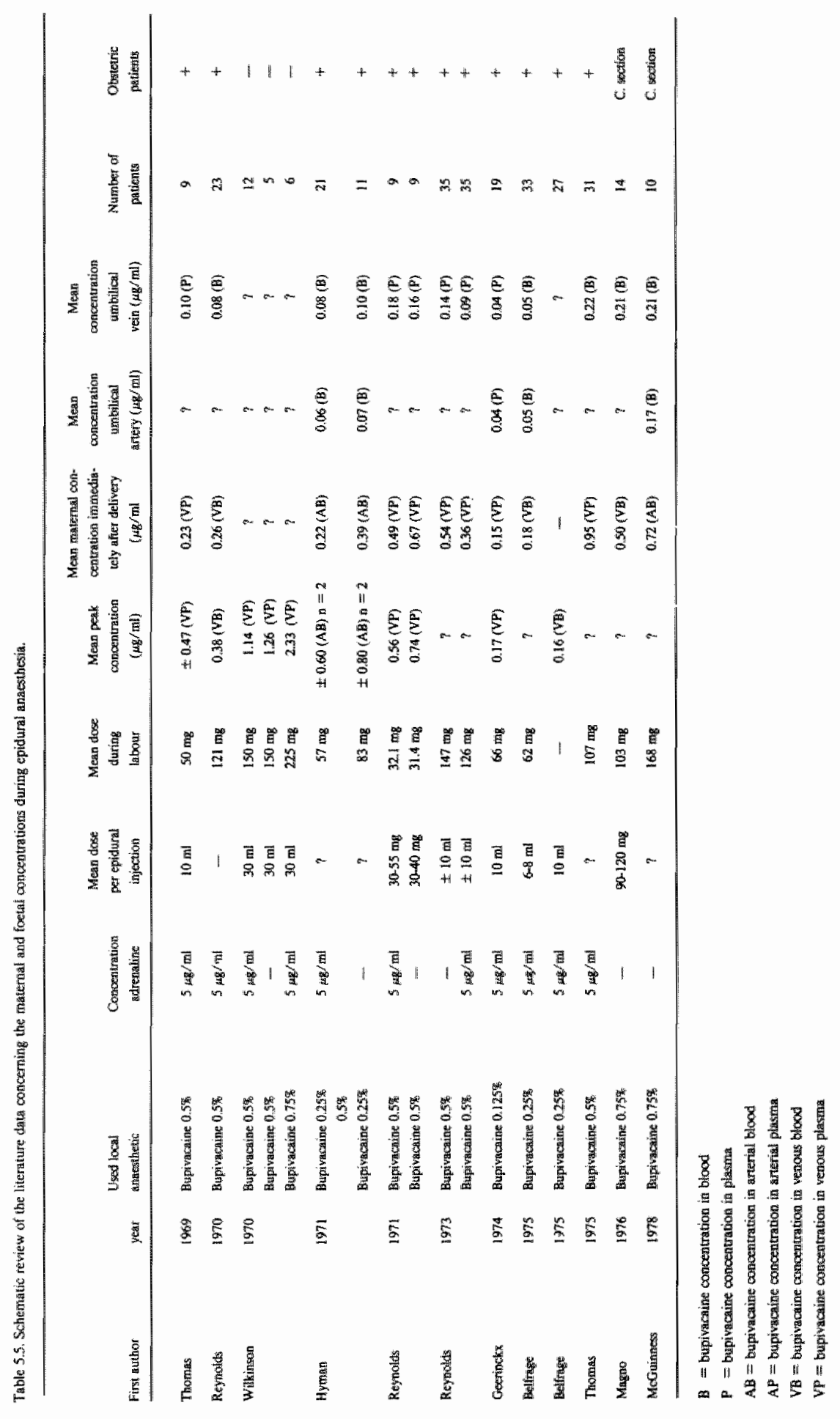


foetonitatemal $\mathrm{pH}$ difference increases, so the foetomaternal concentration ratio increases.

\subsubsection{Matemal and foetal concentrations of local anaesthetic agents in the blood}

Resorption of the local anaesthetic from the richly vascular epidural space into the circulation is dependent on a number of factors. Of course, in the first instance the physiochemical properties of the local anaesthetic are important. Then of course the dose is important and also whether or not adrenaline is added.

The concentrations are higher in arteriall blood than in venous blood (Tucker et al., 1970-b; Belfrage et al., 1975-c; Tucker and Mather, 1975). Vasoconstriction of the peripheral vascular system and redistribution of the local anaesthetic have been put forward as possible reasons for this. In the case of epidural anaesthesia with bupivacaine, the highest concentration in the maternal arterial blood is achieved in 15 to 30 minutes. The arterial concentration is then 20 to 40 per cent higher then the venous concentration (Tucker et al., 1970-b). In the adult ninety per cent of the local anaesthetic is found in the plasma and ten per cent in the erythrocytes (Moore et al., 1971). This also explains the fact that the concentrations of the local anaesthetic in the plasma are higher than in blood. Of course, this difference increases if the hematocrit increases.

\subsubsection{Bupivacaine concentrations during epidural anaesthesia}

Most authors are of the opinion that on using bupivacaine, low blood levels are present in the mother and in the fetus and that there is little cumulative effect (Thomas et al, 1969; Reynolds and Taylor, 1970; Tucker et al., 1970-b; Hyman and Shnider, 1971; Reynolds and Taylor, 1971; Reynolds et al., 1973; Geerinckx et al., 1974; Belfrage et al., 1975-a +b; Thomas et al., 1975; Magno et al., 1976). Table 5.5 gives a schematic summary of the most important studies. This table also gives the average peak concentrations as well as the concentration in the umbilical artery. These research results are to be explained on the basis of the following considerations:

1. Bupivacaine has a relatively high affinity for plasma proteins (Tucker et al., 1970-a) and as a result of this, there is little free circulating bupivacaine in the maternal blood. Passage through the placenta is, amongst other things, dependent on the concentration gradient of the unbound proportion of the local anaesthetic. Therefore, on theoretical grounds the view that the foetal bupivacaine concentration remains low in comparison to the maternal concentration would seem to be justified.

2. Only the freely circulating and electrically neutral molecule is capable of penetrating membranes. At a given $\mathrm{pH}$, the concentration of the electrically neutral part of the local anaesthetic depends on the dissociation constant of the local anaesthetic used. At a given $\mathrm{pH}$, the percentage of unionised base that is available for transplacental transport is different. For example at a $\mathrm{pH}$ of 7.4 for bupivacaine, lidocaine and mepivacaine, respectively 18,26 and 36 per cent. This also contributes to the low foetal bupivacaine concentrations.

3. Bupivacaine is a local anaesthetic which has a long-lasting and fairly powerful effect. 
The consequence of this is that in comparison with other local anaesthetics, one can usually apply much lower doses. The lower the applied dose in the epidural space, the lower the blood levels of the local anaesthetic will remain.

4. The strong tissue binding of bupivacaine leads to a strong bond between the tissue in the epidural space and the bupivacaine. The long-lasting effect of bupivacaine is partly attributed to this (depot formation). On the other hand, this also means that absorption out of the epidural space is relatively slight and because of that the maternal and foetal blood levels stay low (Tucker and Mather, 1975).

Among other things, the foetal blood concentrations are dependent on the maternal blood concentration. Only the non protein-bound fraction can traverse the placenta. Placental passage of bupivacaine is a passive diffusion process of the unbound fraction (Covino, 1977). Because of the great capacity to bind with plasma proteins and the strong tissue binding of bupivacaine, the plasma level in the foetus is low, namely 25 to 30 per cent of the maternal concentration (Taylor, 1971; Reynolds and Reynolds et al., 1973; Belfrage et all., 1975-a +b; Jouppila et al., 1978-d). These are average values but there is a large inter-individual dispersion. The foetus has less capacity to bind the local anaesthetic to plasma proteins. This means that the unbound bupivacaine fraction in the foetus is relatively higher than in the mother.

\subsubsection{Addition of adrenaline}

One would suppose that because of its vasoconstrictive properties, adrenaline would prolong the duration of effect of the local anaesthetic and reduce its toxicity because the concentration of the local anaesthetic in the blood would remain lower. The duration of the epidural anaesthesia with bupivacaine and other long acting local anaesthetics seems. not to be influenced by the addition of adrenaline (Reynolds and Taylor, 1971; Reynolds et al., 1973; Buckley et al., 1978). However, Bromage (1978) and Buckley et al., (1978) are of the opinion that adding adrenaline improves the intensity and quality of the anaesthesia. In the use of many other local anaesthetics, particularly ones where the effect is short term, the favourable effect of adrenaline on the duration of the epidural anaesthesia is beyond doubt (Zador et al., 1974; Abouleish, 1977; Bromage, 1978).

The effect of the addition of adrenaline to bupivacaine on its blood concentration is variably stated in the literature. A number of authors have the opinion that the addition of adrenaline to bupivacaine has no effect on the blood level of the local anaesthetic (Moore et al., 1970; Willkinson and Lund, 1970; Tucker and Mather, 1975). However, other authors are of the opinion that addition of adrenaline causes the levels of bupivacaine in the blood to be reduced (Reynolds and Taylor, 1971; Reynolds et al., 1973; Hyman and Shnider, 1971). Reynolds et al., (1973) found that the peak plasma levels in both the mother and the child were lower when adrenaline was added in comparison to when it was not. The concentration ratio between the umbilical vein and the maternal plasma did not change after addition of adrenaline. In earlier investigations they found an increased ratio following addition of adrenaline (Reynolds and Taylor, 1971). 


\subsubsection{Toxic effects of the local anaesthetic agent}

Local anaesthetics are partly resorbed out of the epidural space and reach and influence other organs via the circulation. Local anaesthetics, in keeping with their function, affect membranes that are involved in the conduction of electrochemical stimuli. Thus, the heart and the central nervous system are organs that can become affected by local anaesthetics. The toxic effects of a drug are dependent more on tissue concentration than concentration in the blood. The tissue concentration of a local anaesthetic is, amongst other things, dependent on the distribution coefficient between blood and tissue (Finster et al., 1972). In an animal experiment (rabbits), Hollmën (1973) demonstrated that the foetal tissue-blood distribution (for heart and brain tissue) was about 50 per cent lower with bupivacaine than with lidocaine.

\subsubsection{Toxic effects on the central nervous system}

Local anaesthetic agents reach rather high concentrations in the cerebrospinal fluid (Wilkinson and Lund, 1970) and can elicit toxic phenomena. As blood concentrations of the local anaesthetics rise so the following sequense of complaints develop: stiff tongue, dizziness, tinnitus, visual disturbances, and lethargy. The objective signs of the commencement of toxicity are: unclear speech, twitching of facial muscles and muscles in the distal ends of the extremities. If the blood concentration rises still further then convulsions may develop. A further increase will cause depression of the central nervous system in which the convulsions disappear and respiration is reduced, eventually to the point of apnea. In addition, a negative effect will be exercised on the cardiovascular system due to depression of the vasomotor centre.

The toxic concentrations of bupivacaine have never been determined for certain. Jorfeldt et al., (1968) have stated that there is a chance of convulsions at an arterial plasma level of $4 \mu \mathrm{g} / \mathrm{ml}$. In animal experiments on the rhesus monkey, convulsions occurred at a mean arterial plasma bupivacaine concentration of $4.5 \pm 1.7 \mu \mathrm{g} / \mathrm{ml}$ (Munson et al., 1975). Reynolds (1971-b) proposed that there would be slight toxic phenomena at a venous plasma concentration of $1.6 \mu \mathrm{g} / \mathrm{ml}$. On average, this level would be reached if $440 \mathrm{mg}$ bupivacaine were to be used for epidural anaesthesia within a time period of 18 hours (Reynolds et al., 1973). In animal experiments with cats, hypoxia, hypercapnia and acidosis lowered the threshold above which convulsions occurred (Englesson, 1974).

If epidural anaesthesia is carried out carefully, it is most improbable that toxic blood concentrations would be reached. If they nonetheless occur then it is almost always the result of intravenous injection of the local anaesthetic agent caused by the tip of the catheter coming into one of the vessels in the internal vertebral venous plexus.

\subsubsection{Toxic effects on the cardiovascular system}

Similarly, local anaesthetics have a potential inhibitory effect on the heart. At toxic doses, local anaesthetics can cause a reduction in the depolarisation velocity of the heart. Moreover, the myocardium can be so far inhibited that hypotension develops and even heart failure (Abouleish, 1977). In the literature there is a lot of information about cardiovascular changes as a result of intravenous infusion of the local anaesthetic. 
Jorfeldt et al., (1968) administered intravenous local anaesthetics to volunteers such that peak concentrations for bupivacaine of 1.5 to $3 \mu \mathrm{g} / \mathrm{ml}$ were reached without this leading to cardiovascular depression. The same was experienced with lidocaine and mepivacaine at plasma concentrations of between 4 and $8 \mu \mathrm{g} / \mathrm{ml}$. Scott et al., (1971) gave patients who were under light halothane anaesthesia an intravenous dose of 150 $\mathrm{mg}$ lidocaine over a period of 90 seconds. The maximum plasma concentration that was reached was between 4.9 and $8.7 \mu \mathrm{g} / \mathrm{ml}$. In these patients a short-lasting negative inotropic effect on the heart arose. The cardiac output fell by 16 per cent whereas the central venous pressure rose by 30 per cent. Scott (1975) suggested that at venous concentration of bupivacaine of $2 \mu \mathrm{g} / \mathrm{ml}$ would produce toxic effects if the dose was given quickly. Bromage (1978) suggested that local anaesthetics could be administered at relatively high doses without producing serious depression of the cardiovascular system provided that the sympathetic nervous system remained intact. However, if this was partly incapacitated (as in epidural anaesthesia and general anaesthesia) then one loses a vascular compensation mechanism and this can lead to serious hemodynamic complications. De Jong and Heavner (1973) investigated the effects of a bolus injection of lidocaine in the cat. The lidocaine dose was given approximately 12 times faster than in most other studies and produced a serious cardiovascular depression which was associated with a fall in blood pressure and ventricular tachycardia. In in vitro perfusion studies of the human foetal heart using mepivacaine, Andersson et al., (1970) demonstrated that the atrioventricular and intraventricular conduction times were increased and the contraction force decreased. This effect was more pronounced if there was acidosis. In general, the toxic effects of local anaesthetic agents increase if there is acidosis (Andersson et al., 1970; Englesson, 1974). In acidosis the following equilibrium shifts to the right:

$$
\mathrm{A}+\mathrm{H}^{+} \leftrightharpoons \mathrm{AH}^{+}
$$

This means that the ionised part of the local anaesthetic increases. This positive cation is hydrophilic and as such is unable to penetrate the membrane. It seems that there is a paradox in which on the one hand the toxic effect increases during acidosis but on the other, the ability of the local anaesthetic to penetrate falls. It may probably be concluded from these contradictory data that the acidotic shift in $\mathrm{pH}$ affects the cell membranes and this could explain the above-mentioned results (Bromage, 1978). Sjöstrand and Widman (1973) and Widman (1975) are of the opinion that the increased toxic effects of local anaesthetic agents in acidosis is the result of an intracellular acidosis in which a large proportion of the local anaesthetic that is present inside the cell is in the ionised state. This ionised form is not able to penetrate the membrane and is intracellularly locked up, as it were. This situation could be the trigger to unexpected toxic reactions. 



\section{Side effects and complications of epidural anaesthesia}

As with any other form of analgesia, there may be side effects and complications with epidural anaesthesia. If the side effects are not diagnosed in good time and then treated, this may lead to serious complications. This chapter will examine more closely what the maternal side effects and complications of epidural anaesthesia may be.

\subsection{Cardiovascular effects of epidural anaesthesia}

Epidural anaesthesia can influence the maternal cardiovascular system mainly in the following three ways:

1. Blockade of part of the sympathetic nervous system.

2. Influence of the local anaesthectic on the vascular system.

3. Influence of the adrenaline added to the local anaesthetic agent on the vascular system.

\section{1 .1 Blockade of part of the sympathetic nervous system}

Epidural anaesthesia produces not only a blockade of the sensory nerve fibres but also blocks sympathetic nerve fibres. Heavner and de Jong (1974) were able to show that the preganglionic nerve fibres are the most sensitive to local anaesthetic agents. Thus one can accept that during epidural anaesthesia, the sympathetic blockade will surpass the sensory nerve fibre blockade in terms of extent and intensity. The blockade of the sympathetic nervous system brings about a reduction in the peripheral vascular resistance and pooling of the venous blood in the area concerned. As a result of this, venous return to the heart is reduced. The reduced cardiac output which this causes, combined with the reduced peripheral vascular resistance may lead to a reduction in blood pressure. If a pregnant woman lies on her back the venous return can seriously be hindered because of the possible pressure of the pregnant uterus on the inferior vena cava and aorta, so the combination of sympathetic blockade and supine position may trigger serious blood pressure reduction. Similarly, uteroplacental perfusion will also be reduced if the woman is in supine position as a result of the compression of the aorta by the gravid uterus which will occur to a greater or lesser extent.

The peripheral vascular resistance and the mechanical activities of the heart will also be affected by the catecholamine levels. During epidural anaesthesia there is less anxiety and pain, thus endogenous catecholamine production will be reduced in comparison to women who are not administered any analgesia (Ledermann et al., 1977; Shnider et al., 1983). Furthermore, the sympathetic innervation of the adrenal gland will be totally or partly blocked during obstetric epidural anaesthesia. The adrenal gland is innervated 
from the fifth thoracic upto and including the first lumbar segment. Celander (1954) found that in the cat there was a twenty-fold increase in catecholamine release during stimulation of the splanchnic nerve. It would appear that one cannot rule out reduced catecholamine production in obstetric epidural anaesthesia due to blockade of the sympathetic innervation of the adrenal gland.

The sympathetic innervation of the heart arises from the first to the fifth thoracic spinal segments inclusive. If this sympathetic innervation were to become blocked by epidural anaesthesia, there would be a reduction in the chronotropic and inotropic drive to the myocardium. However, blockade of these spinal segments during obstetric epidural anaesthesia would be an exceptional situation.

\subsubsection{The influence of the local anaesthetic on the maternal caridovascular system}

Epidural anaesthesia can cause changes in the vascular system. This is partly due to blockade of sympathetic nerve fibres but the changes are also the result of a direct influence of the local anaesthetic on the cardiovascular system of the mother. The effect of local anaesthetics on the mechanical activity of the heart has been intensively studied. Covino and Vassallo (1976) on the basis of literature data came to the conclusion that at non-toxic doses (such as in epidural anaesthesia), local anaesthetics produce slight, if any, increase in blood pressure. This is the result of a slight increase in cardiac output, heart rate and peripheral vascular resistance. At toxic doses the contraction force of the heart would be reduced and the blood pressure would fall. The effect of local anaesthetics on the vascular wall is biphasic. At low, non-toxic doses vasoconstriction arises and there is an increase in peripheral vascular resistance. At toxic doses there is peripheral vasodilatation and a reduction of the peripheral vascular resistance.

Jorfeldt et al., (1968) demonstrated that on intravenous administration of local anaesthetics (lidocaine and mepivacaine) concentrations of between 4 and $8 \mu \mathrm{g} / \mathrm{ml}$ produced an increase in blood pressure and cardiac output. Bupivacaine concentrations between 1.5 and $3 \mu \mathrm{g} / \mathrm{ml}$ caused also no depression of the cardiovascular system. Of course, these data do not have the same validity during epidural anaesthesia because in that situation there is also a partial blockade of the sympathetic nervous system.

\subsubsection{The influence of the added adrenaline on the maternal cardiovascular system}

The influence of adrenaline on the cardiovascular effects of high $\left(\mathrm{T}_{5}\right)$ epidural anaesthesia was thoroughly studied by Bonica et al., (1971). In 12 human non-pregnant volunteers, the effects of lidocaine alone were compared with those of lidocaineadrenaline. Epidural anaesthesia with plain lidocaine produced a 5-10 per cent change in cardiac output, total peripheral resistance and mean arterial pressure. However, during epidural anaesthesia with lidocaine-adrenaline a 49 per cent increase in total peripheral resistance occurred and this resulted in a 10 per cent decrease in mean arterial pressure. All of these changes were significantly greater than those produced by lidocaine alone. The different cardiovascular performances of the plain lidocaine and the adrenaline containing epidural solutions were attributed exclusively by the authors to the beta-stimulating effects of adrenaline. Bromage (1978) interprets the results of Bonica and his colleagues in a different way, he is of the opinion that there is an 
additional meural explanation. Due to the added adrenaline the intensity of the sympathetic denervation increases and this results in a more pronounced cardiovascular disturbance.

\subsection{Recognised perforation of the dura mater}

The percentage of dura perforations is greatly dependent on the experience of the person carrying out the anaesthesia. If the percentage of dural perforations goes beyond 1 per cent then this demands a review of the epidural puncture technique and of the materials used (Bromage, 1978). Most dural perforations occur in the hands of inexperienced personnel or in training situations. Crawford (1972-a) detailed a 7.6 per cent dural perforation rate. The population studied amounted to 923 patients who were given lumbar epidural anaesthesia during childbirth. What was involved here was the first group of 923 epidural punctures in a teaching clinic. On further analysis it emerged that the percentage of dural perforations fell as experience increased. If the person undergoing training has performed less than ten epidural punctures the number of dural perforations is 13 per cent. If between 10 and 49 punctures have been done then the percentage is 6 . The percentage falls to 2 if the doctor has done more than 60 epidural punctures. Crawford (1972-b) saw the percentage of dural perforations fall to $3.2 \mathrm{per}$ cent in his training clinic on completing the second 1000 epidural punctures. Between 1973 and 1979,8638 deliveries were done under epidural anaesthesia: the frequency of dura perforations was 0.4 per cent (Doughty, 1980). It must be appreciated that in a pregnant woman or one in childbirth, the anatomical proportions of the epidural space are infavourable as compared with non-pregnant counterparts. The perforations were usually done with the Tuohy needle (Crawford, 1972-b). However, it is also possible to perforate the dura mater with the catheter, especially if it is a stiff one with a straight and sharp end.

Generally one is in no doubt if the dura mater is perforated - a copious quantity of cerebrospinal fluid flows out via the needle. In a few cases however, there can be doubt as to whether the liquid is cerebrospinal fluid or a small quantity of the local anaesthetic leaking back. A few methods of differentiating between cerebrospinal fluid and local anaesthetic are mentioned below:

\section{Temperature:}

If the liquid is cold then probably it is the local anaesthetic, if it is at body temperature then one can take it that it is probably cerebrospinal fluid.

\section{Glucose content:}

With the aid of a bedside glucose determination one can determine the glucose content of the liquid. If glucose is present then probably the dura mater has been perforated and cerebrospinal fluid is leaking out.

3. $p H$ :

Generally a distinction between cerebrospinal fluid and local anaesthetic can also be 
made depending on the $\mathrm{pH}$ of the liquid. Cerebrospinal fluid has a $\mathrm{pH}$ of about 7 whereas the usual local anaesthetics have a pH which is lower than 5 .

Headache is the most frequent symptom following dural perforation. Crawford (1978) is of the opinion that there is a strongly positive correlation between the frequency of occurrence and seriousness of the headache with the diameter of the perforation opening. About 70 per cent of patients with a dural perforation develop the classical picture of post-spinal headache if no other therapy is given than bed rest and relative over-filling of the vascular system (Crawford, 1978). The headache can occur as a frontal pain or an occipital one and some patients have neck pain. True meningism, however, is seldom observed and usually the neck pain is the result of keeping the head still in a cramp-like fashion, done to minimise the headache. The headache begins about 12 hours after delivery and seldom during labour. Patients often say that on the fifth postpartum day, the headache has lessened and on the sixth day it has for the most part disappeared. In some patients this period of headache lasts somewhat longer. Crawford (1978) speaks of a nine day headache. This occurs in patients who following dural perforation were encouraged to bear down during the second stage or who had a double dural tap. If the headache is only slight then bed rest and administration of analgesics can usually solve the problem. However, if there is serious headache then most authors advise the injection of an isotonic saline solution into the epidural space.

With the following therapeutic measures, Craft et al., (1973) observed a fall in the frequency of post-spinal headache from 76.5 per cent to 12.5 per cent:

1. Immediately after delivery, $60 \mathrm{ml}$ of isotonic saline solution is injected into the epidural space.

2. After a few hours this procedure is repeated.

3. Forced fluids ( 3 I daily either orally or intravenously).

4. The application of a tight abdominal binder for 3 days.

With the following regime a fall from 70 per cent to 23 per cent in frequency of post-spinal headache was observed by Crawford (1978):

1. Hartmann's solution is infused via an epidural catheter at a dose of 1.51 per 24 hours. This therapeutic measure is continued for between 24 and 36 hours.

2. During this period patients are confined to bed rest.

3. In order to avoid constipation the patients are given laxatives.

In order to combat post-spinal headache, Gormley (1960) introduced the 'blood patch". Here, $10 \mathrm{ml}$ of the patient's blood, obtained in a sterile manner, is injected into the epidural space so that the opening in the dura mater is filled with a blood clot.

Crawford used this technique if his measures described above did not lead to the desired results. He obtained a success rate of 100 per cent if he used $20 \mathrm{ml}$ of blood instead of 10 ml. Ostheimer et all., (1974), Abouleish et al., (1975), Abouleish (1978), and Bart and Wheeler (1978) achieved a success rate of about 90 per cent. The epidural space has its 
greatest diameter in the median line so one must always aim to perforate the flaval ligament with the Tuohy needle in the median line. Use of a supple, not soo stiff an epidural catheter is advocated from the point of view of prevention of dural perforation. The patient must be made thoroughly aware that the success of the epidural puncture and the avoidance of dural perforation is also dependent on her cooperation. With restless patients the chance of dural perforation increases. Further, in order to prevent dural perforation, one should guard against rotating the Tuohy needle while the point of the needle is in the epidural space.

\subsection{Unrecognized perforation of the dura mater}

One of the most serious complications of epidural anaesthesia can be caused by administering the local anaesthetic to the wrong place. This may be subarachnoidai, intravenous or subdural. The dose of the local anaesthetic needed for epidural anaesthesia is about five to ten times higher than the dose needed for subarachnoid anaesthesia (Abouleish, 1977). Thus subarachnoid injection of the local anaesthetic that was intended for epidural injection may produce so-called total spinal block. The symptoms of total spinal block consist of serious cardiovascular depression, apnoe and loss of consciousness. Treatment must be aimed at maintaining and supporting the vital functions of circulation and respiration and at combatting hypotension. Very often this serious complication can be avoided by doing an aspiration test prior to administration of the local anaesthetic via the catheter. Literature data show that consistent administration of a test dose cannot always prevent total spinal block. This is probably explicable on the basis of too low a test dose or too short a time interval between test dose and therapeutic dose (Scott, 1977-a +b). Philip and Brown (1976) describe a case in which total spinal block developed on administering a top-up dose after successful epidural anaesthesia had been achieved following the first injection via the catheter. It can be concluded from this that the catheter had in the course of time probably perforated the dura mater. A possible cause could be an increase in cerebrospinal fluid pressure and distention of the dural sac during a contraction which enabled the catheter tip to'erode' the dura and finally to perforate it.

\subsection{Extensive epidural block}

An extensive epidural block may arise if too high a dose of local anaesthetic is given or if it is injected with too much force during an uterine contraction if the pressure in the epidural space is increased. The local anaesthetic may then reach the uppermost thoracic segment or even the cervical segments, with all the consequences that that entails. Between the dura mater and the arachnoid there is a potential space. If the local anaesthetic is injected into this space a very extensive nerve block can develop (Bromage, 1978).

\subsection{Injection of the local anaesthetic into an epidural vein}

Puncture of a vein in the extensive internal vertebral venous plexus with the needle or the catheter is no rarity. Providing that there are no coagulation disorders, the bleeding generally stops in a short time. During pregnancy and labour this complication occurs 
more frequently because the internal vertebral venous plexus is distended during pregnancy as a result of collateral circulation. The collateral circulation dewelops because the inferior vena cava may be partly obstructed by the gravid uterus. If the entire dose of local anaesthetic is injected into an epidural vein, toxic phenomena are usually triggered. Bonica (1972) arbitrarily divided the symptoms of the toxic reactions into slight, moderate and serious groups. With slight toxic doses the patients complain of palpitation, a metalic taste, dryness of the mouth and throat, tinnitus, vertigo and headache. The patients often manifest excitement and confusion sometimes vomiting. If the levels of the local anaesthetic in the blood rise then moderate toxic reactions occur which are characterised by a progressive worsening of the above-mentioned symptoms. The patients become more confused, sleepy and loose consciousness and develop muscular twitchings, and in serious situations, convulsions. Normal respiration is hindered by the convulsions and hypoxia and cyanosis occur, this is coupled with hypertension and tachycardia. The serious toxic reactions are characterised by coma, serious hypotension, bradycardia and a reduced respiratory function which often leads to apnoe. Usually the respiratory phenomena precede the vascular symptoms (Bonica, 1972). If the blood concentrations of the local anaesthetic agent gradually increase then the above-mentioned three phases follow one another successively.

Injection of the local anaesthetic into one of the epidural veins can often be prevented by the following measures:

1. One must try to introduce the epidural catheter as carefully as possible into the median line because the veins are mainly located in the lateral parts of the epidural space.

2. An aspiration test should always be done before injecting the local anaesthetic into the epidural catheter. If blood is aspirated then the catheter should be withdrawn a little. If the aspiration test is still positive then it is better to repeat the puncture in another intervertebral space.

3. A test dose should always be given prior to administering the full therapeutic dose.

4. The epidural catheter should not be pushed too far into the epidural space because the risk of rupturing a vein increases.

If there is adrenaline in the local anaesthetic then one notices almost immediately that the catheter is in a blood vessel because of the effect of the adrenaline on the vascular system. If there is no adrenaline in the local anaesthetic one can identify the intravenous localisation of the catheter by the occurrence of the symptoms as described above.

\subsection{Breakage of the epidural catheter or of the Tuohy needle}

Breakage of the epidural catheter is a rarity and is usually to be ascribed to careless epidural puncture technique. It is usually caused by pulling back the catheter while the Tuohy needle is still in place so that the sharp edge of the needle is able to cut off a piece of the catheter. The needle must always first be withdrawn. Some catheters become brittle and fragile if they remain in situ for several days and then they may break off. Most modern epidural catheters in use now no longer have this disadvantage. In the 
literature there is a concensus of opinion that says that if it gives rise to no complaints, a bit of broken off catheter does not demand surgical intervention (Bonica, 1972; Abouleish, 1977; Crawford, 1978; Bromage, 1978). If a bit of Tuohy needle breaks off then surgical exploration must follow. Breaking off of a Tuohy needle is always to be ascribed to a rough and technically wrong puncture technique.

\subsection{Neurological complications}

In view of the anatomical proporties, direct damage to the spinal cord with the Tuohy needle or the catheter can practically be excluded as long as the puncture site is lower than the second lumbar vertebra. On pushing the catheter up into the epidural space it is possible that the tip of the catheter hits a nerve root. This will be accompanied by pain or paresthesia in the dermatome concerned. If this happens, the catheter should not be pushed any further forward in order to prevent damage to the nerve. In such cases, it is better to withdraw the catheter a little. If the patient continues to experience pain then under no circumstances the local anaesthetic agent should be injected for if it is injected into a nerve there can be temporary or permanent damage to the nerve caused by compression and ischemia (Usubiaga, 1975). Crawford (1972-b) mentioned a few patients who experienced numbness of the lateral part of the thigh up to six weeks after the delivery. Crawford does not come to a clear conclusion as to whether this was connected with the epidural anaesthesia. Usubiaga (1975) observed paresthesia in 0.07 per cent of patients after epidural anaesthesia.

Because of compression, haematoma formation in the epidural space can also cause neurological problems. The epidural space has an extensive venous plexus and this can be lacerated with the Tuohy needle or the epidural catheter and give rise to bleeding into the epidural space. Usually, this bleeding stops after a short time without producing neurological complications. However, if there are any coagulation disorders, or if the patient is using anticoagulants then the chance of haematoma formation is increased and with it so is the risk of neurological phenomena. Most authors are of the opinion that coagulation disorders or the use of anticoagulants represent a contraindication for epidural anaesthesia (Abouleish, 1977; Crawford, 1978; Bromage, 1978). Whether or not this also applies to low dose subcutaneous heparin therapy, which is being applied more and more, is a matter of current discussion. If an epidural haematoma causes neurological phenomena then it must be surgically treated.

The blood supply of the spinal cord is vulnerable and very sensitive to sudden hypotension. The spinal arteries have a very low resting tone and are not very sensitive to vasoactive agents in comparison with the rest of the circulation (Bromage, 1978). Thus blood flow through the capillary bed is mainly dependent on the difference in pressure between the arterial and venous sides of the vascular bed. This difference in pressure is determined by the arterial blood pressure and the pressure on the venous side of the vascular bed. In pregnancy the venous plexus in the epidural space serves as collateral circulation because of the pressure of the gravid uterus on the inferior vena cava. If the woman lies on her back, the blood loading in the epidural venous space will further increase and this situation will have a negative effect on the above-mentioned pressure difference. The combination of arterial hypotension and venous engorgement 
will on theoretical grounds endanger the blood supply to the spinal cord and could bring about the so-called anterior spinal artery syndrome. The syndrome is characterised by paresis or paralysis of the legs and this is due to ischemia of the anterior two thirds of the lower part of the spinal cord.

In experiments on dogs, it has been demonstrated that this syndrome arises if adrenaline is injected into the epidural space (Catterberg and Insausti, 1964). In this investigation, the adrenaline dose was 100 to 600 times higher than that which is normally used in clinical situations. Bromage (1978) considers it to be most unlikely that adrenaline at a concentration of $1: 200,000$ or $1: 300,000$ could lead to ischaemia of the spinal cord. In his monograph, Bromage (1978) refers to seven patients with this syndrome who are mentioned in the literature. They were all surgical patients who were older than 55 years. It is probably that this syndrome may arise during epidural anaesthesia in patients with one or more of the above-mentioned etiological factors and arteriosclerotic spinal arteries. However, it seems unlikely that it would occur in obstetric epidural anaesthesia.

Horner's syndrome is a benign complication that may occur during epidural anaesthesia. The sympathetic innervation that controls pupil size arises from the cervical spinal segments. If these sympathetic fibers were to be blocked by epidural anaesthesia then Horner's syndrome would result (Abouleish, 1977). However, Horner's syndrome has also been observed to occur in women in childbirth whose hypalgesia level goes no further than the seventh thoracic spinal segment (Mohan and Potter, 1975; Carrie and Mohan, 1976). Collier (1975) has put forward two explanations for the blockade of the cervical sympathetic nerves: extensive paravertebral spread of the local anaesthetic and spread of the local anaesthetic via the internal vertebral venous plexus.

\subsection{Inflammatory processes in the epidural space}

Infection of the epidural space may lead to cellulitis, epidural abscess, arachnoiditis, myelitis or a combination of several of these conditions. Such serious complications, fortunately, are extremely rare. The symptoms consist of severe back pain, fever, neck stiffness and leukocytosis. Investigation of the cerebrospinal fluid reveals an elevated protein content and a leukocytosis. The myelogram always exhibits anomalies. If an epidural abscess is diagnosed, it should be surgically drained and then the patients should be treated with antibiotics. Although epidural infections are usually caused by bacteremia, one should try to observe as strict asepsis as possible during the introduction of the catheter and during the whole procedure of the epidural anaesthesia. It is also advisable to use a new sterile disposable syringe for every repeat injection of local anaesthetic into the catheter. Due to fear of infections, bacterial filters have been introduced which can be placed between the syringe and the catheter or Tuohy needle. Abouleish et al., (1977) came to the conclusion in their study that use of bacterial filters made no difference to the results of bacterial cultures of samples taken at different levels of the catheter. Bromage (1978) subscribes to this opinion. Various authors (Bromage, 1978; Crawford, 1978) consider the use of a filter to be desirable for other reasons: if ampoules are used then the thought of glass particles in the local anaesthetic is unimaginably horrible. These glass particles will be sieved out by the filter, as will some 
other impurities. In recent decades there has been regular mention of granulomas in the epidurall space caused, for example, by talc particles. It is possible that this problem can be partly avoided by the routine use of filters. It would seem that vials are to be preferred over ampoules from the point of view of prevention of contamination. When the puncture is made with the Tuohy needle, a piece of punched-out epidermis can be brought into the epidural space with the tip of the needle. This can be the cause of the formation of a cyst in the epidural space. It sometimes takes years before such a cyst clinically manifests itself. In order to prevent this complication it seems a good idea to make a small incision in the skin prior to making the puncture with the Tuohy needle.

\subsection{Headache and back pain}

Mention has already been made in section 6.2 of the headache which arises following perforation of the dura mater. Moir and Davidson (1972), Grove (1973), Crawford (1978) and Jouppila (1978-c) found no difference in the frequency of the occurrence of headache after birth between those who had had epidural anaesthesia during labour and those who had not.

If the puncture is not done atraumatically, or if a lot of fluid is injected into the tissues around the epidural space, the patients may complain of slight back pain for one or two days. This pain increases with movement and subsides with rest (Bromage, 1978).

\subsection{Bladder dysfunction following epidural anaesthesia}

Bladder dysfunction occurs in about 15 per cent of patients post partum (Abouleish, 1977). This is mainly caused by the birth of the child and possible trauma as a result of assisted delivery and is not dependent on whether or not epidural anaesthesia was given during labour (Crawford, 1972-a; Grove, 1973; Jouppila, 1978-c). In order to prevent catheterisation of the bladder during delivery as far as possible, it is advocated that the patient be encouraged into spontaneous micturition before the epidural anaesthesia is carried out and before each top-up dose.

\subsection{Allergic reactions to the local anaesthetic agent}

Allergic reactions to the local anaesthetic are extremely rare. These reactions occur more frequently with the ester type of local anaesthetic than with the amide type (Abouleish, 1977). According to Bromage (1978), the literature has never mentioned a properly documented case of allergic reaction to the amide type of local anaesthetic. The allergic reactions may vary from urticaria, conjunctivitis and rhinitis to Quincke"s oedema in association with bronchospasm. The most serious situations involve anaphylactic shock. In establishing a differential diagnosis, the following conditions must be considered: overdose of the local anaesthetic, overdose of adrenaline, vasovagal collapse and oversensitivity to the chemical substances which are added to the local anaesthetic to preserve it.

\subsection{Shivering}

About a third of the women who are given epidural anaesthesia during labour start to shiver (Bromage, 1978). The exact cause of this is not clear. Probably, the cause has to 
do with a short-lasting disturbance in temperature regulation as a result of the sudden vasodilatation (Bromage, 1978). Webb et al., (1981) found no correlation between the temperature of the local anaesthetic agent administered and the frequency of occurrence of shivering. The precise cause of this phenomenon remains unclarified. 


\section{Patients and methods}

The investigation described in this thesis was carried out in the department of obstetrics and gynecology of the 'De Wever Ziekenhuis" at Heerlen in the period March 1977 to March 1979. It involved a prospective, non-randomised study into the effects of epidural anaesthesia during labour on:

1. The foetal heart rate and the short term and long term irregularity in the foetal heart rate.

2. The uterine contractions.

3. The acid-base balance of mother and child.

4. The concentration of the local anaesthetic in the maternal plasma and in the plasma of the umbilical cord.

5. The maternal blood pressure and heart rate.

All the patients were informed beforehand about the nature and aims of the investigation and were involved in the investigation only after informed consent.

\subsection{Patients}

In order to be included in this investigation, the patients had to meet the following selection criteria:

1. Healthy primiparae aged between 18 and 25 years.

2. Undisturbed pregnancy with amenorrhoea between weeks 37 and 42 weeks.

3. Single pregnancy.

4. No use of sedatives, analgesics nor spasmolytic agents during the previous four weeks of pregnancy, nor during labour.

5. Foetus in occiput presentation.

6. Foetal head engaged in the pelvis.

7. Cervical dilatation between 3 and $6 \mathrm{~cm}$.

8. No use of oxytocic agents.

9. No contra-indications for the following procedures: a. amniotomy

b. placing of a scalp electrode

c. positioning of an intra-uterine pressure catheter.

10. Prior to the investigation, a normal foetal heart rate pattern (assessed according to Hon's criteria, 1968).

The women thus selected were not randomly assigned to one of two groups but after they had given their permission to be involved in the investigation they were allowed to choose for themselves whether they wanted to be in the control group or in the epidural group. The women in the control group were given absolutely no form of pharmacological anaesthesia whilst all the women in the epidural group were given a lumbar epidural anaesthesia. 


\subsection{IComparison of the control group with the epidural group}

As the division of the women over the two groups was not accomplished at random, the two groups had to be compared with regard to variables which might effect the outcome of labour. The results are shown in table $7.1-7.7$.

The differences were tested by means of a so called t-test procedure in the case of a quantitative variable and a chi-square test for a $2 \times 3$ table in the case of a qualitative variable (table 7.2) or Fisher's exact test for a $2 \times 2$ table in the case of yes/no variable (e.g. table 7.6). The t-test procedure consists of a preliminary F-test comparing the variances in both groups, followed by Student's t-test for two samples if the variances do not and by the Welch t-test if the variances do differ significantly.

The control group consisted of 22 women, the epidural group of 20 . No significant differences were found between the two groups as regards age, body height, body weight and duration of amenorrhea (table 7.1).

Table 7.I Age, body height, body weight and duration of amenorrhoea in the control group and in the epidural group $(\tilde{x} \pm S D)$.

\begin{tabular}{lccc}
\hline & control group & epidural group & p value \\
\hline age (years) & $26.3 \pm 3.0$ & $25.9 \pm 3.5$ & $>0.1$ \\
body height (cm) & $164.7 \pm 5.7$ & $164.9 \pm 6.4$ & $>0.1$ \\
body weight (kg) & $70.9 \pm 7.8$ & $73.2 \pm 8.5$ & $>0.1$ \\
duration of amenorrhea & $283 \pm 5$ & $283 \pm 5$ & $>0.1$ \\
\hline
\end{tabular}

The position of the foetal head in the birth canal at the start of the investigation is given for both groups in table 7.2 .

Table 7.2 Position of the foetal head in the birth canal at the start of the investigation in the control group and the epidural group.

\begin{tabular}{|c|c|c|c|c|}
\hline & \multicolumn{2}{|c|}{$\begin{array}{c}\text { control group } \\
n=22\end{array}$} & \multicolumn{2}{|c|}{$\begin{array}{c}\text { epidural group } \\
n=20\end{array}$} \\
\hline & $n$ & 管 & $n$ & 䇰 \\
\hline \multicolumn{5}{|l|}{$\mathrm{OA}$} \\
\hline LOA & 5 & 22.7 & 5 & 25.0 \\
\hline \multicolumn{5}{|l|}{ ROA } \\
\hline \multicolumn{5}{|l|}{ LOT } \\
\hline ROT & 12 & 54.6 & 8 & 40.0 \\
\hline \multicolumn{5}{|l|}{$O P$} \\
\hline LOP & 5 & 22.7 & 7 & 35.0 \\
\hline ROP & & & & \\
\hline
\end{tabular}

No significant difference was found between the two groups regarding position of the foetal head $(p>0.1)$. 
At the start of the investigation the average dilatation in the control group amounted to $4.4 \mathrm{~cm}$ while the average dilatation in the epidural group amounted to $4.7 \mathrm{~cm}$ (table 7.3). The time between the start of the investigation and full dilatation was on average 170 minutes in the control group and 219 minutes in the epidural group (table 7.3). The average duration of the second stage in the control group was 38 minutes whereas this was on average, 40 minutes in the epidural group (table 7.3).

Table 7.3 Dilatation at the start of the investigation, time period between start of investigation and full dilatation, duration of the second stage $(\bar{x} \pm S D)$ in the control group and in the epidural group.

control group epidural gromp p value

$\mathrm{n}=22 \quad \mathrm{n}=20$

dilatation at start of

investigation $(\mathrm{cm})$

$4.4 \pm 1.6$

$4.7 \pm 0.8$

$>0.1$

time between start of investigation and full dilatation (min)

$170 \div 77$

$219 \pm 143$

$>0.1$

duration of the second

stage (min)

$38 \pm 23$

$40 \pm 21$

$>0.1$

In 18 patients in the control group the membranes were artificially ruptured, whereas in the epidural group this was the case for 10 patients. This difference proved to be just significant $(p=0.05)$. Furthermore, it emerged that there was a significant difference between the two groups as far as the time was concerned between rupture of the membranes and the start of the investigation (table 7.4). It may probably be concluded from this that where the foetal membranes were ruptured early in the first stage irrespective of whether this was artificial or not - the women expressed a preference for inclusion in the epidural group.

Table 7.4 Time interval between rupture of the membranes and the start of the investigation $(\bar{x} \pm S D)$ in the control group and the epidural group.

$\begin{array}{ccc}\text { control group } & \text { epidural group } & \text { p value } \\ n=22 & n=20 & \end{array}$


No significant differences between the two groups were found as regards birth weight and placental weight (table 7.5).

Table 7.5 Birth weight of the child and the weight of the placenta in the control group and in the epidural group $(\bar{x} \pm S D)$.

\begin{tabular}{|c|c|c|c|}
\hline & $\begin{array}{c}\text { control group } \\
n=22\end{array}$ & $\begin{array}{l}\text { epidural group } \\
n=20\end{array}$ & p walue \\
\hline birth weight (g) & $3316 \pm 396$ & $3520 \pm 397$ & $>0.1$ \\
\hline placenta weight $(\mathrm{g})$ & $441 \pm 81$ & $477 \pm 93$ & $>0.1$ \\
\hline
\end{tabular}

Since umbilical cord problems can have an effect on the foetal condition, it was investigated if entanglement of the fetus by the umbilical cord occurred significantly more often in one group than in the other. The difference between the two groups was not significant (table 7.6).

Table 7.6 Number of umbilical cord entanglements in ihe control group and in the epidural group.

$\begin{array}{ccc}\text { control group } & \text { epidual group } & \text { p value } \\ n=22 & n=20 & \end{array}$

number of patients in whom

there was entanglement

10

4

$>0.1$

Table 7.7 gives the number of operative deliveries as well as the type of delivery and the indication.

Table 7.7 The number of operative deliveries in the control group and in the epidural group.

\begin{tabular}{llcc}
\hline $\begin{array}{l}\text { type of } \\
\text { delivery }\end{array}$ & $\begin{array}{l}\text { indication for } \\
\text { operative delivery }\end{array}$ & control group & epidural group \\
\hline $\begin{array}{l}\text { fradycardia } \\
\text { frolonged } \\
\text { second stage }\end{array}$ & 3 & 4 \\
$\begin{array}{l}\text { bradycardia } \\
\text { extraction }\end{array}$ & 0 & 0 \\
\hline $\begin{array}{l}\text { prolonged } \\
\text { second stage }\end{array}$ & 1 & 3 \\
\hline
\end{tabular}


It emerges from table 7.7 that in the epidural group operative delivery was carried out seven times on the indication of prolonged second stage. In the control group this was the situation in only three cases. This difference is not significant $(p=0.15)$.

\subsection{Epidural puncture technique}

The epidural puncture technique which was used in this investigation has already been described in chapter 4.1. Epidural puncture was successful at the first attempt for all the women. No serious complications occurred during or after the epidural puncture.

\subsubsection{Dosage of the local anaesthetic agent}

Bupivacaine (Marcaine ${ }^{\circledR}$ ) was used as the local anaesthetic at a concentration of 0.25 per cent to which adrenaline was added at a concentration of 1:200,000. After injection of a test dose of $2 \mathrm{ml}, 8 \mathrm{ml}$ was administered via the catheter five minutes later. A top up dose of $8 \mathrm{ml}$ was given every two hours $(2 \mathrm{ml}$ test dose and five minutes later $6 \mathrm{ml}$ therapeutic dose). During the second stage no top-up dose was given, not even when the 2 hour period had passed. Based on a clinical condition, a single exception was made here for one patient - just prior to vacuum extraction this patient was given a top-up dose.

Before the administration of the local anaesthetic, an intravenous infusion of isotonic saline solution was given. $400 \mathrm{ml}$ was administered in a period of between five and ten minutes with a view to obtaining good filling of the vascular system.

\subsubsection{The level of the epidural hypalgesia}

The level of epidural hypalgesia was assessed following every dose of local anaesthetic into the epidural space. This test was done with the aid of a neurological needle which was used to determine the uppermost and lowermost limits of reduced sensitivity. Furthermore, testing was also done to find out whether there were any unblocked segments within the hypalgesic area. The test was done in both the right and left halves of the body at 30, 60,90 and 120 minutes after every epidural injection. No unblocked segments were found in any of the patients. In three of the patients there was asymmetry between the left and right body halves as regards hypalgesia but was limited to one dermatome. The most distal dermatome is given in the tables for these patients. Thirty minutes after the first epidural injection there was satisfactory anaesthesia in all the patients. Using the above-mentioned testing, it was determined that in all patients the tenth to twelfth thoracic segments inclusive were blocked. It has already been stated in chapter two that during the dilatation phase pain stimuli are conducted via afferent nerves which make contact with the central nervous system at the level of the tenth to twelfth thoracic segments inclusive. It is therefore important that these segments are blocked during epidural anaesthesia. Table 7.8 gives the uppermost limit of the hypalgesic area 30 and 90 minutes after administration of the first epidural injection for the various patients. Table 7.9 gives the lowermost limit for the various patients. 
Table 7.8 Upper limit of hypalgesic area, 30 and 90 minutes after the first epidural injection.

\begin{tabular}{lcc}
\hline $\begin{array}{l}\text { upper limit of } \\
\text { bypalgesic area }\end{array}$ & $\begin{array}{c}30 \text { min after } \\
\text { the first } \\
\text { epidural injection } \\
\mathbf{n}\end{array}$ & $\begin{array}{c}90 \text { min after } \\
\text { the first } \\
\text { epidural injection } \\
\mathbf{n}\end{array}$ \\
\hline $\mathbf{T}_{4}$ & $\mathbf{1}$ & - \\
$\mathbf{T}_{5}$ & - & 2 \\
$\mathrm{~T}_{6}$ & 1 & 1 \\
$\mathbf{T}_{7}$ & 3 & - \\
$\mathbf{T}_{8}$ & 3 & 2 \\
$\mathbf{T}_{9}$ & 4 & 1 \\
$\mathbf{T}_{10}$ & 8 & 14 \\
$\mathbf{T}_{11}$ & - & - \\
$\mathbf{T}_{12}$ & - & - \\
\hline
\end{tabular}

Table 7.9 Lower limit of hypalgesic area, 30 and 90 minutes after the first epidural injection.

\begin{tabular}{|c|c|c|}
\hline $\begin{array}{l}\text { lower limit of } \\
\text { hypalgesic area }\end{array}$ & $\begin{array}{c}30 \text { min after } \\
\text { the first } \\
\text { epidural injection } \\
\text { n }\end{array}$ & $\begin{array}{c}90 \mathrm{~min} \text { after } \\
\text { the first } \\
\text { epidural injection } \\
\mathrm{n}\end{array}$ \\
\hline $\mathbf{L}_{4}$ & - & 1 \\
\hline $\mathbf{L}_{\mathrm{s}}$ & - & 1 \\
\hline$S_{1}$ & - & - \\
\hline$S_{z}$ & - & 1 \\
\hline $\mathrm{s}_{\mathrm{y}}$ & 3 & - \\
\hline$S_{4}$ & - & - \\
\hline$S_{s}$ & 17 & 17 \\
\hline
\end{tabular}

Following a top-up dose of the local anaesthetic into the epidural space there was always satisfactory analgesia and the hypalgesic level always reached the tenth thoracic spinal segment. The fourth thoracic spinal segment was reached as the highest hypalgesic level. Following a top-up dose the fifth sacral spinal segment was always reached, representing the lower limit of the hypalgesic area.

\subsection{Calculation of the parameters from the foetal cardiotocogram}

\subsection{The heart rate pattern}

The foetal heart rate pattern was recordled throughout the entire period beginning with the start of the investigation up to the birth of the child and this was done for all the 
patients in the control group and in the epidural group. The foetal heart rate pattern was taken from the foetal ECG on the basis of the time interval between two successive $R$ peaks. The foetal ECG was obtained via a foetal scalp electrode (Corometrics spiral electrode B-2462). The foetal tachogram was recorded on paper using a Hewlett Packard cardiotocograph (HP 8030A). Similarly, the foetal ECG was recorded on a four-channel analog magnetic tape recorder (HP 3964A). The running speed of the analog recorder was $2.38 \mathrm{~cm} / \mathrm{s}$. All the patients were positioned in the left or right lateral position during the first stage of labour. If any patient was in the supine position for a short period - for whatever reason - this was recorded on one of the channels of the analog recorder. The recorded foetal ECG for such a period was not included in the study. An exception was made only for the ten minute period following an epidural injection. During this period the woman was put into a half-sitting position. The foetal ECG that was recorded with the patient in this position was included in the study. The same channel of the analog recorder was used to register other data by marking, e.g. "atypical disturbances" (such as vaginal examination, foetal blood sampling, micturition and defecation), the moment of full dilatation and the moment where patients actively assisted in bearing down. ECG recorded during periods of atypical disturbances were not included in the study either.

\subsubsection{1 $R$ peak detection in the foetal PQRST complex}

A digital computer system was used off line to determine the RR interval from the ECG recorded on the analog recorder. In order to make good $R$ peak detection possible a bandpass filter (15-60 Hz) was used to filter the foetal ECG. Detection of the $R$ peak was done using a level detection procedure. During playback from the analog recorder the bandpass filter was adjusted interactively if necessary in order to guarantee optimal $\mathbf{R}$ peak detection. The RR interval length was stored digitally in the memory of a PDP-1 1 computer in units of 0.8 milliseconds.

\subsubsection{Artefact rejection}

The artefacts which occurred in the RR interval signal were rejected in a manner such as described by Van Geijn et al., (1980). The method is based on an analysis of the distribution of the RR interval differences in relation to the RR interval duration (Jongsma et al., 1978) and is summarised below.

In the first instance, an $R R$ interval $t_{i+1}$ was accepted provided that it met the following criteria:

$$
t_{i}-0.43 d_{i}<t_{i+i}<t_{i}+d_{i}
$$

Where $d_{i}=t_{i}-300$, with $d_{i}$ at least $20 \mathrm{~ms}$. $t_{i}$ and $t_{i+i}$ are successive RR intervals. In the second place, $\mathrm{t}_{\mathrm{i}+1}$ was only accepted if at least three successive RR intervals matched the above-mentioned formula. 


\subsubsection{The parameters calculated from the foetal heart rate}

Over successive periods of 30 seconds, the following parameters were calculated from the RR interval:

1. The median interval duration (RR interval length).

2. The interval difference index (ID index).

3. The long-term irregularity index (LTI index).

De Haan (1971) demonstrated the strong relationship between the short term irregularity index (beat to beat fluctuations) and the duration of the heart period. In order to compare beat to beat fluctuations at different heart rate levels, a correction for heart rate must be made. The ID index was developed for this reason (Van Geijn et al., 1980). The ID index quantifies the difference between successive RR intervals over a period of 30 seconds and simultaneously takes into account the RR interval duration present at any moment during these 30 seconds. The ID index is defined as the interquartile range over 30 seconds of:

$g_{i}\left(t_{i}-t_{i-1}\right) \quad(i=2, \ldots \ldots, n)$

In this formula $g_{i}$ is weighting factor that is dependent on the actual mean $R \mathbf{R}$ interval duration. $t_{i-1}$ and $t_{i}$ are successive RR-interval lenghts.

The slower fluctuations of the foetal heart rate are quantified by means of the LTI index. This index was developed by de Haan (1971). The LTI index is defined as the interquartile range over 30 seconds of:

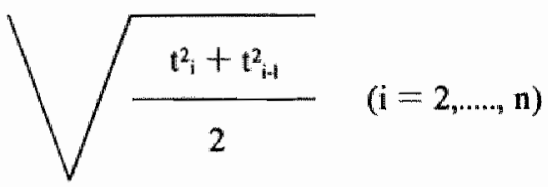

These foetal heart rate parameters were determined only between uterine contractions. In the ten seconds prior to a contraction and the thirty seconds immediately after one, no heart rate parameters were determined. Thus, the analysis of the heart rate parameters was done partly on the basis of the detected uterine contractions. The way in which the contractions were recognised and the beginning and end of a contraction detected are discussed in section 7.3.2.1. If there were artefacts present for more than ten per cent of a 30 second period then the parameters were not calculated.

\subsubsection{The tocogram}

The uterine contractions were measured with a transvaginal, transcervical, intraamniotically positioned pressure catheter which was filled with physiological saline solution. An angiography catheter was used (William Cook Europ APS type BP). This 
was a Charriere 7, pig-tail catheter with one end - standing opening and 12 side standing openings.

This catheter was connected to a Hewlett Packard pressure transducer (HP 1280B) which in turn was connected to a cardiotocograph (HP 8030A). The height of the transducer was adjusted to the level of the uterine fundus. Calibration of the transducer was done prior to each recording and was achieved by means of a mercury manometer. At regular intervals the catheter was flushed with isotonic saline solution in order to keep the catheter properly open. The pressure signal coming from the cardiotocograph was fed to the analog recorder (HP 3964A). Recording of the intra-uterine pressure was preceded by a pressure calibration of $0-100 \mathrm{mmHg}$. This calibration defined the start of the recording. The uterine contractions were recorded for all of the patients during the whole of labour. The uterine contractions that occurred during atypical disturbances (defecation, micturition, vaginal examination and foetal blood sampling) were noted and were not included in the study. Since uterine contractions are also dependent on the position of the woman, uterine contractions occurring during short periods when the woman was in the supine position were also noted and not included in the study. The only exception to this was the ten minute period following an epidural injection. In this period the woman was in a half-sitting position. The uterine contractions that were recorded in this period were included in the study.

\subsubsection{Signal analysis}

The pressure signal that was recorded on the analog recorder was processed off line in a digital computer system (PDP-11 computer). The pressure signal was filtered by a low pass filter $(2.5 \mathrm{~Hz})$. The filtered signal was fed to the analog input of the computer system. The contractions were detected from the pressure curve. The pressure signal was automatically segmented into tone and contractions using a detection and classification program (Kurver, 1978). The beginning and end of a contraction was detected by a rise or fall rate exceeding $0.2 \mathrm{mmHg} / \mathrm{s}$. A number of parameters (i.a. the duration of the rise and fall of the contraction) were used in the classification phase to make a distinction between contractions and disturbances.

\subsubsection{Calculation of the contraction parameters}

The following parameters were determined for all contractions (disturbances were excluded from further analyses):

\section{The amplitude:}

The amplitude was defined as the pressure difference between zero and the maximum of the contraction (figure 7.1). The amplitude was determined from the digitally filtered pressure curve (moving average, window width: $20 \mathrm{~s}$ ). For the contractions where the patient did not actively assist in bearing down this corresponds with the maximum of the unfiltered pressure. The maximum of the contraction was expressed in $\mathrm{mmHg}$. Throughout the whole of the recording, the median value of the amplitude was worked out for every five minute period. 


\section{The contraction period:}

The contraction period was defined as the time interval between the beginnings of two successive contractions (figure 7.1). The contraction periods were expressed in seconds. The median value for the contraction period was worked out for every five minute period during the whole of the recording.

\section{The active pressure area:}

In this study, the uterine activity was also quantified by calculating the area under the intra-uterine pressure curve. The active pressure area was defined as the total area between the curve and the tone (figure 7.1). Between the contractions the tone was
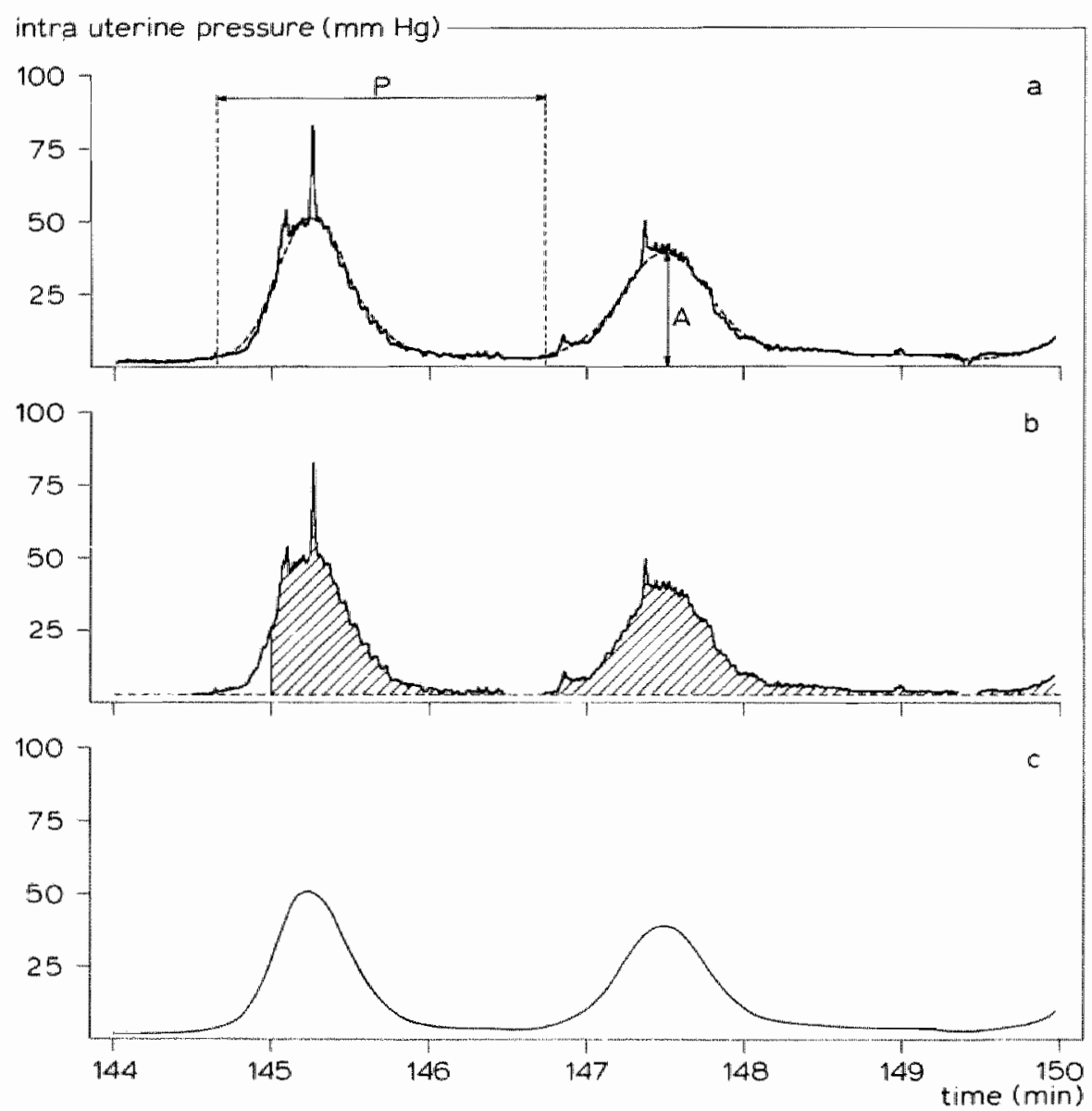

Figure 7.I

a. The uterine contraction curve and the digitally filtered pressure curve (dotted curve). $P=$ comiraction period $A=$ amplitude.

b The active pressure area for a time period of 5 minutes (hatched area).

c. The digitally filtered pressure curve (see also the dotted curve in figure 7.1-a). 
calculated as the average pressure between the end of one contraction and the start of the next one, provided that this period lasted for at least 30 seconds. During contractions the tone was interpolated using a third degree polynomial. During the whole of the recording period, the active pressure area was calculated every five minutes. However, no area was calculated if there was any annotation of an atypical disturbance for more than 30 per cent of the five minute period. If there was an atypical disturbance for between 0 and 30 per cent of the five minute period then the calculated area for the rest of the period was increased in compensation. The pressure areas were expressed in mmHg.min.

\subsubsection{Studied periods}

In the epidural group, the period commencing 30 minutes prior to administration of the epidural anaesthesia was regarded as a base-line control recording period. The effect of the epidural anaesthesia on the foetal cardiotocogram (CTG) was studied both by comparing the CTG from the base-line period with that from the period following the administration of the epidural anaesthesia and by comparing the parameters of the foetal CTG in the control group with those of the epidural group during the last 90 minutes of the first stage. In order to exclude pre-existent differences in CTG parameters, the base-line period of the epidural group was compared with the first 30 minutes of recording in the control group (base-line period of the control group).

Next, a detailed description and schematic representation of the periods studied is presented.

1. The first 30 minutes of recording from the women in the control group (base-line period of the control group) were compared with the 30 minutes prior to administration of epidural anaesthesia in the epidural group (base-line period of the epidural group). The periods to be compared are represented schematically in figure 7.2

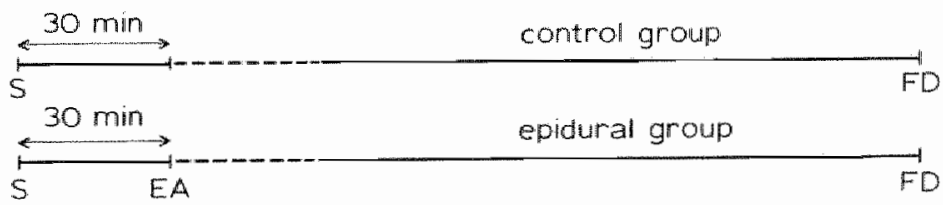

Figure 7.2 Schematic representation of the base-line periods compared in the control and epidural groups.

$S=$ start of the investigation, $E A=$ epidural anaesthesia, $F D=$ full dilatation.

Just before point ' $S$ ' an intra-uterine pressure catheter and a foetal scalp electrode were applicated. These procedures can an effect on foetal heart rate. On the basis of the results in section 8.1.2, it was dediced to shorten the base-line period in both groups to 15 minutes, as far as the heart rate parameters were concerned (cf. figure 8.3). 
2. The base-line period in the epidural group was compared with the 120 minute lasting observation period immediately following administration of the epidural anaesthesia. For heart rate parameters the base-line period was 15 minutes and for contraction parameters it was 30 minutes. The periods to be compared are represented schematically in figure 7.3.

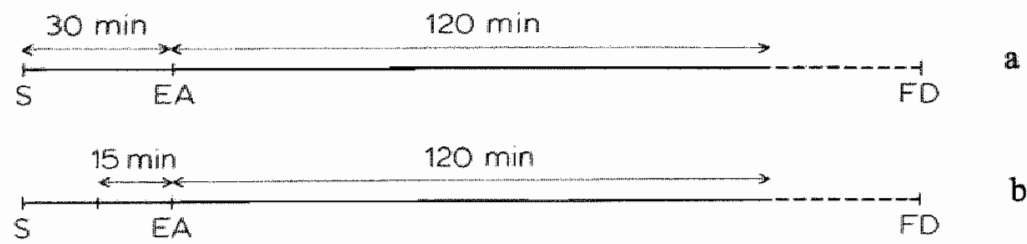

Figure 7.3 Schematic representation of the period's to be compared before and after epidural anaesthesia.

$S=$ start of the investigation, $E A=$ epidural anaesthesia, $F D=$ full dilatation

a. concerns the contraction parameters. $b$. refers to the foetal heart rate parameters.

3. The control group and the epidural group were compared with one another from the point of view of the CTG parameters during the last 90 minutes of the first stage. The periods to be compared are represented schematically in figure 7.4.

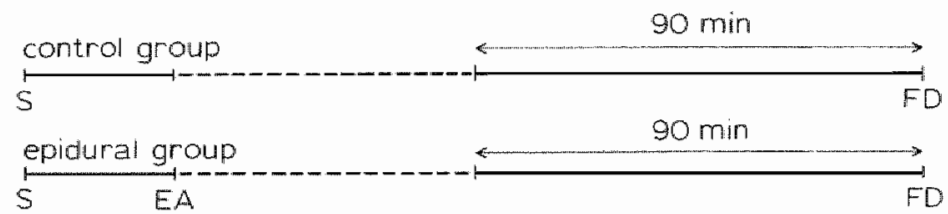

Figure 7.4 Schematic representation of the periods to be compared in the control group and epidural group.

$S=$ start of the investigation, $E A=$ epidural anaesthesia $F D,=$ full dilatation

The moment of full dilatation was determined by vaginal examination. Vaginal examination was done every 2 hours. At a dilatation of between 7 and $10 \mathrm{~cm}$, vaginal examination was done every hour. If full dillatation was suspected on the basis of other observations (e.g. decelerations in the foetal heart rate pattern or maternal efforts to bear down) then vaginal examination was carried out sooner.

\subsubsection{Data handling and statistical analysis}

Prior to statistical analysis, further data reduction of the heart rate parameters took place. The recordings were subdivided into five minute time periods and for each five minute period the median of the heart rate parameters was calculated. The parameters per five minute period formed the basis for further statistical analysis of both the heart rate and the uterine activity. The mean was calculated for each CTG parameter in each. period studied (see section 7.3.3) per patient. Then the group average was calculated together with its associated standard deviation. Differences between the group averages. 
were tested with the t-test procedure and differences between periods in the same group were tested with the paired sample t-test. Three methods were used to study the trend of a parameter:

1. Visual assessment of the course of the parameter in relation to time for individual patients. This is a subjective method, not appropriate to generalised conclusions. But studying the individual graphs leads to detection of extreme situations and it gives a good survey of the individual patients.

2. Visual assessment of the graph of averages. For each time period of five minutes, the average value of the whole group at that moment was calculated. Since in this situation average values are used one may suppose that individual variations are more or less balanced out so that any systematic increase or decrease of the parameter that may be present is made more easily recognisable. However, this method has the following disadvantages:

a. The average course does not have to correspond to a single individual course.

b. The average course may be too much affected by extreme values in specific patients.

3. Calculation of the mean and standard deviation of the slopes of linear regression lines for each patient. This mean slope was tested for deviation from zero by means of the one sample t-test. This method produces reliable results provided that the individual graphs show predominantly a similar course in one direction.

These three approaches were used in combination, in order to establish any common tendency in the individual curves, which showed large variations both within and between patients.

\subsection{Methods concerning the maternal and foetal acid-base balance}

The maternal acid-base balance was determined at the following three moments during labour:

1. At the start of the investigation.

2. At full dilatation.

3. Immediately post partum.

The foetal acid-base balance was determined at the following two moments during labour:

1. At full dilatation.

2. Immediately post partum (from the umbilical artery and vein).

\subsection{Blaod sampling}

Venous blood was used to determine maternal acid-base balance. Blood was taken from one of the veins in the forearm without ligation of the arm. The foetal acid-base balance was determined using blood that had been taken from the foetal scalp (Saling, 1962). A 
glass capillary with a curved tip and containing a heparin thread was used to take the blood from the foetal scalp.

Immediately after delivery the umbilical cord was clamped off and blood samples were taken at once from both the umbilical vein and artery for determination of the acid-base parameters.

\subsubsection{Determination method}

The acid-base balance was determined immediately after sampling of the blood. A Corning 175 Automatic pH/Blood Gas System was used for the measurements of blood $\mathrm{pH}, \mathrm{pCO}_{2}, \mathrm{pO}_{2}$ and calculation of the base-excess. Measurement of $\mathrm{pCO}_{2}$ and $\mathrm{pO}_{2}$ in this equipment is respective accomplished with a severinghaus electrode, and with a Clark electrode. The Siggard-Andersen nomogram was used to calculate the bicarbonate and the base excess.

\subsubsection{Statistical analysis}

The t-test procedure (see section 7.1.1) was used in order to test whether the blood gas parameters differed significantly from one another in the two groups. The test was applied two sidedly at the five per cent level. Student's paired sample t-test was used to test the difference in acid-base parameters between two periods in the same group (two sidedly at the five per cent level).

\subsection{Method for determining the concentration of bupivacaine in the maternal blood} plasma and in blood plasma from the umbilical cord

In order to determine the bupivacaine concentration in the plasma, $5 \mathrm{ml}$ samples of blood were taken from an arm vein at different moments for 15 women from the epidural group. Blood was sampled prior to administration of the epidural anaesthesia. Then blood was sampled at the following times: 10, 15, 30, 45, 90 and 120 minutes after administration of the epidural anaesthesia. The blood was immediately centrifuged and stored at $-20^{\circ} \mathrm{C}$. Six patients were given one or more top-up doses; 30,90 and 120 minutes after each top-up dose maternal venous blood was sampled for determination of bupivacaine concentration.

\subsubsection{Materials and methods}

The determination method that was used in this study was described by Verheesen et al., (1980). The technique is essentialy based on isolation of bupivacaine hydrochloride from the serum using active charcoal and then extraction with dichloromethane. After dry vaporisation the residue is dissolved in water and determined by gas chromatography over three per cent SE-30 at $250^{\circ} \mathrm{C}$. The method is briefly summarised below:

\section{Reagents}

1. Active charcoal (BDH Chemicals Ltd, cat. number 33032). A suspension of $0.4 \mathrm{~g}$ in 0.1 litre $0.75 \mathrm{mmol} / \mathrm{I} \mathrm{HCl}$ is prepared before use.

2. Dichloromethane (analytical grade).

3. Standard solution of bupivacaine- $\mathrm{HCl}, 50 \mathrm{mg} / 1$. 


\section{Extraction}

In a $10 \mathrm{ml}$ centrifuge tube $1 \mathrm{ml}$ of serum is mixed with $2 \mathrm{ml}$ of charcoal suspension, vortexed for 30 seconds and centrifuged 2 minutes. The supernatant is removed by suction, $1 \mathrm{ml}$ of dichloromethane is added, mixed for 45 seconds (Vortex) and filtered over glass wool into a $3 \mathrm{ml}$ tube. The charcoal is rinsed with $1 \mathrm{ml}$ of dichloromethane (Vortex) and the combined organic extracts are evaporated to dryness in a nitrogen stream at $40^{\circ} \mathrm{C}$. The residu in the tube is dissolved in $20 \mu \mathrm{l}$ of water and $2 \mu \mathrm{l}$ of this solution are applied on the gas chromatography column.

\section{Gas chromatography}

A Packard-Becker chromatograph (model 427) is used with normal flame ionisation detector, equipped with a silanized spiral glass column, length $180 \mathrm{~cm}$, internal diameter $0.2 \mathrm{~cm}$, packed with $3 \%$ SE 30 on Gaschrome Q (100120 mesh) (Applied Science lab.). Temperatures: oven $250^{\circ} \mathrm{C}$, detector $300^{\circ} \mathrm{C}$, injection canal $300^{\circ} \mathrm{C}$. Carrier gas: nitrogen $2.7 \mathrm{~kg} / \mathrm{cm}^{2}$ (40 p.s.i.). Attenuation $10 \times 8$. The standard solution $(50 \mathrm{mg} / 1$ bupivacaine- $\mathrm{HCl}$ ) is diluted tenfold with water prior to use. A sample of $2 \mu l$ of the diluted standard (thus containing $10 \mathrm{ng}$ bupivacaine- $\mathrm{HCl}$ ) is applied directly on the column.

\subsubsection{Calculation}

Bupivacaine concentration $=\frac{\text { peak height sample }}{\text { peak height standard }} \times 8.9 \times \frac{100}{64} \times 10 \mu \mathrm{g} / 1$

Standard $10 \mathrm{ng}$ bupivacaine-HCL in $2 \mu \mathrm{l}$ corresponds to $8.9 \mathrm{ng}$ of the free base; recovery in extraction is $64 \%$ (table 7.10); dilution factor of sample is 10 .

Table 7.10 Efficiency of the extraction.

\begin{tabular}{llll}
\hline \hline $\begin{array}{l}\text { Bupivacaine-HCl } \\
\text { added } \\
(\mu \mathrm{g} / 1)\end{array}$ & $\mathrm{n}$ & $\%$ Recovery & VC \\
\hline 50 & 12 & 57 & 5.0 \\
100 & 12 & 64 & 4.3 \\
200 & 12 & 66 & 3.8 \\
300 & 12 & 69 & 3.6 \\
mean recovery & & 64 & 4.2 \\
\hline
\end{tabular}

Verheesen et al., (1980) demonstrated that there was a linear relationship between peak height and the concentration. The use of an internal standard was not necessary provided the analysis was performed in duplicate. The variation coefficient (VC) is $5 \%$ for a series of duplicates $(n=80)$. The detection limit is $5 \mu \mathrm{g} / 1$. 


\subsection{Methods concerning maternal blood pressure and maternal heart rate}

Both the maternal blood pressure and the maternal heart rate were the subjects of study.

\subsubsection{Maternal blood pressure}

Bllood pressure was measured using the Korotkow ausculatory method. This was done every ten minutes throughout the whole of the investigation period and was done on all of the patients in the control group and in the epidural group. The blood pressure was always measured by the same researcher and during the measurement the woman was always in the lateral position.

Furthermore, the timing of the blood pressure measurement was al ways arranged so that it fell into a period between uterine contractions. As has already been said, the patients in the con trol group were given an intravenous infusion of $400 \mathrm{ml}$ isotonic saline solution in a period of between five and ten minutes, prior to administration of the epidural anaesthesia. Before the intravenous infusion, each patient had her blood pressure measured twice with an interval of ten minutes. Immediately after the intravenous infusion blood pressure was again measured and then once more after ten minutes. Immediately after the second measurement the local anaesthetic was injected via the epidural catheter in order to obtain epidural anaesthesia. Moreover, blood pressure was measured every ten minutes during the whole of the investigation. On one occasion a clinically relevant hypotension made it necessary to administer an extra intravenous infusion ( $200 \mathrm{ml}$ isotonic saline solution in five minutes). In the control group too, blood pressure was measured every ten minutes throughout the whole of the investigation period.

\subsubsection{Studied periods}

The blood pressures were compared with one another during the following periods:

1. The two blood pressure values that were available per patient prior to administration of the intravenous infusion were compared with the two blood pressure values that were available per patient after the intravenous infusion. Figure 7.5 gives a schematic representation of this.

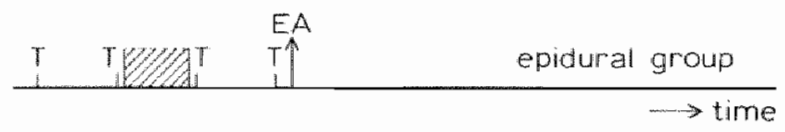

Figure 7.5 Schematic representation of the measured blood pressures before and after intravenows infusion.

$E A=$ epidural anaesthesia. $T=$ blood pressure measurement, $/ / / / / /$ intravenous infusion.

2. The four blood pressure values that were available per patient prior to administration of the epidural anaesthesia were compared with the six blood pressure values that were measured per patient in the first hour after the administration of the epidural anaesthesia. Figure 7.6 gives a schematic representation of this. 


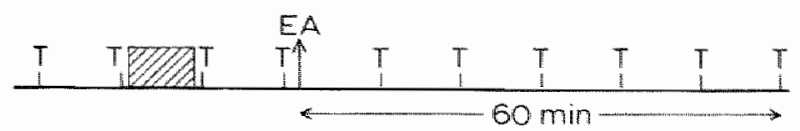

Figure 7.6 Schematic representation of the periods compared in the epidural group. For legends see figure 7.5 .

3. The blood pressure values that were measured in the first hour following administration of the epidural anaesthesia were compared with the blood pressure values that were measured in the first hour of the control group. Figure 7.7 gives a schematic representation of this.

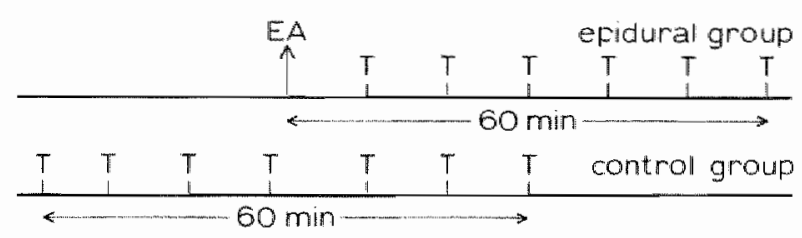

Figure 7.7 Schematic representation of the periods in which the blood pressures were compared in the control group and epidural group. For legends see figure 7.5.

4. The control group and the epidural group were compared with regard to the blood pressure values that were measured in the last 90 minutes of the first stage. Figure 7.8 gives a schematic representation of this.

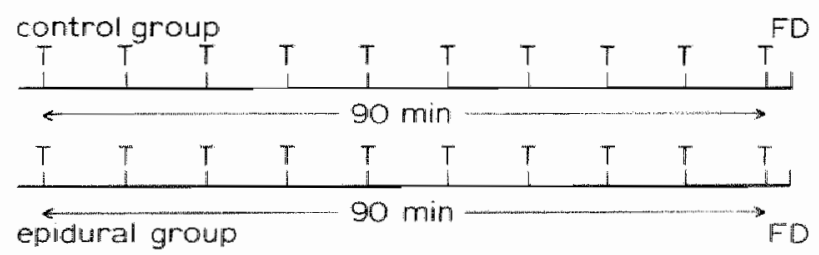

Figure 7.8 Schematic representation of the periods to be compared. For legends see figure 7.5. $F D=$ full dilatation

\subsubsection{Statistical analysis}

The significance of differences between the two groups of patients was investigated by means of the t-test procedure (see section 7.1.1) applied two sidedly at the five per cent level. Two way analysis of variance was applied with classification variables 'patient' and 'time of observation' in order to compare parameter values observed before and after intravenous infusion. Three levels of 'time of observation' were distinguished: one before infusion (two observations) and two after infusion (first and second observation after infusion).

In order to test the correlations between blood pressure values and foetal heart rate 
parameters among patients, Pearson's coefficient of correlation, r, was first computed for pairs of simultaneous observations of these parameters for each patient separately. Then the Fisher-Hotelling transformation was computed:

$u=\{z-(3 z+r) / 4 n\} \sqrt{n-1}$

with $z=1 / 2 \ln \{(1+r) /(1-r)\}$

Where $\mathrm{n}$ is the number of pairs of observations. The mean value $\bar{u}$ of $u$ over the patients was tested by referring $\overline{\mathrm{u}} \sqrt{ } \mathrm{k}(\mathrm{k}=$ number of patients) to a table of the normal distribution.

\subsubsection{The maternal heart rate}

The maternal ECG was recorded on a four channel analog recorder (HP 3964A) for all the patients in the control group and in the epidural group. Processing of the maternal ECG was done in the same manner as has been described for the foetal ECG (section 7.3.1). Similarly, the $R$ peak detection and the rejection of artefacts was identical.

Maternal ECG that was recorded during periods when the woman was either in the supine position or during periods of atypical disturbance were not included in the study. The RR interval was calculated, only in between contractions. The RR interval was not calculated for the ten seconds prior to a contraction nor for the 30 seconds following one. The RR interval was also not callculated where artefacts were present for more than ten per cent of each 30 second period. The periods studied and the data handling and statistical analysis were the same as for the foetal heart rate (sections 7.3.3 and 7.3.4). 


\section{Results referring to the foetal heart rate parameters}

\subsection{Investigation of possible pre-existent differences between the groups}

Since the treatment allocation (control, epidural anaesthesia) was not random, it had to be investigated whether there were pre-existent (selection induced) differences between the two groups regarding the heart rate parameters. The groups were compared during the base-line control recording periods (figure 8.1 ). This base-line periods were defined in section 7.3.3

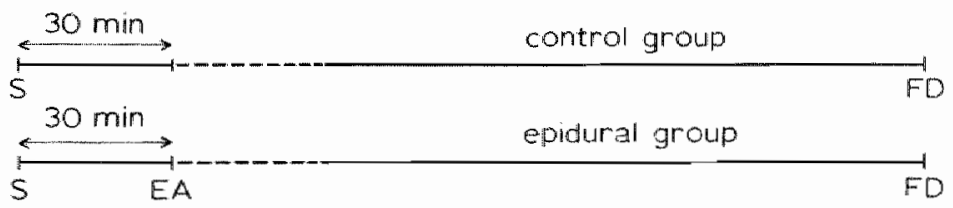

Figure 8.1 Schematic representation of the periods to be compared.

$S=$ stant of the investigation, $E A=$ epidural anaesthesia, $F D=$ full dilatation

\subsubsection{The mean of the foetal heart rate parameters in the base-line period}

Table 8.1 shows the results concerning the mean of the RR interval length, the ID index and the LTI index. The table also shows whether or not there was a significant difference between the two groups with respect to the three heart rate parameters. Recording of the foetal ECG in the first 30 minutes failed in one patient in the control group, due to a technical problem, for this reason the control group amounts to only 21 patients in the table.

Table 8. I The mean values of the foetal heart rate parameters in the base-line period of the control group and of the epidural group $(\bar{x} \pm S D)$.

\begin{tabular}{lccc}
\hline & $\begin{array}{l}\text { RR interval } \\
\text { length (ms) }\end{array}$ & LTI index & ID index \\
\hline $\begin{array}{l}\text { control group } \\
\mathrm{n}=21\end{array}$ & $447 \pm 27$ & $17.2 \pm 4.9$ & $11.1 \pm 3.4$ \\
$\begin{array}{l}\text { epidural group } \\
\mathrm{n}=20\end{array}$ & $447 \pm 44$ & $16.6 \pm 8.1$ & $9.8 \pm 3.4$ \\
$\mathrm{p}$ walue & $>0.1$ & $>0.1$ & $>0.1$ \\
\hline
\end{tabular}

No significant differences emerged between the control and epidural group as far as the mean values of the respective heart rate parameters were concerned. 


\subsubsection{The trend of the foetal heart rate parameters in the base-line period}

Recording of the foetal ECG was started after attachment of the electrode to the foetal scalp and the introduction of the pressure catheter into the uterus. It is known that these procedures can have an effect on the foetal heart rate. For this reason the individual graphs of the RR interval were rather critically reviewed. This was done in both the epidural group and in the control group.

\subsubsection{The epidural group}

The individual graphs relating the course of the foetal $R R$ interval length to time were visually assessed. In nine foetuses there was an initial increase in the duration of the $R R$ interval and in four foetuses a clecrease in the RR interval length was observed. In the remaining seven foetuses neither a clear increase nor a clear decrease was observed. In the visual assessment of the graph of averages (figure 8.2) it emerged that there was a tendency towards an initial increase. Examining the individual graphs it was noticeable that the course of the RR interval length in the last 15 minutes of the period was more stable than it was in the first 15 minutes. In order to quantify this, the within patient standard deviation was calculated over the whole 30 minute period and over the last 15 minutes of the period. In so doing it emerged that the within patient standard deviation fell from 14.6 to 10.2. In view of these findings it was decided for safety's sake to shorten the base-line period in the epidural group to the 15 minute period prior to the administration of the epidural anaesthesia. Since the LTI index and the ID index are calculated from the RR interval length, the same decision was made for these parameters.

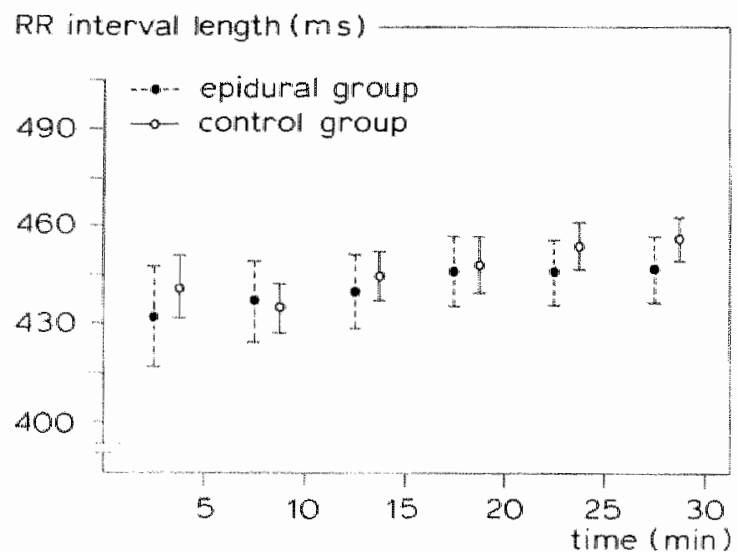

Figure 8.2 Mean foetal RR interval length \pm SEM in milliseconds per five minute period, in the base-line reconding period of the epidural group and the control group.

The change in the foetal heart rate parameters was determined by comparing the values in the first half of the base-line period with the values in the second half of this period. Table 8.2 gives the mean change of the foetal heart rate parameters. Student's paired sample t-test was used to test the diferences. It emerged that the RR interval length significantly increased. This confirmed once more the correctness of the decision to shorten the base-line period to 15 minutes. 
Table 8.2 The mean change of the foetal heart rate parameters in the epidural group on comparison of two successive periads of 15 minutes in the base-tine period $\left(x^{-} \pm S D\right)$.

\begin{tabular}{lccc}
\hline & $\mathrm{n}$ & mean increase & p value \\
\hline RR interval length (ms) & 16 & $+8.2 \pm 11.2$ & $<0.05$ \\
LTI index & 16 & $-2.0 \pm 11.2$ & $>0.1$ \\
D index & 16 & $-1.5 \pm 2.0$ & $>0.1$ \\
\hline
\end{tabular}

\subsubsection{The control group}

Due to a technical problem recording of the foetal ECG failed in one patient in the first 30 minutes. With respect to the trend of the foetal heart rate parameters similar findings were found in the control group and in the epidural group. Visual assessment of the individual graphs of the control group showed that there was no common course. In eight foetuses there was an initial increase of the RR interval length. In two foetuses there was a decrease in the $R R$ interval length and in eleven foetuses no clear trend at all could be discerned. Just as in the epidural group, the course of the RR interval length in the last 15 minutes of the period studied was more stable than it was in the rest of this period. This was also apparent in the within patient standard deviation which amounted to 19.5 over the whole period of 30 minutes but 16.5 in the last 15 minutes of the period. Just as in the epidural group, an electrode was fitted to the foetal scalp and an intra-uterine pressure catheter was introduced before the start of the recording. For these reasons the base-line period in the control group was also shortened to the last 15 minutes.

The change in foetal heart rate parameters was determined by comparing the values in the first half of the base-line period with the values in the second half of this period. Table 8.3 gives the mean change of the heart rate parameters. Student's paired sample t-test was used to test the differences. Just as in the epidural group, it emerged that there was a significant increase in the foetal $R R$ interval length.

Table 8.3 The mean change of the foetal heart rate parameters in the control group on comparison of two successive periods of 15 minutes in the base-line period ( $\bar{x} \pm S D$ ).

\begin{tabular}{lccc}
\hline & $\mathrm{n}$ & mean change & p value \\
\hline RR inteval length & 20 & $+12.7 \pm 18.2$ & $<0.05$ \\
LT index & 20 & $-0.3 \pm 11.0$ & $>0.1$ \\
ID index & 20 & $-1.1 \pm 4.5$ & $>0.1$ \\
\hline
\end{tabular}


8.1.2.3 Investigation of possible pre-existent differences between the two groups in the shortened base-line period

The shortened base-line period of the epidural group was compared with that period in the control group. Figure 8.3 gives a schematic representation of the periods to be compared.

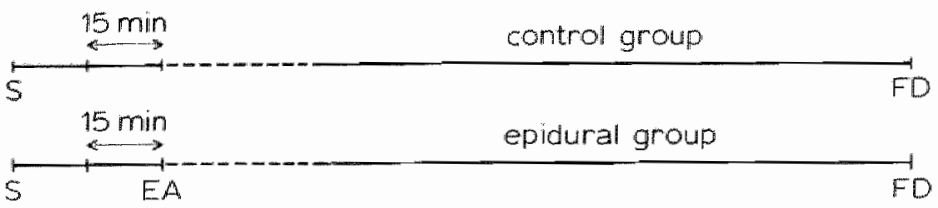

Figure 8.3. Schematic represtentation of the periods to be compared.

$S=$ stan of the investigation, $E A=$ epidural anaesthesia, $F D=$ full dilatation

Table 8.4 gives the results concerning the mean of the three foetal heart rate parameters.

Table 8.4 The mean of the three foetal heart rate parameters in the shortened base-line period $(\bar{x} \pm$ SD) in the control group and in the epidural group.

\begin{tabular}{lccc}
\hline & $\begin{array}{l}\text { RR interval } \\
\text { length (ms) }\end{array}$ & LTI index & ID index \\
\hline $\begin{array}{l}\text { control group } \\
\mathrm{n}=21\end{array}$ & $451 \pm 28$ & $17.1 \pm 6.4$ & $11.4 \pm 4.5$ \\
$\begin{array}{l}\text { epidural group } \\
\mathrm{n}=20\end{array}$ & $447 \pm 43$ & $15.8 \pm 7.1$ & $9.6 \pm 3.3$ \\
$\mathrm{p}$ value & $>0.1$ & $>0.1$ & $>0.1$ \\
\hline
\end{tabular}

There was no significant difference between the control group and the epidural group as far as the mean values of the respective foetal heart rate parameters were concerned at the start of the investigation.

\subsection{The changes of the foetal heart rate parameters following administration of epidural} anawesthesta

In order to gain insight into possible changes in foetal heart rate parameters due to the epidural anaesthesia, a period prior to the epidural anaesthesia was compared with a period after administration of the epidural anaesthesia. It emerges from section 8.1.2.1 that in the period of 15 minutes prior to administration of the epidural anaesthesia (base-line period), there is a relatively stable situation as far as the heart rate parameters are conoerned.

For this reason, that period was compared with a period of 120 minutes following the administration of the epidural anaesthesia. The graphs of averages of the foetal $\mathbb{R R}$ interval length, LTI index and ID index are presented in figure 8.9, 8.11 and 8.13. After 120 minutes 
the woman was either given a top-up dose of the local anaesthetic into the epidural space or the second stage was begun after $\mathbf{1 2 0}$ minutes or it was already in progress. The period studied after administration of the epidural anaesthesia was always limited to the first stage. Figure 8.4 gives a schematic representation of the periods to be compared.

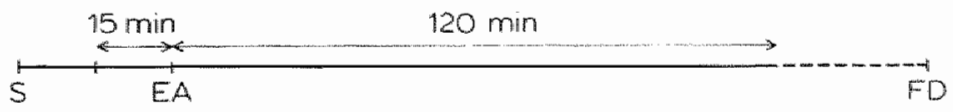

Figure 8.4 Schematic representation of the periods to be compared

$S=$ start of the investigation, $E A=$ epidural anaesthesia, $F D=$ full dilatation.

The change of the foetal heart rate parameters was calculated per patient. To realise this, the mean value in the base line period was subtracted from the mean value in the 120 minute observation period. The mean change for the whole group was calculated together with its associated standard deviation (table 8.5 ). Student's paired sample t-test was applied two sidedly at the five per cent level to investigate if the change differed significantly from zero.

Table 8.5 The mean changes of the foetal heart rate parameters ( $R R$ interval length. $L T$ index, ID index) on comparison of the 120 minute period after administration of the epidural anaesthesia with the 15 minute base-line period ( $\bar{x} \pm S D$ )

\begin{tabular}{ccc}
\hline $\begin{array}{c}\text { RR interval length (ms) } \\
\mathrm{n}=20\end{array}$ & $\begin{array}{c}\text { LTI index } \\
\mathrm{n}=20\end{array}$ & $\begin{array}{c}\text { ID index } \\
\mathrm{n}=20\end{array}$ \\
\cline { 2 - 3 }$-1.0 \pm 18.5$ & $-0.9 \pm 7.0$ & $+0.8 \pm 2.4$ \\
$\mathrm{p}>0.1$ & $\mathrm{p}>0.1$ & $\mathrm{p}>0.1$ \\
\hline
\end{tabular}

It emerged that no significant changes occurred in the foetal RR interval length, LTI index or ID index.

To detect a short lasting change in the RR interval length, LTI index or ID index, the 120 minute observation period following the administration of the epidural anaesthesia was divided into four successive periods of thirty minutes. For every foetus and for each thirty minute period the change with respect to the base-line period was calculated. Then the mean change together with it's SEM was calculated for every thirty minute period. Student"s paired sample t-test was used to investigate whether the change differed significantly from zero. Figure $8.5,8.6$ and 8.7 present the results. 


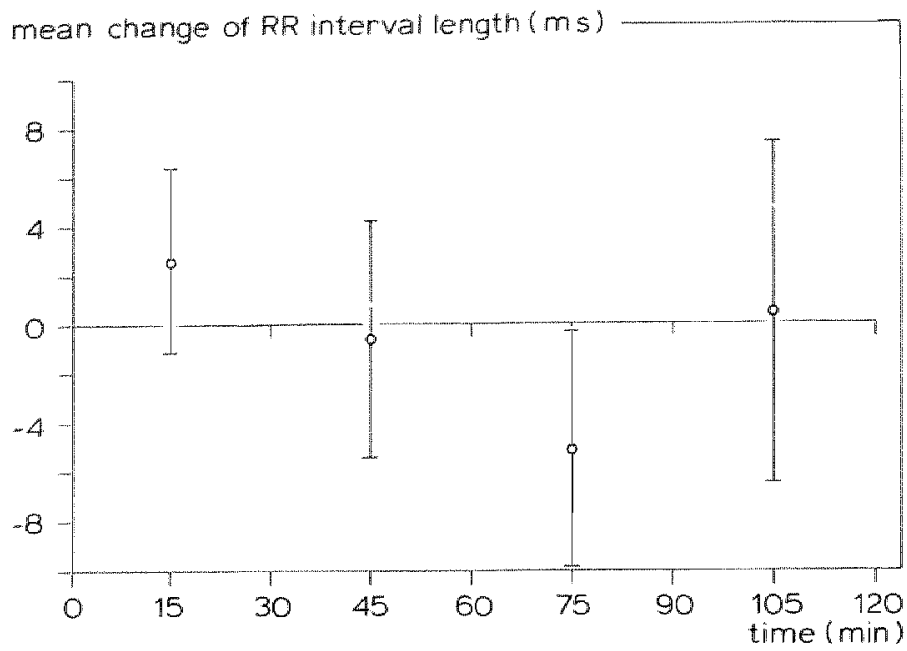

Figure 8.5 Change in the foetal RR intenval length following administration of epidural anaesthesia as compared with the base-line period $(\bar{x} \pm S D)$.

mean change of the LTI index

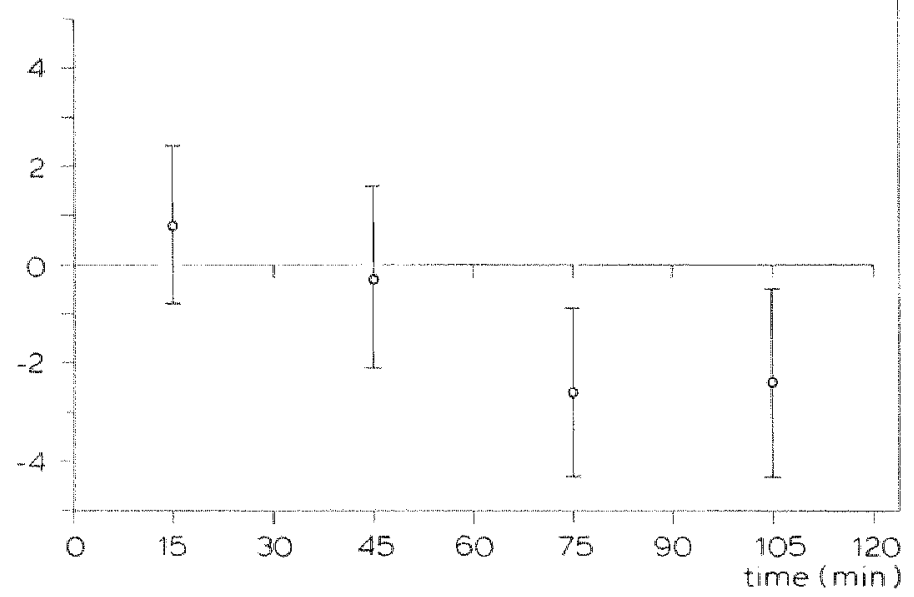

Figure 8.6 Change in the foetal LTT index following administration of epidural anaesthesia as compared with the base-dine period 


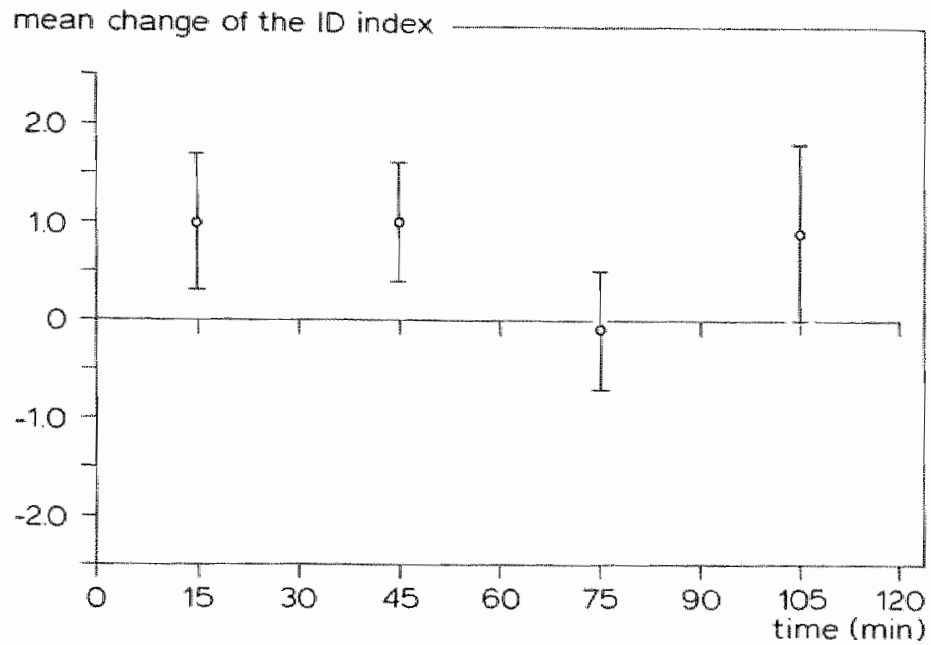

Figure 8.7 Change in the foetal $D$ index following administration of epidural anaesthesia as compared with the base-line period.

It appeared that there were no significant changes in the thirty minute periods with respect to the base-line period. Visualy assessing figure 8.6 a negative tendency for the LTI index could possible be detected (see also section 8.3.2).

In five patients hypotension occurred in the 120 minute period after administration of the epidural anaesthesia. Hypotension was defined as a systolic blood pressure lower than 100 $\mathrm{mmHg}$ (section 12.1.5). Since hypotension may have an effect on the foetal heart rate (section 5.2.1.1), it was investigated if the mean change of the foetal heart rate parameters (with regard to the base-line period) differed between the hypotensive women and the normotensive women (table 8.6).

Table 8. 6 The change of the foetal heart rate parameters as compared to the base-line period ( $R R$ interval length $L$ LT index, ID index) in the hypotensive women and in the normotensive women ( $\tilde{x}$ $\pm S D$ ).

\begin{tabular}{lccc}
\hline & $\begin{array}{l}\text { RR interval } \\
\text { length }(\mathrm{ms})\end{array}$ & LTI index & ID index \\
\hline $\begin{array}{l}\text { normotensive } \\
\text { women }(\mathrm{n}=15)\end{array}$ & $-2.5 \pm 19.2$ & $-2.0 \pm 7.4$ & $+0.5 \pm 2.7$ \\
$\begin{array}{l}\text { hypotensive } \\
\text { women }(\mathrm{n}=5)\end{array}$ & $+3.6 \pm 17.5$ & $+2.4 \pm 4.7$ & $+1.5 \pm 0.8^{*}$ \\
p value & $>0.1$ & $>0.1$ & $>0.1$ \\
\hline
\end{tabular}

*significant increase $(\mathrm{p}<0.05)$ 
In the normotensive women the increase in the ID index turned out not to be significant. However it was striking that the foetal ID index increased significantly, if the systolic maternal bloodpressure fell below $100 \mathrm{mmHg}$ after administration of the epidural anaesthesia $(1.5 \pm 0.8 ; \mathrm{p}<0.05)$. It appears from table 8.6 that there were no significant differences between the hypotensive and the normotensive women.

8.3 The trend of the foetal heart rate parameters in the 120 minute period after administration of the epidural anaesthesia

\subsection{RR interval length}

The individual graphs of the foetal RR interval length versus time during the two hour period immediately after the epidural anaesthesia were visually assessed. In the majority of the foetuses a fall in the RR interval length was observed. However, there was no common trend. In eleven foetuses a decrease in RR interval length was seen. In three foetuses there was an increase and in six foetuses no clear trend couldi be discerned. As an example, figure 8.8 presents the individual graphs of a group of six foetuses, in which three foetuses show a decrease, one foetus an increase and in two foetuses is no clear trend demonstrable.
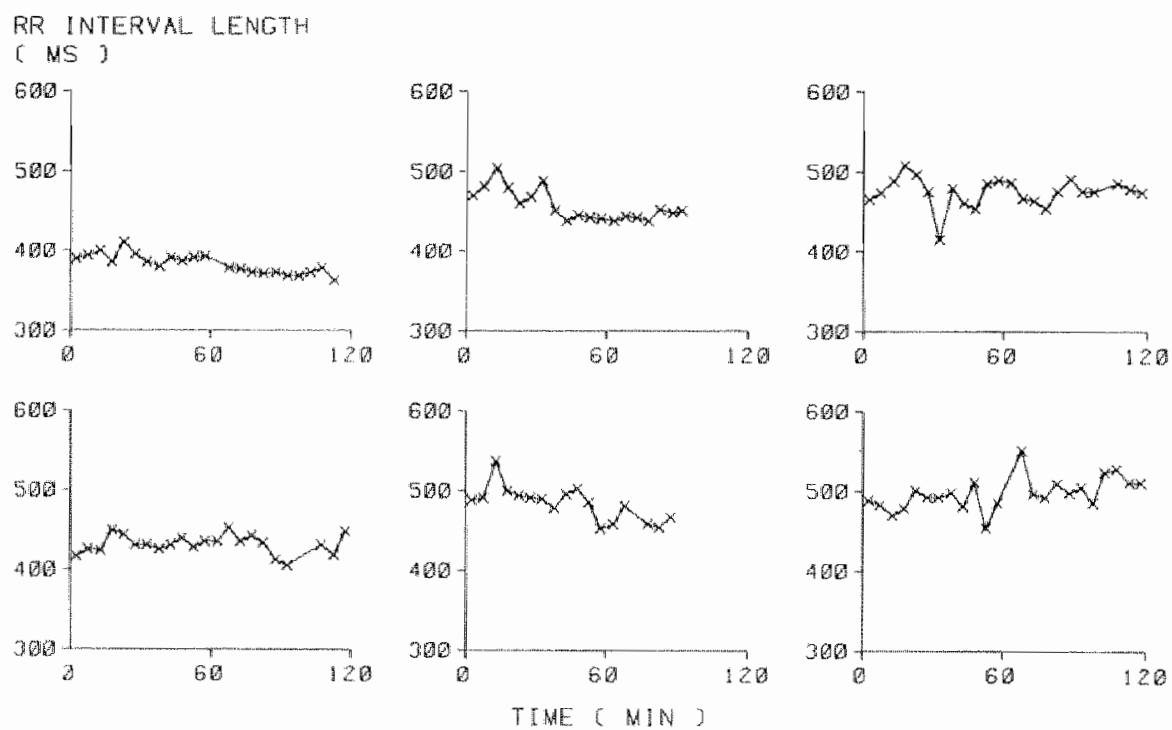

Figure 8.8 The course of the foetal RR interval length in six patients in the 120 minute period following the epidural anoesthesia

Visual assessment of the graph of averages revealed no clear effect of epidural anaesthesia on the course of the foetal heart rate (fig. 8.9). 


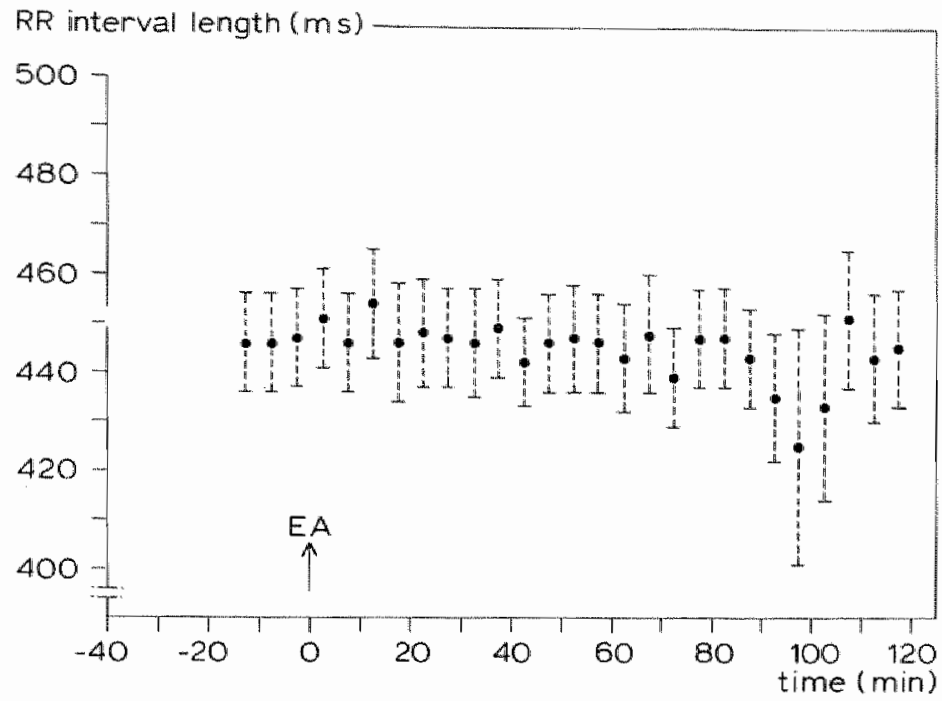

Figure 8.9 Mean foetal RR interval length \pm SEM in milliseconds per five minute period, from 15 minutes before epidural anaesthesia to 120 minutes afier epidural anaesthesia.

Furthermore, the slope over the 120 minute period following administration of the epidural anaesthesia was calculated per patient. This slope was calculated using linear regression. The mean slope was $-0.13 \mathrm{~ms} / \mathrm{min}$ with a standard deviation of 0.29 , not reaching significance $(p=0.06)$.

\subsubsection{LTT index}

Visualy assessing the individual graphs a large variation within patients was apparant, also appearing from a large value $(S D=7.8)$ of the within patient standard deviation. Comparing the individual graphs a strong variation between the various patients is noticeable too, corresponding with a large between patient standard deviation (SD' 25.6). Despite the large within patient variability in 8 patients a clear decrease of the LTI index with time could be observed and in none of the other 12 patients a clear positive trend could be discerned. Fig. 8.10 gives a group of six examples of the course of the LTI index in individual patients. Three of these six patients show a decrease of the LTI index. 
LTI INDEX
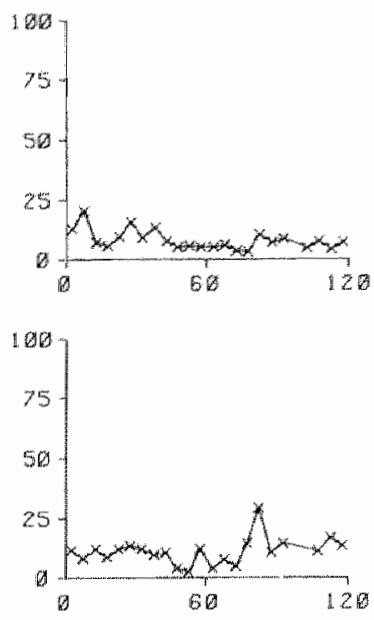
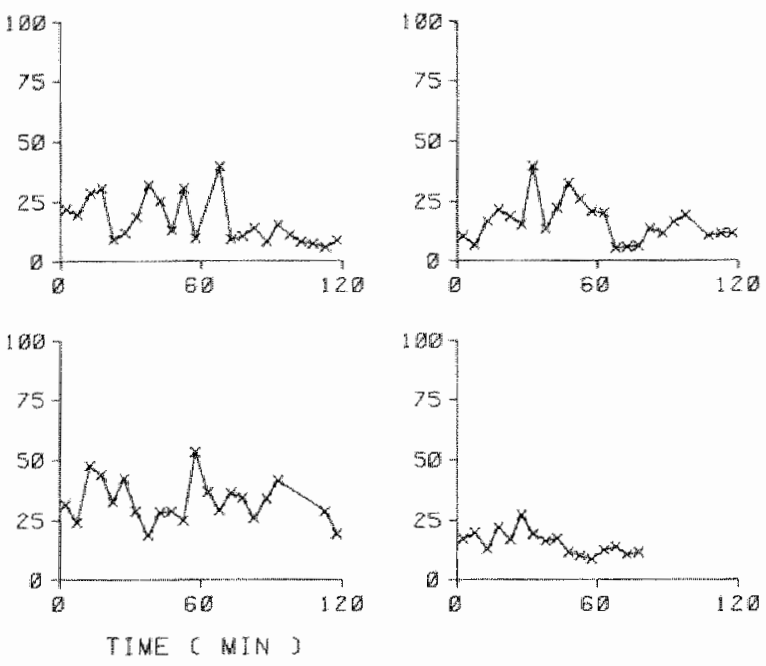

Figure 8.10 The caurse of the foetal LTT index its six patients in the 120 minute period following the epidural anciesthesia.

LTI index

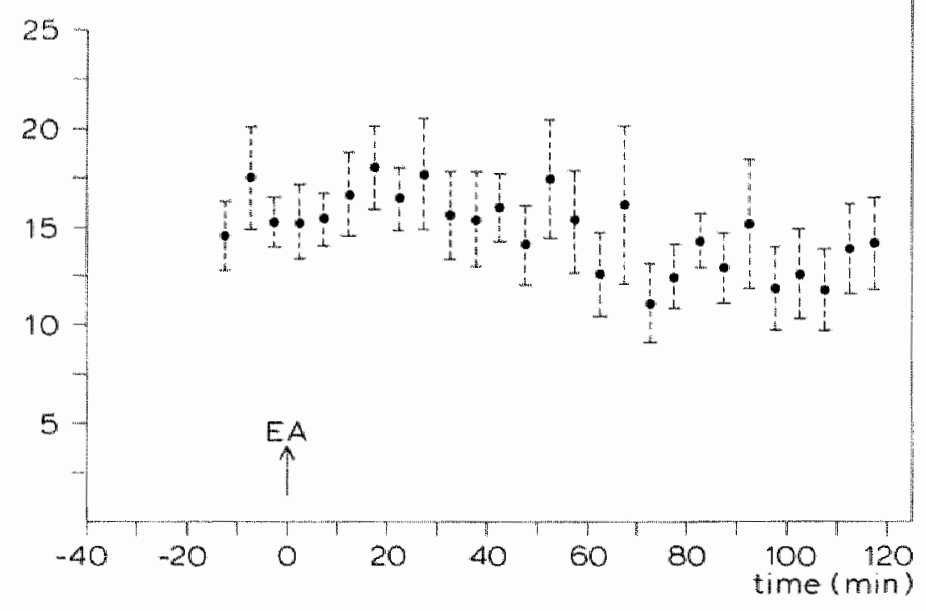

Figure 8.11 Mean foetal LTI index \pm SEM per five minute period from 15 minutes before epidural anaesthesia to 120 minutes after epidural anaesthesia. 
Visual assessment of the graph of averages (figure 8.11) revealed a fall of the LTI index with time after an initial increase. It appeared, however, from section 8.2 (figure 8.6) that this increase was not significant. This graph shows that the standard error of the mean is large. This in particular is connected with the great standard deviation between patients which has already been mentioned.

Finally, the slope of the LTI index was determined using linear regression. The mean slope was $-0.05 \pm 0.06$, which is highly significant $(\mathrm{p}<0.001)$.

With some reservation it may nontheless be concluded that, on the basis of the three approaches selected (visual assessment of the individual graphs, visual assessment of the graph of averages and calculation of the slopes), in the period studied there was a negative tendency for the LTI index.

\subsubsection{ID index}

Just like the RR interval length and the LTI index the individual graphs of the ID index were visually assessed. The fluctuations in the individual foetuses were quantified with the within patient standard deviation which amounted to 3.1. The difference between the foetuses was expressed by the between patient standard deviation which was 13.7. Study of the various graphs revealed no common course and neither was there any recognisable general trend. In five foetuses a rising ID index in relation to time was observed and in five others a decreasing trend was observed. In the other ten foetuses there was no definite trend. That the course of the individual graphs was very irregular may be seen from the graphs which are presented in figure 8.12.
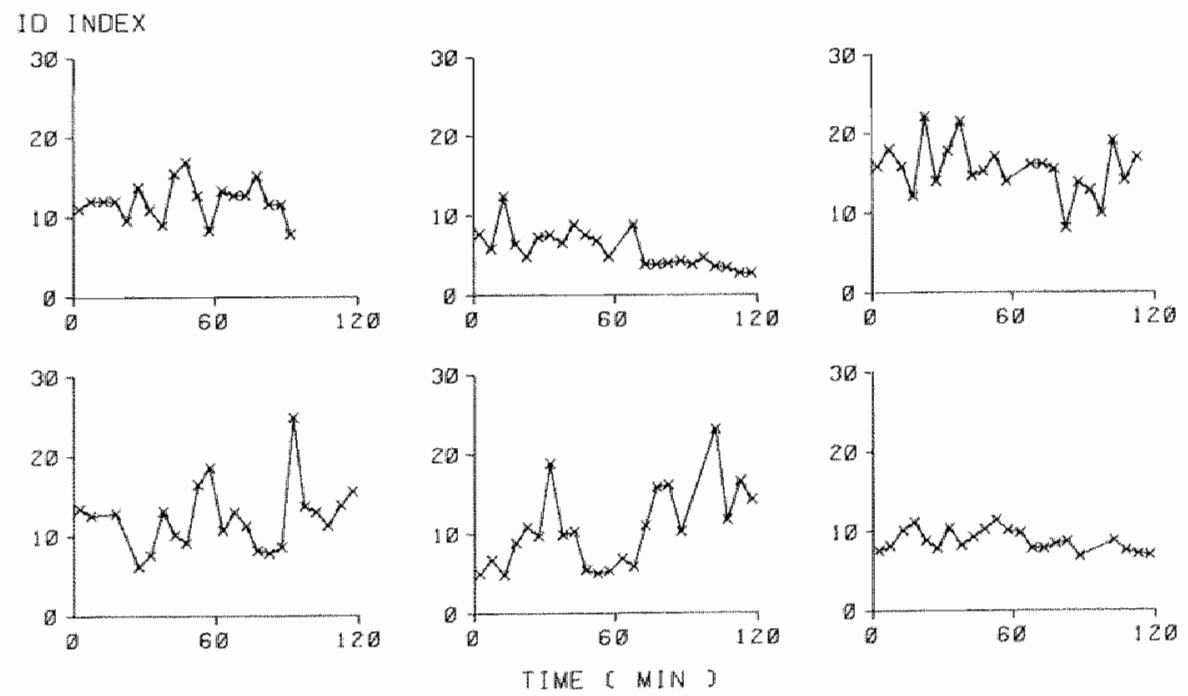

Figure 8.12 The course of the foetal $I D$ index in six patients in the 120 minute period following the administration of the epidural anaesthesia. 
On visual assessment of the graph of averages (figure 8.13), no definite trend could be discerned.

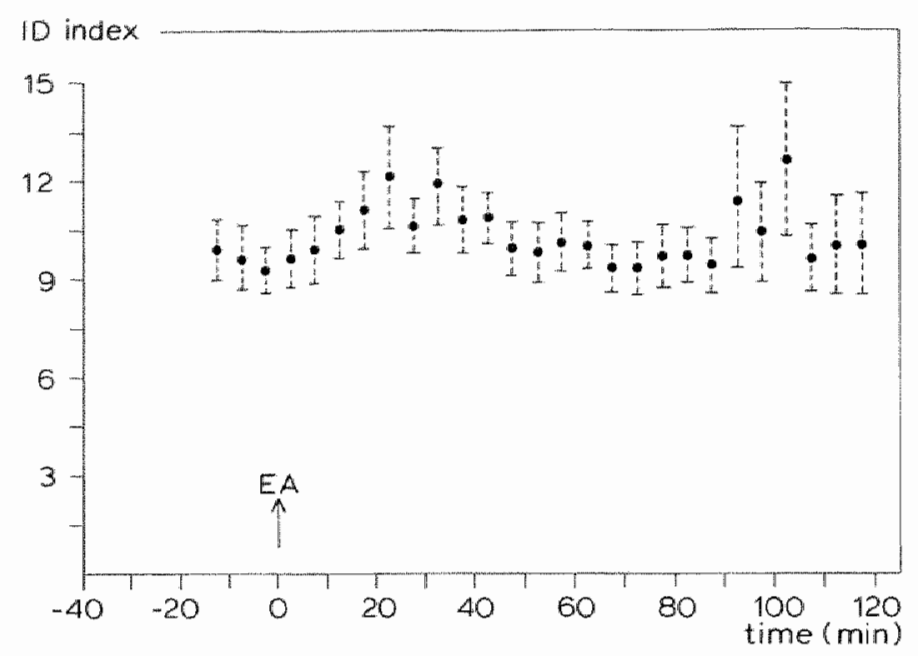

Figure 8.13 Mean foetal $I D$ index $\pm S E M$ per five minute period from 15 minutes before epidural anaesthesia to 120 minutes after epidural anaesthesia.

On studying figure 8.13 , it would seem that there was a temporary increase in the ID index in the first 45 minutes immediately after the epidural anaesthesia. This phenomenon was also encountered in the individual graphs of six foetuses, one of these six foetuses had a drop of the systolic blood pressure below $100 \mathrm{mmHg}$. In 13 foetuses this increase could not be detected and in one foetus there was even a fall in the ID index during the period concerned. Thus, it is certainly no constantly occurring phenomenon. Furthermore, it appeared from figure 8.7, that there was no significant change in the ID index in any of the four successive thirty minute periods after administration of the epidural anaesthesia with respect to the base-line period.

The slope was also calculated per foetus and from that, the mean slope for the whole group. This slope did not differ significantly from zero. In view of the above-mentioned data, it seems improbable that there was any clear trend in the ID index following administration of the epidural anaesthesia.

8.4 Study of the foetal heart rate parameters during the last ninety minutes of the first stage Finally, the control group and the epidural group were compared with one another during the last 90 minutes of the first stage. Figure 8.14 gives a schematic representation of the periods that were compared with one another. 


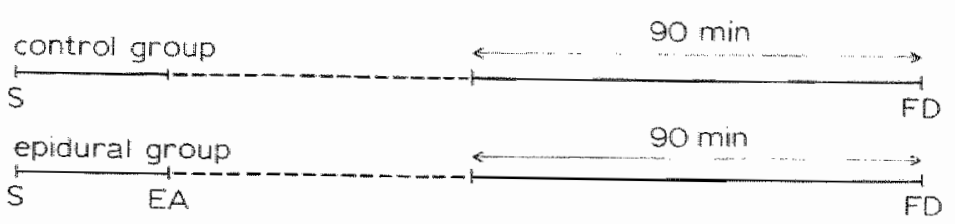

Figure 8.14 Schematic representation of the periods to be compared

$S=$ start of the investigation, $E A=$ epidural anaesthesia, $F D=$ full dilatation

\subsection{The mean of the foetal heart rate parameters during the last ninety minutes of the first} stage

The results in this observation period concerning the mean of the RR interval length, the LTI index and the LD index are given in table 8.7.

Table 8.7 The mean of the foetal heart rate parameters during the last 90 minutes of the first stage ( $\bar{x} \pm$ $S D)$ in the control group and in the epidural group.

\begin{tabular}{lccc}
\hline & $\begin{array}{l}\text { RR interval } \\
\text { length (ms) }\end{array}$ & LTI index & ID index \\
\hline $\begin{array}{l}\text { control group } \\
\mathrm{n}=22\end{array}$ & $455 \pm 26$ & $18.0 \pm 6.4$ & $11.0 \pm 3.1$ \\
$\begin{array}{l}\text { epidural group } \\
\mathrm{n}=20\end{array}$ & $435 \pm 38$ & $12.8 \pm 4.6$ & $10.5 \pm 3.8$ \\
$\mathrm{p}$ value & $<0.05$ & $<0.005$ & $>0.1$ \\
\hline
\end{tabular}

From these results it appears that the $\mathrm{RR}$ interval length in the control group was on average 20 ms longer than in the epidural group, this difference was just significant. This means that the foetal heart rate was higher in the epidural group than in the control group. With regard to the slower fluctuations in the foetal heart rate pattern (quantified by the LTI index), there was a very significant difference between the two groups. The LTI index in the epidural group was lower than in the control group. These significant differences between the two groups do not necessarily have to be based on a decreased foetal RR interval length and LTI index in the epidural group but, for example, could also be caused by an increase of the RR interval length and LTI index in the control group. In order to investigate this, the change in the RR interval length and the LTI index in the last ninety minutes of the first stage with respect to the base-line period was calculated per patient. This was done for both the control group and the epidural group. Student's paired sample t-test (applied two sidedly at the five per cent level of significance) was used to determine whether the change differed significantly from zero. Whether or not there was a difference between the two groups was investigated with student's two sample $t$-test (applied two sidedly at the five per cent level of significance). The results are given in table 8.8 . 
Table 8.8 Change of the foetal RR interval length and LTI index (last 90 minutes of the first stage minus the base-line period, in the control group and in the epidural group.

\begin{tabular}{lcccccccccc}
\hline & & Contral group & & & Epidural group & & $\begin{array}{c}\text { Difference } \\
\text { between } \\
\text { groups }\end{array}$ \\
\hline & $\mathrm{n}$ & $\dot{\mathrm{x}}$ & $\mathrm{SD}$ & $\mathrm{p}$ value & $\mathrm{n}$ & $\overrightarrow{\mathrm{x}}$ & $\mathrm{SD}$ & $\mathrm{p}$ value & $\mathrm{p}$ value \\
\hline $\begin{array}{l}\mathrm{R} R \\
\begin{array}{l}\text { interval } \\
\text { length (ms) }\end{array}\end{array}$ & 21 & +1.8 & 20.0 & $>0.1$ & 20 & -11.6 & 26.3 & $0.05<\mathrm{p}<0.1$ & $0.05<\mathrm{p}<0.11$ \\
$\begin{array}{l}\text { LTI } \\
\text { index }\end{array}$ & 21 & +1.2 & 7.9 & $>0.1$ & 20 & -1.1 & 5.3 & $>0.1$ & $>0.1$ \\
\hline
\end{tabular}

From table 8.8 it emerged that in the control group there were no significant changes. In the epidural group there was a nearly significant decrease of the RR interval length.

Figures 8.15 to 8.17 present the graphs of averages of the three heart rate parameters for both the control and epidural groups.

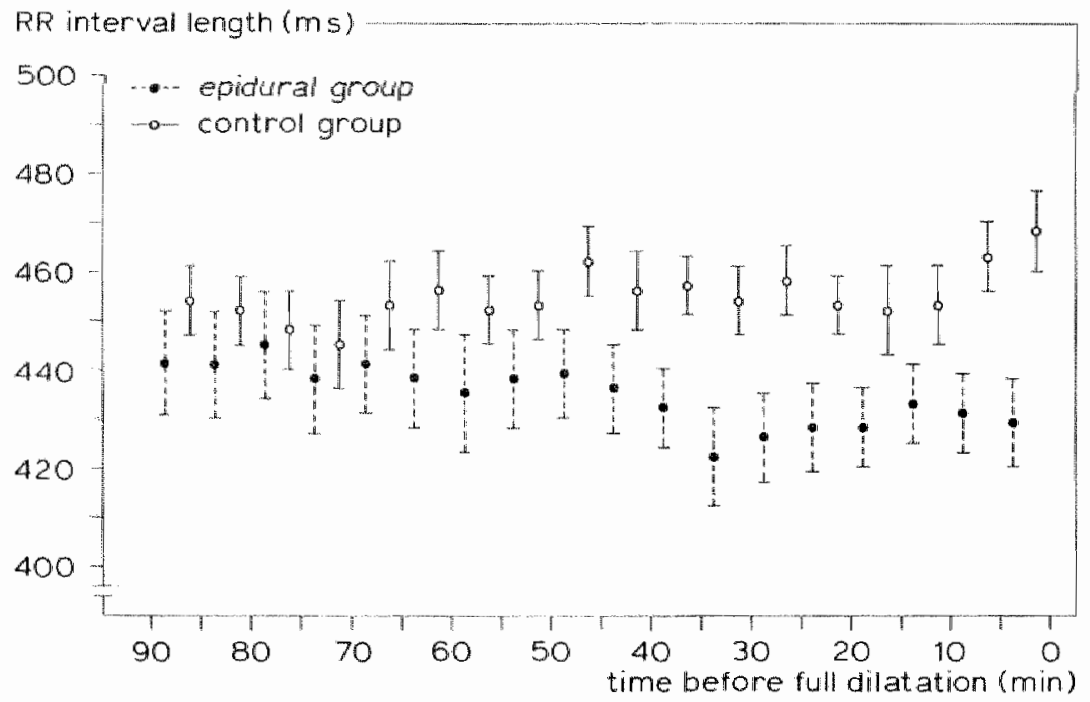

Figure 8.15 Mean foetal $R R$ interval length \pm SEM in milliseconds (ms) per five minute period during the last minety minutes of the first stage. 
ID index

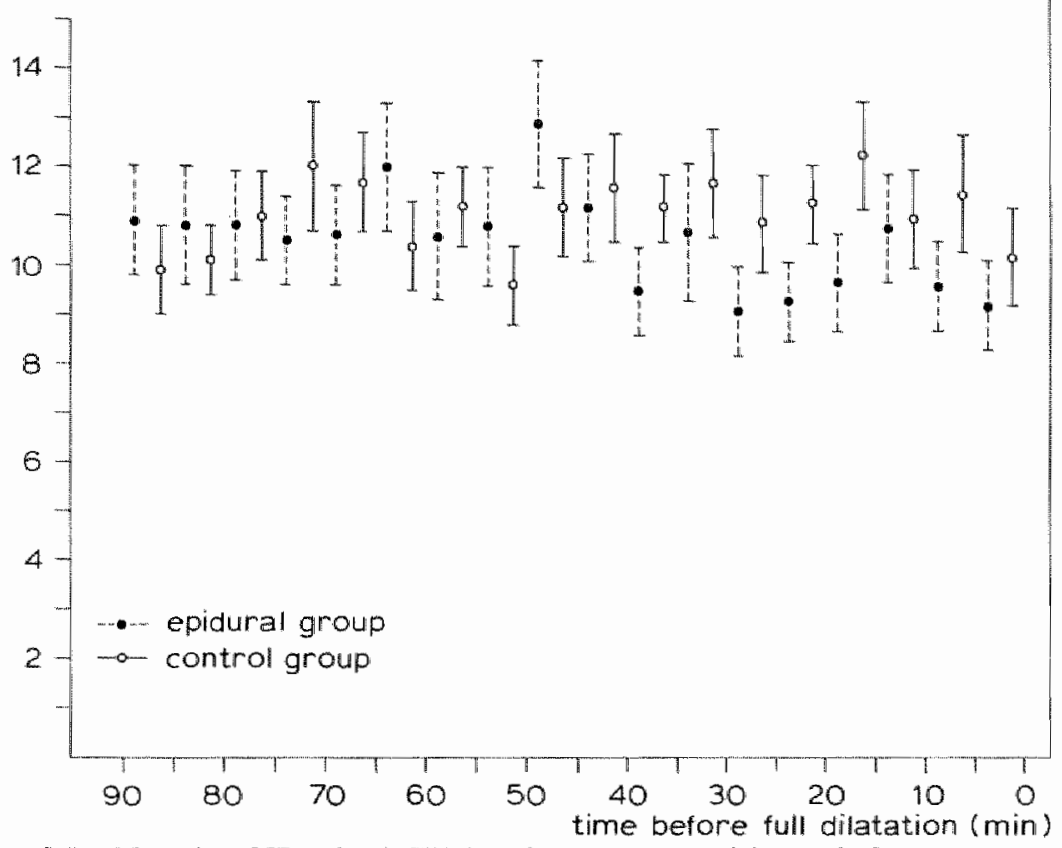

Figure 8.16 Mean foetal ID index \pm SEM per five minute period during the last nimety minutes of the first stage.

LTI index

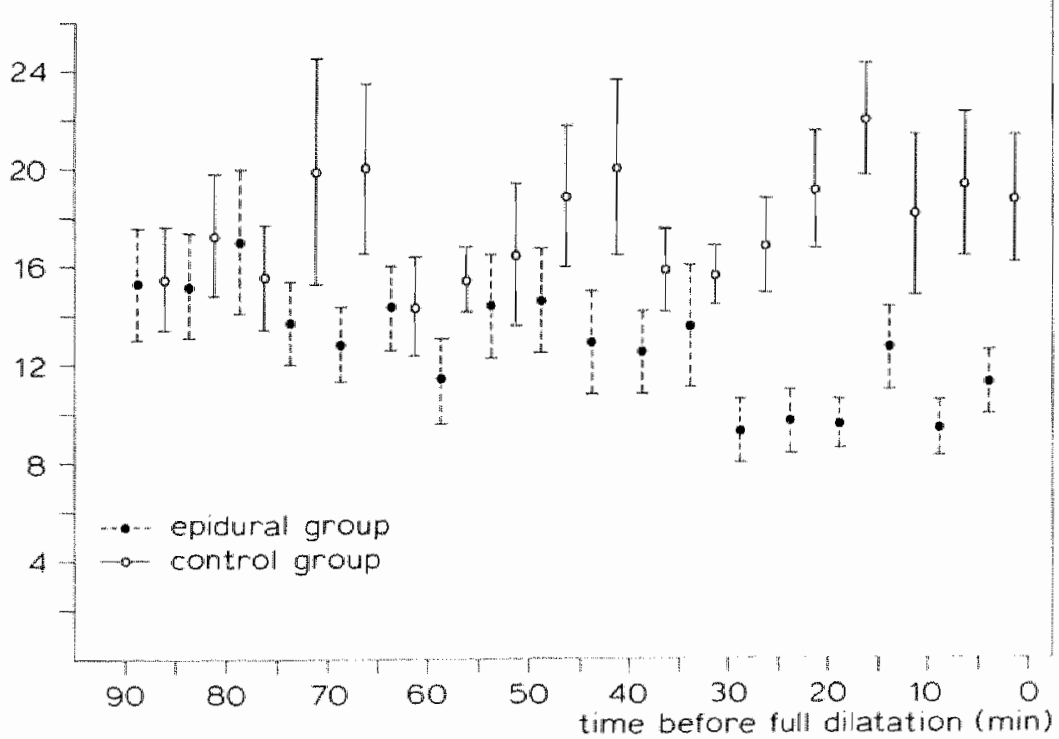

Figure 8.17 Mean foetal LTI index \pm SEM per five minute period during the last ninety minutes of the first stage. 
8.4.2 The trend of the foetal heart rate parameters during the last ninety minutes of the first siage

In eight patients the administration of the local anaesthetic via the epidural catheter coincided with a point in time of ninety minutes prior to full dilatation. In ten patients the administration occurred between 90 and 120 minutes prior to full dilatation. Two patients were given a top-up dose 75 minutes prior to full dilatation. In view of this variable timing of the epidural injections with regard to the period studied, it did not seem sensible to investigate a possible trend in this period.

Of course, in the control group the trend of the foetal heart rate parameters could be studied. Figure 8.15 suggests a possible tendency towards an increase in the RR interval. length. Study of individual graphs, however, failed to reveal any common course. In three of the foetuses there was an increase, in four foetuses a decrease occurred and in fifteen foetuses no trend could be discerned. The mean slope calculated for the RR interval length did not differ significantly from zero. In view of the above-mentioned data it seems justifiable to conclude that in the control group there was no definite trend with regard to the $\mathbb{R} R$ interval length in the last 90 minutes of the first stage. Study of the graphs of averages (figures 8.16 and 8.17) and of individual graphs failed to reveal any definite trend in the LTI index or in the ID index. Neither did the calculated mean slopes differ significantly from zero.

8.5 The relationship between the maternal blood pressure and the foetal heart rate parameters in the 120 minute period following administration of epidural anaesthesia In the literature (section 5.2.1.1) it has been cleariy shown that a fall in the maternal blood pressure can have an effect on the foetal heart rate. The method used to test the correlations between maternal blood pressure values and foetal heart rate parameters among patients was described in section 7.6.1.2.

The systolic blood pressure (SBP) and the mean arterial pressure (MAP) were taken as the blood pressure parameters. The mean arterial pressure is defined as follows:

$$
\mathrm{MAP}=(2 \mathrm{DBP}+\mathrm{SBP}) / 3
$$

where $\mathrm{DBP}=$ diastolic blood pressure.

The foetal heart rate parameters were the RR interval length, the LTI index and the ID index.

The $\mathrm{p}$ values for the mean transformed correlation coefficients are given in table 8.9.

Table 8.9 The p values of the mean transformed correlation coefficients between the maternal blood pressure parameters and the foetal heart rate parameters in the 120 minute period following administration of epidural anaesthesia.

\begin{tabular}{lccc}
\hline & $\begin{array}{c}\text { RR interval } \\
\text { length }\end{array}$ & LTI index & ID index \\
\hline systolic blood pressure & 0.58 & 0.31 & 0.84 \\
mean arterial pressure & 0.17 & 0.16 & 0.20 \\
\hline
\end{tabular}


It appears from table 8.9 that there is no significant correlation between the blood pressure parameters and the foetal heart rate parameters in this investigation.

\subsection{The relationship between the maternal plasma bupivacaine concentration and the} foetal heart rate parameters in the 120 minute osservation period following administration of epidural anaesthesia.

In order to test the correlations between foetal heart rate parameters and the maternal plasma bupivacaine concentration, Pearson's coefficient of correlation (r) was used. + The coefficient of correlation was computed for the maximum achieved plasma bupivacaine concentration (see section 11) and the change of the foetal heart rate parameters in the 120 minute observation period with respect to the pre-anaesthetic base-line period. In fifteen patients bupivacaine concentrations were determined, in one of these fifteen patients the blood sampling was unsuccessful, at the moment that the maximum bupivacaine concentration was expected. The coefficients of correlation (r) with the significance level are given in table 8.10 .

Table 8.10 Pearson's coefficients of correlation for the maximum maternal plasma bupivacaine concentration and the change of the foetal heart rate parameters in the 120 minute observation period with respect to the base-line period $(n=14)$

\begin{tabular}{|c|c|c|c|}
\hline & $\begin{array}{l}\text { RR interval } \\
\text { length }\end{array}$ & LTI index & ID index \\
\hline $\begin{array}{l}\text { Maximum maternal } \\
\text { bupivacaine } \\
\text { concentration }\end{array}$ & $\begin{array}{c}0.10 \\
(p>0.1)\end{array}$ & $\begin{array}{c}+0.49 \\
0.05<p<0.1\end{array}$ & $\begin{array}{c}+0.16 \\
(p>0.1)\end{array}$ \\
\hline
\end{tabular}

The same procedure was performed for the maximum maternal plasma bupivacaine concentration and the change of the foetal heart rate parameters in the first thirty minutes after administration of epidural anaesthesia with respect to the base-line period. These results are presented in table 8.11.

Table 8.11 Pearson's coefficients of correlation for the maximum maternal plasma bupiracaine concentration and the change of the foetal heart rate parameters in the 30 minute observation period with respect to the base-line period $(n=14)$

\begin{tabular}{lccc}
\hline & $\begin{array}{c}\text { RR interval } \\
\text { length }\end{array}$ & LTI index & ID index \\
\hline $\begin{array}{l}\text { Maximum maternal } \\
\text { bupivacaine } \\
\text { concentration }\end{array}$ & $\begin{array}{c}+0.09 \\
(\mathrm{p}>0.1)\end{array}$ & $\begin{array}{c}+0.45 \\
(\mathrm{p}>0.1)\end{array}$ & $0.05<\mathrm{p}<0.1$ \\
\hline
\end{tabular}

It may be concluded that there were no significant correlations in this study between the 
maximum maternal bupivacaine concentration and the change of the foetal heart rate parameters following the administration of the epidural anaesthesia. However, there was a nearly significant correlation between the maximum maternal bupivacaine concentration and the LTI index in the 120 minute observation period after administration of the epidural anaesthesia. In the first thirty minute period there was a nearly significant correlation with respect to the ID index.

In order to test the correlation between maternal bupivacaine concentrations and foetal heart rate parameters among patients in a more continuous way (and not only the maximum bupivacaine concentration), the Fisher-Hotelling transformation of $r$ was used, as described in section 7.6.1.2. The $\mathrm{p}$ values for the mean transformed correlation coefficients are given in table 8.12.

Table 8.12 The p values of the mean transformed correlation coefficients between the maternal plasma bupivacaine concentration and the foetal heart rate parameters in the 120 minute period following administration of epidural anaesthesia.

\begin{tabular}{lccc}
\hline \hline & $\begin{array}{c}\text { RR interval } \\
\text { length }\end{array}$ & LTI index & ID index \\
\hline $\begin{array}{l}\text { Maternal } \\
\text { bupiwacaine } \\
\text { concentration }\end{array}$ & 0.15 & 0.008 & 0.049 \\
\hline
\end{tabular}

The significant positive correlation between the maternal plasma bupivacaine concentration and the LTI index is striking. There is also a just significant positive correlation between the bupivacaine concentration and the ID index.

Table 8.13 The change in foetal heart rate parameters (last ninety minutes of the first stage minus the base-line period) in the women with one or more top-up dose and those with a single dose $(\ddot{x} \pm S D)$

\begin{tabular}{|c|c|c|c|c|c|c|c|c|c|}
\hline & \multicolumn{4}{|c|}{$\begin{array}{l}\text { Women with } \\
\text { top-up dose }\end{array}$} & \multicolumn{3}{|c|}{$\begin{array}{l}\text { Women with } \\
\text { single dose }\end{array}$} & & \multirow{2}{*}{$\begin{array}{c}\text { Difference } \\
\text { between } \\
\text { groups }\end{array}$} \\
\hline & $n$ & $\bar{x}$ & SD & $P$ value & $\mathrm{n}$ & $\bar{x}$ & SD & $\mathrm{p}$ value & \\
\hline $\begin{array}{l}\text { RR interval } \\
\text { length (ms) }\end{array}$ & 10 & -16.2 & 31.8 & $>0.1$ & 10 & -6.9 & 19.9 & $>0.1$ & $>0.1$ \\
\hline LTI index & 10 & $=1.7$ & 5.4 & $>0.1$ & 10 & -0.6 & 5.5 & $>0.1$ & $>0.1$ \\
\hline ID index & 10 & +0.5 & 3.2 & $>0.1$ & 10 & +1.2 & 2.1 & $>0.1$ & $>0.1$ \\
\hline
\end{tabular}




\subsection{The effect of a top-up dose on the foetal heart rate parameters}

Ten women were given one or more top-up doses via the epidural catheter. In four of the women a single top-up dose was given; in four others a top-up dose was given twice and in the remaining two it was given three times. In order to determine whether the top-up dose had an effect on the foetal heart rate parameters, the change in foetal heart rate parameters in the last ninety minutes of the first stage with respect to the base-line period was determined in both the women who had been given a top-up dose and those who had received only one epidural injection. Student's paired sample t-test was used to determine whether the change differed significantly from zero. Student's two sample t-test was used to test whether there was a difference between the two groups. The results are given in table 8.13.

It appears from table 8.13 that in neither of the two groups there were any significant changes. The differences between the two groups were also not significant.

\subsection{Discussion}

\subsection{Foetal heart rate}

The foetal heart rate in the control group does not change significantly during labour. There is no trend during the last 90 minutes before full dilatation and the mean value during the last 90 minutes of the first stage does not differ from the base-line control period.

The mean foetal heart rate in the epidural group at the start of the investigation is at the same level as in the control group. However in the epidural group a small increase in the foetal heart rate was observed (decreasing RR interval length). The mean foetal heart rate in the epidural group, during the last 90 minutes of the first stage is significantly higher than in the control group. The increase in foetal heart rate is also observed during the two hour observation period following the administration of the epidural anaesthesia. The trend during this period is however just not reaching significance $(p=0.06)$. There are few studies in which the effect of epidural anaesthesia on the basal foetal heart rate has been accurately studied in patients without pregnancy complicating diseases. Hoim (1982) found a slight but significant fall in the foetal heart rate in the first 30 minute period following the epidural anaesthesia administration. In that study the foetal tachogram was visually assessed. The author found no explanation for the observation except that there might be a possible correlation between the maternal and the foetal heart rate. In the study concerned, $7 \mathrm{ml}$ of bupivacaine 0.5 per cent without adrenaline was used. The women in the study were all induced on indications of toxicosis, postmaturity, smal\| for dates, premature rupture of the membranes and diabetes mellitus. Because these data, comparison of the present results with Holm's is not truly possible. Lavin et al., (1981) found no significant change in the foetal heart rate after epidural block, using $12 \mathrm{ml} 0.25 \%$ bupivacaine without adrenaline. Various authors have mentioned the incidental occurrence of bradycardia and tachycardia in the foetal heart rate during epidural anaesthesia (Wingate et al., 1974; Vroman 
et al., 1977; Zador and Nilsson, 1974; Maltau, 1975). The various authors causally related these changes to a reduction in maternal blood pressure or to uterine hypertonus. However, there was no systematic investigation of a slight rise or fall in the basal foetal heart rate under the influence of the epidural anaesthesia.

A possible explanation for the increase of the foetall heart rate may be found in the effect of local anaesthetics on the vascular system. If lidocaine is intravenously administered to adults at a dose rate of $1 \mathrm{mg} / \mathrm{kg}$ body weight, a slight increase in heart rate and cardiac output occurs whilst the vascular resistance exhibits a slight fall (Covino and Vasallo, 1976). Abouleish (1977) is also of the opinion that local anaesthetics at nona doses cause an increase in the heart rate. It is possible that the bupivacaine concentrations that are reached in the foetal blood have the same effect on the foetal heart. Wallis et al., (1976) investigated the effect of epidural anaesthesia on the foetal cardiovascular condition in pregnant sheep. In that study, 1.5 per cent chloroprocaine was used. For some of the animals, 60 to $80 \mu \mathrm{g}$ adrenaline was added. The foetal blood pressure remained stable but the foetal heart rate demonstrated a tendency to rise if adrenaline had been added to the local anaesthetic. However, if the adrenaline was left out, there was a slight reduction of the foetal blood pressure and of the foetal heart rate. It is also possible that the adrenaline that was added to the local anaesthetic in our study caused an increase in the foetal heart rate. This hypothesis is in agreement with the results of Lavin et al., (1981) who found no significant change in the foetal heart rate after epidural block, using $12 \mathrm{ml} 0.25 \%$ bupivacaine without adrenaline. Another possibility is that the foetal heart rate is influenced by the effect of the local anaesthetic agent on the central nervous system of the foetus. In adults plasma lidocaine concentration of 4 to 8 $\mu \mathrm{g} / \mathrm{ml}$ cause an increase in the mean arterial blood pressure due to enhancement of the cardiac output. This increase in cardiac output is mainly due to a rise in heart rate, caused by increased activity of the central sympathetic system whose inhibition is reduced by the depressant local anaesthetics such as chloroprocaine and mepivacaine (Jorfeldt et al., 1968; Bonica et al., 1970; Abouleish, 1977).

In this study a top-up dose had no significant influence on the extent of change that occurred in the foetal RR interval length (section 8.7).

In this study no significant correlations could be found between the maximum maternal plasma bupivacaine concentration and the change of the RR interval length following the administration of the epidural anaesthesia (section 8.6).

If a direct pharmacological effect of the local anaesthetic on the foetal heart or foetal central nervous system is responsible for the higher foetal heart rate in the epidural group, than there seems thus to be no significant concentration dependent correlation between the maternal bupivacaine concentration and the change in foetal heart rate in this study. The maximum maternal bupivacaine concentration in the 120 minute period after administration of the epidural anaesthesia ranges between $125 \mu \mathrm{g} / 1$ and $365 \mu / \|$ (section 11).

Another possible explanation could be sought in an alteration of the uteroplacental blood flow due to epidural anaesthesia (section 5.2.1). There are four potentialities for alteration of uteroplacental blood flow: 
1. The development of a fall in maternal blood pressure during the epidural anaesthesia. Section 8.4 demonstrates that there are no significant correlations between the maternal blood pressure parameters and the foetal RR interval length. In five women who suffered a fall in systolic blood pressure to less than $100 \mathrm{mmHg}$, there were no significant changes observed in the RR interval length (section 8.2). It seems improbable therefore that a reduction in maternal blood pressure in the epidural group has a causal relationship with the difference in foetal heart rate between the two groups.

2. The development of overly strong uterine activity. The tonus was in this thesis no subject of study. However, in the control group there was a significant increase in the amplitude and the active pressure area (chapter 9). This increase did not occur in the epidural group. It's therefore rather improbable that in this study the uteroplacental blood flow was affected by a too strong uterine activity.

3. The possible vasoconstrictor action of the local anaesthetic on the uterine vascular bed. Studying the literature data, it seems valid to suppose that local anaesthetic agents can cause vasoconstriction in the vascular system of the uterus. Possibly this effect only occurs at plasma concentrations that are not normally achieved during epidural anaesthesia (section 5.2.1.3). However, a slight decrease of uteroplacental blood flow can not be ruled out for certain.

4. The possible action of adrenaline on the uterine vascular bed. It can be concluded on the basis of the study by Jouppila et al., (1978-b) that epidural anaesthesia, even when adrenaline has been added to the local anaesthetic agent has no effect on blood flow in the intervillous space (section 5.2.1.4).

\subsubsection{Variability of the foetal heart rate pattern}

There was a possible negative trend in the LTI index during the two hour period following the administration of the epidural anaesthesia (section 8.3.2). In the last ninety minutes of the first stage the LTI index in the epidural group was significantly lower than in the control group (section 8.4).

In this study no significant effect of epidural anaesthesia on the ID index could be demonstrated if the maternal blood pressure remained normal. Section 8.5 demonstrates that there are no significant correlations between the maternal blood pressure parameters and the foetal heart rate variability (LTI index and ID index). However, in the five mothers whose systolic blood pressure fell to less than $100 \mathrm{mmHg}$ a significant increase in the ID index could be observed (section 8.2). Taking the literature data into account, this increased variability could be the result of foetal distress due to a decreased uteroplacental blood flow. In the past much attention has been given to reduced heart rate variability as an indication of foetal distress, but more recent data suggest that increased heart rate variability can be one of the earliest signs of foetal stress in animals. The effects of acute hypoxaemia and respiratory acidosis on foetal heart rate variability have been studied in experimental animals. Martin et al., (1979) found a significant increase in the ID index and in the LTI index, after induced hypoxaemia in the foetal lamb. In the foetal sheep Dalton et al, (1976) observed an increase in foetal heart rate 
variability secondary to hypercapnia. There was a greater increase in variability when the foetus was made sufficiently hypoxic to suppress foetal breathing. Increased foetal heart rate variability has also been described by Parer (1978) as one of the initial signs of foetal distress in sheep. It has also been demonstrated in some human distressed foetuses (Cibils, 1976-a).

A few researchers have pointed to a reduction in the variability of the foetal heart rate pattern during epidural anaesthesia (Belfrage et al., 1975-a; Hehre et al., 1969; Boehm et al., 1975; Raabe et al., 1976; Zador and Nilsson, 1974; Collins et al., 1978). All of the investigators except Hehre et al., (1969) assessed the foetal heart rate pattern visually, this of course allows semiquantitative measurement of the slow variations but not of the beat-to-beat variations. The visual assessment was done employing different assessment criteria. The manner in which the variability was assessed is often not described, nor the way in which the foetal heart rate pattern was obtained. Hehre et al., (1969) continuously determined the interval between two successive heart beats and in calculating the interval difference they took into account the actual heart rate. These therefore are the only researchers in a position to make any statement about the beat-to-beat variations of the foetal heart rate pattern. They noticed a reduction in the beat-to-beat variations immediately after administration of the epidural anaesthesia and this effect continued for only a few minutes.

However, Miller et al., (1978) found in their study a temporary increase in beat-to-beat variability and long term variability after paracervical block. The increased variability began almost immediately after the paracervical block, with the maximum increase occurring at a time when one would expect maximum maternal and foetal lidocaine levels. Following this increase in activity, the variability decreased to below levels found before paracervical block. The authors stated that it is not unreasonable to conclude that paracervical block may cause transient foetal hypoxaemia secondary to reduced uteroplacental blood flow. In our investigation also a temporary increase in the ID index and LTI index is detectable (fig. 8.13 and 8.11 ), but this increase does not reach the significance level of five per cent.

Lavin et al., (1981) found a significant increase in foetal heart rate variability (assessed with a method very similar to the Differential Index proposed by Yeh et al., 1973) after epidural block using $12 \mathrm{ml}$ bupivacaine $0.25 \%$ without adrenaline. This effect was absent when chloroprocaine was used as local anaesthetic. Chloroprocaine is an ester-type local anaesthetic and is degraded by the placenta. It prossesses an extremely short half-life in maternal serum and any small amount that might cross the placenta would be readily metabolized by the foetus. Therefore chloroprocaine would be unlikely to cause direct foetal myocardial depression (Lavin et al., 1981). Furthermore chloroprocaine causes much less uterine artery constriction than lidocaine. Bupivacaine is intermediate between chloroprocaine and lidocaine in its effect on the uterine artery (Joyce et al., 1976). The authors are of the opinion that bupivacaine may have caused minimal distress because of either a direct myocardial effect or a diminished uterine blood flow. Because of the more pronounced effect of lidocaine on the uterine artery and the foetal myocardium, Hehre et al., (1969) and Boehm et al., (1975) found a decrease of the heart rate variability instead of an increase (Lavin et al., 1981). Using chloropro- 
caine, epidural anaesthesia has no effect on foetal heart rate variability, because of it's very low concentration in the foetal circulation and because it's minor effects on uterine vasculature.

Against this background, the results of this study concerning the correlations between maternal bupivacaine concentrations and the variability indices (section 8.6) are interesting. The LTI index showed a highly significant correlation with the maternal bupivacaine concentration. The initial increase (however, not significant) of the LTI index as seen in figure 8.11, coincidences with the maximum bupivacaine concentration. Next there is a negative trend for the LTI index and the bupivacaine concentration. These events result in a significant positive correlation between the bupivacaine level and the LTI index. The ID index shows a temporary nonsignificant increase after epidural block (figure 8.13), with the maximum increase at about the moment of the maximum bupivacaine concentration. There is also a just significant correlation between the ID index and the bupivacaine concentration. Taking the literature data into account, an initial increase in heart rate variability, can be an expression of foetal stress. It can not be excluded that epidural anaesthesia has a slight negative influence on foetal condition, caused by a direct pharmacological effect on the foetal heart or by the vasoconstrictor action of bupivacaine on the uterine artery. However, Belfrage et al., (1975-a) found a reduction in the foetal heart rate variability (visually assessed) without alterations in the foetal acid-base ballance.

Practically all authors are of the opinion that the reduction of heart rate variability is the direct result of a depressor effect of the local anaesthetic on the foetal heart. Belfrage et al., (1975) were unable to establish any correlation between the short-term reduction of foetal heart rate variability and the plasma levels of bupivacaine. Boehm et al., (1975) were equally unable to correlate the reduction of heart rate variability with lidocaine dosage. Whether a top-up dose was given or not, had also no significant influence on the degree of change that occurred in the LTI index and the ID index (section 8.7).

As mentioned in section 5.4.4.1, the local anaesthetic can have an effect on the central nervous system and it is not impossible that the variability of the foetal heart rate pattern is influenced via this route. The present research results cannot further substantiate this hypothesis.

Another explanation for the differences between control group and epidural group could possible be sought in a different incidence of neuro-behavioural states. In state $1 \mathrm{~F}$ the LTI index is lower and the RR interval length longer than in state $2 \mathrm{~F}$ (van der Wildt, 1982). In our study both the LTI index and the RR interval length are lower in the epidural group with respect tot the control group (section 8.4.1). Therefore it is rather impropable that the differences between epidural group and control group are due to a different proportion of time spent in the neuro-behavioural states.

\subsection{Conclusions}

1. During the last ninety minutes of the first stage the foetal heart rate in the epidura! group was significantly higher than in the control group (the difference was about 6 beats per minute). 
2. During the last ninety minutes of the first stage the LTI index in the epidural group was significantly lower than in the control group.

3. If, during the epidural anaesthesia maternal systolic blood pressure fell below 100 $\mathrm{mmHg}$, the ID index rose significantly.

4. There is a significant positive correlation between the maternal plasma bupivacaine concentration and the variability indices.

It cannot be exluded that the changes in foetal heart rate variability are an expression of slight foetal stress. A direct pharmacological effect of the local anaesthetic on the foetal myocardium seems the most probable explanation, but a slight negative influence of the local anaesthetic on the utero-placental blood flow cannot be ruled out. 


\section{Results referring to the contraction parameters}

9.1 Investigation of possible pre-existent differences between the two groups Since the two groups were not composed in a randomised way it would be possible that there could be differences between the groups due to selection. This was investigated by comparing the group averages for the various contraction parameters in the base-line period. Figure 9.1 schematically presents the base-line periods which were compared.

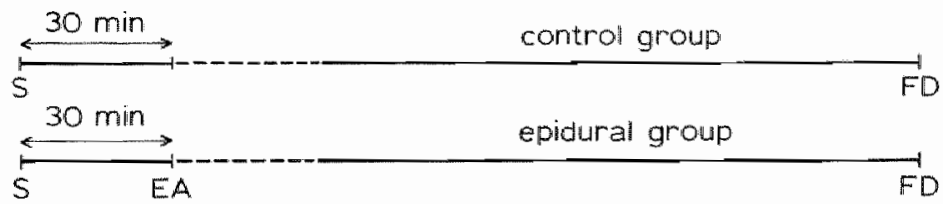

Figure 9.1 Schematic representation of the periods to be compared $S=$ start of the investigation: $E_{A}=$ epidural anaesthesia; $F D=$ full dilatation.

\subsubsection{The mean of the contraction parameters in the base-line period}

Table 9.1 gives the results referring to the mean amplitude, the mean contraction period and the mean active pressure area.

Table 9.1 The mean of the contraction parameters in the base-line period of the control group and the epidural group ( $\bar{x} \pm S D$ ).

\begin{tabular}{lccc}
\hline & $\begin{array}{c}\text { amplitude } \\
(\mathrm{mmHg})\end{array}$ & $\begin{array}{c}\text { contraction } \\
\text { period (s) }\end{array}$ & $\begin{array}{c}\text { active pressure } \\
\text { area (mmHg. min) }\end{array}$ \\
\hline $\begin{array}{l}\text { control group } \\
n=22\end{array}$ & $36.3 \pm 10.7$ & $179 \pm 40$ & $39.1 \pm 16.5$ \\
$\begin{array}{l}\text { epidural group } \\
n=20\end{array}$ & $39.1 \pm 11.6$ & $195 \pm 44$ & $36.3 \pm 15.7$ \\
p value & $>0.1$ & $>0.1$ & $>0.1$
\end{tabular}


The mean values of the various contraction parameters in the control group did not differ significantly from those in the epidural group. In the active pressure area, the first five minutes with the pressure calibration were not included. For this parameters there were only 25 minutes available.

\subsubsection{The trend of the contraction parameters in the base-line period}

From section 8.1.2.1 it emerges that there are indications for a positive trend in the foetal RR interval length in this period in the epidural group. For this reason, the contraction parameters were also examined to see if a particular trend was present. Both the individual graphs and the graphs of averages were visually assessed. However, no definite trend could be discerned and this was true of both the control group and the epidural group. In addition, the slopes of the contraction parameters were calculated, using linear regression analysis. None of these slopes differed significantly from zero. Thus where the contraction parameters were concerned there was no reason to shorten the base-line period, as was the case with the foetal heart rate parameters.

\subsection{The changes of the contraction parameters following administration of epidural anaesthesia}

In order to gain insight into the possible occurrence of changes in the contraction parameters due to the epidural anaesthesia, a period of thirty minutes prior to administration of epidural anaesthesia (base-line period) was compared with a 120 minute observation period after the administration of epidural anaesthesia. The graphs of averages of the amplitude, the contraction period and the active pressure area are presented in figure $9.7,9.9$ and 9.11 .

After 120 minutes the woman was either given a top-up dose of the local anaesthetic or the second stage was begun after 120 minutes or it was already in progress. The period studied after administration of the local anaesthetic was limited to the first stage. Figure 9.2 gives a schematic representation of the periods to be compared.

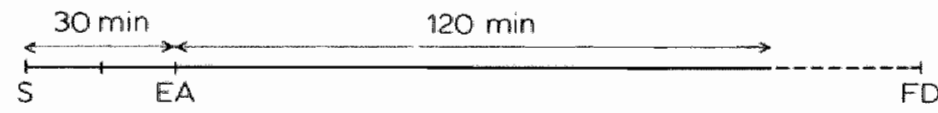

Figure 9.1 Schematic representation of the periods to be compared $S=$ start of the investigation; $E A=$ epidural anaesthesia, $F D=$ full dilatation.

The change in contraction parameters was calculated per patient. To realize this the mean value in the base-line periods was subtracted from the mean value in the 120 minute lasting observation period after the administration of the epidural anaesthesia. The mean change for the whole group was calculated and its standard deviation (table 9.2). Student's paired sample t-test (applied two sidedly at the five per cent significance level) was used to test whether the change was significant.

No significant changes emerged in amplitude, contraction period or active pressure area. There was a slight indication that the amplitude decreased $(p=0.09)$. 
Table 9.2 The mean changes in the contraction parameters on comparison of the 120 minwe observation period following the administration of the epidural anaesthesia with the 30 minute base-line period prior to administration of the epidural anaesthesia $(x \pm S D)$

\begin{tabular}{lcccc}
\hline \hline & $\mathrm{n}$ & $\overline{\mathrm{x}}$ & $\mathrm{sD}$ & $\mathrm{p}$ value \\
\hline amplitude (mmHg) & 20 & -3.0 & 7.6 & $0.05<\mathrm{p}<0.1$ \\
$\begin{array}{l}\text { contraction period (s) } \\
\begin{array}{l}\text { active pressure } \\
\text { area (mmHg. min) }\end{array}\end{array}$ & 20 & -0.54 & 27.8 & $>0.1$ \\
\hline
\end{tabular}

In order to detect a short lasting change in the contraction parameters, the 120 minute observation period following the administration of the epidural anaesthesia was divided into four successive periods of thirty minutes. For every patient and for each thirty minute period the change with respect to the base-line period was calculated. Then the mean change together with its SEM was calculated for every thirty minute period. Student's paired sample t-test was used to investigate whether the change differed significantly from zero. Figure $9.3,9.4$ and 9.5 present the results.

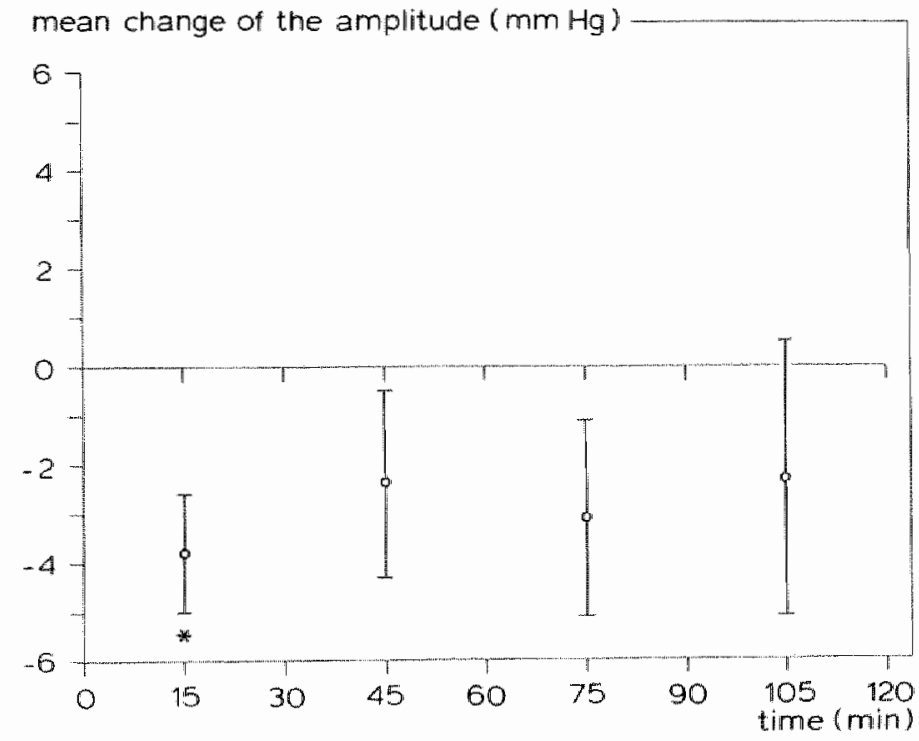

Figure 9.3 Change in amplitude following administration of epidural anaesthesia as compared with the base-line period $(x \pm S E M)$. *: $p<0.05$

It appears from figure 9.3 that there was a significant reduction in the amplitude only in the first thirty minutes following epidural anaesthesia. 


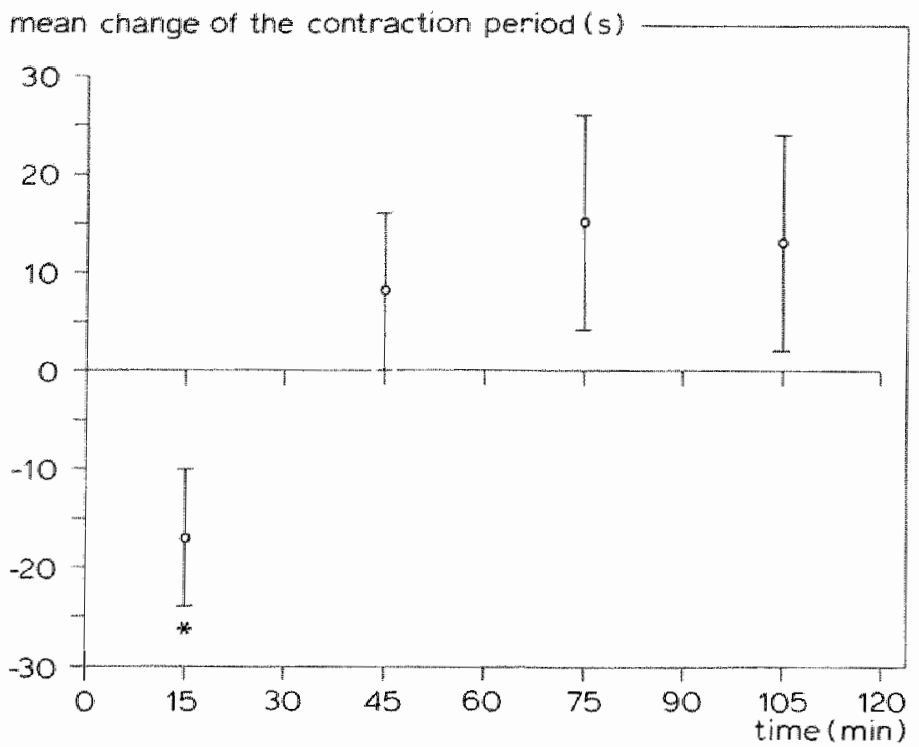

Figure 9.4 Change in the contraction period after administration of epidural anaesthesia as compared with the base-line period $(x \notin S E M) *: p<0.05$

It is apparent from figure 9.4 that in the first thirty minutes following the administration of the epidural anaesthesia, there was a significant reduction in the contraction period.

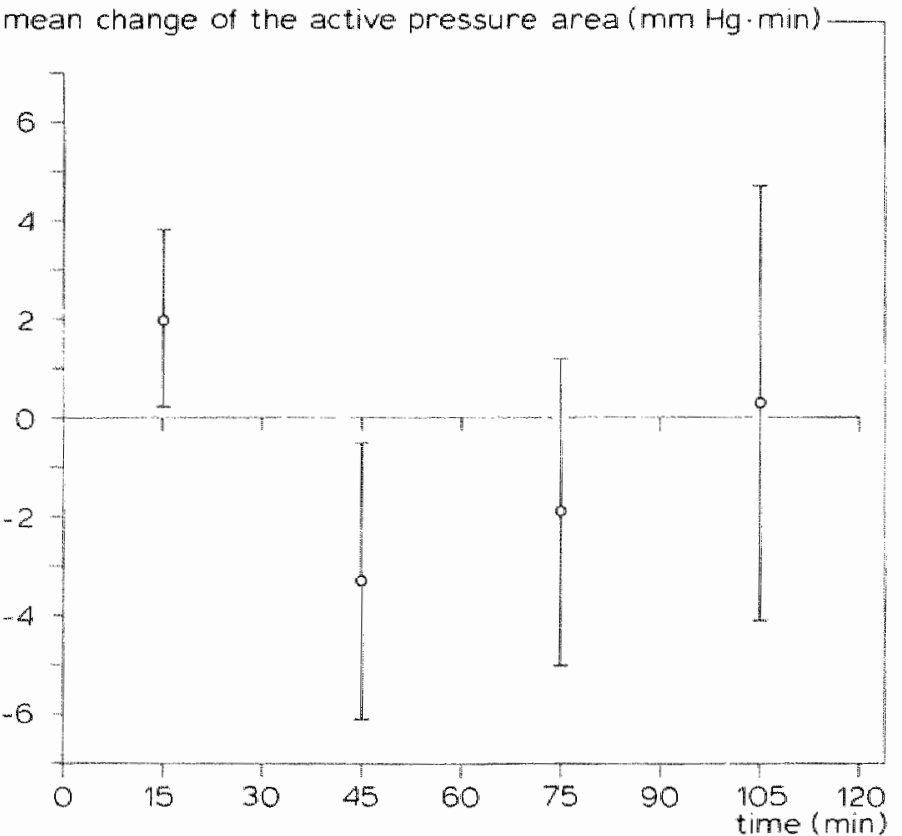

Figure 9.5 Change in the active pressure area after administration of epidural anaesthesia as compared with the base-line period $(x \pm S E M)$ 
It appears from fig. 9.5 that there were no significant changes of the active pressure area in the respective thirty minute periods.

In five women a hypotension occurred in the 120 minute period following the administration of the epidural anaesthesia. Hypotension was defined as a systolic blood pressure that dropped below $100 \mathrm{mmHg}$ (see section 12.1.5).

Since a fall in maternal blood pressure may have an effect on uterine activity (section 5.1.1), it was investigated whether the mean change in the contraction parameters (with respect to the base-line period) differed between the hypotensive women and the normotensive women. Student's two sample t-test (applied two sidedly at the five per cent level of significance) was used to test if there was a difference between the two groups. Table 9.3 presents the results.

Table 9.3 The mean changes in the contraction parameters with respect to the base-line period in the hypotensive women and in the normotensive women $(\bar{x} \pm S D)$

\begin{tabular}{|c|c|c|c|c|c|c|c|c|c|}
\hline & \multicolumn{4}{|c|}{$\begin{array}{c}\text { normotensive } \\
\text { group }\end{array}$} & \multicolumn{4}{|c|}{$\begin{array}{l}\text { hypotensive } \\
\text { group }\end{array}$} & \multirow{2}{*}{$\begin{array}{c}\begin{array}{c}\text { Difference } \\
\text { between } \\
\text { groups }\end{array} \\
\text { p value }\end{array}$} \\
\hline & $\mathrm{n}$ & $\bar{x}$ & SD & p value & $\mathbf{n}$ & $\ddot{x}$ & $\mathrm{SD}$ & $p$ value & \\
\hline $\begin{array}{l}\text { amplitude } \\
\text { (mmHg) }\end{array}$ & 15 & -3.0 & 8.7 & $>0.1$ & 5 & -3.2 & 2.7 & $0.05<p<0.1$ & $>0.1$ \\
\hline $\begin{array}{l}\text { contract- } \\
\text { don pe- } \\
\text { riod (s) }\end{array}$ & 15 & -4.1 & 26.4 & $>0.1$ & 5 & +10.0 & 32.0 & $>0.1$ & $>0.1$ \\
\hline $\begin{array}{l}\text { active } \\
\text { pressure } \\
\text { area (mmH }\end{array}$ & 15 & -1.9 & 11.5 & $>0.1$ & 5 & -2.8 & 6.5 & $>0.1$ & $>0.1$ \\
\hline
\end{tabular}

It appears from table 9.3, that there are no significant changes, neither in the normotensive group nor in the hypotensive group.

The decrease of the amplitude in both groups is about the same, but the standard deviation in the hypotensive group is much smaller, and this results in a nearly significant decrease of the amplitude in the hypotensive group $(p=0.06)$.

\subsection{The trend of the contraction parameters after administration of epidural anaesthesia}

\subsubsection{The amplitude}

The individual graphs concerning the trend of the amplitude during the two hour period. after the administration of the epidural anaesthesia were visually assessed. No clear general trend could be discerned. In four patients there was an increase of amplitude 
with time but in the other sixteen patients no trend could be recognised. Figure 9.6 shows a group of six individual graphs, in two patients an increase can be observed. AMPL ITUOE
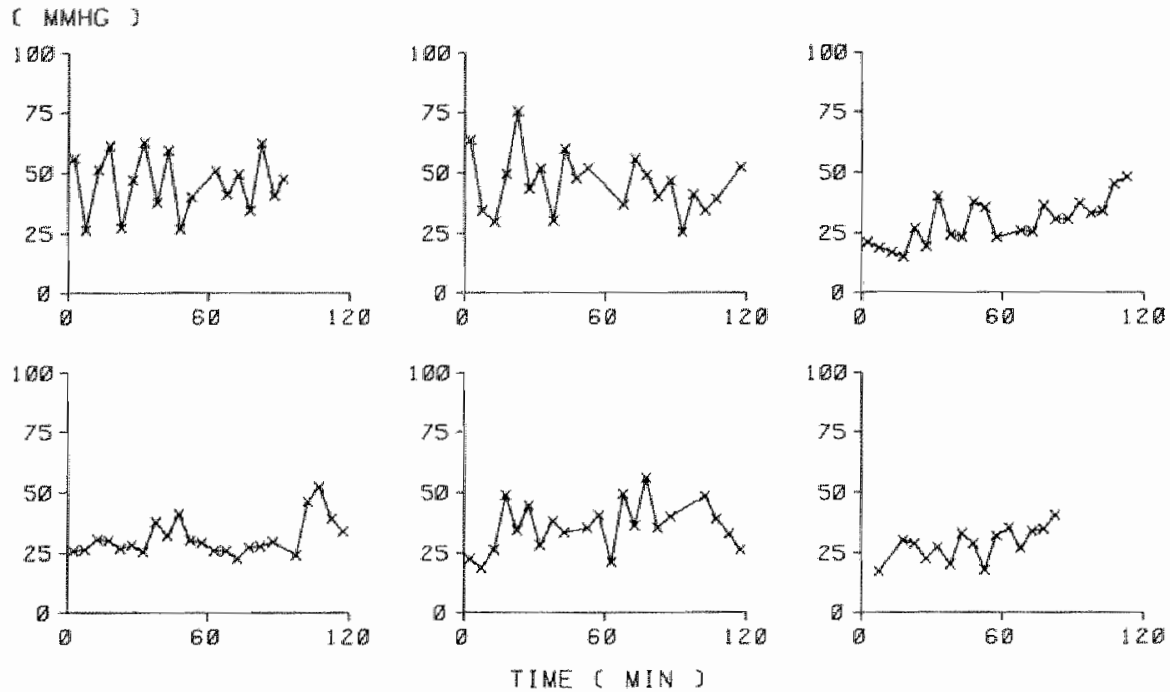

Figure 9.6 The course of the amplitude in six patients in the 120 minute period immediately following the administration of the epidural anaesthesia.

Similarly, on assessing the graph of averages (figure 9.7), no clear trend could be detected.

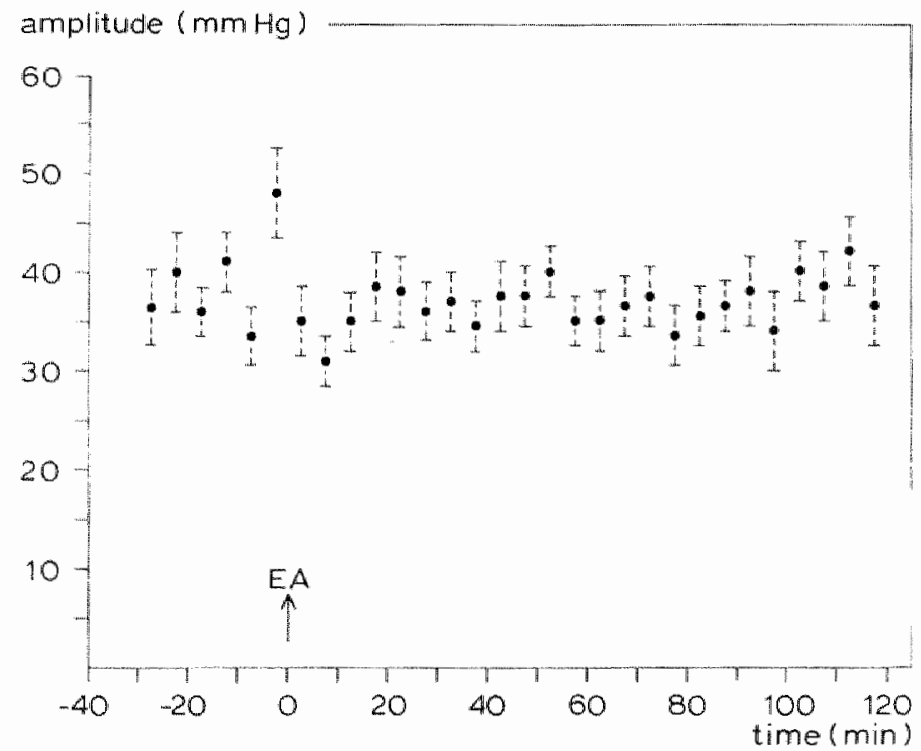

Figure 9.7 Mean amplitude \pm SEM per five minute period from 30 minutes prior to administration of epidural anaesthesia to 120 minutes after administration of epidural anaesthesia. 
Finally, the slope over the 120 minute period following administration of epidurall anaesthesia was calculated per patient. The slope was calculated using linear regression analysis. The mean slope amounted to $0.03 \mathrm{mmHg} / \mathrm{min}$ with a standard deviation of 0.08 . The slope did not differ significantly from zero. In view of the above-mentioned findings, it seems justifiable to conclude that no definite trend was discernible in the amplitude following administration of the epidural anaesthesia.

\subsubsection{The contraction period}

On visual assessment of the individual graphs no common definite trend could be discerned in the period studied. In seven patients the contraction period increased, in two the contraction period developed a decrease and in eleven patients no definite trend could be recognised. Figure 9.8 presents a group of six individual graphs as an example. In three graphs an increase can be detected.
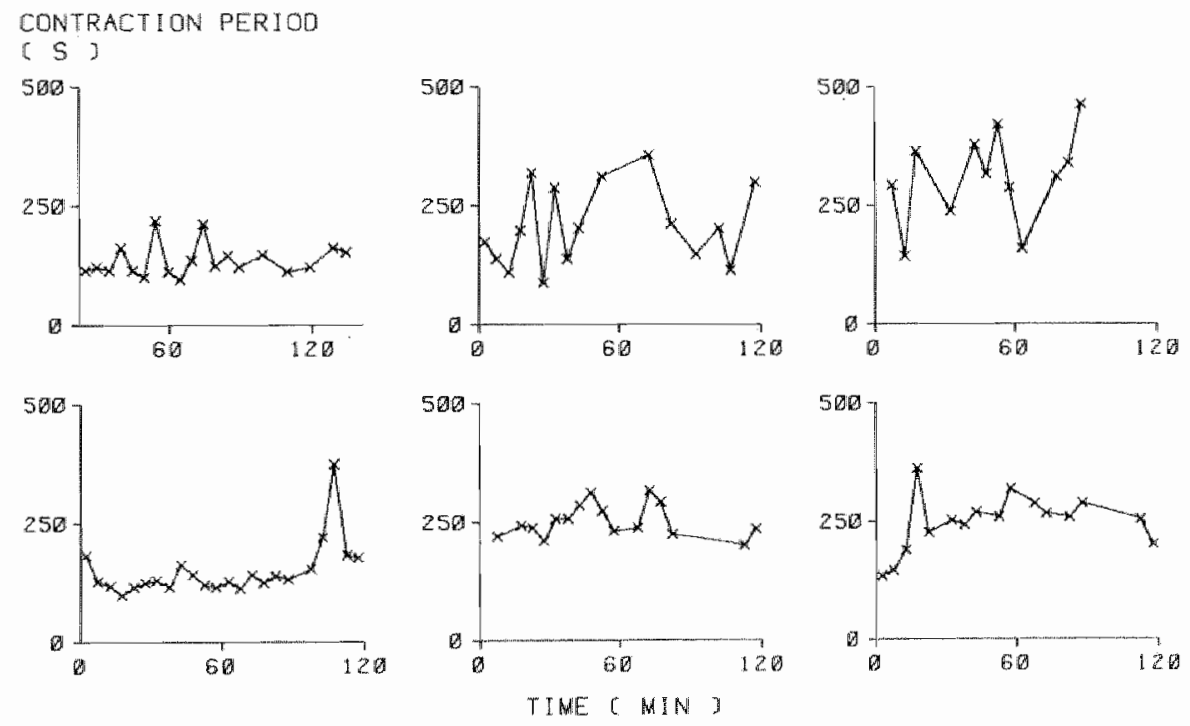

Figure 9.8 The course of the contraction period in six patients in the 120 minute period immediately following the administration of the epidural anaesthesia.

The mean slope was $0.41 \pm 0.52 \mathrm{~s} / \mathrm{min}$, and differed significantly from zero $(p<0.01)$. On studying the graph of averages (figure 9.9) it emerged that the significantly positive slope seemed to be caused mainly by the values in the first part of the graph. On studying the individual graphs it was noted that in thirteen patients there was a certain rise in the first half of the period studied. In one patient there was a fall and in six patients notrend could be recognised. 


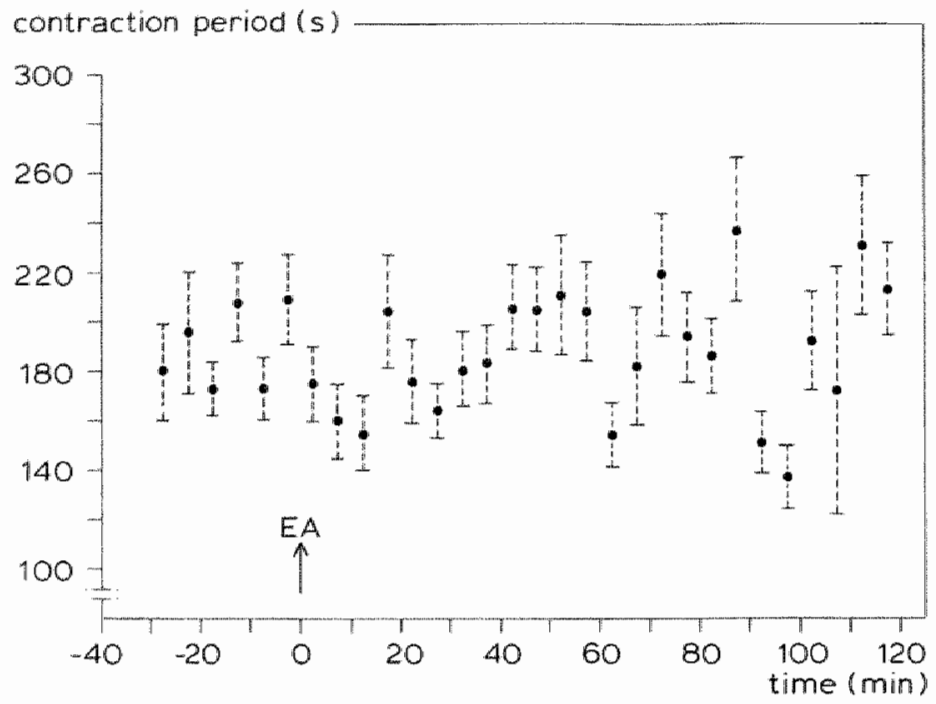

Figure 9.9 Mean contraction period $\pm S E M$ per five minute period from 30 minutes prior to administration of epidural anaesthesia to 120 minutes after administration of epidural anaesthesia.

Based on the mean slope and assessment of the individual graphs and the average graph, a slight tendency to prolongation of the contraction period in the first 60 minutes after administration of epidural anaesthesia could not be ruled out.

ACTI IVE PRESSURE AREA

[ MMHG.MIN ]
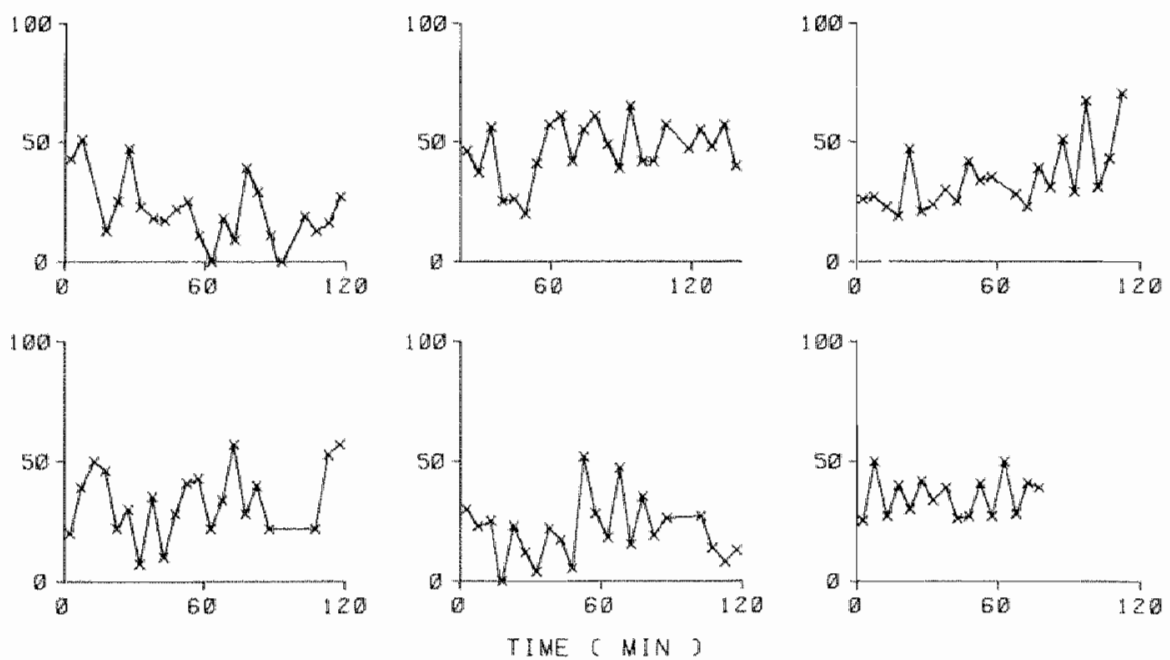

Figure 9.10 The course of the active pressure area in six patients in the 120 minute period immediately following the administration of the epidural anaesthesia. 


\subsubsection{The active pressure area}

On visual assessment of the individual graphs it appeared that there was no common course, and similarly, no definite trend. In three patients an increase in the active pressure area in relation to time was observed. In another three there was a decrease. In the remaining fourteen patients no definite trend could be discerned. Figure 9.10 shows a group of six individual graphs as an example. In one patient an increase is detectable, and in another a decrease.

Similarly, in visual assessment of the graph of averages (figure 9.11) no trend could be recognised. Finally, the slope was calculated per patient using linear regression analysis. The mean slope was $-0.04 \mathrm{mmHg} \cdot \mathrm{min} / \mathrm{min}$ with a standard deviation of 0.18 , and was not significantly different from zero.

In view of the above-mentioned findings it seems justifiable to conclude that there was no definite trend in the active pressure area following the administration of the epidural anaesthesia.

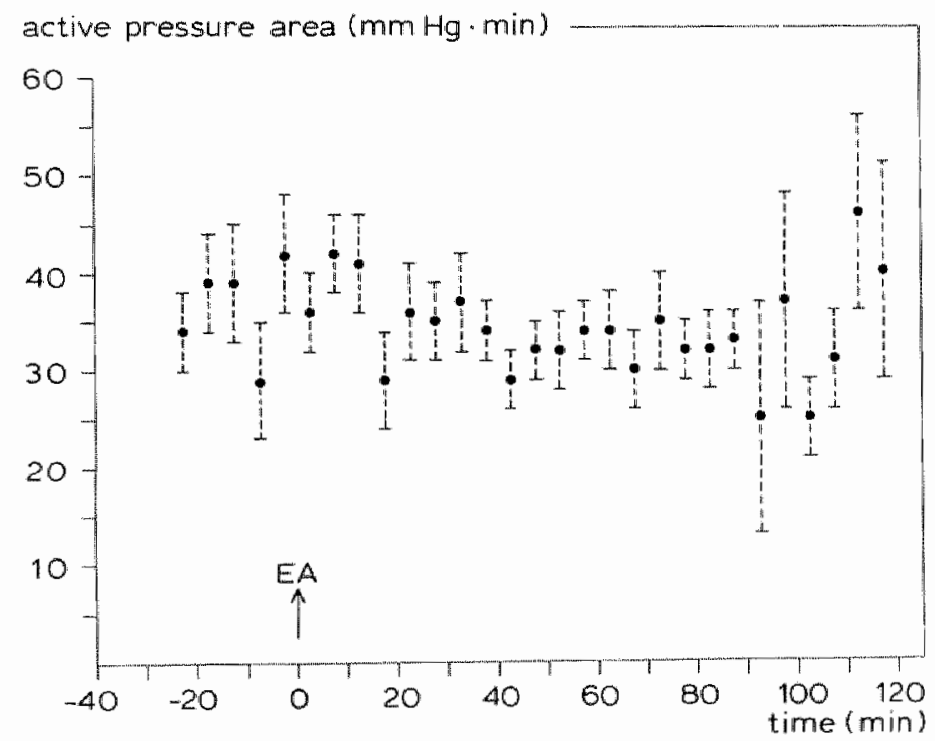

Figure 9.11 Mean active pressure area \pm SEM per five minute period from 25 minutes prior to administration of epidural anaesthesia to 120 minutes after administration of epidural anaesthesia.

9.4 Study of the contraction parameters during the last ninety minutes of the first stage Finally, the control group and the epidural group were compared with one another during the last ninety minutes of the first stage. Figure 9.12 gives a schematic representation of the periods compared. 


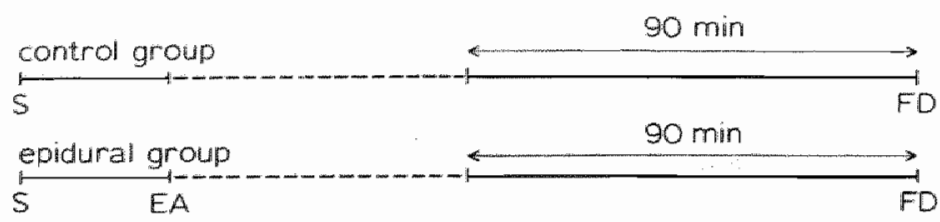

Figure 9.12 Schematic representation of the periods to be compared $S=$ start of the investigation: $E A=$ epidural anaesthesia; $F D=$ full dilatation.

9.4. I The mean of the contraction parameters during the last ninety minutes of the first stage.

Table 9.4 gives the results from this observation period concerning mean amplitude, mean contraction period, and mean active pressure area.

Table 9.4 The mean of the contraction parameters during the last ninety minutes of the first stage in the control group and in the epidural group ( $x \pm S D)$

\begin{tabular}{lccc}
\hline \hline & $\begin{array}{c}\text { amplitude } \\
(\mathrm{mmHg})\end{array}$ & $\begin{array}{c}\text { contraction } \\
\text { period (s) }\end{array}$ & $\begin{array}{c}\text { active pressure } \\
\text { area (mmHg.min) }\end{array}$ \\
\hline $\begin{array}{l}\text { control group } \\
\mathrm{n}=22\end{array}$ & $39.9 \pm 11.0$ & $172 \pm 35$ & $45.9 \pm 1.7$ \\
$\begin{array}{l}\text { epidural group } \\
\mathrm{n}=20\end{array}$ & $38.9 \pm 7.5$ & $189 \pm 44$ & $36.7 \pm 9.4$ \\
$\mathrm{p}$ walue & $>0.1$ & $>0.1$ & $<0.05$ \\
\hline
\end{tabular}

It emerges from table 9.4 that the active pressure area was significantly larger in the control group than in the epidural group. No significant differences between the two groups were found for the other two contraction parameters. It is possible that the increase in uterine activity which is normally seen during labour (Miller at al., 1976; Steer et all, 1984) is absent during epidural anaesthesia. For this reason, the increase in the amplitude during the last ninety minutes of the first stage, as compared with the base-line control period, was calculated per patient. This was done for both the control group and the epidural group. Student's paired sample t-test was used to determine whether the change differed significantly from zero and Student's two sample t-test was used to investigate whether there was a difference in change between the two groups. 
Table 9.5 Change in the contraction parameters (last ninety minutes of the first stage minus the base-line period) in the control group and in the epidural group $(\bar{x} \pm S D)$

\begin{tabular}{|c|c|c|c|c|c|c|c|c|c|}
\hline & \multicolumn{4}{|c|}{ control group } & \multicolumn{4}{|c|}{ epidural group } & \multirow{2}{*}{$\begin{array}{l}\text { difference } \\
\text { between } \\
\text { groups } \\
\text { p value }\end{array}$} \\
\hline & $\mathbf{n}$ & $\ddot{x}$ & $\mathrm{SD}$ & $p$ value & $\mathrm{n}$ & $\dot{x}$ & $\mathrm{SD}$ & p value & \\
\hline $\begin{array}{l}\text { amplitude } \\
\text { (mmHg) }\end{array}$ & 22 & +3.6 & 7.8 & $<0.05$ & 20 & -0.2 & 8.2 & $>0.1$ & $>0.1$ \\
\hline $\begin{array}{l}\text { contract- } \\
\text { ion pe- } \\
\text { riod (s) }\end{array}$ & 22 & -5.9 & 35.2 & $>0.1$ & 20 & -6.0 & 29.4 & $>0.1$ & $>0.1$ \\
\hline $\begin{array}{l}\text { active } \\
\text { pressure } \\
\text { area (mmH }\end{array}$ & 22 & +7.2 & 9.6 & $<0.05$ & 20 & +0.5 & 12.5 & $>0.1$ & $>0.1$ \\
\hline
\end{tabular}

Table 9.5 shows that in the control group there was a significant increase in the amplitude and in the active pressure area, whereas this was not the case in the epidural group. However, the difference in change between the two groups was not significant.

The graphs of averages of the three parameters from both the control group and the epidural group are presented in figures 9.13 to 9.15 .

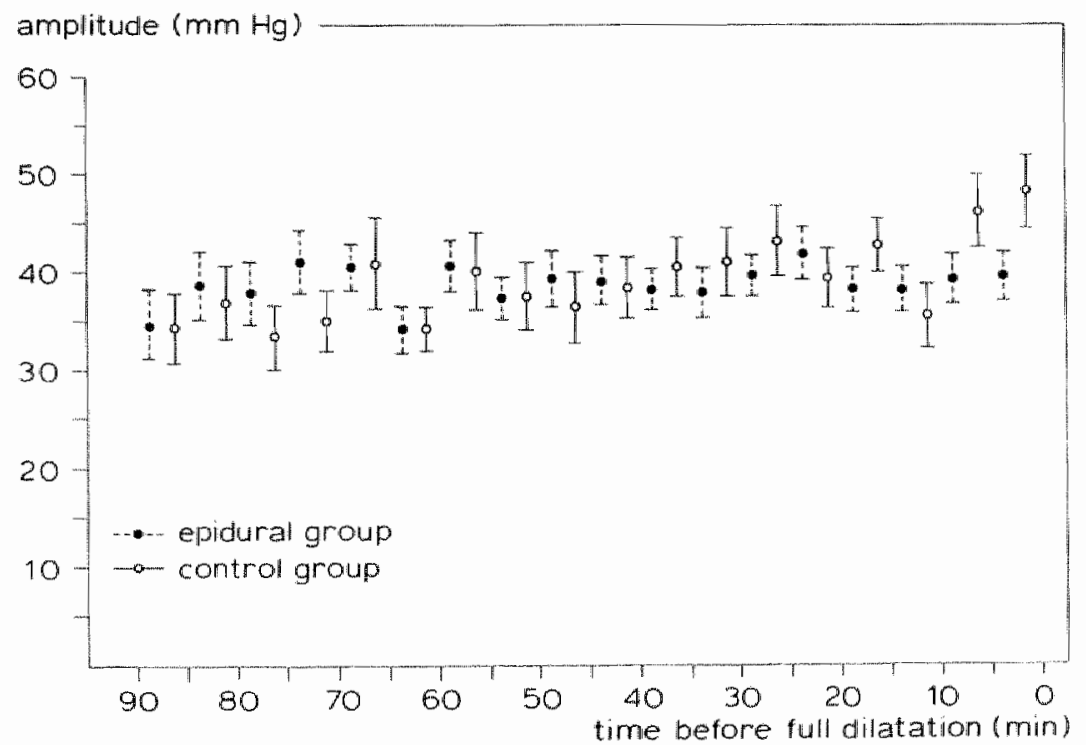

Figure 9.13. Mean amplitude \pm SEM per five minwte period during the last ninety minutes of the first stage 


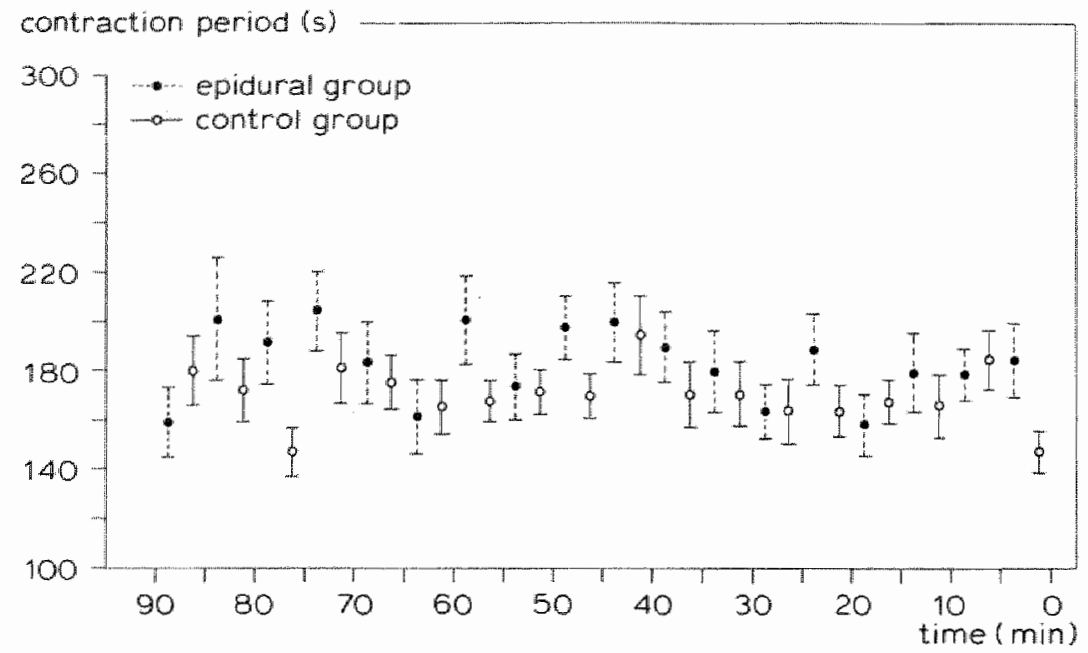

Figure 9.14 Mean contraction period \pm SEM per five minute period during the last ninety minutes of the first stage

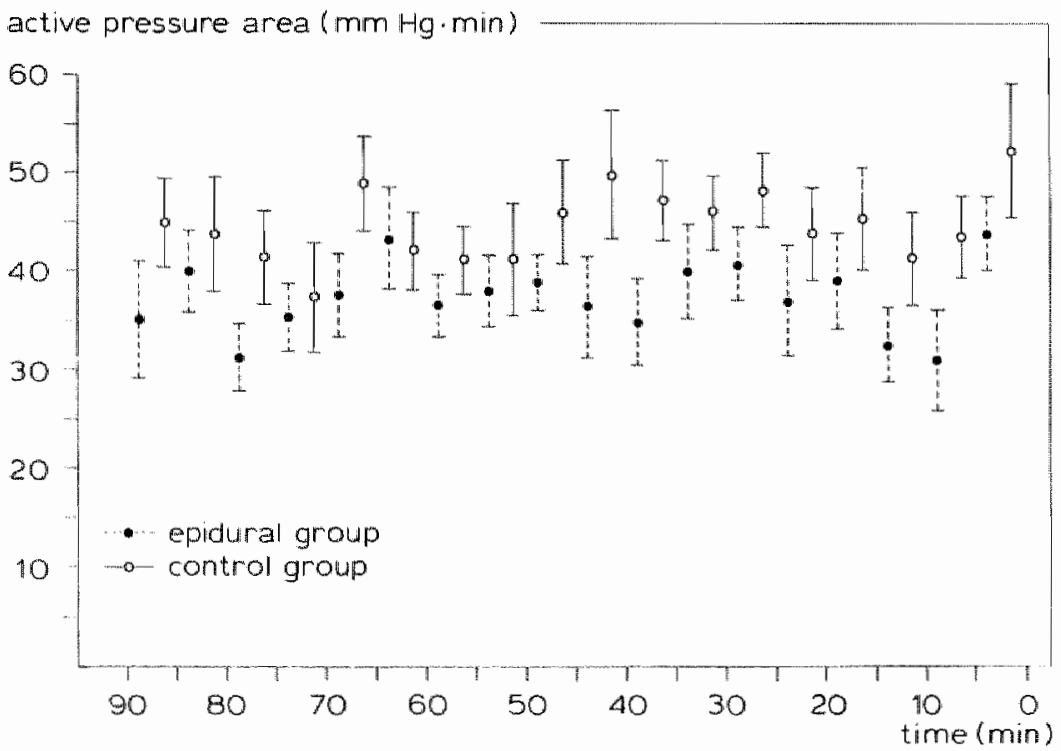

Figure 9.15 Mean active pressure area \pm SEM per five minute period during the last ninety minutes of the first stage 


\subsubsection{The trend of the contraction parameters during the last ninety minutes of the first stage}

For the same reasuns as mentioned in section 8.4 .2 , no attempt to investigate a possible trend in the epidural group was made here either.

Study of figure 9.13 indicates the existence of a positive trend for the amplitude in the control group. An increase in the amplitude was observed in the individual graphs for ten patients. In one patient there was a decrease and in eleven patients no definite trend could be discerned. The mean slope, as calculated by linear regression analysis, was 0.11 $\pm 0.18 \mathrm{mmHg} / \mathrm{min}$. This slope was significantly different from zero $(\mathrm{p}<0.05)$. It seems justifiable to conclude that during the last ninety minutes of the first stage there was a positive trend for the amplitude in the control group. Neither study of the individual graphs and graphs of averages nor by calculation of the slopes were any indications found for a particular trend in contraction period or active pressure area in the control group.

\subsection{The effect of the hypalgesic level on the contraction parameters}

In section 5.1 .5 the relationship between a high hypalgesic level and the uterine activity was discussed. In three patients the level of hypalgesia reached beyond the seventh thoracic spinal segment $\left(T_{7}\right)$ during the last ninety minutes of the first stage. In these three women the level of hypalgesia extended to respectively the fourth, fifth and sixth thoracic spinal segments. In none of these three patients did hypotension arise despite the extensive sympathetic blockade that must have been present in these women. Since a hypalgesic level beyond $T_{7}$ may have a negative effect on uterine activity, it was investigated whether the mean change in contraction parameters (with respect to the base-line period) differed between the women with a hypalgesia level of beyond $T_{7}$ and the women with a hypalgesia level that was lower than $T_{7}$. Student's paired sample $t$-test was used to investigate if the change differed significantly from zero. Student's two sample t-test was used to determine if there was a difference between the two groups. The results are given in table 9.6 . 
Table 9.6 The change in contration parameters (last minety minutes of the first stage minus the base-line periodj of the women with a hypalgesic level going beyond $T_{7}$ and of the women with a hypalgesic levell lower than $T_{7}(\ddot{x} \pm S D)$

\begin{tabular}{lccccccccc}
\hline & \multicolumn{3}{c}{$\begin{array}{c}\text { hypalgesic level } \\
\text { beyond } \mathrm{T}_{7}\end{array}$} & & \multicolumn{2}{c}{$\begin{array}{c}\text { hypalgesic level } \\
\text { lower than } \mathrm{T}_{7}\end{array}$} & $\begin{array}{c}\text { difference } \\
\text { between } \\
\text { groups }\end{array}$ \\
\hline & $\mathrm{n}$ & $\overline{\mathrm{x}}$ & $\mathrm{SD}$ & $\mathrm{p}$ value & $\mathrm{n}$ & $\overline{\mathrm{x}}$ & $\mathrm{SD}$ & $\mathrm{p}$ value & $\mathrm{p}$ value \\
\hline $\begin{array}{l}\text { amplitude } \\
\text { (mmHg) }\end{array}$ & 3 & +3.4 & 67 & $>0.1$ & 17 & -0.8 & 8.4 & $>0.1$ & $>0.1$ \\
$\begin{array}{l}\text { contraction } \\
\text { period(s) }\end{array}$ & 3 & -25 & 37 & $>0.1$ & 17 & -3 & 28 & $>0.1$ & $>0.1$ \\
$\begin{array}{l}\text { active } \\
\text { pressure area } \\
\text { (mmHg.min) }\end{array}$ & 3 & +6.5 & 11.5 & $>0.1$ & 17 & -0.5 & 2.7 & $>0.1$ & $>0.1$ \\
\hline
\end{tabular}

It emerges from table 9.6 that in neither of the two groups there were any significant changes and neither was there any significant difference between the two groups.

\subsection{The effect of a top-up dose on the contraction parameters}

Ten women were given one or more top-up doses via the epidural catheter. In four of the women a single top-up dose was given; in four others a top-up dose was given twice and in the remaining two it was given three times. The mean time interval between the last top-up dose and full dilatation was $104 \pm 17$ minutes (range 78 to 124 minutes). In order to investigate whether the top-up dose had an effect on the contraction parameters, the change in contraction parameters in the last ninety minutes of the first stage with respect to the base-line period was determined in both the women who had been given a top-up dose and those who had received only one epidural injection. Student's paired sample t-test was used to see if the change differed significantly from zero. Student's two sample t-test was used to test whether there was a difference between the two groups. The results are given in table 9.7. 
Table 9.7 The change in contraction parameters (last ninety minutes of the frrst stage minus the base-line periad) in the women with one or more top-up dose and those with a single dose ( $\overline{ \pm} \pm \mathrm{SD})$

\begin{tabular}{lcccccccccc}
\hline & \multicolumn{3}{c}{$\begin{array}{c}\text { women with } \\
\text { top-up dose }\end{array}$} & & $\begin{array}{c}\text { women with } \\
\text { single dose }\end{array}$ & $\begin{array}{c}\text { difference } \\
\text { between } \\
\text { groups }\end{array}$ \\
\hline & $\mathrm{n}$ & $\overline{\mathrm{x}}$ & $\mathrm{SD}$ & $\mathrm{p}$ value & $\mathrm{n}$ & $\overline{\mathrm{x}}$ & $\mathrm{SD}$ & $\mathrm{p}$ value & $\mathrm{p}$ value \\
\hline $\begin{array}{l}\text { amplitude } \\
\text { (mmHg) }\end{array}$ & 10 & +3.3 & 8.3 & $>0.1$ & 10 & -3.7 & 6.7 & $>0.1$ & $0.05<\mathrm{p}<0.1$ \\
$\begin{array}{l}\text { contraction } \\
\text { period(s) }\end{array}$ & 10 & -14 & 34 & $>0.1$ & 10 & +1 & 25 & $>0.1$ & $>0.1$ \\
$\begin{array}{l}\text { active } \\
\text { pressure area } \\
\text { (mmHg.min) }\end{array}$ & 10 & +5.1 & 11.8 & $>0.1$ & 10 & -4 & 12 & $>0.1$ & $>0.1$ \\
\hline
\end{tabular}

It emerges from table 9.7 that in neither of the two groups there were any significant changes. The increase in amplitude in the women who received one or more top-up doses was nearly significantly larger than in the women who received only a single dose $(p=0.053)$. The women, who got a single dose, had a mean base-line value of $40.6 \pm$ $11.6 \mathrm{mmHg}$. The women, who got top-up doses had a mean base-line value of $37.6 \pm$ $12.1 \mathrm{mmHg}$. The difference is not significant $(\mathrm{p}>0.1)$.

9.7 The relationship between the maternal blood pressure and the contraction parameters in the 120 minute period following administration of the epidural anaesthesia The relationship between the maternal blood pressure and uterine activity was detailed in section 5.1.1, for this reason the correlation was calculated between the maternal blood pressure parameters (systolic blood pressure and mean arterial pressure), and the contraction parameters. The way in which the correlation was calculated is described in section 7.6.1.2. The $p$ values for the transformed correlation coefficients are given in table 9.8 . 
Table 9.8 The values of the mean transformed correlation coefficients between the maternal blood pressure parameters and the contraction parameters in the 120 minute period following administration of the epidural anaesthesia

\begin{tabular}{lccc}
\hline amplitude & $\begin{array}{c}\text { contraction } \\
\text { period }\end{array}$ & $\begin{array}{c}\text { active pressure } \\
\text { area }\end{array}$ \\
\hline $\begin{array}{l}\text { systolic blood } \\
\text { pressure }\end{array}$ & 0.52 & 0.90 & 0.43 \\
$\begin{array}{l}\text { mean arterial } \\
\text { pressure }\end{array}$ & 0.60 & 0.02 & 0.56 \\
\hline
\end{tabular}

It emerges from table 9.8 that there was a significant positive relationship between the mean arierial blood pressure and the contraction period. Ten of the individual correlation coefficients ( $r$ ) were positive and ten negative. The significant $p$ value $(0.02)$ however, was mainly due to an extremely high correlation of +0.9995 in one patient. If the $p$ value was again calculated leaving out this patient then it emerges that $p$ was larger than 0.1 . In view of this consideration, one should be extremely cautious in interpreting this result. In this case it is quite likely that the two per cent significance which was obtained is coincidental.

\subsection{Discussion}

\subsubsection{The amplitude}

Various authors have observed a reduction in the amplitude following epidural anaesthesia administration (section 5.1). In this study there was a slight indication for a reduction of the amplitude comparing the 120 minute period following administration of the epidural anaesthesia with the base-line period (section 9.2). However, after administration of the epidural anaesthesia there was no significant trend in the course of the amplitude (section 9.3.1). During the last ninety minutes of the first stage there was no significant difference between the control group and the epidural group from the point of view of amplitude (section 9.4). Abouleish (1977) is of the opinion that blockade of the sympathetic nerves which innervate the uterus can have an inhibitory effect on uterine activity, thus, the level of hypalgesia could have an effect on the amplitude. However, in this study, no significant change in the amplitude was found in the 3 women whose hypaigesic level went beyond the seventh thoracic spinal segment (section 9.5). This finding agrees with the results of the studies by Vasicka and Kretchmer (1961) and Vasicka et al., (1964) who found that levels of sensory anaesthesia as high as $T_{5}$, did not affect intensity of the uterine contractions, provided that epidural anaesthesia was not accompanied by hypotension. It appears from table 9.3 that there is no significant decrease of the amplitude neither in the normotensive nor in the hypotensive women. Table 9.5 showed a significant increase of the amplitude in the control group during labour, whilst this increase failed to appear in the epidural group. It 
seems that the increase in uterine activity, which is normally seen during labour (Miller et al., 1976; Steer et al., 1984) is absent during epidural anaesthesia.

Our study can best be compared with that of Raabe and Belfrage (1976). These authors used the same local anaesthetic agent in the same dosage. Just as in our study, they only started the epidural anaesthesia when the cervical dilatation was four to five $\mathrm{cm}$. It is not clear whether the positioning of the women was standardised in their study. In ten of the twenty five women uterine activity was stimulated with oxytocin. They found a reduction in uterine activity (Montevideo Units) and in the amplitude during the first thirty minutes following administration of the epidural anaesthesia. Uterine activity increased again between thirty and forty minutes after epidural block and attained the same level as it had been during the last ten minutes prior to epidural anaesthesia. The reduction in uterine activity (Montevideo Units) was due to a significant reduction in amplitude, the contraction frequency, however, remained unchanged. In this study, no change in uterine activity (active pressure area) was found even in the first thirty minutes following administration of the epidural anaesthesia. The amplitude, showed a significant reduction in the first thirty minute period as compared with the base-line period (fig. 9.3).

In the first ten minutes after the epidural anaesthesia had been administered, the women were in a half sitting position but thereafter they stayed in the lateral position. It might be possible that the reduction in amplitude was wholly or partly due to the half sitting position. For this reason, the amplitude was calculated over the time period of ten to thirty minutes after epidural anaesthesia and over the period ten to forty minutes after epidural anaesthesia. In both cases there was a significant reduction, respectively $-3.0 \pm 1.2 \mathrm{mmHg}(\mathrm{p}<0.05)$ and $-3.1 \pm 1.5 \mathrm{mmHg}(\mathrm{p}<0.05)$. It therefore seems unlikely that the observed reduction of amplitude in the first thirty minute period is mainly due to the position of the woman.

As far as the amplitude is concerned, these results are in agreement with those of Raabe and Belfrage (1976).

\subsubsection{The contraction period}

No significant changes in the contraction period are evident on comparison of the 120 minute period following epidural anaesthesia with the base-line period (section 9.2). Based on the mean slope and assessment of individual graphs and of the graph of averages, a slight tendency towards prolongation of the contraction period during the first sixty minutes following administration of the epidural anaesthesia could not be excluded in some of the women (section 9.3.2). No significant differences were found between the control group and the epidural group in the last ninety minutes of the first stage (section 9.4). No significant changes in the contraction period occurred even in the hypotensive women nor in women whose level of hypalgesia extended above the seventh thoracic spinal segment (section 9.2 and 9.5).

Only Alexander and Franklin (1966) found a reduction in the contraction frequency after administration of epidural anaesthesia. In that study, the mean reduction in contraction frequency was 37 per cent. The local anaesthetic was given by the caudal route and the nature and dosage of the local anaesthetic agent were not mentioned. It is 
also not clear from the study by these authors what the position of the women was and whether or not their positions changed during the investigation. All authors are of the opinion that epidural anaesthesia has no effect on the contraction frequency (section 5.1). The conclusion that our results are in agreement with this concensus seems justified.

It is apparent from figure 9.4 that in the first thirty minutes following the administration of the epidural anaesthesia, there was a significant reduction in the contraction period. It might be possible that the decrease in the contraction period was wholly or partly due to the half sitting position of the women during the first ten minutes after the administration of the epidural anaesthesia. For this reason, the change in the contraction period was also calculated for the period of ten minutes to thirty minutes after epidural anaesthesia and for the period ten minutes to forty minutes after epidural anaesthesia. The reduction was respectively $-18 \pm 9 \mathrm{~s}(0.05<\mathrm{p}<0.1)$ and $-16 \pm 5 \mathrm{~s}(\mathrm{p}<0.05)$. These results indicate that it is improbable that the observed decrease of the contraction period is mainly due to the position of the patient. This initial decrease in the contraction period is followed by an increase as seen in section 9.3.2.

\subsubsection{The active pressure area}

On comparison of the 120 minute period following epidural anaesthesia with the base-line period, it emerged that no significant changes occurred (section 9.2). During the last ninety minutes of the first stage the active pressure area was significantly larger in the control group than in the epidural group (section 9.4). It appeared from table 9.5 that in the control group the active pressure area significantly increased during labour, whilst the increase was absent in the epidural group. The increase in uterine activity which normally occurs during labour fails to appear during epidural anaesthesia.

Significant changes in the active pressure area were found in neither hypotensive women nor in women whose level of hypalgesia extended beyond the seventh thoracic spinal segment. Tyack et al., (1973) found no significant changes in the pressure area after administration of epidural anaesthesia. They used caudal epidural anaesthesia with bupivacaine containing no adrenaline. The dose was considerably higher than in our study, namely between 35 and $80 \mathrm{mg}$.

Schellenberg (1977) investigated the effect of top-up doses on the pressure area. Bupivacaine 0.25 per cent without adrenaline was used at a dose of $25 \mathrm{mg}$. No significant change occurred in the pressure area following top-up doses in women who were induced with oxytocin nor in women whose labour begun spontaneously.

Ten women in our study were given a top-up dose. It was investigated whether this second injection had a possible effect on the active pressure area. To do this, the two hour period after the first epidural injection was compared with the two hour period after the second epidural injection with Student's paired sample t-test. It emerged that in these ten women there was a slight, insignificant, increase in the active pressure area following the repeat injection. Even if the thirty minute period before the second epidural injection was compared with the two hour period after the second injection, an insignificant increase was found. Finally, the pre-anaesthetic base-line period was compared with the period from 15 minutes to 45 minutes after the top-up dose. Here too 
an insignificant increase in the active pressure area was found. It is apparent also from section 9.6 that top-up doses did not cause any significant changes in the active pressure area.

No significant changes in the active pressure area occurred in the epidural group. Only on comparison with the control group it appeared that the increase in the active pressure area was absent during epidural anaesthesia. This resulted in a significantly lower pressure area in the epidural group during the last ninety minutes of the first stage. There are no reports in the literature of studies in which the results obtained during epidural anaesthesia have been compared with a control group receiving no kind of pain control. In our study we used bupivacaine 0.25 per cent to which adrenaline had been added at a concentration of $5 \mu \mathrm{g} / \mathrm{ml}$. In section 5.1 .2 the effect of adrenaline on uterine activity has already been discussed. One of the most important studies from the point of wiew of this problem is the one by Jouppila et al., (1977). These authors found that in sixteen patients to whom segmental epidural anaesthesia was administered using 4 to $5 \mathrm{ml}$ bupivacaine 0.5 per cent without adrenaline, there was a non-significant increase in Montevideo Units. In fifteen other patients 4 to $5 \mathrm{ml}$ bupivacaine 0.5 per cent with added adrenaline $(5 \mu \mathrm{g} / \mathrm{ml})$ was used for the epidural anaesthesia. In this group a non-significant reduction in Montevideo Units was observed. However, the difference between the two groups was indeed significant. It is therefore quite possible that the increase in uterine activity that normally occurs during labour (as in our control group) did not happen in the epidural group because of the adrenaline that had been added to the local anaesthetic.

\subsection{Conclusions}

In the control group there was a significant increase in the amplitude and the active pressure area. This increase which normally occurs during labour did not occur with epidural anaesthesia. This resulted in this study in a significantly larger active pressure area in the control group than in the epidural group during the last ninety minutes of the first stage.

During the first thirty minutes after the epidural anaesthesia was administered a significant reduction in the amplitude and the contraction period occurred. Although the uterine activity in the epidural group was less than in the control group, the time interval between the start of the investigation and full dilatation differed not significantly between the two groups (table 7.3). 



\section{Results concerning the effect of epidural anaesthesia on the maternal and foetal acid-base balance}

The method of analysis and the point in time when the maternal and foetal blood gases were analysed have been described in section 7.4. Section 10.1 discusses the results of the maternal acid-base balance and section 10.2 those of the foetal acid-bace balance. In section 10.3 foetomaternal $\mathrm{pH}$ differences are discussed.

\subsection{The maternal acid-bace balance}

As has already been mentioned (section 7.4), maternal blood gas analysis were performed at the start of the investigation, at full dilatation and post partum. This was done for both the patients in the control group and those in the epidural group. The results from these observations are presented in tables 10.1 and 10.2.

Table 10.1 Maternal acid-base balance in the control group at different moments in the in vestigation (venous blood)

\begin{tabular}{|c|c|c|c|c|c|c|c|c|c|c|c|c|}
\hline \multicolumn{5}{|c|}{ Start of investigation } & \multicolumn{4}{|c|}{ Full dilatation } & \multicolumn{4}{|c|}{ Post partum } \\
\hline $\begin{array}{l}\text { Pat- } \\
\text { ient }\end{array}$ & $\mathrm{pH}$ & $\begin{array}{c}\mathrm{BE} \\
(\mathrm{mmol} / \mathrm{l})\end{array}$ & $\begin{array}{l}\mathrm{pCO}_{2} \\
(\mathrm{kPa})\end{array}$ & $\begin{array}{c}\mathrm{pO}_{2} \\
(\mathrm{kPa})\end{array}$ & $\mathrm{pH}$ & $\begin{array}{c}\mathrm{BE} \\
(\mathrm{mmol} / \mathrm{T})\end{array}$ & $\begin{array}{l}\mathrm{pCO}_{2} \\
(\mathrm{kPa})\end{array}$ & $\begin{array}{c}\mathrm{pO}_{2} \\
(\mathbf{k P a})\end{array}$ & pH & $\begin{array}{c}\mathrm{BE} \\
(\mathrm{mmol} / \mathrm{l})\end{array}$ & $\begin{array}{l}\mathrm{pCO}_{2} \\
\left(\mathrm{kP}^{\prime} \mathrm{a}\right)\end{array}$ & $\begin{array}{c}\mathrm{pO}_{2} \\
(\mathrm{kPa})\end{array}$ \\
\hline 1 & 7.44 & -1.0 & 4.3 & 5.5 & 7.57 & -5.0 & 2.0 & 7.7 & 7.38 & -6.0 & 3.9 & 4.4 \\
\hline 2 & 7.46 & +1.0 & 4.5 & 6.9 & 7.45 & -2.0 & 4.0 & 7.1 & 7.44 & -6.0 & 3.11 & 8.0 \\
\hline 3 & 7.45 & +8.0 & 6.5 & 18.5 & 7.44 & -3.5 & 3.7 & 6.4 & 7.33 & -8.0 & 4,4 & 8.1 \\
\hline 4 & 7.46 & -5.0 & 3.2 & 5.9 & 7.45 & $=4.0$ & 3.5 & 6.7 & 7.30 & $\cdot 9.0$ & 4.5 & 6.4 \\
\hline 5 & 7.43 & -1.0 & 4.4 & 5.3 & 7.41 & -3.0 & 4.3 & 4.4 & 7.318 & -30 & 4.6 & 4.5 \\
\hline 6 & 7.60 & 0.0 & 2.5 & 7.3 & 7.52 & -6.5 & 2.3 & 6.9 & 7.29 & -14.5 & 3.1 & 7.7 \\
\hline 7 & 7.58 & +10.0 & 4.5 & 2.3 & 7.41 & -6.0 & 3.6 & 4.5 & 7.41 & -7.0 & 3.3 & 8.8 \\
\hline 8 & - & - & $\ldots$ & - & 7.25 & -120 & 4.5 & 4.8 & 7.40 & -8.5 & 3.1 & 7.2 \\
\hline 9 & 7.39 & -1.0 & 5.3 & 5.0 & 7.46 & -4.0 & 3.2 & 5.9 & 7.38 & -7.5 & 3.6 & 7.2 \\
\hline 10 & 7.45 & +1.0 & 4.7 & 6.5 & 7.51 & 0.0 & 3.6 & 14.6 & 7.40 & -4.0 & 4.1 & 11.2 \\
\hline $1 \mathbb{1}$ & 7.41 & -1.0 & 4.8 & 5.3 & 7.38 & -2.0 & 5.1 & 5.3 & 7.32 & -6.5 & 4.8 & 5.9 \\
\hline 12 & - & - & - & - & 7.51 & -2.0 & 3.2 & 7.5 & 7.41 & -7.0 & 3.5 & 6.9 \\
\hline 13 & 7.56 & -2.5 & 2.5 & 4.3 & 7.55 & -3.0 & 2.5 & 5.7 & 7.31 & -9.0 & 4.1 & 6.7 \\
\hline 14 & 7.48 & -4.0 & 3.2 & 5.6 & 7.40 & -5.5 & 3.9 & 6.4 & 7.44 & -3.0 & 4.1 & 6.1 \\
\hline 15 & 7.47 & -2.0 & 3.6 & 11.2 & 7.45 & -6.0 & 4.3 & 4.9 & 7.33 & -7.5 & 4.4 & 5.9 \\
\hline 16 & - & - & - & - & 7.48 & -1.0 & 3.7 & 9.0 & 7.36 & -5.0 & 4.5 & 4.8 \\
\hline 17 & 7.50 & +1.0 & 3.9 & 8.0 & 7.47 & 0.0 & 4.0 & 3.9 & 7.37 & -3.0 & 5.1 & 4.9 \\
\hline 18 & - & - & - & - & 7.41 & -2.5 & 4.4 & 6.0 & 7.40 & -3.0 & 3.7 & 8.0 \\
\hline 19 & 7.52 & +11.0 & 5.7 & 16.6 & 7.44 & 0.0 & 4.5 & 5.2 & 7.32 & -8.0 & 4.4 & 7.2 \\
\hline 20 & 7.46 & 0.0 & 4.4 & 4.8 & 7.62 & -4.0 & 1.7 & 14.9 & 7.32 & -10.0 & 3.7 & 5.9 \\
\hline 21 & - & - & - & - & 7.43 & -4.0 & 3.7 & 9.3 & 7.41 & -5.0 & 3.7 & 8.6 \\
\hline 22 & 7.47 & +6.0 & 5.3 & 8.6 & - & - & - & - & 7.38 & -6.0 & 4.0 & 7.2 \\
\hline
\end{tabular}


Table 10.2 Maternal acid-base balance in the epidural group at different moments in the investigation (venous blood)

\begin{tabular}{|c|c|c|c|c|c|c|c|c|c|c|c|c|}
\hline \multicolumn{5}{|c|}{ Start of in vestigration } & \multicolumn{4}{|c|}{ Full dilatation } & \multicolumn{4}{|c|}{ Post partum } \\
\hline $\begin{array}{l}\text { Pat- } \\
\text { ient }\end{array}$ & $\mathrm{pH}$ & $\begin{array}{c}\mathrm{BE} \\
(\mathrm{mmol} / \mathrm{l})\end{array}$ & $\begin{array}{l}\mathrm{pCO}_{2} \\
(\mathrm{kPa})\end{array}$ & $\begin{array}{c}\mathrm{pO}_{2} \\
(\mathrm{kPa})\end{array}$ & $\mathrm{pH}$ & $\begin{array}{c}\mathrm{BE} \\
(\mathrm{mmol} / \mathrm{l})\end{array}$ & $\begin{array}{l}\mathrm{pCO}_{2} \\
(\mathrm{kPa})\end{array}$ & $\begin{array}{c}\mathrm{pO}_{2} \\
(\mathrm{kPa})\end{array}$ & $\mathrm{pH}$ & $\begin{array}{c}\mathrm{BE} \\
(\mathrm{mmol} / \mathrm{l})\end{array}$ & $\begin{array}{l}\mathrm{pCO}_{2} \\
(\mathrm{kPa})\end{array}$ & $\begin{array}{r}\mathrm{pO}_{2} \\
(\mathrm{kPa})\end{array}$ \\
\hline 1 & 7.45 & -20 & 3.9 & 12.9 & 7.45 & -4.0 & 3.5 & 10.0 & 7.46 & -3.0 & 2.9 & 9.2 \\
\hline 2 & 7.43 & - & - & - & 7.49 & -2.0 & 3.2 & 7.7 & 7.45 & -6.0 & 3.1 & 7.8 \\
\hline 3 & 7.52 & -1.0 & 3.2 & 7.7 & 7,49 & $=2.0$ & 3.3 & 12.4 & 7.54 & -4.0 & 2.4 & 13.7 \\
\hline 4 & 7.50 & -2.0 & 3.2 & 5.5 & 7.44 & 0.0 & 4.5 & 4.5 & 7.50 & -2.5 & 3.2 & 5.5 \\
\hline 5 & 7.50 & -1.5 & 3.3 & 14.5 & 7.40 & -3.0 & 4.5 & 5.6 & 7.48 & +6.5 & 5.5 & 14.8 \\
\hline 6 & 7.50 & 0.0 & 3.6 & 16.6 & 7.47 & -5.0 & 3.1 & 13.7 & 7.54 & -2.0 & 2.9 & 13.6 \\
\hline 7 & 7.41 & -2.0 & 4.4 & 9.0 & 7.52 & -3.0 & 2.9 & 13.6 & 7.35 & -7.0 & 4.3 & 5.5 \\
\hline 8 & 7.42 & -2.0 & 4.3 & 7.7 & 7,48 & -4.0 & 3.1 & 4.1 & 7.44 & -5.0 & 3.3 & 6.0 \\
\hline 9 & 7.44 & -5.0 & 3.5 & 14.4 & - & - & - & $=$ & 7.38 & -4.0 & 4.4 & 4.4 \\
\hline 10 & 7.40 & -5.0 & 3.8 & 15.2 & 7.50 & -1.0 & 3.5 & 12.6 & 7.40 & -5.0 & 4.0 & 15.3 \\
\hline 11 & 7.40 & -3.5 & 4.1 & 6.8 & 7.40 & -2.0 & 4.7 & 6.8 & 7.44 & -4.5 & 3.5 & 10.5 \\
\hline 12 & 7.43 & -6.0 & 3.3 & 10.0 & 7.52 & +3.0 & 3.7 & 8.1 & 7.47 & -3.0 & 3.3 & 16.1 \\
\hline 13 & 7.47 & -0.5 & 4.0 & - & 7.45 & -3.0 & 3.7 & 7.6 & 7.44 & -7.0 & 2.9 & 13.3 \\
\hline 14 & 7.43 & +1.0 & 49 & 5.1 & 7.45 & -4.5 & 3.3 & 10.4 & - & - & - & - \\
\hline 15 & 7.45 & -4.0 & 3.5 & 8.5 & 7.50 & -2.5 & 3.2 & 13.3 & 7.43 & -6.0 & 3.2 & 11.6 \\
\hline 16 & 7.48 & - & - & 18.8 & 7.45 & -5.0 & 3.3 & 7.2 & 7.36 & -10.5 & 3.2 & 8.9 \\
\hline 17 & 7.50 & +4.0 & 4.5 & 6.5 & 7.44 & +1.0 & 4.7 & 6.5 & 7.48 & +3.5 & 4.7 & 6.7 \\
\hline 18 & 7.45 & -4.0 & 3.6 & 11.2 & 7.44 & -2.0 & 4.0 & 13.3 & 7.47 & -3.0 & 3.5 & 11.0 \\
\hline 19 & 7.44 & +1.0 & 4.7 & 11.3 & 7.47 & -11.0 & 3.9 & 9.3 & 7.49 & -2.0 & 3.5 & 128 \\
\hline 20 & 7.46 & -30 & 3.5 & 6.7 & 7.41 & -1.0 & 4.5 & 5.8 & 7.40 & -4.0 & 4.0 & 5.3 \\
\hline
\end{tabular}

10.1.1 The maternal acid-base balance at the start of the investigation

Table 10.3 presents the mean values for the $\mathrm{pH}, \mathrm{BE}, \mathrm{pCO}_{2}$ and $\mathrm{pO}_{2}$ in the control group and the epidural group as well as the $\mathrm{p}$ values for the differences between them.

Table 10.3 Maternal acid-base balance at the stan of the investigation in the control group and the epidural group $(\bar{x} \pm S D)$.

\begin{tabular}{llll}
\hline \hline & control group & epidural group & p value \\
\hline $\mathrm{pH}$ & $\begin{array}{l}7.48 \pm 0.06 \\
\mathrm{n}=17\end{array}$ & $\begin{array}{l}7.45 \pm 0.04 \\
\mathrm{n}=20\end{array}$ & $>0.1$ \\
$\mathrm{BE}$ & $1.2 \pm 4.7$ & $-2.0 \pm 2.5$ & $<0.05$ \\
$(\mathrm{mmol} / \mathrm{l})$ & $\mathrm{n}=17$ & $\mathrm{n}=18$ & \\
$\mathrm{pCO}_{2}$ & $4.3 \pm 1.1$ & $3.9 \pm 0.05$ & $>0.1$ \\
$(\mathrm{kPa})$ & $\mathrm{n}=17$ & $\mathrm{n}=18$ & \\
$\mathrm{pO}_{2}$ & $7.5 \pm 4.3$ & $10.5 \pm 4.1$ & $<0.05$ \\
$(\mathrm{kPa})$ & $\mathrm{n}=17$ & $\mathrm{n}=18$ & \\
\hline
\end{tabular}


There was a significant difference between the two groups from the point of view of the base excess and the $\mathrm{pO}_{2}$. The base excess in the epidural group was lower than in the control group. This may be explained on the basis of the fact that the women who opted for epidural anaesthesia probably were suffering more pain and therefore demonstrated more muscular activity. Of course, the acid-base balance of such patients had a tendency to shift in the direction of metabolic acidosis (section 5.3.1).

The $\mathrm{pO}_{2}$ in the control group was significantly lower than in the epidural group. Possibly this is explicable on the basis of more manifest hyperventilation among the women who would opt for epidural anaesthesia. In the case of hyperventilation, one would expect that the $\mathrm{pCO}_{2}$ in the epidural group would be lower than in the control group, this was the case, although this difference did not reach the five per cent significance level.

\subsubsection{The maternal acid-base balance at full dilatation}

Table 10.4 presents the average values for the $\mathrm{pH}_{3} \mathrm{BE}, \mathrm{pCO}_{2}$ and $\mathrm{pO}_{2}$ in the control group at full dilatation as well as the $p$ values of the differences among them.

Table 10.4 Maternal acid-base balance at full dilatation in the control group and in the epidural $\operatorname{group}(\bar{x} \pm S D)$

\begin{tabular}{llll}
\hline \hline $\mathrm{pH}$ & control group & epidural group & $\mathrm{p}$ value \\
\hline & $\begin{array}{l}7.46 \pm 0.08 \\
\mathrm{n}=21\end{array}$ & $\begin{array}{l}7.46 \pm 0.04 \\
\mathrm{n}=19\end{array}$ & $>0.1$ \\
$\mathrm{BE}$ & $-3.6 \pm 2.8$ & $-2.1 \pm 2.0$ & $0.05<\mathrm{p}<0.1$ \\
$(\mathrm{mmol} / \mathrm{l})$ & $\mathrm{n}=21$ & $\mathrm{n}=19$ & \\
$\mathrm{pCO}$ & $3.6 \pm 0.9$ & $3.7 \pm 0.6$ & $>0.1$ \\
$(\mathrm{kPa})$ & $\mathrm{n}=21$ & $\mathrm{n}=19$ & \\
$\mathrm{pO}_{2}$ & $7.2 \pm 2.9$ & $9.1 \pm 3.3$ & $0.05<\mathrm{p}<0.1$ \\
$(\mathrm{kPa})$ & $\mathrm{m}=21$ & $\mathrm{n}=19$ & \\
\hline
\end{tabular}

At full dilatation, there were no significant differences between the two groups. The base excess in the control group was lower than in the epidural group. This difference was not significant $(p=0.06)$. The $\mathrm{pO}_{2}$ was lower in the control group than in the epidural group. However, this too proved to be non-significant $(p=0.07)$.

\subsubsection{The immediate post partum maternal acid-base balance}

Table 10.5 presents the average values for the $\mathrm{pH}, \mathrm{BE}, \mathrm{pCO}_{2}$ and $\mathrm{pO}_{2}$ in the control group and in the epidural group immediately post partum as well as the differences between them. 
Table 10.5 The matemal acid-bose balance immediately post partum in the control group and in the epidural group $(x \pm S D)$

\begin{tabular}{llll}
\hline & control group & epidural group & p walue \\
\hline $\mathrm{pH}$ & $7.37 \pm 0.05$ & $7.45 \pm 0.05$ & $<0.001$ \\
& $\mathrm{n}=22$ & $\mathrm{n}=19$ & \\
$\mathrm{BE}$ & $-6.7 \pm 2.8$ & $-3.6 \pm 3.7$ & $<0.005$ \\
$(\mathrm{mmol} / \mathrm{l})$ & $\mathrm{n}=22$ & $\mathrm{n}=19$ & \\
$\mathrm{pCO}_{2}$ & $4.0 \pm 0.6$ & $3.6 \pm 0.7$ & $0.05<\mathrm{p}<0.1$ \\
$(\mathrm{kPa})$ & $\mathrm{n}=22$ & $\mathrm{n}=19$ & \\
$\mathrm{pO}_{2}$ & $6.9 \pm 1.6$ & $10.1 \pm 3.8$ & $<0.001$ \\
$(\mathrm{kPa})$ & $\mathrm{n}=22$ & $\mathrm{n}=19$ & \\
\hline
\end{tabular}

It appeared that immediately post partum there were considerable differences between the two groups. The $\mathrm{pH}$ in the control group was highly significantly lower than in the epidural group. This was also true for the base excess. Concerning the $\mathrm{pCO}_{2}$ there were no significant differences between the two groups $\left(\mathrm{p}=0.06\right.$ ). The $\mathrm{pO}_{2}$ was very significantly higher in the epidural group than in the control group. The abovementioned differences were not yet present at full dilatation (section 10.1.2). During the second stage it would seem that changes had occurred in the maternal acid-base balance. This is further analysed in section 10.1.5.

10.1.4 The changes of the maternal acid-base balance during the first stage of labour The changes in the maternal acid-base balance during the first stage of labour were determined in both groups. For every patient the value obtained at the start of the investigation was subtracted from the value obtained at full dilatation. Then the mean changes with their associated standard deviations were calculated for both groups. Student"s paired sample t-test was used to determine whether the change differed significantly from zero and Student's two sample t-test was used to determine whether there was a difference in change between the two groups. The results are presented in table 10.6 .

It emerged that in the control group, the base excess and the $\mathrm{pCO}_{2}$ had fallen significantly during the first stage. No significant changes were observed during the first stage as far as the $\mathrm{pH}$ and $\mathrm{pO}_{2}$ are concerned. In the epidural group, no changes involving the parameters of the maternal acid-base balance occurred. The base excess appeared to fall more in the control group than in the epidural group $(p=0.008)$. There were no significant differences for the $\mathrm{pH}_{3} \mathrm{pCO}_{2}$ and $\mathrm{pO}_{2}$. Figure 10.1 presents the results graphically once more. 
Table 10.6 Mean change of the matermal acid-base parameters during the first stage in the control group and in the epidural group $(\bar{x} \pm S D)$

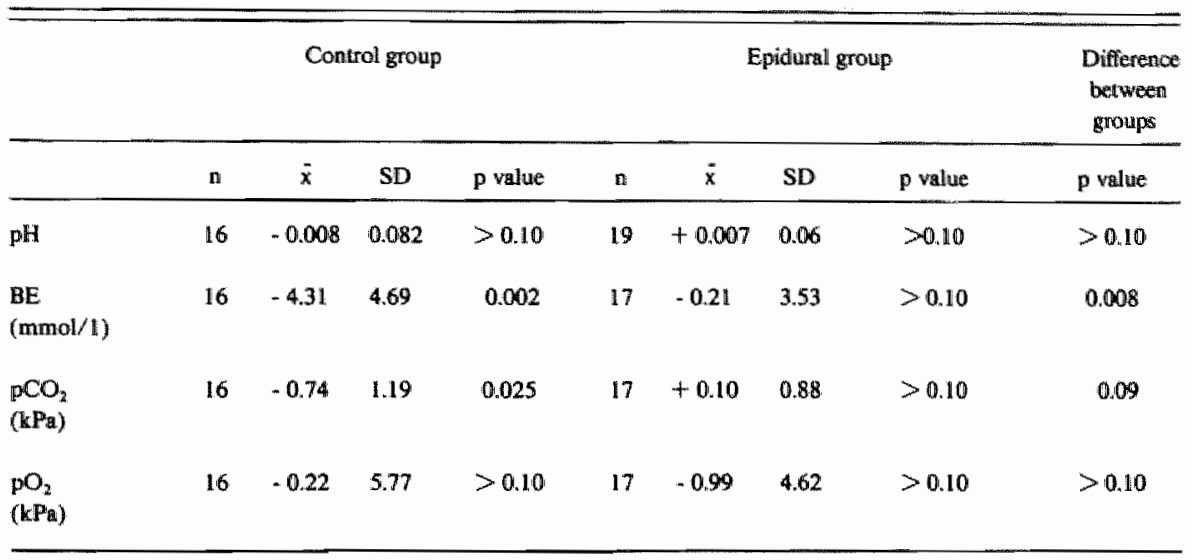

10.1.5 The changes of the maternal acid-base balance during the second stage of labour In the same way as in section 10.1.4 the changes of the maternal acid-base balance during the second stage of labour were calculated. The results are given in table 10.7.

Table 10.7 Mean change of the maternal acid-base parameters during the second stage in the control group and in the epidural group $(\bar{x} \pm S D)$

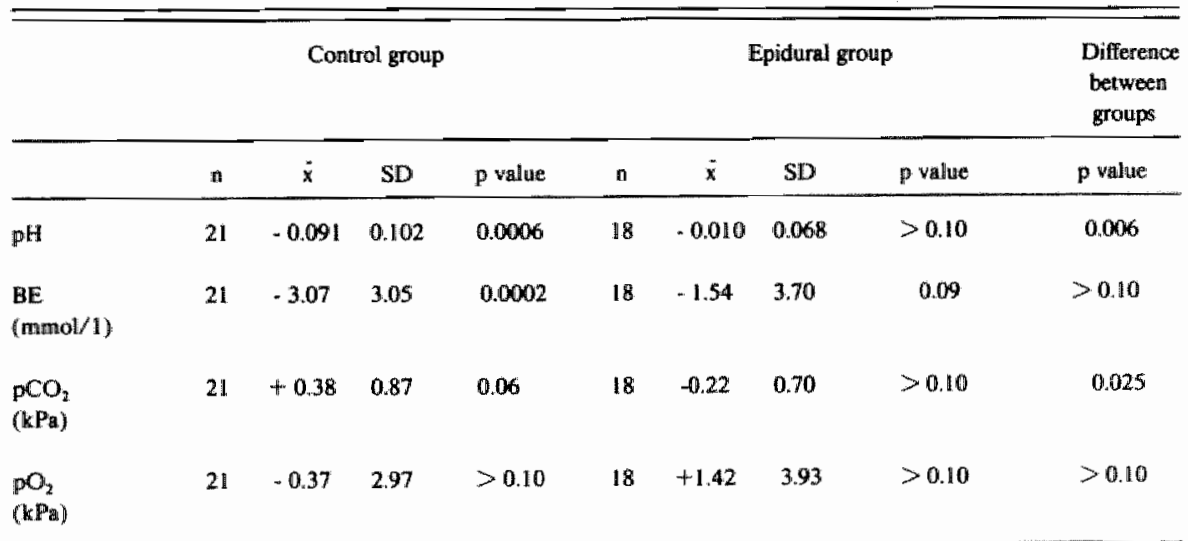

In the control group there was a highly significant decrease in $\mathrm{pH}$ in combination with a highly significant reduction in the base excess. Thus there was a shift in the acid-base balance in the direction of a metabolic acidosis. There was no significant change as far as the $\mathrm{pO}_{2}$ was concerned. The $\mathrm{pCO}_{2}$ rose but this change just failed to reach the five per cent significance level $(\mathrm{p}=0.06)$. There were no significant changes in maternal acid-base parameters in the epidural group during the second stage. It emerged that the 
$\mathrm{pH}$ demonstrated a greater fall in the control group than in the epidural group ( $\mathrm{p}=$ 0.006). The $\mathrm{pCO}_{2}$ showed a non-significant increase in the control group and a non-significant decrease in the epidural group resulting in a significant difference in change between the two groups ( $p=0.025$ ). As far as the base excess and the $\mathrm{pO}_{2}$ are concerned, no significant differences were found in the two groups. Figure 10.1 presents the results graphically.
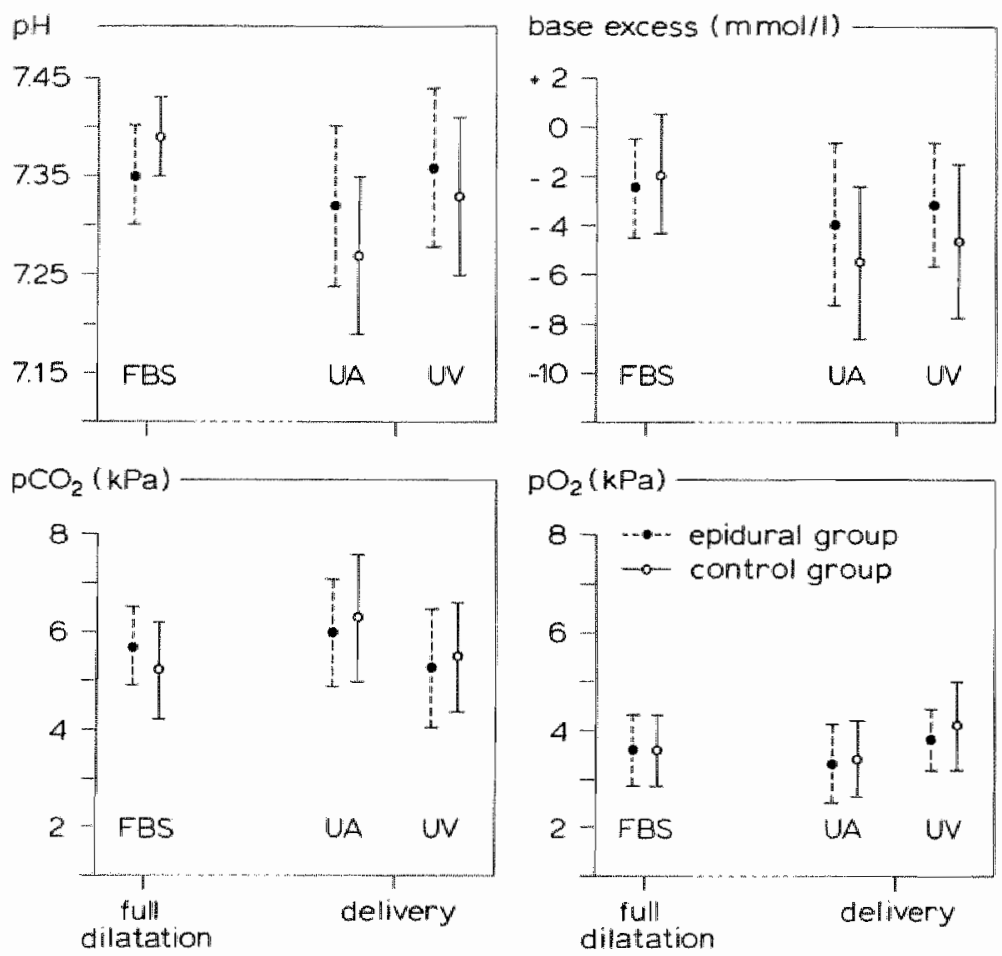

Figure 10.1 Mean maternal acid-base values $\pm S D$ at the different moments during labour

\subsection{The foetal acid-base balance}

It has already been mentioned in section 7.4 that the foetal blood gas analysis was performed at full dilatation and at the birth of the child. Blood samples of the umbilical vein (UV) and umbilical artery (UA) were used for the determination of the acid-base balance immediately after the delivery. The results of these observations are presented in tables 10.8 and 10.9 .

It cannot be excluded that in some cases venous and arterial samples were obtained from the same umbilical vessel. 
Table 10.8 Foetal acid-base balance in the control group at full dilatation and ai birth

\begin{tabular}{|c|c|c|c|c|c|c|c|c|c|c|c|c|}
\hline \multicolumn{5}{|c|}{ Full dilatation } & \multicolumn{5}{|c|}{ Umbilical vein } & \multicolumn{3}{|c|}{ Umbillical artery } \\
\hline $\begin{array}{l}\text { Pat- } \\
\text { ient }\end{array}$ & $\mathrm{pH}$ & $\begin{array}{c}\mathrm{BE} \\
(\mathrm{mmol} / \mathrm{l})\end{array}$ & $\begin{array}{l}\mathrm{pCO}_{2} \\
(\mathrm{kPa})\end{array}$ & $\begin{array}{c}\mathrm{pO}_{2} \\
(\mathrm{kPa})\end{array}$ & $\mathrm{pH}$ & $\begin{array}{c}\mathrm{BE} \\
(\mathrm{mmol} / \mathrm{l})\end{array}$ & $\begin{array}{l}\mathrm{pCO}_{2} \\
(\mathrm{kPa}) \\
\end{array}$ & $\begin{array}{c}\mathrm{pO}_{2} \\
(\mathrm{kPa})\end{array}$ & pH & $\begin{array}{c}\mathrm{BE} \\
(\mathrm{mmol} / \mathrm{l})\end{array}$ & $\begin{array}{l}\mathrm{pCO}_{2} \\
(\mathrm{kPa}) \\
\end{array}$ & $\begin{array}{c}\mathrm{pO}_{2} \\
(\mathrm{kPa})\end{array}$ \\
\hline 1 & 7.45 & -2.0 & 4.0 & 5.1 & 7.37 & -5.0 & 4.3 & 5.5 & 7.32 & $=5.0$ & 5.3 & 4.0 \\
\hline 2 & 7.38 & 0.0 & 5.9 & 3.0 & 7.37 & -5.0 & 4.5 & 4.7 & 7.31 & -3.0 & 4.7 & 4.8 \\
\hline 3 & 7.35 & -2.5 & 59 & 3.5 & - & - & - & - & 7.25 & -5.0 & 7.2 & 3.7 \\
\hline 4 & 7.39 & -3.0 & 4.7 & 4.6 & 7.22 & -9.0 & 6.4 & 3.2 & 7.12 & -6.0 & 8.1 & 3.9 \\
\hline 5 & 7.42 & +1.0 & 5.5 & 4.0 & 7.18 & -7.0 & 8.2 & 3.6 & 7.17 & -7.0 & 8.5 & 3.3 \\
\hline 6 & 7.41 & -30 & 4.3 & 4.3 & 7,20 & -9.5 & 6.7 & 4.4 & 7.14 & -10.5 & 7.7 & 3.2 \\
\hline 7 & 7.36 & -5.0 & 4.5 & 2.4 & 7.38 & -6.0 & 3.9 & 3.7 & 7.31 & -5.0 & 5.3 & 3.3 \\
\hline 8 & 7.43 & -3.0 & 4.0 & 3.2 & 7.17 & -11.0 & 6.7 & 3.5 & 7.19 & -12.0 & 5.9 & 3.2 \\
\hline 9 & 7.43 & 0.0 & 3.5 & 3.5 & 7.31 & -5.5 & 5.3 & 3.5 & 7.29 & -5.0 & 6.1 & 3.2 \\
\hline 10 & 7.39 & +2.0 & 6.1 & 2.9 & 7.36 & -2.0 & 5.5 & 4.4 & 7.25 & -2.0 & 8.4 & 2.4 \\
\hline 11 & 7.32 & -2.0 & 6.3 & 4.5 & 7.38 & -3.0 & 5.1 & 4.9 & 7.35 & -3.0 & 5.5 & 4.5 \\
\hline 12 & 7.36 & -1.0 & 6.0 & 2.9 & 7.33 & -5.0 & 5.1 & 4.4 & 7.27 & -4.0 & 7.0 & 2.8 \\
\hline 13 & 7.47 & -1.5 & 3.7 & 3.1 & 7.43 & -1.0 & 4.3 & 3.1 & 7.41 & $-3,0$ & 4.1 & 2.9 \\
\hline 14 & 7.38 & -7.0 & 3.7 & 3.3 & 7.43 & +1.0 & 5.1 & 5.2 & - & - & - & -- \\
\hline 15 & 7.34 & -4.5 & 5.5 & 4.0 & 7.36 & -4.0 & 4.8 & 3.3 & 7.30 & -6.0 & 5.6 & 2.9 \\
\hline 16 & 7.35 & -1.0 & 6.1 & 2.7 & 7.37 & -2.0 & 5.5 & 3.1 & 7.37 & -1.0 & 5.7 & 2.8 \\
\hline 17 & 7.36 & +1.0 & 6.7 & 3.1 & 7.35 & 0.0 & 6.4 & 3.6 & 7.29 & -4.0 & 6.4 & 2.8 \\
\hline 18 & 7.35 & -1.0 & 6.0 & 4.3 & 7.38 & -2.0 & 5.1 & 5.9 & 7.36 & -3.0 & 5.3 & 4.0 \\
\hline 19 & 7.40 & - & - & - & 7.27 & -6.0 & 6.0 & 3.5 & 7.24 & -10.0 & $5: 2$ & 3.2 \\
\hline 20 & 7.44 & +2.0 & 5.1 & 3.6 & 7.38 & -4.0 & 4.8 & 3.5 & - & - & - & - \\
\hline 21 & 7.35 & -3.5 & 5.2 & 4.7 & 7.23 & -6.5 & 7.0 & 3,7 & 7.15 & -11.0 & 7.5 & 1.7 \\
\hline 22 & 7.40 & -5.0 & 4.0 & 3.7 & 7.35 & -5.0 & 4.8 & 5.3 & 7.27 & -5.0 & 6.5 & 4.4 \\
\hline
\end{tabular}


Table 10.9 Foetal acid-base balance in the epidural group ai full dillatation and at birth

\begin{tabular}{|c|c|c|c|c|c|c|c|c|c|c|c|c|}
\hline \multicolumn{5}{|c|}{ Full dilatation } & \multicolumn{4}{|c|}{ Umituilical vein } & \multicolumn{4}{|c|}{ Umbilical artery } \\
\hline $\begin{array}{l}\text { Pat- } \\
\text { ient }\end{array}$ & $\mathrm{pH}$ & $\begin{array}{c}\mathrm{BE} \\
(\mathrm{mmol} / \mathrm{l})\end{array}$ & $\begin{array}{l}\mathrm{pCO}_{2} \\
(\mathrm{kPa})\end{array}$ & $\begin{array}{c}\mathrm{pO}_{2} \\
(\mathrm{kPa})\end{array}$ & pH & $\begin{array}{c}\mathrm{BE} \\
(\mathrm{mmol} / \mathrm{l})\end{array}$ & $\begin{array}{l}\mathrm{pCO}_{2} \\
\text { (k.Pa) }\end{array}$ & $\begin{array}{l}\mathrm{pO}_{2} \\
(\mathrm{kP} \cdot \mathrm{a})\end{array}$ & $\rho \mathrm{H}$ & $\begin{array}{c}\mathrm{BE} \\
(\mathrm{mmol} / \mathrm{l})\end{array}$ & $\begin{array}{l}\mathrm{PCO}_{2} \\
\left(\mathrm{kPa}^{2}\right)\end{array}$ & $\begin{array}{l}\mathrm{PO}_{2} \\
(\mathrm{kPa})\end{array}$ \\
\hline $\mathbb{1}$ & 7.32 & -3.0 & 6.0 & 4.0 & 7.40 & -20 & 4.7 & 4.7 & 7.40 & -40 & 43 & 3.6 \\
\hline 2 & 734 & -4.0 & 5.3 & 3.6 & 7.42 & -2.0 & 4.7 & 4.0 & 7.40 & -2.0 & 47 & 4.1 \\
\hline 3 & 7.33 & -2.0 & 6.3 & 3.9 & 7.38 & -4.0 & 4.5 & 3.2 & 7.32 & -3.5 & 59 & 2.5 \\
\hline 4 & - & - & - & $-\cdots$ & 7.47 & +1.5 & 4.4 & 3.9 & 7.36 & -1.0 & 5.9 & 2.7 \\
\hline 5 & 7.31 & -3.0 & 6.4 & 2.9 & 7.44 & +1.0 & 4.8 & 3.3 & 7.42 & +4.0 & 6.0 & 2.9 \\
\hline 6 & 7.33 & -1.5 & 6.4 & 2.8 & 7.17 & -7.0 & 8.4 & 3.1 & 7.11 & -12.0 & 8.0 & 3.5 \\
\hline 7 & - & - & - & - & 7.38 & -5.0 & 4.3 & 5.2 & 7.27 & -6.0 & 6.4 & 4. 1 \\
\hline 8 & 7.42 & -10 & 4.7 & 3.5 & 7.44 & $=3.0$ & 3.7 & 3.6 & 7.37 & -4.0 & 4.8 & 2.7 \\
\hline 9 & 7.47 & $\ldots$ & $\ldots$ & - & 7.37 & -2.0 & 5.5 & 3.7 & 7.34 & -1.0 & 6.5 & 2.3 \\
\hline 10 & 7.31 & -3.0 & 6.3 & 3.2 & 7.23 & -7.0 & 6.9 & 3.7 & 7.23 & -7.0 & 7.0 & 3.2 \\
\hline 11 & 7.32 & -4.0 & 5.6 & 3.2 & 7.39 & -2.0 & 5.2 & 3.6 & 7.28 & -4.0 & 6.7 & 3.4 \\
\hline 12 & 7.38 & -6.0 & 4.0 & 4.8 & 7.35 & -3.0 & 5.5 & 3.7 & 7.35 & -3.0 & 5.3 & 3.6 \\
\hline 13 & 7.35 & -4.0 & 5.2 & 3.2 & 7.43 & -3.0 & 4.1 & 3.9 & 7.36 & -3.0 & 5.3 & 3.1 \\
\hline 14 & 7.37 & -4.0 & 4.8 & 5.1 & 7.37 & -2.0 & 5.3 & 3.5 & - & - & - & - \\
\hline 15 & 7.37 & -1.0 & 5.6 & 2.7 & 7.44 & -2.0 & 4.1 & 4.4 & 7.42 & -2.5 & 4.3 & 4.5 \\
\hline 16 & 7.38 & -1.0 & 5.3 & 3.9 & 7.32 & -4.5 & 5.6 & 3.2 & 7.30 & -4.0 & 6.3 & 2.7 \\
\hline 17 & 7.42 & +3.5 & 5.9 & 3.9 & 7.31 & -0.5 & 7.0 & 4.0 & 7.30 & -3.5 & 6.4 & 5.5 \\
\hline 18 & 7.30 & -2.0 & 6.8 & 2.7 & 7.28 & -8.0 & 5.2 & 4.0 & 7.23 & -50 & 7.8 & 2.5 \\
\hline 19 & 7.31 & -2.0 & 6.7 & 3.7 & 7.39 & -4.0 & 4.5 & 4.1 & 7.26 & -8.0 & 5.6 & 2.9 \\
\hline 20 & 7.32 & -2.0 & 6.3 & 3.6 & 7.30 & -2.5 & 6.8 & 2.7 & - & - & - & - \\
\hline
\end{tabular}

10.2.1 The foetal acid-base balance at full dilatation

The mean values of the $\mathrm{pH}, \mathrm{BE}, \mathrm{pCO}_{2}$ and $\mathrm{pO}_{2}$ in the control group and in the epidural group at full dilatation, as well as the $\mathrm{p}$ values for the differences between them are presented in table 10.10 .

Table 10.10 The foelal acid-base balance at full dilatation in the control group and in the epidural group $(\bar{x} \pm S D)$

\begin{tabular}{llll}
\hline & control group & epidiural group & p walue \\
\hline $\mathrm{pH}$ & $\begin{array}{l}7.39 \pm 0.04 \\
\mathrm{n}=22\end{array}$ & $\begin{array}{l}7.35 \pm 0.05 \\
\mathrm{n}=18\end{array}$ & $<0.05$ \\
& $-1.9 \pm 2.4$ & $-2.4 \pm 2.0$ & $>0.1$ \\
$\mathrm{BE}$ & $\mathrm{n}=21$ & $\mathrm{n}=17$ & \\
$(\mathrm{mmol} / 1)$ & $5.2 \pm 1.0$ & $5.7 \pm 0.8$ & $<0.05$ \\
$\mathrm{pCO}_{2}$ & $\mathrm{n}=21$ & $\mathrm{n}=17$ & \\
$(\mathrm{kPa})$ & $3.6 \pm 0.7$ & $3.6 \pm 0.7$ & $>0.1$ \\
$\mathrm{pO}_{2}$ & $\mathrm{n}=21$ & $\mathrm{n}=17$ & \\
$(\mathrm{kPa})$ & & & \\
\hline
\end{tabular}


At full dilatation, the $\mathrm{pH}$ in the control group was significantly higher than in the epidural group. The $\mathrm{pCO}_{2}$ was significantly lower in the control group than in the epidural group. There was no significant difference between the two groups with respect to $\mathrm{BE}$ and $\mathrm{pO}_{2}$.

\subsubsection{The acid-base balance in the umbilical vein and umbilical artery}

The mean values of the $\mathrm{pH}, \mathrm{BE}, \mathrm{pCO}_{2}$ and $\mathrm{pO}_{2}$ in the control group and in the epidural group as well as the differences between them are presented in tabie 10.11.

Table 10.11 The foetal acid-base balance in the umbilical cord vessels in the control group and in the epidural group $(\hat{x} \pm S D)$

\begin{tabular}{|c|c|c|c|c|}
\hline & & control group & epidural group & p value \\
\hline \multirow{2}{*}{$\mathrm{pH}$} & UA & $\begin{array}{l}7.27 \pm 0.08 \\
n=20\end{array}$ & $\begin{array}{l}7.32 \pm 0.08 \\
\mathrm{n}=18\end{array}$ & $0.05<\mathrm{p}<0.1$ \\
\hline & UV & $\begin{array}{l}7.33 \pm 0.08 \\
\mathrm{n}=21\end{array}$ & $\begin{array}{l}7.36 \pm 0.08 \\
n=20\end{array}$ & $>0.1$ \\
\hline \multirow{2}{*}{$\begin{array}{l}\mathrm{BE} \\
\text { (mmoll) }\end{array}$} & UA & $\begin{array}{l}-5.5 \pm 3.1 \\
\mathrm{n}=20\end{array}$ & $\begin{array}{l}-3.9 \pm 3.3 \\
\mathrm{n}=18\end{array}$ & $>0.1$ \\
\hline & & $\begin{array}{l}-4.6 \pm 3.1 \\
n=20\end{array}$ & $\begin{array}{l}-3.1 \pm 2.5 \\
\mathrm{n}=18\end{array}$ & $>0.1$ \\
\hline \multirow{2}{*}{$\begin{array}{l}\mathrm{pCO}_{2} \\
(\mathrm{kPa})\end{array}$} & UA & $\begin{array}{l}6.3 \pm 1.3 \\
n=20\end{array}$ & $\begin{array}{l}6.0 \pm 1.1 \\
n=18\end{array}$ & $>0.1$ \\
\hline & UV & $\begin{array}{l}5.5 \pm 1.1 \\
\mathbf{n}=21\end{array}$ & $\begin{array}{l}5.3 \pm 1.2 \\
\mathrm{n}=20\end{array}$ & $>0.1$ \\
\hline \multirow{2}{*}{$\begin{array}{l}\mathrm{pO}_{\mathrm{p}} \\
(\mathrm{kPa})\end{array}$} & UA & $\begin{array}{l}3.4 \pm 0.8 \\
n=20\end{array}$ & $\begin{array}{l}3.3 \pm 0.8 \\
n=18\end{array}$ & $>0.1$ \\
\hline & UV & $\begin{array}{l}4.1 \pm 0.9 \\
n=21\end{array}$ & $\begin{array}{l}3.8 \pm 0.6 \\
\mathrm{n}=20\end{array}$ & $>0.1$ \\
\hline
\end{tabular}

From table 10.11 it appears that there were no significant differences between the two groups. The mean pH (UA) in the epidural group was higher than in the control group, but this difference did not reach the 5 per cent level of significance.

In connection with the interpretation of blood gas analysis, it is important to have insight into the number of operative deliveries and the reason as to why these were done (section 7.1.1). The two groups have again been compared following exclusion of those patients who had an operative delivery. The results are presented in table 10.12. 
Table 10.12 The foetal acid-base balance at birh with exclusion of aperative deliveries

\begin{tabular}{|c|c|c|c|c|}
\hline & & control group & epidural group & $p$ value \\
\hline \multirow{2}{*}{$\mathrm{pH}$} & UA & $\begin{array}{l}7.27 \pm 0.09 \\
n=15\end{array}$ & $\begin{array}{l}7.33 \pm 0.07 \\
\mathrm{n}=12\end{array}$ & $0.05<\mathrm{p}<0 . \mathrm{I}$ \\
\hline & uV & $\begin{array}{l}7.33 \pm 0.08 \\
n=16\end{array}$ & $\begin{array}{l}7.38 \pm 0.07 \\
\mathrm{n}=12\end{array}$ & $>0.1$ \\
\hline \multirow{2}{*}{$\begin{array}{l}\mathrm{BE} \\
\text { (mmol) }\end{array}$} & UA & $\begin{array}{l}-5.4 \pm 3.1 \\
\mathrm{n}=15\end{array}$ & $\begin{array}{l}-3.5 \pm 3.1 \\
n=12\end{array}$ & $>0.1$ \\
\hline & $\begin{array}{l}\text { A) } \\
\text { UV }\end{array}$ & $\begin{array}{l}-4.5 \pm 2.9 \\
\mathrm{n}=16\end{array}$ & $\begin{array}{l}-3.0 \pm 2.8 \\
n=12\end{array}$ & $>0.1$ \\
\hline \multirow{2}{*}{$\begin{array}{l}\mathrm{pCO}_{2} \\
(\mathrm{kPa})\end{array}$} & UA & $\begin{array}{l}6.4+1.4 \\
n=16\end{array}$ & $\begin{array}{l}5.9 \pm 11 \\
\mathrm{n}=12\end{array}$ & $>0.1$ \\
\hline & UV & $\begin{array}{l}5.5 \pm 1.1 \\
\mathrm{n}=16\end{array}$ & $\begin{array}{l}5.0 \pm 0.8 \\
n=12\end{array}$ & $>0.1$ \\
\hline \multirow{2}{*}{$\begin{array}{l}\mathrm{pO}_{2} \\
(\mathrm{kPa})\end{array}$} & UA & $\begin{array}{l}3.3 \pm 0.8 \\
n=15\end{array}$ & $\begin{array}{l}3.4 \pm 0.6 \\
n=12\end{array}$ & $>0.1$ \\
\hline & UV & $\begin{array}{l}4.2 \pm 0.9 \\
n=16\end{array}$ & $\begin{array}{l}4.0 \pm 0.6 \\
\mathrm{n}=12\end{array}$ & $>0.1$ \\
\hline
\end{tabular}

From table 10.12 too, it emerges that there were no significant differences between the two groups. As appeared from table 7.6 there were in the control group 10 patients with umbilical cord entanglements, and in the epidural group 4 . When these patients were excluded, it emerged that there were also no differences between the two groups with respect to the foetal acid-base balance.

10.2.3 The change of the foetal acid-base balance during the second stage of labour The changes in the foetal acid-base balance during the second stage of labour were determined in both groups (with respect to the umbilical artery and the umbilical vein). For every patient the value obtained from the umbilical cord was subtracted from the value obtained at full dilatation. Then the mean changes with their associated standard deviations were calculated for both groups.

Student's paired sample t-test was used to determine whether the change differed significantly from zero and Student's two sample t-test was used to determine whether there was a difference in change between the two groups. The results with regard to the umbilical artery are presented in table 10.13. In table 10.14 the results are given with respect to the umbilical vein. 
Table 10.13 Mean change of foetal acid-base parameters during the second stage (umbilical anery)

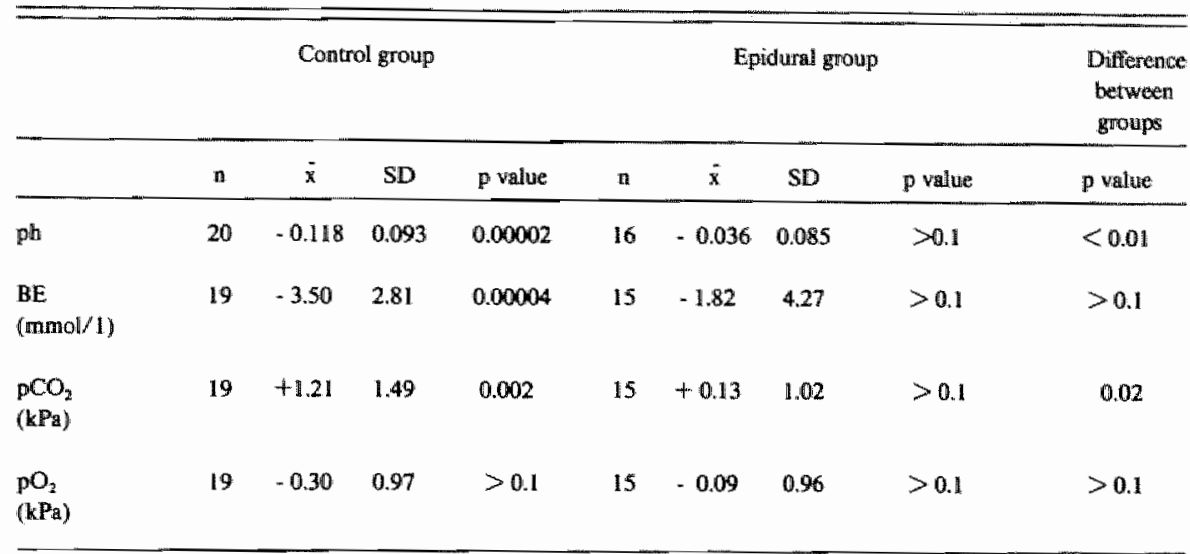

From table 10.13 it appears that in the control group the $\mathrm{pH}$ and the base excess highly significantly decreased during the second stage and that the foetal $\mathrm{pCO}_{2}$ increased hingly significantly in that period whereas the foetal $\mathrm{pO}_{2}$ did not change significantly. In the epidural group there were no significant changes during the second stage. It emerged that the $\mathrm{pH}$ in the control group decreased significantly more than in the epidural group $(p=0.01)$.

Furthermore, it appeared that the increase of the $\mathrm{pCO}_{2}$ in the control group was significantly greater than in the epidural group $(p=0.02)$. No significant differences were found as far as changes in base excess and $\mathrm{pO}_{2}$ were concerned.

Table 10.14 presents the mean change of foetal acid-base parameters during the second stage (umbilical vein).

Table 10.14 Mean change of foetal acid-base parameters during the second stage (umbilical vein)

\begin{tabular}{|c|c|c|c|c|c|c|c|c|c|}
\hline & \multicolumn{4}{|c|}{ Control group } & \multicolumn{4}{|c|}{ Epidural group } & \multirow{2}{*}{$\begin{array}{c}\begin{array}{c}\text { Differenci } \\
\text { between } \\
\text { groups }\end{array} \\
\text { p value }\end{array}$} \\
\hline & $n$ & $\dot{x}$ & SD & $P$ walue & $\mathrm{n}$ & $\bar{x}$ & SD & p walue & \\
\hline $\mathrm{pH}$ & 21 & -0.065 & 0.095 & 0.005 & 18 & +0.004 & 0.082 & $>0.1$ & 0.02 \\
\hline $\begin{array}{l}\mathrm{BE} \\
\text { (mnol/li) }\end{array}$ & 20 & -2.75 & 3,74 & 0.004 & 17 & -0.91 & 3.05 & $>0.1$ & $>0.1$ \\
\hline $\begin{array}{l}\mathrm{pCO}_{2} \\
(\mathrm{kPa})\end{array}$ & 20 & +0.44 & 1.42 & $>0.1$ & 17 & -0.39 & 1.27 & $>0.1$ & 0.07 \\
\hline $\begin{array}{l}\mathrm{pO}_{2} \\
(\mathrm{kPQ})\end{array}$ & 20 & +0.48 & 0.96 & 0.04 & 17 & +0.12 & 0.86 & $>0.1$ & $>0.1$ \\
\hline
\end{tabular}


From table 10.14 it appears that the pH and the base excess in the control group show a highly significant decrease. The $\mathrm{pO}_{2}$ increases significantly in the control group However, in the epidural group no significant changes occur. Furthermore, there is a significant difference in $\mathrm{pH}$ change between the two groups during the second stage of labour. No significant changes were found between the two groups as far as changes in base excess, $\mathrm{pCO}_{2}$ and $\mathrm{pO}_{2}$ were concerned. Figure 10.2 presents the results graphically.
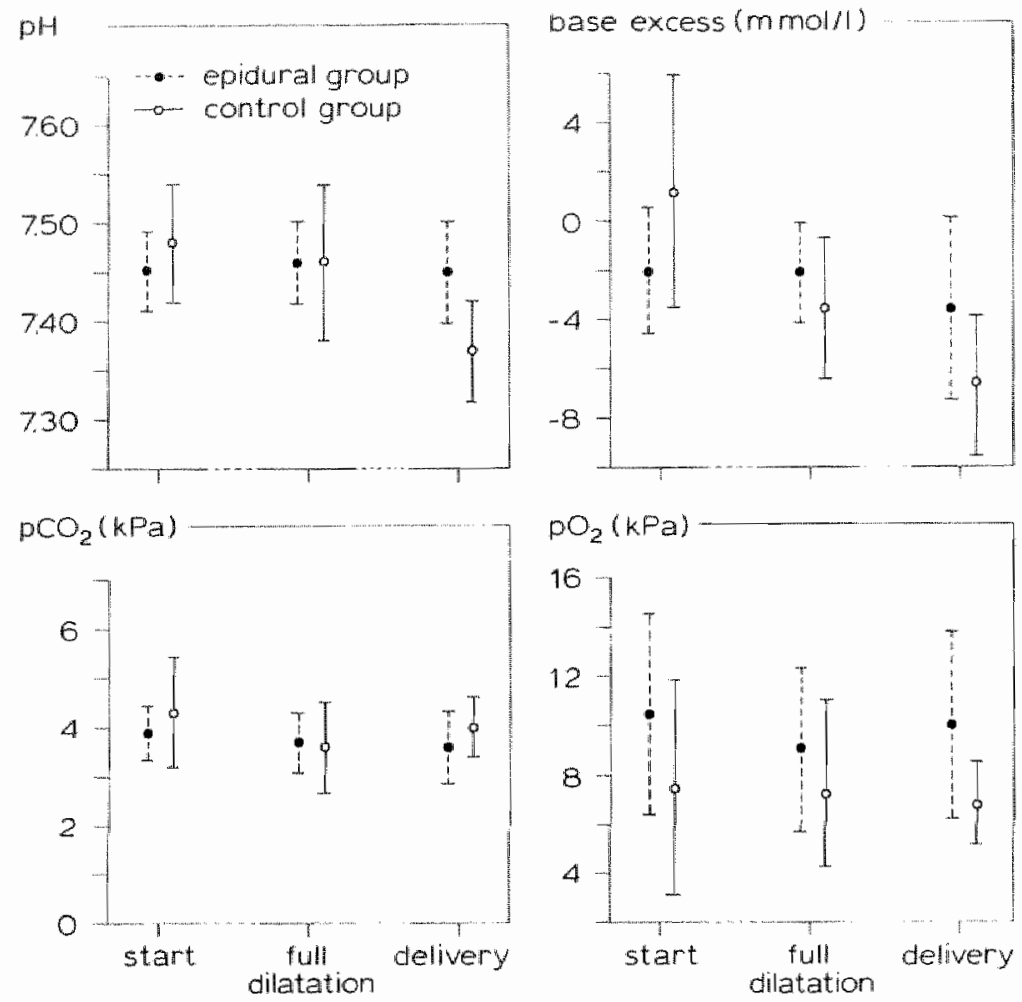

Figure 10.2 Mean foetal acid-base values $\pm S D$ arfull dilatation ( FBS = foetal blood sampling) and in the umbilical artery (UA) and in the umbilical vein (UV)

\subsection{The foeto-maternal $\mathrm{pH}$ differences}

There have been various authors who have stressed the importance of the foeto-maternal pH difference (Jacobson and Rooth, 1971; Pearson and Davies, 1974-a+b). Table 10.15 presents the values for the foeto-maternal $\mathrm{pH}$ differences which were obtained at full dilatation and at birth of the child. At birth of the child the foeto-maternal $\mathrm{pH}$ difference was calculated both on venous and arterial umbilical acid-base values. It is to be understood that foeto-maternal $\mathrm{pH}$ difference is defined as the maternal $\mathrm{pH}$ minus the foetal $\mathrm{pH}$. Table 10.15 also shows whether there were significant differences between the control and epidural groups with respect to the foeto-maternal $\mathrm{pH}$ differences. 
Table 10.15 The foeto-maternal pH difference (delia $p H$ ) at full dilatation and at binth with respect to arterial and venous umbilical analysis in the cortrol and epidural groups

\begin{tabular}{llll}
\hline & control group & epidural group & p value \\
\hline $\begin{array}{l}\text { delta } \mathrm{pH} \text { at } \\
\text { full dilatation }\end{array}$ & $\begin{array}{l}0.07 \pm 0.07 \\
\mathrm{n}=21\end{array}$ & $\begin{array}{l}0.11 \pm 0.04 \\
\mathrm{n}=17\end{array}$ & $<0.05$ \\
$\begin{array}{l}0.10 \pm 0.09 \\
\mathrm{n}=20\end{array}$ & $\begin{array}{l}0.12 \pm 0.10 \\
\mathrm{n}=18\end{array}$ & $>0.1$ \\
birth (UA) & $0.04 \pm 0.09$ & $0.11 \pm 0.09$ & \\
delta $\mathrm{pH}$ at & $\mathrm{n}=21$ & $\mathrm{n}=19$ & 0.1 \\
birth (UV) & & & \\
\hline
\end{tabular}

It appears from these data that the foeto-maternal $\mathrm{pH}$ difference at full dilatation in the control group was significantly smaller than in the epidural group. At birth there was no significant difference between the two groups with respect to the delta $\mathrm{pH}$.

\subsection{Discussion}

\subsubsection{The maternal acid-base balance during the first stage of labour}

There were significant differences between the control group and the epidural group at the start of the investigation, prior to the administration of the epidural anaesthesia. The base excess in the epidural group was significantly lower than in the control group (section 10.1.1). It seems probable that the women who opted for epidural anaesthesia had more pain. From section 5.3.1.1 it emerged that such patients could experience a shift in the acid-base balance in the direction of metabolic acidosis. In women who experience a lot of pain, such as those women who opted for epidural anaesthesia, there is a change in the breathing pattern in the sense of hyperventilation. The hyperventilation during labour is also often the result of the breathing technique that the women learn on antenatal courses for expectant mothers. Hyperventilation shifts the acid-base balance towards alkalosis. In agreement with this, the $\mathrm{pO}_{2}$ of those women who were to opt for epidural anaesthesia, was significantly higher than in the women from the control group (section 10.1.1). One might expect that the $\mathrm{pCO}_{2}$ of the women opting for epidural anaesthesia would be lower because of the hyperventilation. The $\mathrm{pCO}_{2}$ of these women was on an average lower than in the women fom the control group but on testing, this difference turned out to be not significant (section 10.1.1). Despite the fact that the women who opted for epidural anaesthesia probably had more pain, there was no significant difference between the two groups from the point of view of $\mathrm{pH}$. Probably on the one hand the pain caused random muscular activity and thus a shift in the acid-base balance towards metabolic acidosis but on the other hand also led to hyperventilation and a shift in the acid-base balance in the direction of respiratory alkalosis. The net effect on the $\mathrm{pH}$ is therefore difficuit to gauge and possibly even neutral. It is also possible that the tendency to metabolic acidosis present in normal 
labour is largely compensatory in nature (Pearson and Davies, 1973-a). In the control group during the first stage, significant changes occurred (table 10.6). The base excess and the $\mathrm{pCO}_{2}$ fell significantly. However, the $\mathrm{pH}$ and the $\mathrm{pO}_{2}$ did not alter significantly during the first stage. The pain which the women in the control group experienced led on the one hand to muscullar activity and concommitant shift of the acid-base balance in the direction of metabolic acidosis and therefore to a fall in base excess, but on the other hand, the pain led to hyperventilation and a resultant shift in the acid-base balance in the direction of respiratory alkalosis and therefore to a fall in the $\mathrm{pCO}_{2}$. Hyperventilation and muscular activity exercised opposite effects on the $\mathrm{pH}$ and this therefore did not change significantly during the first stage of labour.

It is likely that the level of catecholamines in the maternal blood rises due to the pain and stress that is experienced during labour. It is possible that the increased catecholamine level contributes to the shift of the acid-base balance towards metabolic acidosis (section 5.3.1.5). No significant changes in the acid-base balance occurred in the epidural group during the first stage (section 10.1.4). This is probably due to the fact that the women experienced no pain and therefore the factors that have an effect on acid-base balance (random muscular activity and hyperventilation) remained absent. Probably, the catecholamine lewel in these women would be lower than in the women from the control group.

The results concerning the epidural group from this thesis are in agreement with the research results of Pearson and Davies (1973-a); Thalme et al., (1974-a); Jouppila and Hollmen (1976) and Zador and Nilsson (1974). As far as the control group is concerned, comparison of our results with those reported in the literature is difficult because the women who served as controls in other studies often received other forms of analgesia (section 5.3.1.1).

In a control group who received no form of pharmacological analgesia, Holm (1982) found a decrease in $\mathrm{pCO}_{2}$ and in base excess and an increase in $\mathrm{pH}$ and $\mathrm{pO}_{2}$. It is not clear from Holm's study whether the changes were significant. From the figures quoted one would think that the base excess and $\mathrm{pCO}_{2}$ were significantly reduced but even on studying the figures, it is not clear whether the increase in $\mathrm{pH}$ and $\mathrm{pO}_{2}$ was significant. These results do not conflict with the present ones. If the increase in $\mathrm{pH}$ and $\mathrm{pO}_{2}$ was indeed significant in Holm's study then hyperventilation could be a possible explanation. In our study no significant increase in $\mathrm{pH}$ or $\mathrm{pO}_{2}$ was found (section 10.1.4). It is possible that a different breathing technique for the two groups of women could account for a possible difference in research results.

One should be cautious with the interpretation of the $\mathrm{pO}_{2}$ results. Due to the sampling method employed, it is not possible to rule out that there was a certain amount of contamination with air in some of the samples.

\subsubsection{The maternal acid-base balance during the second stage of labour}

A shift towards metabolic acidosis occurred in the acid-base balance for the control group during the second stage. The $\mathrm{pH}$ and the base excess decreased significantly (section 10.1.5). The $\mathrm{pCO}_{2}$ and the $\mathrm{pO}_{2}$ did not alter significantly, probably because the periods of apnea and hyperventilation alternated during the second stage of labour. 
The above mentioned changes in the maternal acid-base balance were probably the result of the muscular activity that was done by the woman while bearing down. In the epidural group no significant changes occurred in the acid-base balance (section 10.1.5).

The pushing reflex will be partly or totally blocked during epidural anaesthesia. In consequence of this, the patients from the epidural group will perform less muscular work than the patients from the control group. Due to the increased muscular activity in the control group, with respect to the epidural group, there will be a more pronounced shift to a metabolic acidosis in the control group (section 10.1.5). Furthermore, the periods of apnea during the expulsive efforts will probably be longer in the control group than in the epidural group. This explains perhaps the difference in $\mathrm{pCO}_{2}$ change between the two groups (section 10.1.5).

This conclusion is supported by the results of Pearson and Davies (1973-b); Thalme et al., (1974-a); Vroman et al., (1977) and Holm (1982). The seriousness of the acidosis which the women develop during delivery is dependent on the duration and intensity of expulsive efforts and this will be linked to the degree to which the epidural anaesthesia inhibits the pushing reflex during the second stage of labour.

\subsubsection{The foetal acid-base balance}

Although the maternal $\mathrm{pH}$ at full dilatation was the same in both groups, there was a significant difference between the two groups in terms of the foetal $\mathrm{pH}$. The foetal $\mathrm{pH}$ in the epidural group was significantly lower than in the control group (section 10.2.1). The $\mathrm{pCO}_{2}$ in the epidural group was significantly higher than in the control group even though the maternal $\mathrm{pCO}_{2}$ at that moment was more or less the same in the two groups (section 10.2.1 and 10.1.2). It is perhaps possible that one may conclude from these findings that the gas exchange across the placenta was negatively affected by the epidural anaesthesia. The fact that the delta $\mathrm{pH}$ in the control group was smaller than in the epidural group could support this (section 10.3).

Pearson and Davies (1974-a) found a higher $\mathrm{pH}$ and base excess in the control group at full dilatation. Thalme et al., (1974-a) were unable to find any difference in $\mathrm{pH}$ or base excess between epidural and control groups at full dilatation. Zador and Nilsson (1974) did find a higher $\mathrm{pH}$ and base excess in the epidural group, as did Jouppila and Hollmén (1976). These results run contrary to those from the present work but the women in the control groups mentioned above received other forms of analgesia (i.a. nitrousoxyde/oxygen, pethidine and chlorpromazine). This probably explains the difference in the findings. In Holm's study (1982) there was no significant difference in $\mathrm{pH}$ between epidural and control groups at full dilatation, here the patients of the control group received no other form of analgesia. However, the $\mathrm{pH}$ in the patient group which received pethidine was significantly lower than in the epidural group and in the control group. Holm (1982), however, was studying high risk deliveries in which there was labour induction using intravenous oxytocin. The pathology (indication criteria) was perhaps not evenly divided between the three groups and therefore interpretation of these data is problematic.

During the second stage metabolic acidosis occurred in the control group (section 
10.2.3). The $\mathrm{pH}$ and the base excess decreased significantly. In the epidural group no significant changes occurred in the foetal acid-base parameters during the second stage (section 10.2.3). This also seems to a large extent to be a reflection of the maternal acid-base balance. From section 10.1.5 it emerges that the maternal acid-base balance during the second stage did not change in the epidural group. These results are in agreement with those of Pearson and Davies (1974-b). Holm (1982) did find a significant reduction in $\mathrm{pH}$ with respect to umbilical artery analysis but not with respect to umbilical vein analysis. Zador and Nilsson (1974) are similarly of the opinion that the fall of $\mathrm{pH}$ in the epidural group was less pronounced than in the control group (which did receive other froms of analgesia!).

At birth there was no significant difference in acid-base parameters between the two groups. At full dilatation there had been significant differences between the two groups but as a result of the changes described above these differences were no longer present at the time of birth. At birth there was no longer any significant difference between the two groups with respect to the delta $\mathrm{pH}$.

The fact that the women in the control groups in studies reported in the literature had received various other pharmacological forms of analgesia again becomes a problem on attempting to compare the results of the present work with those from the literature. The best thing is to compare the results with those of Holm (1982) who found in nulliparae no significant difference between the epidural group and the control group.

\subsection{Conclusions}

On the basis of the results, the following conclusions seem to be justified:

1. During the first stage no significant changes occurred in the maternal acid-base balance in the epidural group. In contrast, the base excess and the $\mathrm{pCO}_{2}$ in the control group fell significantly.

2. During the second stage no significant changes occurred in the maternal acid-base balance in the epidural group. In contrast, there was a shift of the acid-base balance towards metabolic acidosis in the control group.

3. In reflection of the changes in the maternal acid-base balance during the second stage no changes occurred in the foetal acid-base balance in the epidural group whereas in the control group there was a shift in te direction of metabolic acidosis.

4. At full dilatation, the foetal $\mathrm{pH}$ in the control group was higher than in the epidural group. The foetal $\mathrm{pCO}_{2}$ was significantly lower in the control group than in the epidural group. The delta $\mathrm{pH}$ was significantly lower in the control group than in the epidural group at full dilatation.

5. At birth there were no significant differences between the two groups with respect to the foetal acid-base balance. 


\section{Bupivacaine concentrations in maternal plasma and in umbilical cord plasma}

As has already been discussed in section 7.5 , blood samples were taken at set times from the arm vein in fifteen women from the epidural group. This was done in order to determine the bupivacaine concentration. The bupivacaine concentration was determined prior to administration of epidural anaesthesia and then at 10,15, 30, 45, 90 and 120 minutes after administration of epidural anaesthesia. Furthermore, the maternal bupivacaine concentration was determined immediately after delivery. Immediately after the birth of the child a mixed umbilical arterial and venous blood sample was taken and the bupivacaine concentration in the plasma of the foetal blood was determined.

\section{I Bupivacaine concentrations in maternal plasma}

The bupivacaine concentrations that were measured at the above-mentioned points in time are given in table 1.1.1.

Table 11.1 Bupiwacaine concentrations in the maternal plasma at set times in the epidural group

\begin{tabular}{|c|c|c|c|c|c|c|c|}
\hline $\begin{array}{l}\text { Pa- } \\
\text { tient }\end{array}$ & $\begin{array}{c}\text { Base-line } \\
\text { value }\end{array}$ & $\begin{array}{l}10 \mathrm{~min} \\
(\mu \mathrm{g} / 1)\end{array}$ & $\begin{array}{l}15 \mathrm{~min} \\
(\mu \mathrm{g} / \mathrm{l})\end{array}$ & $\begin{array}{l}30 \mathrm{~min} \\
(\mu \mathrm{g} / \mathrm{I})\end{array}$ & $\begin{array}{l}45 \min \\
(\mu \mathrm{g} / 1)\end{array}$ & $\begin{array}{r}90 \mathrm{~min} \\
(\mu \mathrm{g} / \mathrm{ll})\end{array}$ & $\begin{array}{c}120 \mathrm{~min} \\
(\mu \mathrm{g} / \mathrm{A})\end{array}$ \\
\hline 1 & $<5$ & 170 & 170 & 145 & 110 & 95 & 50 \\
\hline 2 & $<5$ & 80 & 140 & 110 & 65 & 55 & 40 \\
\hline 3 & $<5$ & 190 & 230 & 160 & 135 & 120 & 95 \\
\hline 4 & $<5$ & 245 & 275 & 250 & 205 & 135 & - \\
\hline 5 & $<5$ & 250 & 275 & 205 & 165 & 130 & 90 \\
\hline 6 & $<5$ & 195 & 215 & 110 & 90 & 70 & - \\
\hline 7 & $<5$ & 230 & 295 & 195 & 165 & 140 & 105 \\
\hline 8 & $<5$ & - & 125 & 130 & $\ldots$ & 105 & 100 \\
\hline 9 & $<5$ & - & 225 & 270 & 205 & 160 & 135 \\
\hline 10 & $<5$ & 170 & 185 & 145 & 105 & 85 & - \\
\hline 11 & $<5$ & 175 & 200 & 140 & 130 & 110 & - \\
\hline 12 & $<5$ & 145 & 160 & 110 & 75 & 70 & 65 \\
\hline 13 & $<5$ & 250 & 2110 & 130 & 115 & 100 & - \\
\hline 14 & $<5$ & - & 170 & 110 & 105 & 75 & 75 \\
\hline 15 & $<5$ & 355 & 365 & 275 & 265 & 210 & - \\
\hline mean & & 205 & 216 & 166 & 138 & 111 & 84 \\
\hline $\mathrm{SD}$ & & 69 & 65 & 59 & 57 & 40 & 30 \\
\hline
\end{tabular}


The gaps for the 120 minute values represent women who reached full dilatation within 120 minutes of administering the epidural anaesthesia and during the second stage no bupivacaine concentrations were determined. The other remaining missing readings are the result of technical incompleteness.

The mean values and associated standard deviations are presented graphically in figure 11.1.

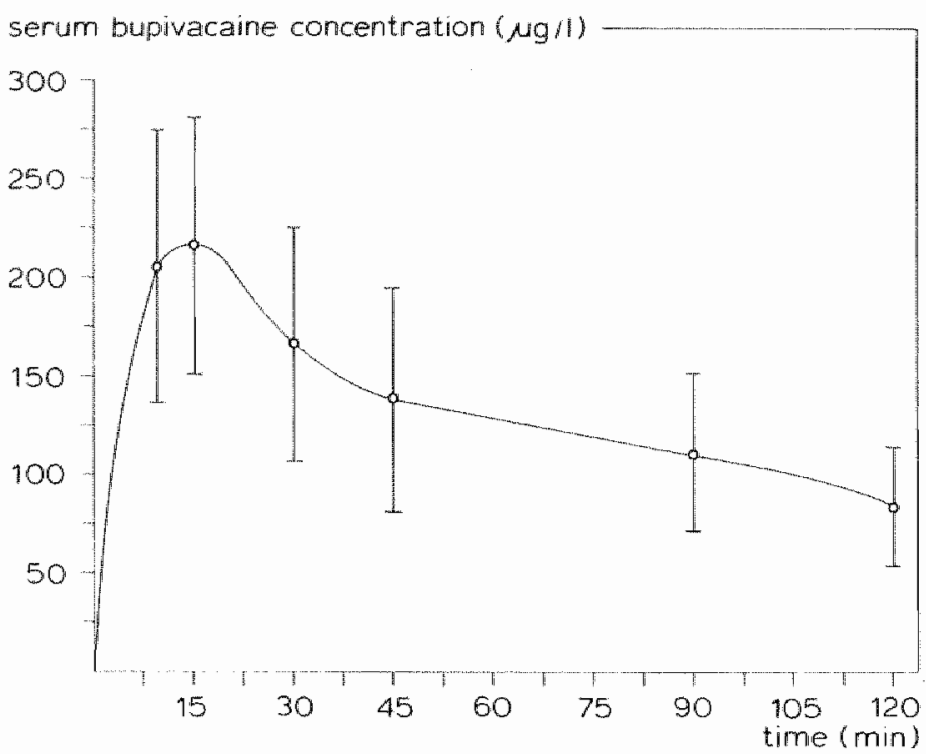

Figure 11.I The mean bupivacaine concentration in the maternal plasma ( $\ddot{x} \pm S D)$ at the various points in time after administration of the epidural anaesthesia.

In figure 11.2 the course of the bupivacaine concentrations in four individual women are presented as an example. 


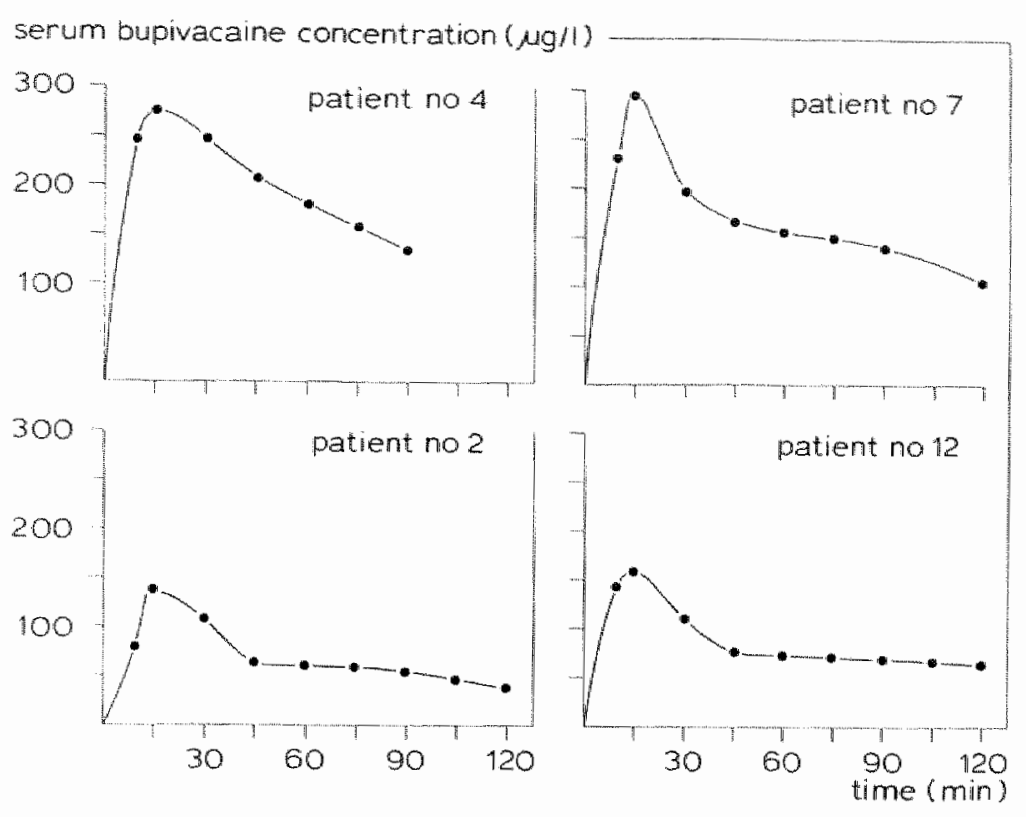

Figure 11.2 The course of the plasma bupivacaine concentration ( $\mu \mathrm{g} / \mathrm{l})$ in four individual women during the 120 minute period following the epidural anaesthesia.

From table 11.1, figure 11.1 and figure 11.2 it emerges that the peak concentration is reached between fifteen and thirty minutes after injection of the local anaesthetic into the epidural space. It would only be possible to identify the precise peak concentration and the point at which it was reached with more frequent sampling. It can be seen from figure 11.I that the spread between the various patients is rather large.

\subsection{Bupivacaine concentrations in maternal plasma following top-up doses}

One or more top-up doses were given to six patients. Three patients received 1, one patient 2 and two patients 3 top-ups. Maternal venous blood was sampled at 30,90 and 120 minutes after each top-up dose and the bupivacaine concentration was determined. The highest bupivacaine concentration measured after a top-up dose was $395 \mu \mathrm{g} / \mathrm{l}$. The woman concerned received an injection into the epidural space of $8 \mathrm{ml}$ bupivacaine 0.25 per cent just prior to a vacuum extraction. Fifteen minutes later the child was born and, according to the protoccol, maternal and foetal blood was then sampled so that the bupivacaine concentration could be determined (patient number 3 in table 11.1). Figure 11.3 presents the bupivacaine concentrations in this patient in relation to time. 


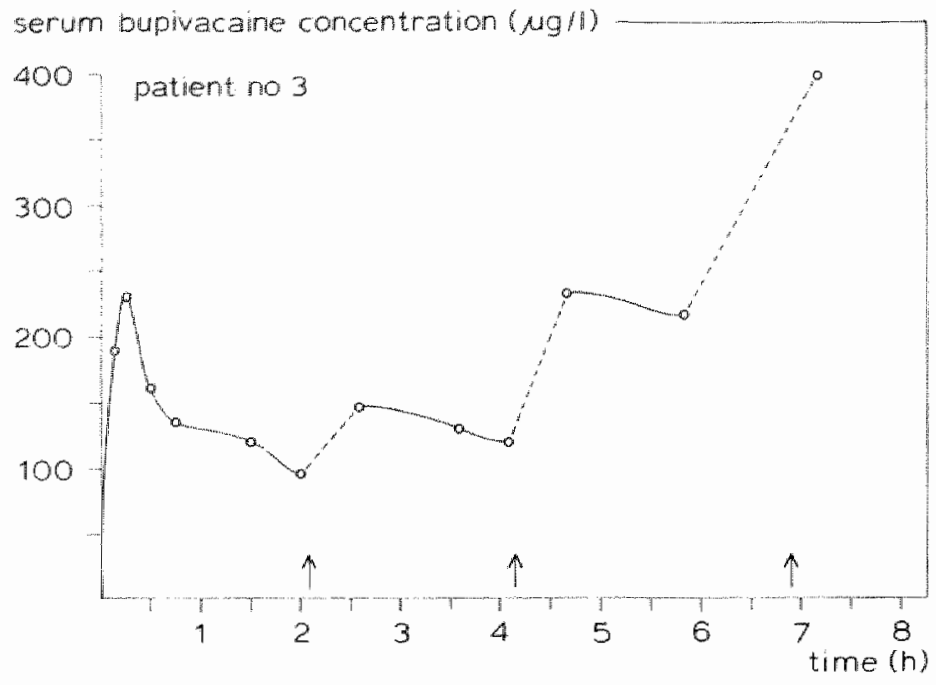

Figure 11.3 Bupivacaine concentrations ( $\mu \mathrm{g} / \mathrm{l}$ ) in relation to time. The arrows indicate the top-up injections.

Figure 11.4 shows the bupivacaine concentrations against time for another patient (patient number 5 in table 11.1). This woman was also given three top-up injections.

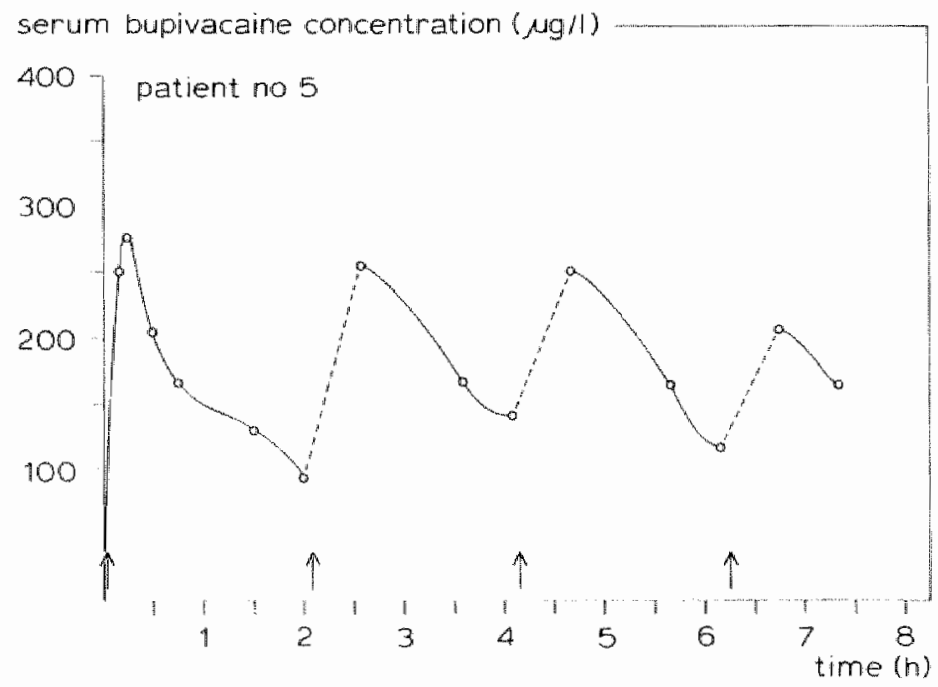

Figure 11.4 Bupivacaine concentrations $(\mu g / l)$ in relation to time. The arrows indicate the top-up injections. 
The bupivacaine concentrations would indoubtedly have been higher 10 to 15 minutes after the top-up dose than is indicated in this study which measured bupivacaine concentrations at 30,90 and 120 minutes after repeat injections.

\subsection{Bupivacaine concentrations in umbilical cord plasma}

Immediately after delivery blood was taken from a vein in the maternal arm and also fom the umbilical cord (mixed arterial and venous blood). The bupivacaine concentration in the blood plasma was determined. The values for these determinations are given in table 11.2.

Tabie 11.2 Bupivacaine concentrations in the plasma from the umbilical cord and the maternat blood, immediately after delivery and quotient of these concentrations.

\begin{tabular}{lccc}
\hline Patient & $\begin{array}{c}\text { Bupivacaine concen- } \\
\text { tration in umbilical } \\
\text { cord plasma }(\mu \mathrm{g} / 1)\end{array}$ & $\begin{array}{c}\text { Bupivacaine concen- } \\
\text { tration in maternal } \\
\text { plasma }(\mu \mathrm{g} / \mathrm{l})\end{array}$ & Quotient \\
\hline 1 & 15 & 45 & 0.33 \\
2 & 10 & 30 & 0.33 \\
3 & 90 & 395 & 0.23 \\
4 & 35 & 100 & 0.35 \\
5 & 45 & 165 & 0.27 \\
6 & 20 & 60 & 0.33 \\
7 & 35 & 165 & 0.21 \\
8 & 25 & 80 & 0.31 \\
9 & - & - & 0.31 \\
10 & 20 & 65 & 0.40 \\
11 & 40 & 100 & 0.26 \\
12 & 50 & 190 & 0.27 \\
13 & 20 & 75 & 0.20 \\
14 & 30 & 150 & 0.39 \\
15 & 65 & 165 & 0.30 \\
\hline mean & 36 & 128 & 0.06 \\
\hline SD & 22 & 93 & \\
\hline
\end{tabular}

Too little serum was obtained from patient 9 to measure bupivacaine concentration.

Table 11.3 presents a number of clinical data that are relevant in interpreting the bupivacaine concentration in the umbilical plasma. 
Table 111.3 Statistical data referring to the interpretation of the bupivacaine concentrations in the umbilical serum

\begin{tabular}{lcccccc}
\hline & \multicolumn{2}{l}{$\begin{array}{l}\text { Plasma bupivacaine } \\
\text { concentration }(\mu \mathrm{g} / 1)\end{array}$} & $\begin{array}{l}\text { Total } \\
\text { dose } \\
(\mathrm{mg})\end{array}$ & $\begin{array}{c}\text { No. of } \\
\text { doses }\end{array}$ & $\begin{array}{c}\text { FDD } \\
(\mathrm{min})\end{array}$ & $\begin{array}{l}\text { LDD } \\
(\mathrm{min})\end{array}$ \\
\cline { 2 - 7 } Umbilical cond Maternal & 36 & 128 & 39.3 & 1.8 & 260 & 145 \\
$\mathrm{SD}$ & 22 & 93 & 19.9 & 1.1 & 157 & 56 \\
Rangc & $10-90$ & $30-395$ & $25-85$ & $1-4$ & $104-583$ & $15-218$ \\
$\mathrm{n}$ & 14 & 1.4 & 14 & 14 & 14 & 14 \\
\hline
\end{tabular}

FDD $=$ interval between first dose and delivery

$\mathrm{LDD}=$ interval between last dose and delivery

The mean of the umbilical/maternal bupivacaine serum concentration quotient was 0.30 with a standard deviation of 0.06 . The correlation coefficient between the time interval between the last epidural injection and the birth of the child with the abovementioned quotient was -0.07 and this is not significant.

\subsection{Discussion}

The bupivacaine concentrations that were reached in the maternal venous plasma in this study were comparable with those reached in the study by Belfrage et al., (1975-a). These researchers used the same local anaesthetic at the same dose. Just as in the present study, Belfrage et al. added adrenaline to the local anaesthetic at a concentration of 5 $\mu \mathrm{g} / \mathrm{ml}$. In Belfrage's study the bupivacaine concentrations were measured in venous blood and not in venous plasma as was done in our study. Ten minutes after administration of the epidural anaesthesia in our study the mean bupivacaine concentration was $205 \mu \mathrm{g} / 1$ with a standard deviation of $69(\mathrm{n}=12)$. At the same point in time in Belgrage's study the mean bupivacaine concentration was $148 \mu \mathrm{g} / \mathrm{l}$ with a standard deviation of $59(n=17)$. Thirty minutes after administration of epidural anaesthesia these concentrations were respectively $166 \pm 59 \mu \mathrm{g} / \mathrm{l}(\mathrm{n}=15)$ and $133 \pm 48 \mu \mathrm{g} / 1 \mathrm{l}(\mathrm{n}=$ 18). The bupivacaine concentrations are significantly lower in Belfrage's study than in the present study. The difference is attributable to the fact that the bupivacaine concentrations were measured in plasma in our study but were measured in full blood in the study by Belfrage et al. (1975-a). Ninety per cent of the local anaesthetic is to be found in the plasma and only ten per cent in the erythrocytes (Moore et al., 1971). Suppose that the average hematocrit was 0.35 , then in the study by Belfrage et al., the concentration in the serum ten minutes after administration of the epidural anaesthesia could be calculated as follows: 
This result is the same bupivacaine concentration as was measured in our study ten minutes after administering the epidural anaesthesia. Thirty minutes after administration of the epidural anaesthesia Belfrage et al. (1975-a), found a concentration of 133 ugl in venous blood. With a hematocrit of 0.35 this would mean a serum concentration of:

$$
90 / 100 \times 133 \times 100 / 65=184 \mu \mathrm{g} / 1
$$

In our study, a concentration of $166 \mu \mathrm{g} / 1$ was measured at this point in time. In the study by Belfrage et al. (1975-a), the maternal bupivacaine concentration reached a higher level after the second injection than after the initial dose. The difference in drug concentration 20 minutes after the first injection and 20 minutes after the second injection was significant and corresponded to a mean increase of about 50 per cent.

The toxic serum concentrations for bupivacaine have never been established with certainty. Moore et al., (1977) and Jorfeldt et al., (1968) state that with a plasma concentration of $4000 \mu \mathrm{g} / \mathrm{l}$ there is a risk of convulsions. Experiments on the rhesus monkey show that convulsions usually occur at plasma concentrations of $4500 \mu \mathrm{g} / \mathrm{l}$ (Munson et al., 1975). Reynolds et al., (1973) suggested that slight toxic phenomena would occur in the central nervous system at a plasma concentration of $1600 \mu \mathrm{g} / \mathrm{l}$. Jorfeldt et al., (1968) administered bupivacaine to volunteers such that peak concentrations of between 1500 and $3000 \mu \mathrm{g} / \mathrm{l}$ were reached and this failed to produce depression of the cardiovascular system. Scott (1975) suggested that there would be toxic effects on the circulatory system at a bupivacaine concentration of $2000 \mu \mathrm{g} / \mathrm{l}$ - if the dose was given speedily. In our study, the above-mentioned toxic concentrations were never reached.

It emerges from the study by Belfrage et al. (1975-a), that the maximum foetal bupivacaine concentrations were reached between 10 and 30 minutes after the epidural injection. The foeto-maternal concentration ratio increased from 0.16 to 0.26 during the first 30 minutes but remained fairly stable over the next 70 minutes. Twenty minutes after a top-up dose, the concentration ratio fell significantly to 0.13 .

In our study, the mean quotient between the bupivacaine concentration in the umbilical cord and that in the maternal plasma was $0.30 \pm 0.06$ (table 11.2). This quotient is in agreement with literature data (Reynolds and Taylor, 1971; Reynolds et al., 1973; Belfrage et al., 1975-a; Jouppila et al., 1978-d). 



\section{The effect of epidural anaesthesia on maternal blood pressure and maternal heart rate}

\section{I The effect of epidural anaesthesia on maternal blood pressure}

The method by which maternal blood pressure was measured and the points in time when it was measured have been described in section 7.6.

\subsubsection{The effect of intravenous infusion on maternal blood pressure}

In the first instance, it was determined whether the blood pressure changed on infusion of $400 \mathrm{ml}$ isotonic saline solution. This infusion was administered over a period of ten minutes. Two blood pressure readings taken ten minutes apart prior to the administration of the intravenous infusion were compared with two blood pressure readings after the infusion. Figure 12.1 presents a schematic representation of this.

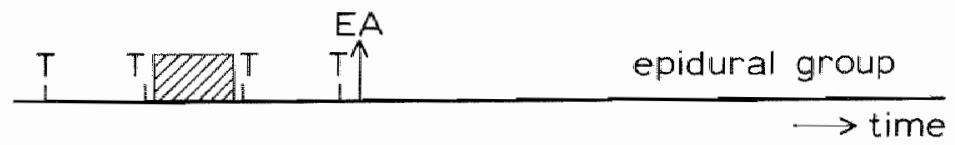

Figure 12.1 Schematic representation of the maternal blood pressures compared before and after intravenous infusion. $T=$ blood pressure measurement, $E A=$ epidural anaesthesia. $T$ The hatched area indicates the intravenous infusion.

On testing by two way analysis of variance (section 7.6.1.2) it emerged that neither the systolic nor the diastolic blood pressure had been significantly changed by the intravenous infusion.

\subsubsection{The maternal blood pressure before and after administration of the epidural anaesthesia}

The blood pressure that was measured prior to administering the epidural anaesthesia was compared with measurements taken in the first hour after the administration of the epidural anaesthesia. Student's paired sample t-test was used to test the difference (two sidedly at the five per cent level). The one hour period was selected because it is precisely in this period when the largest effect might be expected. The sympathetic blockade is the most manifest in this period and furthermore, it is precisely in this period when the concentration of bupivacaine in the maternal serum is the highest. Since it emerged from section 12.1.1 that the intravenous infusion had no significant effect on the blood pressure, the blood pressure measurements obtained prior to the intravenous infusion were also utilised for this analysis. Figure 12.2 gives a schematic representation of the blood pressure measurements to be compared. 


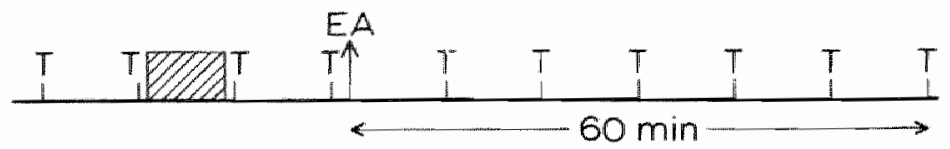

Figure 12.2 Schematic representation of the maternal blood pressures to be compared before and after administration of the epidural anaesthesia. $T=$ bload pressure measurement, $E A=$ epidural anaesthesia. The hatched area indicates the intravenous infusion.

The mean values of the systolic blood pressure, diastolic blood pressure and mean arterial pressure in the period before epidural anaesthesia are respective $128 \pm 11$ $\mathrm{mmHg}, 78.4 \pm 7.8 \mathrm{mmHg}$ and $94.8 \pm 7.3 \mathrm{mmHg}$.

The mean decrease in systolic blood pressure was $11 \mathrm{mmHg}(\mathrm{SD}=10)$ and highly The significantly different from zero $(p<0.001)$. The diastolic blood pressure fell on average by $8 \mathrm{mmHg}(\mathrm{SD}=9)$. This reduction was also highly significantly different from zero ( $\mathrm{p}$ $<0.002)$. The reduction in mean arterial pressure was also calculated. The mean arterial blood pressure MAP was defined as follows:

$$
\mathrm{MAP}=(\mathrm{SBP}+2 \mathrm{DBP}) / 3
$$

where SBP indicates the systolic blood pressure and DBP the diastolic blood pressure. bloodpressure $(\mathrm{mm} \mathrm{Hg})$
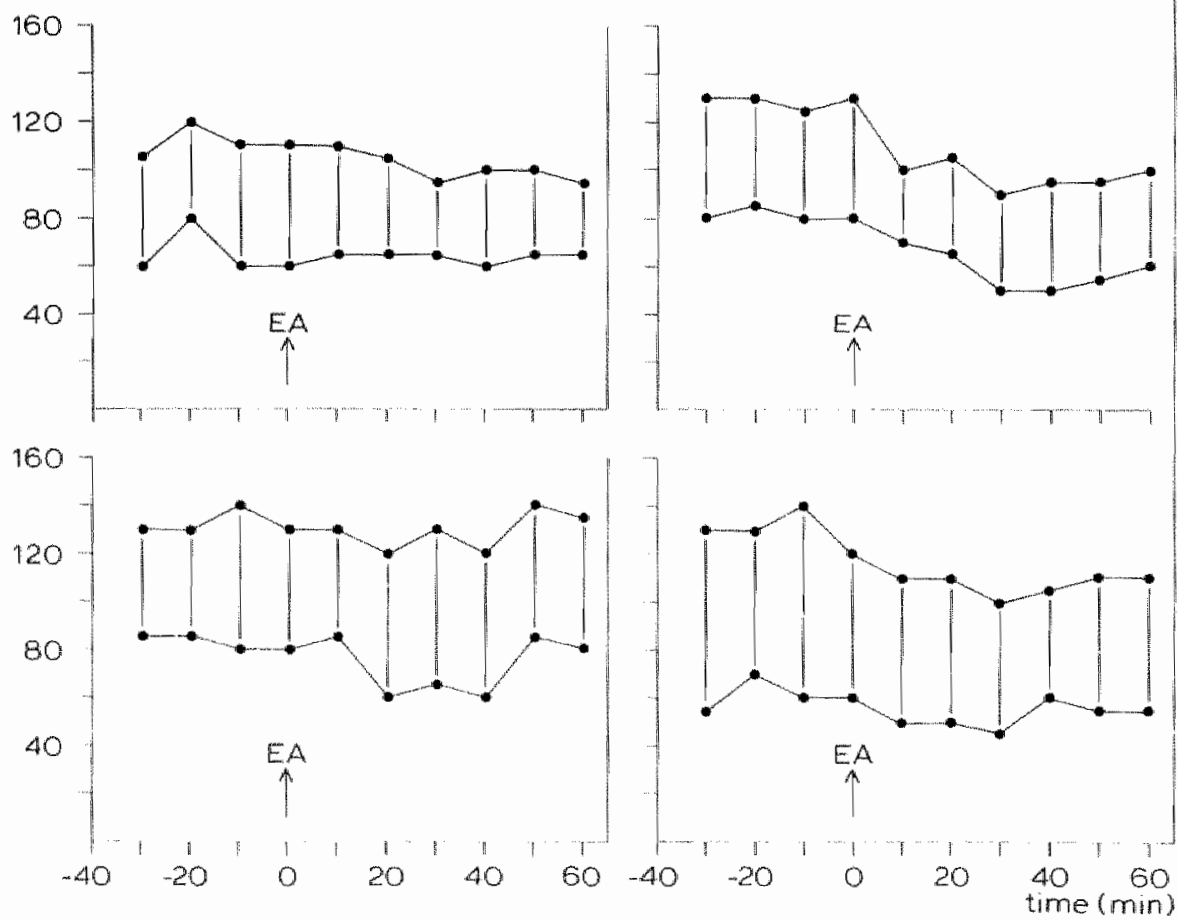

Figure 12.3 The course of the maternal systolic and diastolic blood pressure in a group of 4 patients from 30 minutes before epidural anaesthesia to 60 minutes after. 
The mean reduction was $9 \mathrm{mmHg}$. (SD $=8$ ). This reduction was highly significantly different from zero $(p<0.001)$.

Figure 12.3 gives as an example a graphic representation of the course of the blood pressure values before and after epidural anaesthesia for a group of four patients.

12.1.3 The maternal blood pressure following administration of the epidural anaesthesia versus the maternal blood pressure in the control group

The blood pressures that were measured in the first sixty minutes following the administration of the epidural anaesthesia were compared with the blood pressures that were measured in the first sixty minutes of the control group. Figure 12.4 presents a schematic representation of this.

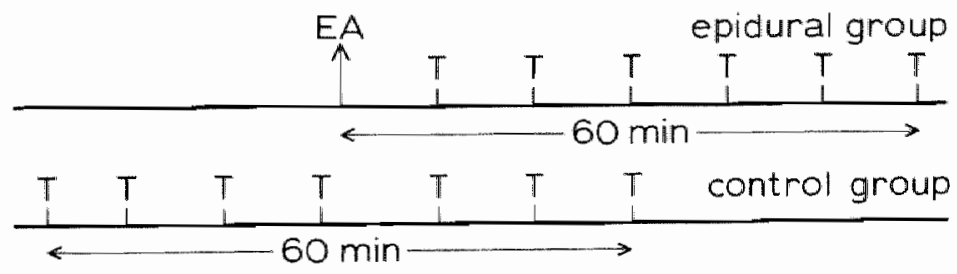

Figure 12.4 Schematic representation of the maternal blood pressures to be compared in the first sixty minutes after administration of epidural anaesthesia and in the first sixty minutes of the control group. $T=$ blood pressure measurement, $E A=$ epidural anaesthesia.

Table 12.1 presents the mean maternal systolic and mean maternal diastolic blood pressures in the control group and in the epidural group.

Table 12.1 Mean maternal systalic and mean maternal diastolic blood pressure in the control group and in the epidural group during the sixty minute periods $(\dot{x} \pm S D)$

\begin{tabular}{lcc}
\hline & $\begin{array}{c}\text { systolic blood pressure } \\
(\mathrm{mmHg})\end{array}$ & $\begin{array}{c}\text { diastolic blood pressure } \\
\text { (mmHg) }\end{array}$ \\
\hline $\begin{array}{l}\text { control group } \\
\mathrm{n}=22\end{array}$ & $123 \pm 9$ & $72 \pm 8$ \\
$\begin{array}{l}\text { epidural group } \\
\mathrm{n}=20\end{array}$ & $117 \pm 14$ & $70 \pm 10$ \\
p value & $>0.1$ & $>0.1$
\end{tabular}

It can be seen from table 12.1 that there was no significant difference between the two groups in systolic and diastolic blood pressure. 
12.1.4 The maternal blood pressure in the control group and in the epidural group during the last ninety minutes of the first stage

The blood pressures of the patients in the control group and in the epidural group during the last ninety minutes of the first stage were compared with one anohter. Figure 12.5 presents a schematic representation of the periods to be compared.

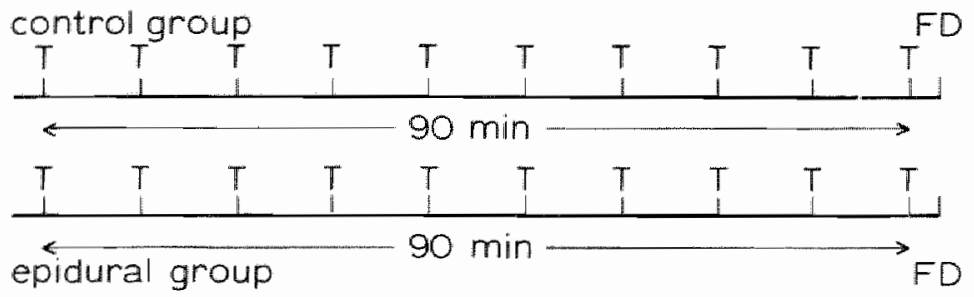

Figure 12.5 Schematic representation of the periods to be compared $T=$ blood pressure measurement, $F D=$ full dilatation.

Table 12.2 gives the mean systolic and diastolic blood pressure in the control group and in the epidural group.

Table I2.2 Mean maternal systolic and mean maternal diastolic blood pressure in the control group and in the epidural group during the sixty minute periads $(\bar{x} \pm S D)$

\begin{tabular}{lcc}
\hline & $\begin{array}{c}\text { systolic blood pressure } \\
(\mathrm{mmHg})\end{array}$ & $\begin{array}{c}\text { diastolic blood pressure } \\
(\mathrm{mmHg})\end{array}$ \\
\hline $\begin{array}{l}\text { control group } \\
\mathrm{n}=22\end{array}$ & $123 \pm 9$ & $72 \pm 10$ \\
$\begin{array}{l}\text { epidural group } \\
\mathrm{n}=20\end{array}$ & $119 \pm 12$ & $71 \pm 10$ \\
$\mathrm{p}$ value & $>0.1$ & $>0.1$ \\
\hline
\end{tabular}

It emerges from table 12.2 that in the last ninety minutes of the first stage there was no significant difference between the two groups with respect to systolic and diastolic blood pressure.

\subsubsection{The frequency of occurrence of maternal hypotension}

The occurrence of hypotension is often expressed as a percentage in the literature. Of course, the definition of hypotension used is then of great importance (section 5.2.2.1). If hypotension is defined as a systolic blood pressure lower than $100 \mathrm{mmHg}$, then in our study it occurred in 25 per cent of the patients. In contrast, if it is defined as a systolic blood pressure of less than $80 \mathrm{mmHg}$ then hypotension occurred in only 5 per cent of the patients. 
Jouppila et al., (1977) referred to hypotension as a fall in systolic blood pressure of more than $25 \%$. If this definition is applied to our investigation then hypotension occurred in one $(5 \%)$ of the patients. Hypotension following a top-up dose occurred in only one patient and in only two did it occur during the last ninety minutes of the first stage (table 12.3).

Table 12.3 The number of patients in whom hypotension occurred according to the variows definitions of hypotension and according to the period in which it occurred.

\begin{tabular}{|c|c|c|c|c|}
\hline $\begin{array}{l}\text { definiton } \\
\text { of } \\
\text { hypothemsion }\end{array}$ & $\begin{array}{l}\text { after } \\
\text { first } \\
\text { dose }\end{array}$ & $\begin{array}{l}\text { during the } \\
\text { last } 90 \text { min } \\
\text { of the } \\
\text { first stage }\end{array}$ & $\begin{array}{l}\text { after } \\
\text { top-up } \\
\text { dose }\end{array}$ & $\begin{array}{l}\text { total number of patients } \\
\text { for whom at some time } \\
\text { during epictural anaesthesin } \\
\text { hypothension occured }\end{array}$ \\
\hline $\begin{array}{l}\text { systolic } \\
\text { blood pressure } \\
<100 \mathrm{mmHg}\end{array}$ & 5 & 2 & 1 & 5 \\
\hline $\begin{array}{l}\text { systolic } \\
\text { blood pressure } \\
<80 \mathrm{mmHg}\end{array}$ & 1 & - & - & 1 \\
\hline $\begin{array}{l}\text { fall in } \\
\text { systolic blood } \\
\text { pressure }>25 \%\end{array}$ & 1 & 1 & - & 1 \\
\hline
\end{tabular}

\subsection{The effect of epidural anaesthesia on maternal heart rate}

The method by which the maternal heart rate was measured and calculated has been described in section 7.6.2. That section also describes in which periods the maternal RR interval length was studied.

\subsection{Investigation of possible pre-existent differences between the groups}

Because the division of the women over the two groups was not accomplished at random, it is possible that there were differences between the groups as a result of the selection procedure. In order to invstigate whether there were pre-existent differences between the two groups with respect to the RR interval length, the two groups were compared against ine another during the periods which are schematically presented in figure 12.6 .

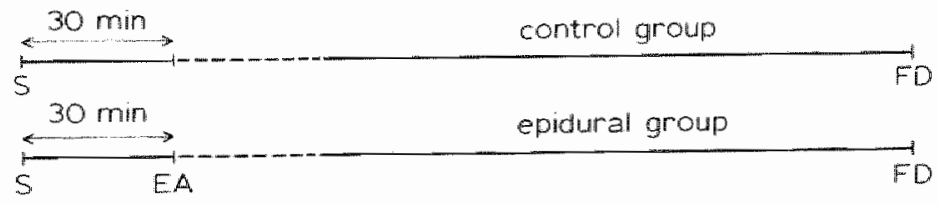

Figure 12.6 Schematic representation of the periods to be compared $S=$ start of investigation. $E A=$ epidural andesthesia, $F D=$ full dilatation. 
The results referring to the mean of the RR interval length in this period are given in table 12.4. The table also shows whether there was a significant difference between the two groups with respect to the RR interval length.

Table 12.4 The maternal RR interval length in the base-line recording period for the control group and for the epidural group $(\tilde{x} \pm S D)$

\begin{tabular}{lccl}
\hline \hline & $\begin{array}{c}\text { control group } \\
\mathrm{n}=22\end{array}$ & $\begin{array}{c}\text { epidural group } \\
\mathrm{n}=20\end{array}$ & p value \\
\hline RR interval length (ms) & $801 \pm 103$ & $754=111$ & $>0.1$ \\
\hline
\end{tabular}

It emerges from table 12.4 that there was no pre-existent difference between the two groups with respect to the mean RR interval length.

\subsubsection{Changes in the maternal $R R$ interval length following administration of epidural anaesthesia}

In order to gain insight into possible changes in maternal $R R$ interval length due to the epidural anaesthesia, the base-line recording period was compared with the 120 minutes lasting observation period after administration of the epidural anaesthesia. After 120 minutes the woman was either given a top-up dose of the local anaesthetic into the epidural space or the second stage was begun after 120 minutes, or it was already in progress. The observation period studied after administration of the epidural anaesthesia was thus always limited to the first stage of labour. Figure 12.7 gives a schematic representation of the periods to be compared.

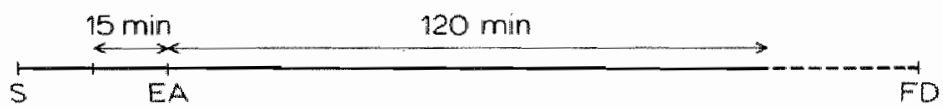

Figure 12.7 Schematic representation of the periods compared $S=$ start of investigation, $E A=$ epidural anaesthesia, $F D=$ full dilatation.

The change of the $R R$ interval length was calculated per patient. To realise this the mean value in the base-line period was subtracted from the mean value in the 120 minute lasting observation period. The mean change for the whole group with its associated standard deviation was $-36,6 \pm 82,9 \mathrm{~ms}$. By testing with Student's paired sample t-test, it turned out to be not significant $(0.05<p<0.1)$. In visual assessment of figure 12.8 , it is clear that immediately after epidural anaesthesia, the maternal $R R$ interval length decreases.

On the basis of theoretical considerations one might suppose that the effect of epidural anaesthesia on the maternal heart rate is greatest in the first sixty minutes after administration of the epidural anaesthesia. It is in that period that the blood pressure fall is usually the greatest and the bupivacaine concentration the highest. For this reason the 120 minutes observation period following administration of the epidural anaesthesia 


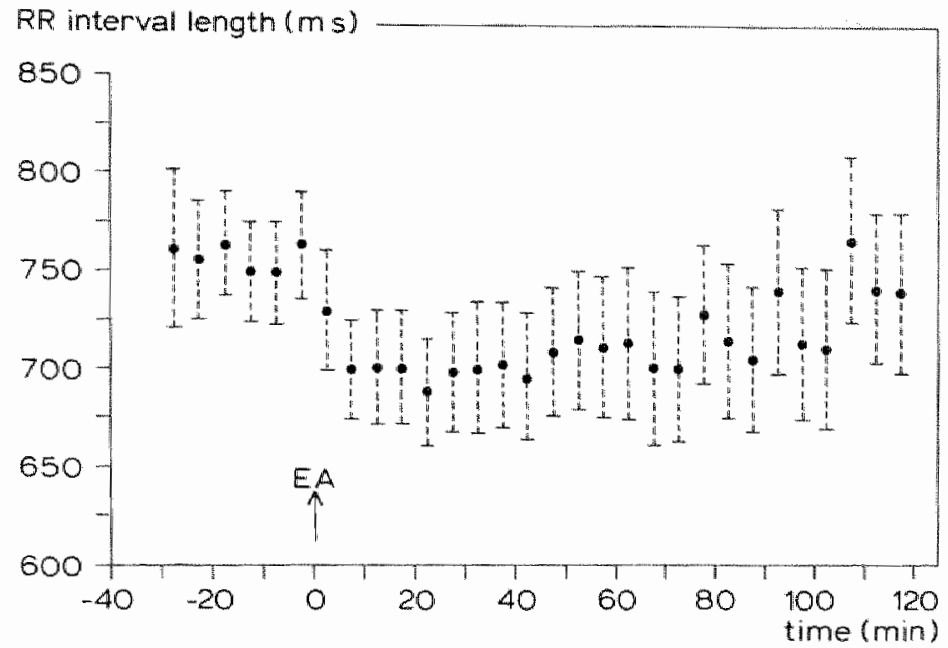

Figure 12.8 Mean maternal $R R$ interval length $\pm S E M$ in milliseconds (ms) per five minute period from 30 minutes prior to epidural anaesthesia to 120 minutes after epidural anaesthesia.

was divided into four successive periods of thirty minutes. For each of these thirty minute periods the mean change in RR interval length as compared with the base-line period was calculated. Student's paired sample t-test (applied two-sidedly at the five per cent significance level) was used to determine whether the change differed significantly from zero. Figure 12.9 presents the results of these calculations.

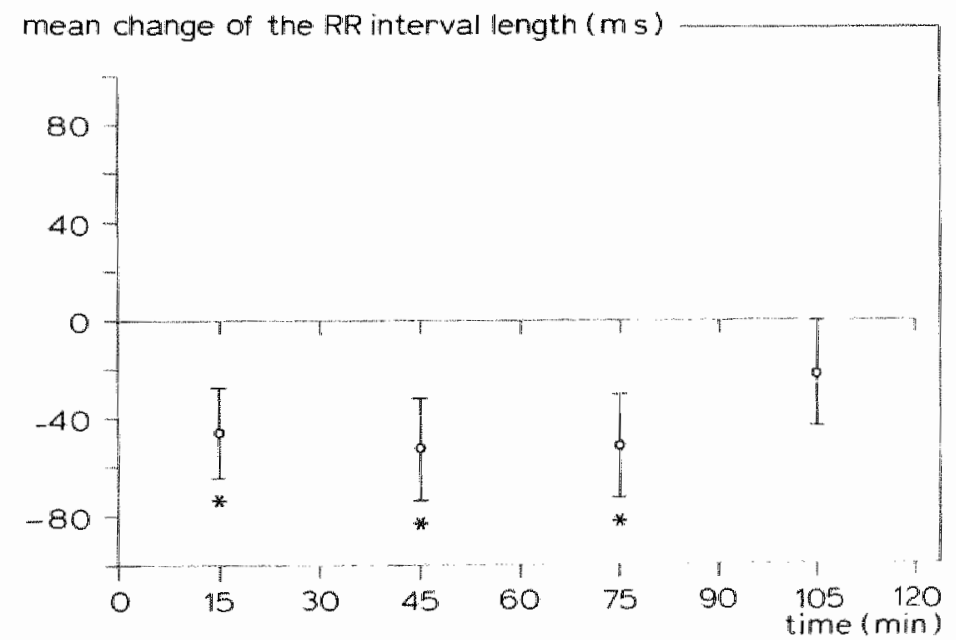

Figure 12.9 Mean change in the maternal $R R$ interval length following administration of epidural anaesthesia compared to the base-line period ( $x \pm S E M)$. The zero value represients the mean value of the maternal RR interval length in the base-line period. :p $<0.05$. 
From figure $12.9 \mathrm{it}$ appears that the RR interval length is significantly lower in the periods 0-30 minites, 30-60 minutes, 60-90 minutes after epidural anaesthesia as compared with the base-line period. In the last period the decrease is not significantly different from zero.

12.2.3 The maternal RR interval length during the last ninety minutes of the first stage of labour

The control group and epidural group were compared against one another with respect to the mean RR interval length during the last ninety minutes of the first stage. Figure 12.10 gives a schematic representation of the periods compared.

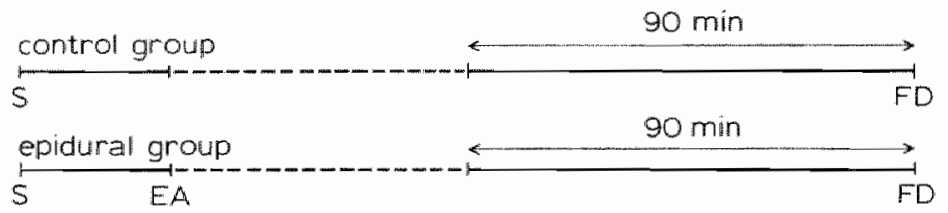

Figure 12.10 Schematic representation of the periods compared $F D=$ full dilatation.

Table 12.7 gives the mean values for the RR interval length in the control and epidural groups. The table also shows whether there was a significant difference between the two groups with respect to the RR interval length.

Table 12.7 The mean maternal RR interval length during the last ninety minutes of the first stage in the control group and in the epidural group $(\vec{x} \pm S D)$

\begin{tabular}{lccc}
\hline $\begin{array}{c}\text { control group } \\
n=22\end{array}$ & $\begin{array}{c}\text { epidural group } \\
n=20\end{array}$ & p value \\
\hline $\begin{array}{l}\text { RR interval } \\
\text { length (ms) }\end{array}$ & $789 \pm 123$ & $677 \pm 129$ & $p<0.01$ \\
\hline
\end{tabular}

It emerges from table 12.7 that the maternal RR interval length during the last ninety minutes of the first stage in the epidural group was significantly lower than in the control group.

Figure 12.11 shows a graphic representation of the mean values for the RR interval length in relation to time. 


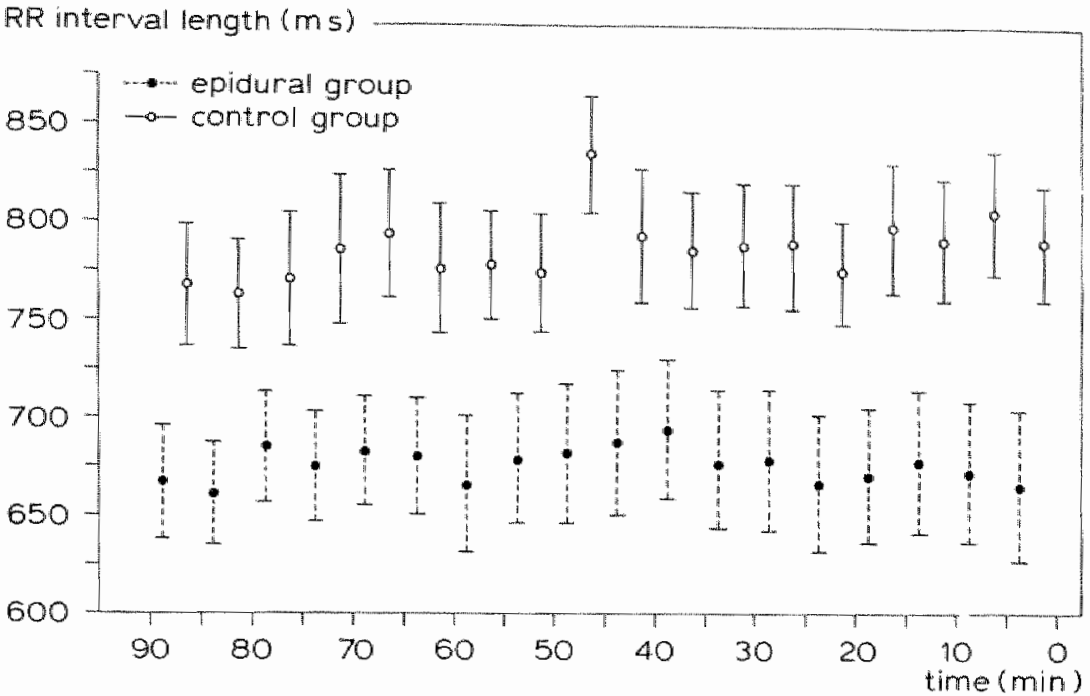

Figure 12.11 Mean maternal RR interval length \pm SEM in milliseconds (ms) per five minute period during the last ninety minutes of the first stage.

\section{Discussion}

It emerged from section 12.1 .2 that the systolic blood pressure, diastolic blood pressure and mean arterial pressure prior to administration of epidural anaesthesia were higher than in the sixty minute period after administration of epidural anaesthesia. The mean decrease of the systolic, diastolic and mean arterial blood pressure, was respective $11 \pm$ $10 \mathrm{mmHg}, 8 \pm 9 \mathrm{mmHg}$, and $9 \pm 8 \mathrm{mmHg}$. This reduction in maternal blood pressure values is highly significant. Thus, a decrease in blood pressure had occurred following the administration of the epidural anaesthesia despite the infusion of $400 \mathrm{ml}$ isotonic saline solution and despite the fact that the women were in the lateral position.

Before epidural anaesthesia the blood pressure in the epidural group is higher than in the first sixty minutes in the control group, but after epidural anaesthesia the blood pressure in the epidural group is lower than in the control group. Differences between epidural group and control group are not reaching significance. The reader is referred to sections 5.1.1 and 6.1.1 for consideration of the etiology of the blood pressure reduction during epidural anaesthesia. The frequency with which the hypotension occurred is, amongst other factors, dependent on the definition of hypotension that is applied (section 5.2.1.1). In this study the number of patients was too small to permit a reliable statement about the frequency of occurrence of hypotension during epidural anaesthesia. However, the percentages of hypotension according to the criteria that are given in table 12.3 do not contradict the literature data as described in table 5.3.

From section 12.2.2 it appeared that there was a significant decrease of the maternal RR interval length in the first ninety minutes after administration of the epidural anaesthesia as compared with the base-line period. During the last ninety minutes of the first stage of 
labour, the matemal RR interval length in the control group was significantly longer than in the epidural group (section 12.2.3).

Epidural anaesthesia can affect the cardiovascular system in at least six different possible ways:

1. Segmental sympathetic efferent blockade with resulting vasodilatation.

2. Paralysis of cardiac sympathetic nerve fibers from the upper five thoracic segments, with loss of chronotropic and inotropic drive to the myocardium, resulting in bradycardia and loss of ejection force.

3. Blockade of the innervation of the adrenal gland, with a possible decrease in catecholamine output.

4. Vascular absorption of local anaesthetic from the epidural space. At non-toxic doses this leads to a slight increase in cardiac output, heart rate and peripheral resistance. At toxic doses the contraction force of the heart would fall and so would blood pressure.

5. Vascular absorption of adrenaline from the epidural space. The beta receptor stimulation of adrenaline may lead to an increase in cardiac output and a reduction in peripheral vascular resistance.

6. The removal of labour pain, fear and anxiety causes the maternal heart rate to be reduced.

The neural effects of epidural anaesthesia and the systemic consequences of drug absorption are inseparable. With small epidural doses the systemic effects of the absorbed local anaesthetic agent may be negligible in comparison to the effects of neural blockade (Bromage 1978). Attempts to explain the net results of epidural blockade in terms of any one of these effects alone does not give an accurate description of events. The net result of epidural anaesthesia on the cardiovascular system is dependent on the extent to which each of the above mentioned factors is influenced. The net effect therefore is difficult to predict.

It is probably that the increase in the maternal heart rate in our study was mainly caused by the decrease in blood pressure due to epidural anaesthesia. It is also possible that at low doses the local anaesthetic agent has a positive chronotopic effect on the heart (Covino and Vassallo, 1976). Adrenaline that is added to the local anaesthetic at a concentration of $5 \mu \mathrm{g} / \mathrm{ml}$ is to some extent resorbed from the epidural space and as a result has a predominantly betamimetic effect which may therefore contribute to the increase in the maternal heart rate (Bonica et al., 1971). Bonica et al ${ }_{-,}$(1971) investigated the effects of high $\left(T_{5}\right)$ epidural blockade on the circulatory system in nineteen non-pregnant volunteers. They used $18-22 \mathrm{ml} 2$ per cent lidocaine. The mean arterial pressure and the total peripheral resistance fell significantly if adrenaline was added to the local anaesthetic. At the same time, the cardiac output and the heart rate increased significantly. If the adrenaline was left out these changes were present to a much lesser extent. The results from our investigation do not contradict the findings of Bonica and his colleaques. 
The conclusion seems justified that under the influence of epidural anaesthesia the maternal blood pressure decreases on average and the maternal heart rate on average increases. 



\section{Samenvattende bespreking}

In deze studie wordt de invloed van epidurale anaesthesie onderzocht op de volgende fysiologische parameters:

1. De foetale hartfrequentie en de variabiliteit in het foetale hartritme.

2. De weenactiviteit.

3. Het zuur-base evenwicht van de barende en haar foetus.

4. De bloeddruk van de barende.

5. De hartfrequentie van de barende.

In hoofdstuk 1 wordt ingegaan op enkele algemene aspecten van pijnbestrijding tijdens de baring en op de voorwaarden waaraan de ideale vorm van pijnbestrijding zou moeten voldoen. Tevens wordt een kort overzicht gegeven van de verschillende vormen van pijnbestrijding, die toegepast kunnen worden tijdens de baring. Epidurale en subarachnoïdale anaesthesie zijn de enige twee vormen van regionale anaesthesie, die zowel de pijn tijdens de ontsluitingsperiode als tijdens de uitdrijvingsperiode kunnen wegnemen.

In hoofdstuk 2 wordt ingegaan op de oorzaak van de baringspijn. Tijdens de ontsluitingsperiode wordt de pijn hoofdzakelijk veroorzaakt door het ontsluiten van de baarmoederhals. De pijn tijdens het uitdrijvingstijdperk ontstaat echter door rekking van de weefsels van vagina, vulva en perineum. De pijnprikkels die ontstaan tijdens de ontsluitingsperiode bereiken het centrale zenuwstelsel op het niveau van het $10^{\mathrm{C}}$ thoracale tot en met het $1^{e}$ lumbale ruggemergsegment. De pijn, die echter tijdens het uitdrijvingstijdperk ontstaat wordt voortgeleid naar het $2^{\mathrm{c}}, 3^{\mathrm{e}}$ en $4^{\mathrm{e}}$ sacrale ruggemergsegment.

In hoofdstuk 3 wordt de anatomie van de epidurale ruimte beschreven. De grootte van de epidurale ruimte wisselt op de verschillende ruggemergniveaus. De doorsnede van het postero-laterale compartiment van de epidurale ruimte is het grootst op lumbaal niveau (4-6 mm). De kans om de dura mater te perforeren tijdens de punctie van de epiduralle ruimte is dus op lumbaal niveau het kleinst. Voor obstetrische epidurale anaesthesie wordt meestal de tweede of derde lumbale intervertebrale ruimte benut, op dat niveau is directe mechanische beschadiging van het ruggemerg uitgesloten. Het myelum reikt meestal niet verder dan de eerste lumbale wervel. Bij flexie van de wervelkolom neemt de ruimte tussen de doornuitsteeksels toe, hetgeen punctie van de epidurale ruimte eenvoudiger maakt. Tevens zal de durazak zich ventraalwaarts verplaatsen tijdens flexie, waardoor de diameter van het achterste compartiment van de epidurale ruimte toeneemt, en de kans op perforatie van de dura mater afneemt.

In hoofdstuk 4 wordt de punctie techniek van de epidurale ruimte besproken. In deze studie is er gebruik gemaakt van de 'loss of resistance' methode. Bij de plaatsbepaling 
van de epidurale ruimte, met deze methode, is het stugge ligamentum flavum van cruciaal belang. De derde lumbale intervertebrale ruimte wordt steeds als punctieplaats benut en de epidurale catheter wordt $3 \mathrm{~cm}$ craniaalwaarts in de epidurale ruimte opgevoerd. Ter preventie van intraveneuze of intrathecale toediening van het locale anaestheticum dient er altijd een aspiratietest door de epidurale catheter te worden verricht. Teneinde een intravasculaire of intrathecale toediening van het locale anaestheticum vroegtijdig te herkennen dient er altijd eerst een testdosis toegediend te worden, ook voorafgaande aan elke herhalingsinjectie.

In hoofdstuk 5 wordt een overzicht gegeven van de belangrijkste literatuurgegevens. Achtereenvolgens worden besproken:

1. De invloed van epidurale anaesthesie op de weenactiviteit.

2. De invloed van epidurale anaesthesie op het foetale hartfrequentie patroon.

3. De invlocd van epidurale anaesthesie op het zuur-base evenwicht van moeder en foetus.

4. Farmacologische aspecten van de locale anaesthetica.

ad. 1 De resultaten van de verschillende onderzoekers met betrekking tot de invloed van epidurale anaesthesie op de uterusactiviteit zijn verschillend. Sommige auteurs vinden een tijdelijke afname van de uterus activiteit na toediening van epidurale anaesthesie, anderen nemen geen verandering waar. Bij het bestuderen van de literatuurgegevens zijn er een aantal factoren aanwijsbaar, die bovenstaande discrepantie mogelijk ten dele kunnen verklaren. Deze factoren zijn:

\section{a. Het optreden van hypotensie}

Hypotensie kan een afname van de weeënactiviteit veroorzaken. Hypotensie tijdens epidurale anaesthesie kan geheel of gedeeltelijk worden voorkomen door een intraveneuze infusie toe te dienen alvorens over te gaan tot epidurale anaesthesie. Voorts dient rugligging van de barende vermeden te worden, ondat dit de frequentie en de ernst van de hypotensie doet toenemen. In niet alle studies zijn deze voorzorgsmaatregelen getroffen.

\section{b. Het toevoegen van adrenaline aan het locale anaestheticum}

In een aantal studies is er adrenaline aan het locale anaestheticum toegevoegd. Op grond van de literatuurgegevens lijkt het gerechtvaardigd te veronderstellen dat adrenaline toegevoegd aan het locale anaestheticum in een concentratie van $5 \mu \mathrm{g} / \mathrm{ml}$, een remmende invloed heeft op de uterus activiteit. Of het verloop van de baring hierdoor ook op significante wijze wordt beïnwloed blijft onduidelijk.

\section{c. De aard en de dosering van het locale anaestheticum}

In de diverse studies verschilt de aard en de dosering van het locale anaestheticum. Dit kan mogelijk voor een deel de discrepantie in resultaten verklaren. 
Er zijn een aantal dierexperimentele en 'in vitro" studies die doen vermoeden dat locale anaesthetica een stimulerend effect hebben op het myometrium. Tijdens epidurale anaesthesie kan dit effect doorgaans bij de mens niet worden aangetoond. Er zijn tevens dierexperimentele en "in vitro' studies die de veronderstelling wettigen dat locale anaesthetica een vasoconstrictie kunnen veroorzaken in het vaatbed van de uterus, en mogelijk langs deze weg invloed zouden kunnen uitoefenen op de uterus activiteit. De plasmaconcentraties van het locale anaestheticum, die tijdens epidurale anaesthesie worden bereikt, zijn waarschijnlijk onvoldoende hoog om dit vasoconstrictie effect te veroorzaken.

\section{d. Het niveau van de epidurale anaesthesie}

In sommige studies wordt er gebruik gemaakt van een zogenaamde 'segmentale' epidurale anaesthesie (alleen blokkade van het $10^{\circ}, 11^{\circ}$ en $12^{\circ}$ thoracale ruggemergsegment), in andere studies is het aantal geblokkeerde ruggemergsegmenten veel groter. De effecten van epidurale anaesthesie in de laatste situatie zijn uiteraard veel groter. Het is niet bekend of epidurale blokkade van de sympathische innervatie van de uterus $\left(5^{\circ}\right.$ thoracale tot en met $2^{\circ}$ lumbale ruggemergsegment) invloed heeft op de uterus activiteit. Sommige auteurs zijn van mening dat blokkade van deze bovengenoemde ruggemergsegmenten vroeg in de ontsluitingsperiode een remmende invloed kan hebben op de uterusactiviteit.

\section{e. Andere medicatie}

In vele studies hebben de barenden analgetica en/of sedativa toegediend gekregen, voordat werd overgegaan tot epidurale anaesthesie. In andere studies kreeg de patiëntenpopulatie die als controle groep diende, sedativa, analgetica of lachgas-zuurstof toegediend. Dit betekent een introductie van één of meerdere variabelen, die potentieel invloed kunnen hebben op de weenactiviteit, hetgeen de interpretatie van de resultaten niet eenvoudig maakt. Voorts is er in vele studies primair of secundair gebruik gemaakt van oxytocine, hetgeen de interpretatie van de resulltaten en de onderlinge vergelijking van de verschillende studies vrijwel onmogelijk maakt.

ad. 2 De literatuurgegevens betreffende de invloed van epidurale anaesthesie op het foetale hartfrequentie patroon zijn tegenstrijdig. In een aantal studies wordt bij een deel van de patiënten een afname van de foetale hartritme variabiliteit waargenomen. Ten aanzien van eventuele veranderingen in de foetale basis hartfrequentie kan geen duidelijke uitspraak worden gedaan op basis van de literatuurgegevens. Epidurale anaesthesie kan het foetale hartfrequentie patroon beinvloeden via een afname van de utero-placentaire doorbloeding en via een direct farmacologisch effect van het locale anaestheticum op het foetale hart en het foetale centrale zenuwstelsel. Gebaseerd op theoretische overwegingen en 
literatuurgegevens zijo er een viertal potentiële mogelijkheden, waardoor epiduralle anaesthesie een verandlering van de uttero-placentaire doorbloeding kan veroorzaken.

a. Het ontstaan van hypotensie bij de barende tijdens epidurale anaesthesie Indien het ontstaan van hypotensie zoveel mogelijk wordt voorkomen, door intra veneuze vulling van het vaatstelsel en zijligging van de barende, tredlen er in aansluiting op de epidurale anaesthesie vrijwel geen pathologische hartfrequentie patronen op.

b. Het ontstaan van een te sterke uterusactiviteit tijdens epidurale anaesthesie Uit dierexperimenteel onderzoek en uit 'in vitro" studies blijkt dat localle anaesthetica, contracties van het myometrium kunnen veroorzaken. Tijdens epidurale anaesthesie ontstaan er echter haemodynamische, humorale en neurogene veranderingen, die elk hun (soms tegengestelde) invloed kunnen doen gellen op de uterusactiviteit. Het directe farmacologische effect van locale anaesthetica op het myometrium is derhalve in klinische studies, waarbij epidurale anaesthesie wordt toegediend, nietgeïsoleerd te quantificeren. Mogelijk zijn barenden, waarbij epidurale anaesthesie wordt toegepast, gevoeliger voor oxytocine.

c. Het potentielle vasoconstrictie effect van het locale anaestheticum op het vaatbed van de uterus

Het lijkt gerechtvaardigd te veronderstellen dat locale anaesthetica een vasoconstrictie kunnen veroorzaken in het vaatbed van de uterus. Dit effect treedt waarschijnlijk pas op bij plasma concentraties, die doorgaans niet bij epidurale anaesthesie worden bereikt.

d. Het potentiële wasoconstrictie effect van adrenaline (toegevoegd aan het locale anaestheticum) op het vaatbed van de werus

Bij het bestuderen van het effect van epidurale anaesthesie op de uteroplacemtaire circulatie, spelen in dit kader twee mechanismen een rol. In de eerste plaats de bereikte concentratie van cathecholaminen in de circulatie tengevolge van de toevoeging van adrenaline aan het locale anaestheticum, en ten tweede de invloed van pijn, angst en spanning van de barende op de spontaan aanwezige concentratie van catecholaminen in de circulatie. Waarschijnlijk bereiken adrenaline concentraties (t.g.v. resorptie uit de epidurale ruimte) tijdens epidurale anaesthesie niet dat kritische niveau dat nodig is om de utero-placentaire circulatic te doen afnemen. Voorst is helt niet uitgesloten, dat pijn en stress tijdens een baring catecholamine concentraties kunnen veroorzaken, die een zodanige hoogte bereiken, dat de intervilleuze doorbloe-

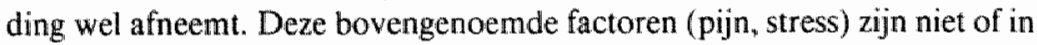
veel mindere mate aanwezig tijdens epidurale anaesthesie, zodat de endogene cathecholamine productie lager zal zijn dan van barenden die geen pijnbe- 
strijding krijgen. Het is mogelijk dat sympathische denervatie wan de uterus door middel van epidurale anaesthesie de bloeddoorstroming wan de uterus gedeeltelijk beschermt tegen vasoconstrictie. Het uitschakelen van een deel van het sympathische zenuwstelsel, waardoor bovengenoemd gunstig effect veroorzaakt wordt, heeft ook repercussies op de tractus circulatorius van de barende, in die zin, dat er een predispositie bestaat voor het ontstaan van hypotensie en dientengevolge voor een afname van de utero-placentaire doorbloeding. Voorts zal sympathische denervatie van de uterus door middel van epidurale anaesthesie geen beschermend effect bieden ten aanzien van het potentiele vasoconstrictie effect van het locale anaestheticum. Dit effect komt niet via de innervatie van de uterus tot stand, maar is het gevolg van een direct farmacologische werking van het locale anaestheticum op de vaatwand. Het netto resultaat van de invloed van epidurale anaesthesie op de uteroplacentaire doorbloeding zal afhangen van de balans tussen de gunstige en ongunstige effecten van epidurale anaesthesie op de utero-placentaire doorbloeding.

Het foetale hartfrequentie patroon kan ook beïnvloed worden door een directe farmacologische invloed van het locale anaestheticum op het foetale hart en het foetale centrale zenuwstelsel. Het lijkt gerechtwaardigd te veronderstellen dat locale anaesthetica in niet toxische doseringen bij de volwassene een toename veroorzaken van de bloeddruk, t.g.v. een toename van zowel dle perifere vaatweerstand als het hartminuutvolume. In toxische doseringen treedt er een bloeddrukdaling en een bradycardie op. Het lijkt zeer waarschijnlijk dat locale anaesthetica eenzelfde effect op het foetale hart-vaat stelsel kunnen hebben. De plasma concentratie van het locale anaestheticum waarbij negatieve effecten optreden in het foetale cardio-vasculaire systeem is niet bekend. De beïnvloeding van het foetale hartfrequentie patroon door het locale anaestheticum behoeft echter niet altijd te berusten op een direct effect op het foetale cardio-vasculaire systeem, maar kan ook veroorzaakt worden door de invloed van het locale anaestheticum op de utero-placentaire doorbloeding of op het foetale centrale zenuwstelsel.

ad. 3 De literatuurgegevens overziende lijkt de conclusie gerechtvaardigd dat epidurale anaesthesie een verschuiving van het zuur-base evenwicht van de barende in de richting van een metabole acidose geheel of gedeeltelijk voorkomt. In relatie tot epidurale anaesthesie wordt in de literatuur melding gemaakt van de volgende drie factoren die invloed zouden kunnen hebben op het zuur-base evenwicht van de barende:

\section{a. Hyperventilatie van de barende}

Als de baring pijnloos verloopt, t.g.v. epidurale anaesthesie zal de door pijn geïnduceerde hyperventilatie afnemen en de invloed van hyperventilatie op het zuur-base evenwicht zal dientengevolge minder worden. 


\section{b. Spierarbeid van de barende}

Tijdens epidurale anaesthesie zal de 'motorische onrust' van de barende afnemen. Voorts is tijdens epidurale anaesthesie de persreflex geheel of gedeeltelijk afwezig, zodat de barende doorgaans minder goed perst tijdens het uitdrijvingstijdperk. Bovengenoemde twee factoren hebben tot gevolg dat er tijdens epidurale anaesthesie minder spierarbeid wordt verricht, waardoor de verschuiving van het zuur-base evenwicht in de richting van een metabole acidose geheel of gedeeltelijk achterwege blijft.

\section{c. Catecholamine concentratie in het bloed van de barende}

Zowel uit dierexperimentele studies als uit onderzoek bij de mens blijkt dat toediening van adrenaline, de lactaat concentratie in het bloed doet toenemen. De literatuurgegevens overziende lijkt het aannemelijk, dat de stress en pijn die bij een aantal barenden aanwezig is, een stijging van de catecholamine concentratie veroorzaakt. Deze stijging treedt waarschijnlijk niet of in veel mindere mate op tijdens epidurale anaesthesie.

De interpretatie van de literatuurgegevens betreffende de invloed van epidurale anaesthesie op het foetale zuur-base evenwicht is moeilijk, omdat in de meeste studies de barenden die als controle groep dienden, andere vormen van pijnbestrijding kregen tijdens de baring. Het lijkt echter waarschijnlijk, dat tijdens epidurale anaesthesie de foetus 'beschermd' wordt tegen een metabole acidose, omdat de moeder minder neigt tot metabole acidose. Indien de uteroplacentaire bloeddoorstroming afneemt tijdens epidurale anaesthesie (b.v. ten gevolge van hypotensie, of een hoge concentratie van het locale anaestheticum in het bloed, waardoor er een vasoconstrictie ontstaat in het vaatbed van de uterus) kan er uiteraard wel een foetale hypoxie ontstaan. Een hoge concentratie van het locale anaestheticum (b.v. tengevolge van een injectie van het locale anaestheticum in een van de veneuze vaten in de epidurale ruimte) kan tevens een daling van de 'cardiac output' van het foetale hart tot gevolg hebben waardoor de oxygenatie van de foetus eveneens in gevaar komt.

ad. 4 Het thans meest gebruikte locale anaestheticum voor epidurale anaesthesie in de verloskunde is bupivacaine. Het molecuulgewicht van dit langwerkende locale anaestheticum bedraagt 324 en de dissociatie constante (pKa) is 8,05 . De meeste auteurs zijn van mening dat bij gebruik van bupivacaine lage bloedconcentraties bij moeder en foetus aanwezig zijn.

Of toevoeging van adrenaline aan het locale anaestheticum invloed heeft op de bereikte bloedconcentratie van het locale anaestheticum, wordt uit de literatuurgegevens niet duidelijk. De resultaten van de verschillende onderzoekers zijn op dit punt tegenstrijdig. Het lijkt wel waarschijnlijk dat toevoeging van adrenaline de intensiteit en de kwaliteit van de epidurale anaesthesie doet toenemen.

Locale anaesthetica worden uit de epidurale ruimte geresorbeerd en kunnen via de circulatie andere organen bereiken en beïnvloeden. Locale anaesthetica hebben 
uit hoofde van hun functie een effect op membranen die zorg dragen voor electro-chemische prikkelgeleiding. Derhalve zijn het hart en het centralle zenuwstelsel organen wier functie gestoord kan raken door locale anaesthetica. De plasma bupivacaine concentratie waarboven toxische reacties optreden is nooit met zekerheid vastgesteld. Waarscijnlijk ligt deze concentratie tussen 1,6 en 4 $\mu \mathrm{g} / \mathrm{ml}$.

In hoofstuk 6 wordt ingegaan op de belangrijkste bijwerkingen en complicaties die epidurale anaesthesie kan hebben ten aanzien van de moeder. Een van de meest voorkomende bijwerkingen is een bloeddrukdaling van de barende. Epidurale anaesthesie kan het hart-vaatstelsel van de moeder voornamelijk langs de volgende drie wegen beïnvloeden:

\section{a. Blokkade van een deel van het sympathische zenuwstelsel}

Dit veroorzaakt een afname van de perifere vaatweerstand, en een afname van de venous return naar het hart. Dit kan aanleiding geven tot een daling van de bloeddruk.

\section{b. De invloed van het locale anaestheticum op de tractus circulatorius}

In niet toxische doseringen veroorzaken locale anaesthetica cen geringe toename van de hartfrequentie, de 'cardiac output' en de perifere vaatweerstand. Het gevolg hiervan is dat de bloeddruk gelijk blijft of iets stijgt. Bij toxische doseringen zal de contractiekracht van het hart afnemen en de bloeddruk dalen. Het effect van locale anaesthetica op de vaatwand is bifasisch. Bij lage, niet toxische concentraties ontstaat er een vasoconstrictie en een toename van de perifere vaatweerstand. Bij toxische concentraties ontstaat er een perifere vasodilatatie en een afname van de perifere vaatweerstand.

\section{c. De invloed van het toegevoegde adrenaline op de tractus circulatorius}

De kans op bloeddrukdaling en de ernst daarvan neemt toe als er adrenaline aan het locale anaestheticum is toegevoegd. Dit effect kan veroorzaakt worden door het beta-sympathico-mimetisch effect dat een lage concentratie adrenaline in de algemene circulatie veroorzaakt. Het is echter ook mogelijk dat t.g.v. het toegevoegde adrenaline de kwaliteit en de intensiteit van de epidurale anaesthesie toeneemt, waardoor ook de sympathicus blokkade in intensiteit toeneemt. Derhalve zal ook de mate van perifere vasodilatatie toenemen.

Het percentage dura perforaties is sterk afhankelijk van de ervaring van de 'epiduralist'. Indien de frequentie van dura perforaties de één procent overschrijdt, verdient dit bezinning op de techniek van de epidurale punctie, alsmede op het gebruikte materiaal. Hoofdpijn is het meest voorkomende symptoom na een dura perforatie. Indien de dura perforatie niet herkend wordt en de dosis van bet locale anaestheticum (bedoeid voor de epidurale ruimte) subarachnoïdaal wordt toegediend kan dit aanleiding geven tot één van de ernstigste complicaties die de epidurale anaesthesie kent, het zogenaamde 'total spinal block". 
In de epidurale ruimte bevindt zich de uitgebreide plexus venosus vertebralis interna. Het aanprikken van een vene van deze plexus is dan ook geen zeldzaamheid. Er dient altijd een aspiratie test door de catheter verricht te worden, teneinde intravasculaire toediening van het locale anaestheticum te voorkomen. Intravasculaire toediening van het locale anaestheticum $\mathrm{kan}$ tot toxische verschijnselen leiden van het centrale zenuwstelsel en de tractus circulatorius.

Neurologische complicaties t.g.v. epidurale anaesthesie zijn uitermate zeldzaam. Het "anterior spinal artery syndroom" als gevolg van epidurale anaesthesie is voor zover bekend nog niet beschreven bij een obstetrische patiènte.

In hoofdstuk 7 wordt de opzet van het eigen onderzoek beschreven. Omdat de indeling van de barenden in de controle groep en in de epidurale groep niet aselect geschiedde, bestaat de mogelijkheid dat de groepen niet goed vergelijkbaar zijn. Ten aanzien van een aantal algemene gegevens worden de controle groep en de epidurale groep met elkaar vergeleken. Het blijkt dat in de controle groep bij 18 barenden de vliezen artificieel gebroken zijn, terwijl dit in de epidurale groep 10 maal het geval is geweest. Dit verschil is juist significant. Voorts blijkt er een significant verschil te bestaan tussen beide groepen wat betreft de tijd die verstrijkt tussen het breken van de vliezen en het begin van het onderzoek. Voor de controle groep bedraagt dit tijdsinterval 96 minuten en voor de epidurale groep 250 minuten, Hieruit mag waarschijnlijk worden geconcludeerd dat barenden waarbij de vliezen vroeg in de ontsluitingsperiode al dan niet artificieel zijn gebroken een voorkeur hebben uitgesproken voor indeling in de epidurale groep. Overigens worden er geen significante verschillen tussen beide groepen gevonden.

Bij de barenden uit de epidurale groep wordt de pijn bestreden met een lumbale epidurale anaesthesie. Bij de eerste injectie van het locale anaestheticum in de epidurale ruimte wordt $10 \mathrm{ml}$ Marcaine $0,25 \%$ toegediend, waaraan adrenaline is toegevoegd in de concentratie van $5 \mu \mathrm{g} / \mathrm{ml}$. Vervolgens wordt elke twee uur een herhalingsinjectie van $8 \mathrm{ml}$ toegediend.

In deze studie wordt de invloed van epidurale anaesthesie bestudeerd op:

1. Enkele parameters van het foetale hartfrequentie patroon

a. foetale basis hartfrequentie (RR interval lengte)

b. langzame variaties in het foetale hartritme (LTI index)

c. snelle variaties in het foetale hartritme (ID index)

2. Enkele parameters van de weenactiviteit

a. de amplitudo

b. de weenfrequentie

c. het actief drukoppervlak

3. Het zuur-base evenwicht van de barende en haar foetus

4. De bloeddruk van de barende

5. De hartfrequentie van de barende (RR interval lengte)

De invloed van epidurale anaesthesie op bovengenoemde parameters wordt op twee manieren onderzocht: 
1. Binnen de epidurale groep wordt een periode voor toediening van epidurale anaesthesie, vergeleken met een periode na toediening van epidurale anaesthesie.

2. Tijdens bepaalde perioden van de baring wordt de epidurale groep vergeleken met de controle groep.

Voorts wordt bij vijftien barenden uit de epidurale groep op gezette tijdstippen de bupivacaine concentratie in veneus plasma bepaald. Ook wordt direct na de geboorte navelstrengbloed afgenomen voor de bepaling van de bupivacaine concentratie.

In hoofdstuk 8 wordt de invloed van epidurale anaesthesie op de foetale hartritme parameters bestudeerd.

Het blijkt dat er bij de start van het onderzoek (nog voordat epidurale anaesthesie wordt gerealiseerd) geen significante verschillen bestaan tussen beide groepen ten aanzien van de hartritme parameters.

Als de uitgangsperiode (15 minuten voor toediening van epidurale anaesthesie) wordt vergeleken met de 120 minuten durende periode na toediening van epidurale anaesthesie, dan blijken er geen significante veranderingen in de foetale hartritme parameters op te treden. Voor die patiënten, waarbij de systolische bloeddruk daalt tot onder 100 $\mathrm{mmHg}(\mathrm{n}=5)$ treedt er echter een significante toename van de ID index op. Dit is mogelijk het gevolg van een afname van de utero-placentaire doorbloeding. In het recente verleden is er veel nadruk gelegd op de correlatie die er zou bestaan tussen een afname van de hartritme variabiliteit en foetale hypoxie. Recent onderzoek laat echter zien dat een toename van de hartritme variabiliteit één van de eerste tekenen van foetale hypoxie kan zijn.

Tijdens de laatste 90 minuten van de ontsluitingsperiode is de foetale hartfrequentie in de epidurale groep significant hoger dan in de controle groep. Gezien de literatuurgegevens zou dit het gevolg kunnen zijn van een directe farmacologische invloed van het locale anaestheticum op het foetale hart en het foetale centrale zenuwstelsel. Er wordt in deze studie echter geen significante correlatie gevonden tussen de maternale bupivacaine concentratie en de mate waarin de foetale RR interval lengte verandert. Een andere mogelijke verklaring voor de hogere hartfrequentie in de epidurale groep kan gezocht worden in de beta-sympathico-mimetische invloed van adrenaline dat aan het locale anaestheticum is toegevoegd. In hoofdstuk 5 is reeds ingegaan langs welke wegen epidurale anaesthesie de utero-placentaire doorbloeding kan beïnwloeden. De hogere foetale hartfrequentie in de epidurale groep zou ook nog veroorzaakt kunnen worden door een afname van de utero-placentaire doorbloeding. Hoewel het op basis van de eigen resultaten niet mogelijk is hierover een uitspraak te doen, lijkt het op grond van de volgende overwegingen niet aannemelijk, dat een verandering in de utero-placentaire doorbloeding verantwoordelijk is voor het verschil in foetale hartfrequentie tussen beide groepen.

a. Er wordi geen significante correlatie gevonden tussen de bloeddruk parameters van de moeder en de foetale RR interval lengte. Het lijkt derhalve onwaarschijnlijk dat 
een afname van de bloeddruk van de barende een causaal verband houdt met het verschil in foetale hartfrequentie tussen beide groepen.

b. Een sterke uterusactiviteit kan eveneens een afname van de utero-placentaire doorbloeding veroorzaken. De tonus is in deze studie niet bestudeerd, zodat hierover geen uitspraak gedaan kan worden. In de controle groep treedt er echter een significante toename op van de amplitudo en het actief drukoppervlak (hoofdstuk 9). Deze toename blijft in de epidurale groep achterwege. Het lijkt daarom niet waarschijnlijk dat de utero-placentaire doorbloeding in nadelige zin wordt beïnvloed door de uterus activiteit.

c. Zoals uit de literatuurgegevens blijkt kunnen locale anaesthetica in hoge doseringen een vasoconstrictie veroorzaken in het vaatbed van de uterus. Dit effect treedt waarschijnlijk op bij concentraties die doorgaans niet bij epidurale anaesthesie worden bereikt. De gemeten bupivacaine concentraties in dit onderzoek zijn laag ten opzichte van de literatuurgegevens (hoofdstuk 11 ), maar een geringe afname van de utero-placentaire circulatie kan uiteraard niet met zekerheid worden uitgesloten.

d. Adrenaline dat toegevoegd is aan het locale anaestheticum zou mogelijk na resorptie uit de epidurale ruimte de utero-placentaire circulatie in nadelige zin kunnen beïnvloeden. In humane studies blijkt dit echter niet het geval te zijn.

Tijdens de laatste 90 minuten van de ontsluitingsperiode is de LTI index in de epidurale groep lager dan in de controle groep. De meeste auteurs zijn van mening, dat een afname van de foetale hartritme variabiliteit wordt veroorzaakt door een direct farmacologisch effect van het locale anaestheticum op het foetale myocard. Ook is het echter mogelijk dat het locale anaestheticum de utero-placentaire doorbloeding in negatieve zin beinvloedt, waardoor de foetale conditie slechter wordt en de hartritme variabiliteit kan veranderen. In dit onderzoek wordt een zeer significante positieve correlatie gevonden tussen het verloop van de bupivacaine concentratie in het plasma van de moeder en de LTI index. Direct na toediening van de epidurale anaesthesie treedt er een kortdurende niet significante toename op van de LTI index. De maximale toename wordt bereikt op het tijdstip, waarop ook de bupivacaine concentratie maximaal is. Daarna nemen zowel de bupivacaine concentratie als de LTI index af. De ID index laat ook een kortdurende niet significante toename zien, na toediening van epidurale anaesthesie.

Gezien de literatuurgegevens kan een tijdelijke toename van de hartritme variabiliteit, een uiting zijn van foetale hypoxic. Het is dan ook niet uit te sluiten, dat epidurale anaesthesie de foetale conditie in geringe mate, in negatieve zin beïnvloed. In overeenstemming hiermee is, dat de foetale $\mathrm{pH}$ bij volledige ontsluiting van de baarmoederhals in de controle groep significant hoger is dan in de epidurale groep. Ook het foetomaternale $\mathrm{pH}$ verschil is in de controle groep significant kleiner dan in de epidurale groep (hoofdstuk 10). De hartritme variabiliteit kan uiteraard ook benvloed worden via een direct farmacologisch effect van het locale anaestheticum op het centrale zenuwstelsel van de foetus. Met de resultaten verkregen uit eigen onderzoek is het echter niet mogelijk deze hypothese verder te onderbouwen.

Er wordt in dit onderzoek geen significante correlatie gevonden tussen de bloeddruk parameters van de barende en de LTI index. 
In hoofstuk 9 wordt de invloed van epidurale anaesthesie op de contractie parameters bestudeerd. Evenals bij de foetale hartfrequentie parameters waren er geen pre-existente verschillen tussen beide groepen aanwezig.

Als de 30 minuten durende uitgangsperiode voor toediening van epidurale anaesthesie wordt vergeleken met de 120 minuten durende observatie periode na toediening van epidurale anaesthesie blijken er geen significante verschillen te bestaan. Tijdens de eerste 30 minuten in aansluiting op de epidurale anaesthesie, treedt er echter een significante afname op van de amplitudo en een significante toename van de weeënfrequentie.

Er kunnen in deze studie geen significante correlaties worden gevonden tussen de bloeddruk parameters van de moeder en de contractie parameters. Ook bij de vijf barenden bij wie een systolische bloeddrukdaling optreedt tot onder $100 \mathrm{mmHg}$, treden geen significante veranderingen op in de contractie parameters. Bij barenden met een hoog hypalgesie niveau $\left(>T_{7}\right)$ en bij barenden die één of meerdere herhalingsinjecties krijgen toegediend, treden er geen significante veranderingen op in de contractie parameters.

Gezien de literatuurgegevens en gezien de resultaten verkregen uit eigen onderzoek lijkt het waarschijnlijk dat de toevoeging van adrenaline aan het locale anaesthetitum verantwoordelijk is voor het verschil in weenactiviteit tussen beide groepen. Hoewel de weenactiviteit (amplitudo, 'active pressure area') in de epidurale groep achterblijft bij die in de controle groep is het tijdsinterval tussen het begin van het onderzoek en volledige ontsluiting niet significant verschillend tussen beide groepen. De gemiddelde ontsluiting bij het begin van het onderzoek was in beide groepen vrijwel gelijk.

In hoofdstuk 10 wordt de invloed van epidurale anaesthesie op het zuur-base evenwicht van moeder en foetus bestudeerd.

Tijdens de ontsluitingsperiode treden er in de epidurale groep geen significante veranderingen op in het zuur-base evenwicht van de moeder. In de controle groep daarentegen. daalt het base excess en de $\mathrm{pCO}_{2}$ significant. De daling van de $\mathrm{pCO}_{2}$ is het gevolg van hyperventilatie, die tijdens pijnlijke uterus contracties optreedt. Deze $\mathrm{pCO}_{2}$ daling treedt dan ook niet op in de epidurale groep. De $\mathrm{pH}$ van de barenden in de controle groep verandert niet significant tijdens de ontsluitingsperiode, dit is het gevolg van een zich ontwikkelende metabole acidose in de controle groep, zich uitend in een significante daling van het base excess. De metabole acidose kan deels compensatoir van aard zijn, maar de meeste auteurs zijn van mening dat een lactaat stijging, die tijdens de baring optreedt, de oorzaak is van de metabole acidose. Mogelijk dat de motorische onrust van de barende (t.g.v. pijn) of de verhoogde catecholamine productie (t.g.v. pijn en stress) oorzakelijk verband houden met de daling van het base excess. Deze factoren zijn niet of in mindere mate aanwezig tijdens epidurale anaesthesie, waardoor de metabole acidose zich niet ontwikkelt. Tijdens de uitdrijvingsperiode ontstaat er in de controle groep een significante verschuiving van het zuur-base evenwicht in de richting van een metabole acidose. Er vinden daarentegen geen significante veranderingen plaats in de epidurale groep. Tengevolge van de spierarbeid, die barenden tijdens het persen verrichten zal er een lactaat stijging ontstaan en dientengevolge een metabole acidose. Bij de barenden uit de epidurale groep is de persreflex geheel of gedeeltelijk onderdrukt waardoor ze minder 
goed zullen meepersen. Dit verklaart waarschijnlijk het achterwege blijven van een metabole acidose in de epidurale groep.

Hoewel de $\mathrm{pH}$ van de moeder bij volledige ontsluiting gelijk is in beide groepen, bestaat er een significant verschil tussen beide groepen ten aanzien van de foetale $\mathrm{pH}$. De gemiddelde $\mathrm{pH}$ in de epidurale groep $(7.35 \pm 0.05)$ was significant lager dan in de controle groep ( $7.39 \pm 0.04)$. Waarschijnlijk als afspiegeling van de veranderingen in het zuur-base evenwicht van de moeder, ontstaan er in de controle groep tijdens de uitdrijvingsperiode significante veranderingen in het foetale zuur-base evenwicht, in de richting van een metabole acidose. In de epidurale groep vinden geen significante veranderingen plaats in het foetale zuur-base evenwicht tijdens de uitdrijvingsperiode. Bij de geboorte bestaan er dan ook geen significante verschillen meer tussen beide groepen ten aanzien van het foetale zuur-base evenwicht.

In hoofdstuk 11 wordt het verloop van de bupivacaine concentratie in het veneuze plasma van de moeder $(n=15)$ bestudeert. De maximale bupivacaine concentratie wordt bereikt tussen 10 en 30 minuten na toediening van de epidurale anaesthesie. De maximale bupivacaine concentratie bedraagt gemiddeld $216 \pm 65 \mu \mathrm{g} / \mathrm{l}$. Aan 6 van de 15 barenden zijn één of meerdere herhalings doseringen toegediend. De hoogst gemeten bupivacaine concentratie na een herhalingsinjectie is $395 \mu \mathrm{g} / 1$.

De toxische plasma concentraties voor bupivacaine zijn nooit met zekerheid vastgesteld. Gezien de literatuurgegevens ligt de toxische drempel-concentratie waarschijnlijk tussen 1600 en $4000 \mu \mathrm{g} / 1$.

De drempel-concentratie waarboven een afname van de utero-placentaire doorbloeding optreedt is bij de mens niet bekend. In het dierexperiment (schaap) treedt een afname van $25 \%$ op van de utero-placentaire doorbloeding, bij een arteriële bloedconcentratie van $1000 \mu \mathrm{g} / \mathrm{l}$ (Greiss et al., 1976). Deze waarneming heeft uiteraard niet dezelfde geldigheid in de humane situatie. Bij paracervicale anaesthesie kunnen mogelijk hoge concentraties van het locale anaestheticum in de arteria uterina worden bereikt, die dan aanleiding kunnen geven tot een afname van de utero-placentaire doorbloeding, en dientengevolge tot bradycardie en hypoxie van de foetus. Uit de literatuurgegevens blijkt dat epidurale anaesthesie waarschijnlijk de utero-placentaire doorbloeding niet in negatieve zin benvloed mits hypotensie van de barende wordt vermeden. Als de epidurale catheter echter in één van de venen van de uitgebreide plexus venosus vertebralis interna ligt, kunnen er mogelijk dermate hoge concentraties van het locale anaestheticum ontstaan, zodat de utero-placentaire doorbioeding wel wordt bedreigd.

Uit de literatuurgegevens blijkt dat de maximale foetale bupivacaine concentratie tussen 10 en 30 minuten na toediening van de epidurale anaesthesie wordt bereikt (Belfrage et al., 1975-a). Het gemiddelde quotient tussen de bupivacaine concentratie in het navelstrengplasma en het plasma van de barende is in dit onderzoek gemiddeld 0,30 $\pm 0,06$. Dit komt overeen met de literatuurgegevens.

In hoofdstuk 12 wordt verder ingegaan op de invloed die epidurale anaesthesie heeft op de bloeddruk en de hartfrequentie van de barende. Het blijkt dat de systolische 
bloeddruk, de diastolische bloeddruk en de 'mean arterial pressure' dalen na toediening van epidurale anaesthesie. Deze significante daling van de bloeddruk treedt op ondanks een intraveneuze infusie van $400 \mathrm{ml}$ fysiologische zoutoplossing en zijligging van de barende.

Er is bij vijf barenden een systolische bloeddrukdaling opgetreden tot onder $100 \mathrm{mmHg}$. Bij één barende daalde de systolische bloeddruk tot onder $80 \mathrm{mmHg}$.

De hartfrequentie van de barende neemt significant toe na toediening van epidurale anaesthesie.

Epidurale anaesthesie kan langs de volgende wegen een invloed uitoefenen op de tractus circulatorius:

1. Sympathicus blokkade tengevolge waarvan een perifere vasodilatatie optreedt en soms een bloeddrukdaling.

2. Blokkade van de sympathische zenuwvoorziening van het hart $\left(T_{1}-T_{5}\right)$, tengevolge waarvan de hartfrequentie en de contractiekracht afnemen. Deze vijf bovenste thoracale ruggemergsegmenten worden slechts zelden geblokkeerd bij obstetrische epidurale anaesthesie.

3. Resorptie van adrenaline (toegevoegd aan het locale anaestheticum) uit de epidurale ruimte. De beta-receptor stimulatie van adrenaline kan leiden tot een toename van de 'cardiac output' en een afname van de perifere vaatweerstand.

4. Resorptie van het locale anaestheticum uit de epidurale ruimte. Bij niet toxische concentraties van het locale anaestheticum, heeft dit een geringe toename van de 'cardiac output', hartfrequentie en perifere vaatweerstand tot gevolg.

5. Blokkade van de innervatie van de bijnier $\left(T_{5}-L_{2}\right)$ hetgeen waarschijnlijk resulteert in een afname van de catecholamine afgifte.

6. Het wegnemen van de baringspijn kan aanleiding geven tot een afname van de hartfrequentie.

De bloeddrukdaling is waarschijnlijk in hoofdzaak verantwoordelijk voor de toename van de hartfrequentie. Resorptie van het locale anaestheticum en het toegevoegde adrenaline uit de epidurale ruimte kunnen door hum farmacologische invloed op het hart eveneens bijdragen tot de toename van de hartfrequentie van de barende. 



\section{Summarizing discussion}

In this study the effect of epidural anaesthesia on the following parameters was investigated:

1. The foetal heart rate and the variability in the foetal heart rate pattern.

2. The uterine activity.

3. The maternal and foetal acid-base balance.

4. The maternal blood pressure.

5. The maternal heart rate.

Chapter 1 considers some general aspects of pain control during childbirth and the criteria to which the ideal form of pain control should adhere. Further, a brief overview is given of the various forms of pain control that can be used during childbirth. Epidural and subarachnoidal anaesthesia are the only two forms of regional aneesthesia that can remove pain during both the first stage and the second stage of labour.

Chapter 2 considers the cause of childbirth pain. During the first stage of labour the pain is mainly attributable to the dilatation of the uterine cervix, however, the pain encountered in the second stage of labour is caused by stretching of the tissues of the vagina, vulva and perineum. The pain impulses which develop during the first stage reach the central nervous system at the level of the tenth thoracic to first lumbar spinal segments. However the pain that arises during the second stage is conducted to the second, third and fourth sacral spinal segments.

In chapter 3 the anatomy of the epidural space is described. The size of the epidural space changes depending on the spinal level. The cross section of the posterolateral compartment of the epidural space is biggest at the lumbar level (4-6 $\mathrm{mm}$ ). Thus the probability of perforating the dura mater during the puncture is smallest at the lumbar level. For obstetric epidural anaesthesia the second or third intervertebral lumbar space is usually chosen. At that level direct mechanical damage to he spinal cord can be excluded. Usually the myelum does not extend any further than the first lumbar vertebra. On flexion of the spine the distance between the spinal crests increases and this makes the puncture of the epidural space simpler. Apart from that, the dural sac is displaced in a ventral direction, as a result of which the diameter of the rearmost compartment of the epidural space increases and the chance of perforation of the dura mater is reduced.

Chapter 4 describes the technique for epidural puncture. In this study the loss of resistance method was used. With this procedure, locating of the epidural space attaches crucial importance to the stiff flaval ligament. The third lumbar intervertebral space was al ways used for the puncture site and the epidural catheter was fed $3 \mathrm{~cm}$ in the cranial direction inside the epidural space. 
In order to prevent intravenous or intrathecal administration of the local anaesthetic agent, an aspiration test via the epidural catheter should always be done. In order to recognize intra vascular or intrathecal administration of the local anaesthetic agent a test dose should always be given, including prior to a top-up dose.

Chapter 5 presenis a riview of the most important literature data. The following are discussed in order:

1. The effect of epidural anaesthesia on the uterine activity.

2. The effect of epidural anaesthesia on the foetal heart rate pattern.

3. The effect of epidural anaesthesia on the maternal and foetal acid- base balance.

4. Pharmacological aspects of the local anaesthetic agents.

ad. 1

The results of the different investigators concerning the effect of epidural anaesthesia on the uterine activity vary. Some authors find that there is a temporary reduction of the uterine activity, others observe no change. On studying the literature data a number of factors can be pointed to which may partly clarify the above mentioned discrepancies. These factors are:

\section{a. The occurrence of maternal hypotension}

Hypotension may cause a reduction in uterine activity. Hypotension during epidural anaesthesia can be wholly or partly prevented by administering an intravenous infusion prior to administering the epidural anaesthesia. Furthermore, the women should be prevented from lying on their backs because this increases the frequency and the seriousness of the hypotension. These precautionary measures were not found in all studies.

\section{$b$. The addition of adrenaline to the local anaesthetic agent}

In a number of studies, adrenaline was added to the local anaesthetic agent. On the basis of the literature data it seems justified to suppose that adrenaline added to the local anaesthetic agent at a concentration of $5 \mu \mathrm{g} / \mathrm{ml}$, has an inhibitory effect on uterine activity. It remains unclear as to whether the course of labour is significantly afected by this.

\section{c. The type and the dose of the local anaesthetic}

In the various studies the type and dose of the local anaesthetic are different. This may partly explain the discrepancies in the results. There are a number of animal experiments and in vitro studies which suggest that local anaesthetics have a stimulatory effect on the myometrium. In humans this effect cannot usally be demonstrated during epidural anaesthesia. There are also animal experiments and in vitro studies that support the supposition that local anaesthetics may cause a vasoconstriction in the vascular bed of the uterus and via this route may possibly exercise an effect on the uterine activity. 
The levels of local anaesthetic in the plasma that are achieved during epidural anaesthesia are probably not high enough to produce this vasoconstriction effect.

\section{d. The level of the epidural anaesthesia}

In some studies, use was made of a so called "segmental" epidural anaesthesia (blockade of only the $10^{\text {th }}, 11^{\text {th }}$ and $12^{\text {th }}$ thoracic spinal segments), in other studies the number of segments blocked is much greater. The effects of epidural anaesthesia in the latter case are much greater of course. It is not known whether sympathetic blockade of the uterus (fifth thoracic to second lumbar spinal segments) by epidural anaesthesia has an effect on uterine activity.

Some authors are of the opinion that blockade of the above-mentioned spinal segments early in the first stage of labour may have an inhibitory effect on uterine activity.

\section{e. Other medication}

In many studies the woman had had analgesics or sedatives administered tot them before they were switched over to epidural anaesthesia. In other studies the patient population who served as controls had been adminstered sedatives, analgesics or a mixture of nitrous oxide-oxygen. This represents the introduction of one or more variables that could have a potential effect on the uterine activity and this does not make interpretation of the results simple.

Furthermore, in many studies there was primary or secondary use of oxytocin, this more or less makes the interpretation of the results and comparison between the various studies impossible.

\section{ad 2}

The literature data referring to the effect of epidural anaesthesia on the foetal heart rate pattern are contradictory. In a number of studies some of the patients were observed to exhibit a reduction of the foetal heart rate variability.

On the basis of the literature data, no clear statement can be made about possible changes to the basal foetal heart rate. Epidural anaesthesia may effect the foetal heart rate pattern via a reduction in the uteroplacental perfusion and also via a direct pharmacological effect of the lo il anaesthetic agent on the foetal heart and the foetal central nervous system. Based on cheoretical considerations and literature data, it would seem that there are four possible ways in which the uteroplacental perfusion could be changed by epidural anaesthesia.

\section{a. The development of maternal hypotension during epidural anaesthesia}

If the development of hypotension is prevented as far as is possible by intravenous filling and by having the woman on her side, practically no pathological heart rate patterns arise following administration of epidural anaesthesia.

b. The development of overly strong uterine activity during epidural aneasthesia It appears from animal experiments and from in vitro studies that local anaesthetic 
agents can cause contractions of the myometrium. During epidural anaesthesia, however, haemodynamic, humoral and neurogenic changes arise and each of these can exercise its (sometimes antagonistic) effect on the uterine activity.

For this reason, the direct pharmacological effect of local anaesthetics on the myometrium in studies where epidural anaesthesia is given cannot be quantified separately. Moreover it is possible that women who are receiving epidural anaesthesia are more sensitive to oxytocin.

c. The potential vasoconstrictive effect of the local anaesthetic on the vascular bed of the uterus

It seems justified to suppose that local anaesthetics can produce a vasconstrictive effect in the vascular bed of the uterus. This effect probably occurs only at plasma levells that are not normally reached in epidural anaesthesia.

d. The potential vasoconstrictive effect of adrenaline (added to the local anaestheticon the vascular bed of the uterus

In studying the effect of epidural anaesthesia on uteroplacental circulation, there are two mechanisms that are relevant to adrenaline- induced vasoconstriction.

Firstly the level of catecholamines achieved in the circulation as a result of the addition of adrenaline to the local anaesthetic agent and secondly the effect of pain, fear and tension in the woman on the spontaneous concentration of catecholamines in the circulation. Its probable that adrenaline concentrations (due to resorption from the epidural space) fail to reach that critical level that is needed to produce a reduction in the uteroplacental circulation. Moreover, it cannot be excluded that pain and stress during chilbirth can produce catecholamine levels that reach such a height that the intervillous perfusion does fall.

These factors, pain and stress, are not present- or are present to a much lesser degree-during epidural anaesthesia; thus endogenous catecholamine production will be lower than in woman who have received no pain control. It is possible that sympathetic denervation of the uterus due to epidural anaesthesia partly protects the uteroplacental circulation against vasoconstriction. The switching off of part of sympathetic nervous system, as a result of which there is the above - mentioned favourable effect, aiso has repercussions on the circulatory system of the woman, in the sense that there is a predisposition towards hypotension and as a result of that, a reduction of the uteroplacental perfusion.

Furthermore, the sympathetic denervation of the uterus due to epidural anaesthesia offers no protective effect against a potential vasoconstrictive effect of the local anaesthetic. This effect is not mediated by the innervation of the uterus but is due to a direct pharmacological effect of the local anaesthetic on the vascular wall. The net effect of epidural anaesthesia on the uterus is dependent on the balance between the favourable and unfavourable effects of epidural anaesthesia on the uteroplacental perfusion.

The foetal heart rate pattern can also be influenced by a direct pharmacological effect of the local anaesthetic on the foetal heart and the foetal central nervous system. It 
seems justifiable to suppose that at non-toxic doses local anaesthetics in adults bring about an increase in blood pressure attributable to both increased peripheral vascular resistance and the cardiac output. At toxic doses blood pressure falls and bradycardia develops. It seems very likely that the local anaesthetics have the same action on the foetal cardiovascular system.

The plasma concentration at which negative effects of local anaesthetics arise in the foetal cardiovasculair system is not know. However, an effect on the foetal heart rate pattern attributable to the local anaesthetic agent does not always have to be due to $\mathrm{a}$ direct pharmacological effect on the foetal cardiovascular system but may also be caused by an effect of the local anaesthetic on uteroplacental blood flow or on the foetal central nervous system.

ad 3

In view of the literature data, the conclusion seems jsutified that epidural anaesthesia wholly or partly prevents a shift in the maternal acid-base balance in the direction of metabolic acidosis. In reference to epidural anaesthesia, the literature mentions the following three factors that could have an effect on the maternal acid-base balance.

\section{a. Hyperventilation}

If the childbirth proceeds painiessly because of epidural anaesthesia, the hyperventilation induced by pain will decrease and the effect of hyperventilation on the acid-base ballance wille therefore be lessened.

\section{b. Muscular activity}

During epidural anaesthesia the "motor unrest" of the woman will fall. Furthermore, in epidural anaesthesia the bearing down reflex is wholly or partly absent so that the woman usally bears down less well during the second stage of labour. Both of the above mentioned factors lead to the consequence that during epidural anaesthesia less muscular work is done and because of this a shift of the acid-base balnce in the direction of metabolic acidosis stays wholly or partly away.

\section{c. Catecholamine concentration}

Both animal studies and research in humas shows that administration of adrenaline causes the blood lactate concentration to rise. In view of literature data, it seems that it can be accepted that the stress and the pain which is present in a number of the woman, causes an increase in the catecholamine concentration.

This increase probably does not occur - or occurs to a much lesser extent- in epidural anaesthesia. The interpretation of the literature data concerning the effect of epidural anaesthesia on the foetal acid-base balance is difficult because in most studies the women who served as controls were given other forms of pain control during labour. tal However, it seems probable that in epidural anaesthsia the foetus is protected against metabolic acidosis because the mother is less prone to metabolic acidosis. If uteroplacental perfusion falls during epidural anaesthesia (for exemple due to hypotension or a high concentration of the local anaesthesic in the blood producing vasoconstriction in the 
vascular bed of the uterus) foetal hypoxia may of course develop. A high concentration of the local anaesthetic (due, for example, to injection into one of the veins in the epidural space) may also produce a fall in the cardiac output of the foetal heart and as a result of this, oxygenation of the foetus may be endangered.

ad 4

At present, the most used local anaesthetic in obstetrics is bupivacaine. The molecular weight oi this long-acting local anaesthetic is 324 and the dissociation constant (pKa) is 8.05. Most authors are of the opinion that when bupivacaine is used maternal and foetal concentrations are low.

It is not clear from the literature whether or not the addition of adrenaline to the local anaesthetic affects the concentrations that the local anaesthetic achieves in the blood. The results of the various authors concerning this matter are contradictory. It does seem probable that addition of adrenaline leads to an increase in the intensity and quality of the epidural anaesthesia.

Local anaesthetics are resorbed from the epidural space and may reach and influence other organs via the circulation. In keeping with their function, local anaesthetics have an effect on membranes responsible for electrochemical conduction of impulses. Thus it is the heart and central nervous system whose function can be disturbed by local anaesthetics. The plasma concentration for bupivacaine above which toxic reactions occur has never been definitively determined. Probably it is between $1.6 \mathrm{and} 4 \mu \mathrm{g} / \mathrm{ml}$.

Chapter 6 considers the most important side-effects and complications that epidural anaesthesia may have on the mother. One of the most frequent side-effects is maternal fall in blood pressure. Epidural anaesthesia can exercise an effect on the cardiovascular system maternal mainly in the following three ways:

\section{a. Blockade of a part of the sympathetic nervous system}

This causes a reduction of the peripheral vascular resistance and a reduction in the venous return to the heart. This may be the trigger for a reduction in blood pressure.

\section{b. The effect of the local anaesthetic on the cardiovascular system}

At non-toxic doses, local anaesthetics cause a slight increase in heart rate, cardiac output and peripheral vascular resistance. The result of this is that the blood pressure remains unchanged or rises slightly. At toxic doses, the contractile force of the heart is reduced and the blood pressure falls. The effect of local anaesthetics on the vascular wall is biphasic. At low, non-toxic concentrations vasoconstriction arises and there is an increase in peripheral vascular resistance. At toxic concentrations peripheral vasodilatation occurs and there is a reduction in peripheral vascular resistance.

\section{c. The effect of the added adrenaline on the cardiovacular system.}

The chance of hypotension and the seriousness of it increases if adrenaline has been added to the local anaesthetic. This effect may be attributable to the betamimetic effect that a low concentration of adrenaline causes in the general circulation. 
However, it is also possible that because of the added adrenaline, the quality and the intensity of the epidural anaesthesia increases with a concomittant increase in intensity of the sympathetic blockade. As a result of this the degree of peripheral vasodilatation will also increase.

The percentage of dural perforations is greatly dependent on the experience of the "epiduralist". If the frequency of dural perforations exceeds the one percent mark, then the technique for the epidural puncture and the material used should be re-examined. Headache is the most common symptom after dural perforation. If the dural perforation is not recognised and the dose of the local anaesthetic (intended for the epidural space) is administered subarachnoidally, this may trigger one of the most serious compilcations, the so-called total spinal block.

The extensive vertebral venous plexus is located in the epidural space. Thus darnaging of one of the veins of this plexus is no rarity. An aspiration test via the catheter should always be done in order te prevent intravascular administration of the local anaesthetic. Intravascular administration of the local anaesthetic can lead to toxic phenomena of the central nervous system and cardiovascular system.

Neurological complications attributable to epidural anaesthesia are exceedingly rare. The anterior spinal artery syndrome resulting from epidural anaesthesia has, as far as is known, no yet been reported in an obstetric patient.

Chapter 7 describes the patients and methods of the present study. Because the distribution of the women into the control group and epidural group was not random, there was the possibility that the groups were not properly comparable.

The control group and the epidural group were compared against one another. It appeared that in the control group the membranes werd artificially ruptured in 18 women whereas in the epidural group this was the case for 10 women. This difference is just significant. Furthermore, it emerged that there was a significant difference between the two groups with regard to the time interval between the rupture of the membranes and the start of the investigation. In the control group this time interval amounted to 96 minutes and in the epidural group it was 250 minutes. From this it may probably be concluded that women whose membranes ruptured early in the first stage of labour, whether this was artificially or not, expressed a preference for inclusion in the epidural group. Apart from this no significant differences were found between the two groups. Pain was controlled in the women in the epidural group by a lumbar epidural anaesthesia. At first injection of the local anaesthetic, $10 \mathrm{ml}$ of Marcaine 0.25 percent, to which adrenaline had been added at a concentration of $5 \mu \mathrm{g} / \mathrm{ml}$, was administered. Thereafter a top-up dose of $8 \mathrm{ml}$ was given every two hours.

In this investigation, the effect of epidural anaesthesia was studied on:

1. Foetal heart rate parameters

a. foetal basal heart rate (RR interval length)

b. long term variability (LTI index)

c. short term variability (ID index) 
2. Uterine activity
a. the amplitude
b. the contraction frequency
c. the active pressure area

3. The maternal and foetal acid-base balance

\section{The maternal blood pressure}

\section{The maternal heart rate ( $R R$ interval length)}

The effect of epidural anaesthesia on the above-mentioned parameters was investigated in two ways. Within the epidural group a period prior to administration of epidural anaesthesia was compared with a period following administration of epidural anaesthesia. During particular periods of labour the epidural group was compared with the control group.

Moreover, the concentration of bupivacaine in venous plasma was checked at particular time intervals for fifteen women from the epidural group. In addition, umbilical cord blood was sampled immediately after birth to determine the bupivacaine concentration.

Chapter 8 studies the effect of epidural anaesthesia on the foetal heart rate parameters. It emerged that at the start of the investigation (but before epidural anaesthesia had been administered) there were no significant differences between the two groups with regard to the foetal heart rate parameters.

On comparing the base-line period ( 15 minutes prior to administration of the epidural anaesthesia) with the 120 minute long period following epidural anaesthesia, it emerged that there were no significant changes in the fetal heart rate parameters.

However, in those patients where there was a reduction in systolic blood pressure to below $100 \mathrm{mmHg}(\mathrm{n}=5)$ there was a significant increase in the ID index. This is possibly the result of a reduction in uteroplacental blood flow. In the recent past there has been much emphasis on the correlation that should exist between a redution in foetal heart rate variability and foetal hypoxia. Recent work, however, has revealed that an increase in the heart rate variability may be one of the first signs of foetal hypoxaemia.

During the last 90 minutes of the first stage the foetal heart rate in the epidural group was significantly higher than in the control group. In view of the literature data, this could be the result of a direct pharmacological effect of the local anaesthetic on the foetal heart and foetal central nervous system. However, in this study, no significant correlation was found between the maternal bupivacaine concentration and the extent to which the foetal RR interwal length changed. Another possible explanation for the higher heart rate in the epidural group may be sought in the betamimetic effect of the adrenaline added to the local anaesthetic.

Chapter 5 already reviewed the routes by which epidural anaesthesia can influence 
uteroplacental blood flow. The higher foetal heart rate in the epidural group could also be caused by a reduction in the uteroplacental perfusion. Although it is not possible to make any statement about this on the basis of the present study, it would seem that in view of the following considerations it cannot be accepted that a change in the uteroplacental perfusion is responsible for the difference in foetal heart rate in the two groups.

a. No significant correlation was found between the maternal blood pressure parameters and the foetal RR interval length. It seems therefore that it is improbable that a reduction in the maternal blood pressure has a causal relationship with the difference in foetal heart rates between the two groups.

b. Strong uterine activity may also cause a reduction in the uteroplacental perfusion. The resting intrauterine pressure was not examined in this study so nothing can be said about this. In the control group however, there was a significant increase in amplitude and active pressure area (Chapter 9). In the epidural group this increase remained absent. It seems unlikely therefore that the uteroplacental blood flow is negatively effected by the uterine activity.

c. As is shown in the literature data, local anaesthetics at high doses can produce a vasoconstrictive effect in the vascular bed of the uterus. This effect probably occurs at concentrations that are not usually reached in epidural anaesthesia. In this study, the bupivacaine concentrations that were measured were low in comparison with the literature data (Chapter 11) but a slight reduction in the uteroplacental circulation can of course not be ruled out with certainty.

d. The adrenaline that is added to the local anaesthetic and then resorbed from the epidural space could unfavourable effect the uteroplacental circulation.

In human studies however, this appears not to be the case.

During the last ninety minutes of the first stage of labour the LTI index in the epidural group was lower than in the control group. Most authors are of the opinion that a reduction in the foetal heart rate variability is caused by a direct pharmacological effect of the local anaesthetic on the foetal myocardium.

However, it is also possible that the local anaesthetic has a negative effect on the uteroplacental perfusion, as a result of which the foetal condition deteriorates and the heart rate variability may change. In this study, a very significant positive correlation was found between the course of the bupivacaine concentration in the maternal plasma and the LTI index.

Immediately after administration of the epidural anaesthesia a short- lasting, non significant increase in the $L T I$ index occured. The maximun increase was reached at the point where the bupivacaine concentracion was at its highest.

Thereafter both the LTI index and the bupivacaine concentration fell. The ID index also exhibited a short-lasting, non-significant increase following administration of the epidu- 
ral anaesthesia. According to the literature data, a temporary increase in heart rate variability may be the initial expression of foetal hypoxaemia.

Thus it cannot be excluded that epidural anaesthesia may to a slight extent negatively influence the foetal condition. The fact that the foetal $\mathrm{pH}$ at full dilatation was significantly higher in the control group than in the epidural group is in keeping with this. The foetomaternal difference in $\mathrm{pH}$ was also significantly smaller in the control group than in the epidural group (Chapter 10 ). The heart rate variability can of course also be effected by a direct pharmacological effect of the local anaesthetic on the central nervous system of the foetus. However, it is not possible to support this hypothesis further with the results that were obtained in the present study.

In this study, no significant correlation was found between the maternal blood pressure parameters and the LTI index.

Chapter 9 studies the effect of epidural anaesthesia on the contraction parameters. Just as with the foetal heart rate parameters, there were no pre-existent differences between the two groups.

On comparison of the 30 minute base-line period prior to administration of the epidural anaesthesia with the 120 minute long observation period following administration of epidural anaesthesia it emerged that there were no significant differences. However in the first 30 minutes following epidural anaesthesia a significant reduction of the amplitude and a significant increase in the contraction frequency occurred.

In this study, no significant correlations could be found between the maternal blood pressure parameters and the contraction parameters. Even in those five women who experienced a reduction in blood pressure to less than $100 \mathrm{mmHg}$, no significant changes in the contraction parameters occurred. No significant changes occurred in the contraction parameters of those women with a high hypalgesia level $\left(>\mathrm{T}_{7}\right)$ nor in women who received one or more top-up doses.

In view of the literature data and the results of the present study, it seems likely that the addition of adrenaline to the local anaesthetic is responsible for the differences in uterine activity between the two groups. Although the uterine activity (amplitude, active pressure area) in the epidural group was retarded in comparison with the control group, the time interval between starting investigation and full dilatation was not significantly different in the two groups. The average dilatation at the start of investigation was practically the same in the two groups.

Chapter 10 studies the effect of epidural anaesthesia on the maternal and foetal acid-base balance. In the epidural group no significant changes occurred in the maternal acid-base balance during the first stage of labour. In contrast, in the control group the base excess and the $\mathrm{pCO}_{2}$ fell significantly. The reduction in $\mathrm{pCO}_{2}$ is the consequence of hyperventilation that occurs during painful contractions of the uterus. Thus, this $\mathrm{pCO}_{2}$ fall would not occur in the epidural group. The $\mathrm{pH}$ of the women in the control group did not change significantly during the first stage of labour. This is because of the development of progressive metabolic acidosis in the control group which manifests itself in a significant reduction of base excess. 
The metabolic acidosis may be partly compensatory but most authors are of the opinion that an increase in lactate occurring during childbirth is the cause of metabolic acidasis. It is possible that the muscalar activity of the woman (because of pain) or the elevated catecholamine production (because of pain and stress) have a causal relationship with the reduction of the base excess. These factors are either not present in epidural anaesthesia or are present to a lesser degree and because of this, the metabolic acidosis does not develop. In the control group there was a significant shift in the acid-base ballance towards metabolic acidosis during the second stage of labour. In contrast to this, in the epidural group no significant changes occured. Because of muscular activity during bearing down, there is an increase in lactate concentration and because of this, metabolic asidosis. In the women in the epidural group the bearing down reflex is wholly or partly inhibited and because of this they are less able to assist in bearing down. This probably explains the fact that there is no metabolic acidosis in the epidural group.

Although at full dilatation the $\mathrm{pH}$ of the mothers in both groups was the same, there was a significant difference between the two groups from the point of view of the foetal $\mathrm{pH}$. The average $\mathrm{pH}$ in the epidural group $(7.35 \pm 0.05)$ was significantly lower than in the control group (7.39 \pm 0.04 ). During the second stage of labour in the control group significant changes in the foetal acid-base balance occurred in the direction of metabolic acidosis. This was probably a reflection of the changes in the acid-base balance of the mother. In the epidural group no significant changes occured in the foetal acid-base balance during the second stage. At birth there were no longer any significant differences in foetal acid-base balance between the two groups.

Chapter 11 studies the course of bupivacaince concentrations in the maternal venous plasma $(n=15)$. The maximum bupivicaine concentration was reached between 10 and 30 minutes after administation of the epidural anaesthesia. The maximum bupivacaine concentration was on average $216 \pm 65 \mu \mathrm{g} / 1$. Six of the 15 women received one or more top-up doses. The highest concentration of bupivacaine measured after a top-up dose was $395 \mu \mathrm{g} / 1$.

The toxic plasma concentration for bupivacaine has never been definitively determined. In view of the literature data, the toxic threshold concentration is probably between 1600 and $4000 \mu \mathrm{g} / \mathrm{l}$.

The threshold concentrarion above which there occurs a reduction in the uteroplacental blood flow is not known for humans. In animal experiments (sheep) a reduction of 25 percent of the uteroplacental blood flow occurs at an arterial blood concentration of $1000 \mu \mathrm{g} / 1$ (Greiss et al., 1976). Of course, this observation does not have the same validity in the human situation. In paracervical anaesthesia it is possible for a high concentration of the local anaesthetic to be achieved in the uterine artery and this could then trigger a reduction in the uteroplacental blood flow. Bradycardia and hypoxia of the foetus could arise as a result of this. It emerges from the literature that epidural anaesthesia probably does not affect uteropiacental blood flow in a negative way provided that maternal hypotension is avoided. However, if the epidural catheter comes to lie in one of the veins of the extensive internal vertebral plexus then it is possible for 
such high concentrations of the local anaesthetic to arise that the uteroplacental blood flow would be threatened.

The literature data shows that the maximum foetal bupivacaine concentration is reached between 10 and 30 minutes after administation of the epidural anaesthesia (Belfrage et al., $1975 \mathrm{a}$ ). In this study the average quotient of the bupivacaine concentration in the umbilical cord plasma and the maternal plasma was $0,30 \pm 0,06$. This is in agreement with the literature data.

Chapter 12 deals with the effect of epidural anaesthesia on the maternal blood pressure and heart rate. It appears that after administration of epidural anaesthesia the maternal systolic blood pressure, the maternal diastolic blood pressure and the maternal mean arterial pressure fall. This significant fall in blood pressure occurred despite an intravenous infusion of $400 \mathrm{ml}$ isotonic saline solution and having the woman lie on their sides. In five of the woman the systolic blood pressure fell to below $100 \mathrm{mmHg}$. In one woman the systolic blood pressure fell to below $80 \mathrm{mmHg}$.

The maternal heart rate increases significantly following administration of epidural anaesthesia.

Epidural anaesthesia may effect the maternal cardiovascular system via the following routes:

1. Sympathetic blockade as a result of wich peripheral vasodilatation occurs and sometimes a reduction in blood pressure.

2. Blockade of the sympathetic innervation of the heart $\left(T_{1}-T_{5}\right)$, as a result of which the heart rate and the contraction force diminish. These five uppermost thoracic spinal segments are only rarely blocked in obstetric epidural anaesthesia.

3. Resorption of adrenaline (added to the local anaesthetic) from the epidural space. The betamimetic action of adrenaline may lead to an increase of the cardiac output and a reduction in peripheral vascular resistance.

4. Resorption of the local anaesthetic from the epidural space. At non-toxic concentrations of the local anaesthetic this results in a slight increase in the cardiac output, heart rate and peripheral vascular resistance.

5. Blockade of the innervation of the adrenal gland $\left(T_{5}-L_{2}\right)$. This probably results in a reduction of catechollamine output.

6. The removal of childbirth pain may trigger a reduction in heart rate.

The fall in blood pressure is probably mainly responsible for the increase in the heart rate. The pharmacological effect of the local anaesthetic and the added adrenaline resorbed from the epidural space may also contribute to the increase in the maternal heart rate. 


\section{References}

Abouleish, E.: Pain control in obstetrics. Philadelphia, J.B. Lippincott Company, 1977.

Abouleish, E.: Epidural blood patch for the treatment of chronic post-lumbar-puncture cephalgia. Anesthesiology 49: 291, 1978.

Abouleish, E., De la Vega, S., Blandiger, I., and Tio, T.O.: Long-term follow-up of epidural blood patch. Anesth. Analg. 54: 459, 1975.

Abouleish, E., Amortegui, A.J., and Taylor, F.H.: Are bacterial filters needed in continuous epidural analgesia for obstetrics? Anesthesiology 46: 351, 1977.

Albright, G.A., Jouppila, R., Hollmen, A.I., Jouppila, P., Vierola, H., and Koivula, A.: Epinephrine does not alter human intervillous blood flow during epidural anaesthesia. Anesthesiology 54: 131, 1981.

Alexander, J.A., and Franklin, R.R.: Effects of caudal anesthesia on uterine activity. Obstet. Gynecol. 27: 436, 1966.

Andersson, K.E., Gennser, G., and Nilsson, E.: Influence of mepivacaine on isolated human foetal hearts at normal and low pH. Acta Physiol. Scand. (Suppl. 353), 80: 34, 1970.

Armstrong, C.M., Bezanilla, F., and Rojos, E.: Destruction of sodium conductance inactivation in squid axons perfused with pronase. J. Gen. Physiol. 62: 375, 1973.

Bart, A.J., and Wheeler, A.S.: Comparison of epidural saline placement and epidural blood placement in the treatment of post-lumbar-puncture headache. Anesthesio$\log y$ 48: 221,1978 .

Baumgarten, K., Tempfer, H., Frhlich, H., and Neumark, J.: Kardiotokogramme unter epiduralanaesthesie (Untersuchungen ber den effect der epidural anaesthesie auf die Wehentätigkeit und die fetale herzfreauenz). In Neumark, J. (ed.): Analgesie und Anaesthesie in der Perinatologie. Wien, München, Bern, Verlag Wilhelm Maudrich, 1978, pp. 79-99.

Beard, R.W., Filskie, G.M., Knight, C.A., and Roberts, G.M.: The significance of the changes on the continuous fetal heart rate in the first stage of labour J. Obstet. Gynaecol. Brit. Cwlth. 78: 865, 1971.

Belfrage, P., Raabe, N., Thalme, B., and Berlin, A.: Lumbar epidural analgesia with bupivacaine in labor. Determination of drug concentration and $\mathrm{pH}$ in fetal scalp 
blood, and continuous fetal heart rate monitoring. Amer. J. Obstet. Gynecol. 121 : $360,1975-$ a.

Belfrage, $\mathbb{P}_{.,}$Berlin, A., Raabe, $N_{\text {., }}$ and Thalme, B.: Lumbar epidural analgesia with bupivacaine in labor. Drug concentration in maternal and neonatal blood at birth and during the first day of life. Amer. J. Obstet. Gynecol. 123: 839, 1975-b

Belfrage, $\mathbb{P}$. , Irestedt, $\mathrm{L}_{\text {., }}$ and Berlin, A.: Concentration of bupivacaine in arterial and venous plasma after epidural anaesthesia in man and after intramuscular administration in dogs. Acta Anaesth. Scand. 19: 1975-c.

Bonica, J.J.: Principles and practice of obstetric analgesia and anesthesia. Philadelphia, F.A. Davis Company, 1972.

Bonica, J.J., Berges, P.U., and Morikawa, K.: Circulatory effects of peridural block. I. Effects of level of analgesia and dose of lidocaine. Anesthesiology 33: 619, 1970.

Bonica, J.J., Akamatsu, T.J., Berges, P.U., Morikawa, K., and Kennedy, W.F.: Circulatory effects of peridural block. II. Effects of epinephrine. Anesthesiology 34: 514, 1971.

Bonica, J.J., Kennedy, W.F., Akamatsu, T.J., and Gerbershagen, H.U.: Circulatory effects of peridural block. III. Effects of acute blood loss. Anesthesiology 36: 219, 1972.

Boehm, F.H., and Growdon, J.H.: The effect of scopolamine on fetal heart rate baseline variability. Amer. J. Obstet. Gynecol. 120: 1099, 1974.

Boehm, F.H., Woodruff, L.F., and Growdon, J.H.: The effect of lumbar epidural anesthesia on fetal heart rate baseline variability. Anesth. Analg. 54: 779, 1975.

Bromage, P.R.: Epidural analgesia. Philadelphia, W.B. Saunders Company, 1978.

Brotanek, V., Vasicka, A., Santiago, A., and Brotanek, J.: The influence of epidural anesthesia on uterine blood flow. Obstet. Gynecol. 42: 276, 1973.

Buckley, F.P., Littlewood, A.G., Covino, B.G., and Scott, D.B.: Effects of adrenaline and the concentration of solution on extradural block with etidocaine. Brit. $J$. Anaesth. 50: 171, 1978.

Caldeyro-Barcia, R., Noriega-Guerra, L., Cibils, L.A., Alvarez, H., Poseiro, J.J., Pose, S.V., Sica-Blanco, Y., Mendez-Bauer, C., Fielitz, C., and Conzales-Panizza, V.H.: Effect of position changes on the intensity and frequency of uterine contractions during labor. Amer. J. Obstet. Gynecol. 80: 284, 1960. 
Carrie, L.E.S., and Mohan, J.: Horner's syndrome following obstetric extradural block. Brit. J. Anaesth. 48: 611, 1976.

Catterberg, J., and Insausti, T.: Paraplejias consecutivas a anestesia peridural (estudio clinico y experimental). Rev. Assoc. Med. Argent. 78: 1, 1964.

Celander, $\mathrm{O}$. : The range of control exercised by the sympathico-adrenal system. A quantitative study on blood vessels and other smooth muscle effectors in the cat. Acta Physiol. Scand. (Suppl. 116) 32: 1, 1954.

Chang, A., and Wood, C.: Fetal acid-base balance. I. Interdependence of maternal and fetal pCO2 and bicarbonate concentration. Amer. J. Obstet. Gynecol. 125: 61, 1976.

Cibils, L.A.: Clinical significance of fetal heart rate patterns during labor. Amer. J. Obstet. Gynecol. 125: 290, 1976-a.

Cibils, L.A.: Response of human uterine arteries to local anesthetics. Amer. J. Obstet. Gynecol. 126: 202, 1976-b.

Cibils, L.A., and Spackman, T.J.: Caudal analgesia in first-stage labor: Effect on uterine activity and the cardiovascular system. Amer. J. Obstet. Gynecol. 84: 1042, 1962.

Cleland, J.G.P.: Paravertebral anesthesia in obstetrics. Experimental and clinical basis. Surg. Gynecol. Obstet. 57: 51, 1933.

Collier, C.B.: Horner's syndrome following obstetric extradural block analgesia. Anesthesia 47: 1342, 1975.

Collins, K.M., Bevan, D.R., and Beard, R.W.: Fluid loading to reduce abnormalities of fetal heart rate and maternal hypotension during epidural analgesia in labour. Brit. Med. J. 2: 1460, 1978.

Comline, R.S., and Silver, M.: The composition of foetal and maternal blood during parturition in the ewe. J. Physiol. 222: 233, 1972.

Covino, B.G., Clinical pharmacology of local anesthetic agents. Advances in regional anaesthesia. In Poppers, P.J., and van Dijk, B. (eds.): Proceedings of the International Symposium on local anaesthetics and regional anaesthesia. The Hague, 1977.

Covino, B.G., Vassallo, H.G.: Local anesthetics. Mechanisms of action and clinical use. New York, Grune and Stratton inc. 1976. 
Craft, J.B., Epstein, B.S., and Coakley, C.S.: Effect of 1 idocaine with epinephrine versus lidocaine (plain) on induced labor. Anesth. Analg. 51: 243, 1972.

Craft, J.B., Epstein, B.S., and Coakley, C.S.: Prophylaxis of dural-puncture headache with epidural saline. Anesth. Analg. 52: 228, 1973.

Crawford, J.S.: Lumbar epidural block in labour: a clinical analysis. Brit. J. Anaesth. 44: $66,1972-\mathrm{a}$.

Crawford, J.S.: The second thousand epidural blocks in an obstetric hospital practice. Brit. J. Anaesth. 44: 1277, 1972-b.

Crawford, J.S.: Principles and practice of obstetric anaesthesia. Oxford, Blackwel Scientific Publications, 1978.

Dalton, K.J., Dawes, G.S., and Patrick, J.: Foetal heart rate variation in sheep. J. Physiol. 256: 37 p., 1976.

Dick-Read, G.: Natural Childbirth. London, William Heinemann, Ltd., 1933.

Dick-Read, G.: Childbirth without fear. New York, Harper and Row, 1959.

Doughty, A.: The organisation and structure of an obstetric epidural servise. In Huisjes, H.J. (ed.): Proceedings van het symposium, Epidurale analgesie -een vorm van pijnbestrijuing in de verloskunde. 's-Gravenhage, 1980.

Dijkhuizen, G.H.: Melkzuur en baring. Thesis, Amsterdam, 1979.

Eichenholz, A., Mulhausen, R.D., Anderson, W.E., and MacDonald, F.M.: Primary hypocapnia: A cause of metabolic acidosis. J. Appl. Physiol. 17: 283, 1962.

af Ekenstam, B., Egner, B., and Petterson, G.: Local Anaesthetics I. N-Alkyl-pyrrolidine and $\mathrm{N}$-alkyl piperidine carboxylic acid amides. Acta Chem. Scand. 11:1.183, 1957.

Eldridge, $F$, and Salzer, $J$.: Effect of respiratory alkalosis on blood lactate and pyruvate in humans. J. Appl. Physiol. 12: 461, 1967.

Englesson, S.: The influence of acid-base changes on central nervous system toxicity of local anaesthestic agents. l. An experimental study in cats. Acta Anaesth. Scand. 18: $79,1974$.

Falconer, A.D., and Powles, A.B.: Plasma noradrenaline levels during labour. Influence of elective lumbar epidural blockade. Anaesthesia 37: 416, 1982. 
Fernandez-Sepulveda, R., and Gomez-Rogers, C.: Single-dose caudal anesthesia. Its effect on uterine contractility. Amer. J. Obstet. Gynecol. 98: 847, 1967.

Finster, M., Morishima, H.O., Boyes, R.N., and Covino, B.G.: The placental transfer of lidocaine and its uptake by fetal tissues. Anesthesiology 36: 159, 1972.

Fisch, L., Sala, N.K., and Schwarcz, R.L.: Effect of cervical dilatation upon uterine contractility in pregnant women and its relation to oxytocin secretion. Amer. J. Obstet. Gynecol. 90: 108, 1964.

Fisher, A., and Prys-Roberts, C.: Maternal pulmonary gas exchange. Anaesthesia 23: $350,1968$.

Gall, D., Choudhry, R., Ung, K.A., Abadir, A., and Tancer, M.L.: Segmental epidural analgesia for labor and delivery. Acta Obstet. Gynecol. Scand. 58: 429, 1979.

Geerinckx, K., Vanderick, G., Van Steenberge, A.L., Bouche, R., and De Muylder, E.: Bupivacaine $0.125 \%$ in epidural block analgesia during childbirth: Maternal and foetal plasma concentrations. Brit. J. Anaesth. 46: 939, 1974.

van Geyn, H.P., Jongsma, H.W., De Haan, J., and Eskes, T.K.A.B.: Analysis of heart rate and beat-to-beat variability: Interval difference index. Amer. J. Obstet. Gynecol. 138: $246,1980$.

Gibbs, C.P., and Noel, S.C.: Response of arterial segments from gravid human uterus to multiple concentrations of lignocaine. Brit. J. Anaesth. 49: 499, 1977.

Goodlin, R.C., and Kaiser, I.H.: The effect of ammonium chloride induced maternal acidosis on the human fetus at term: I. pH, Hb, bloodgases. Amer. J. Med. ScI. 233: $662,1957$.

Gormley, J.B.: Treatment of postspinal headache. Anesthesiology 21: 565, 1960.

Greene, N.M.: Lactate, pyruvate and excess lactate production in anesthetized man. Anesthesiology 22: 404, 1961.

Greiss, F.C.: The uterine vascular bed: Effect of adrenergic stimulation. Obstet. Gynecol. 21: $295,1963$.

Greiss, F.C., and Gobble, F.L.: effect of sympathetic nerve stimulation on the uterine vascular bed. Amer. J. Obstet. Gynecol. 97: 962, 1967.

Greiss, F.C., Still, J.G., and Anderson, S.G: Effects of local anesthetic agents on the uterine vasculatures and myometrium. imer. J. Obstet. Gynecol. 124: 889, 1976. 
Grove, L.H.: Backache, headache and bladder dysfunction after delivery. Brit. J. Anaesth. 45: 1147, 1973.

de Haan, J.: De snelle variaties in het foetale hartfrequentie patroon. Thesis, Free University Amsterdam, 1971.

Hammacher, H.: In Huntingford, P., Hüter, K., and Saling, E. (eds.): Perinatal Medicine, Stuttgart, George Thieme Verlag, 1969, pp 80-93.

Head, H.: On disturbances of sensation with special reference to the pain of visceral disease. Brain 16: 1, 1893.

Heavner, J.E., and De Jong, R.H.: Lidocaine blocking concentrations for B- and C-nerve fibers. Anesthesiology 40: 228, 1974.

Hehre, F.W., Hook, R., and Hon, E.H.: Continuous lumbar peridural anesthesia in obstetrics. VI: The fetal effects of transplacental passage of local anesthetic agents. Anesth. Analg. 48: 909, 1969.

Hendricks, C.H., Cibils, L.A., Pose, S.V., and Eskes, T.K.A.B.: The pharmacologic control of excessive uterine activity with isoxsuprine. Amer. J. Obstet. Gynecol. 82: 1064, 1961.

Henry, J.S., Kingston, M.B., and Maughan, G.B.: The effect of epidural anesthesia on oxytocin-induced labor. Amer. J. Obstet. Gynecol. 97: 350, 1967.

Hollmén, A.: The placental transfer of bupivacaine and lidocaine and their myocardial and cerebral uptake in the rabbit. Acta Anaesth. Scand. 17: 149, 1973.

Hollmén, A., Jouppila, R., Jouppila, P., Koivula, A., and Vierola, H.: Effect of extradural analgesia using bupivacaine and 2-chloroprocaine on intervillous blood flow during normal labour. Brit. J. Anaesth. 54: 837, 1982.

Holm, J.P.: Epidurale analgesie bij risico-bevallingen. Thesis, Groningen, 1982.

Hon, E.H.: An atlas of fetal heart rate patterns. New Haven, Harky Press-Inc., 1968.

Hon, E.H., Reid, B.L., and Hehre, F.W.: The electronic evaluation of fetal heart rate. II. Changes with maternal hypotension. Amer. J. Obstet. Gynecol. 79: 209, 1960.

Humphrey, M., Hounslow, D., Morgan, S, and Wood, C.: A. The influence of maternal posture at birth on the fetus. J. Obstet. Gynaecol. Brit. Cwlth. 80: 1075, 1973. 
Humphrey, M.D., Chang, A., Wood, E.C., and Hounslow, D.: A decrease in fetal pH during the second stage of labour, when conducted in the dorsal position. J. Obstet. Gynaecol. Brit. Cwlth. 81: 600, 1974.

Huovinen, K., Kivalo, I., and Teramo, K.: Fetal effects of lumbar epidural block. In G. Rooth (ed.): Abstracts of free communications. Fifth European congress of perinatal medicine. Stockholm, Almqvist and Wiksel International, 1976, p. 62.

Husemeyer, R.P., and Crawley, J.C.W.: Placental intervillous blood flow measured by inhaled $133 \mathrm{Xe}$ clearance in relation to induction of epidural analgesia. Brit. J. Obstet. Gynaecol. 86: 426, 1979.

Hyman, M.D., and Shnider, S.M.: Maternal and neonatal blood concentrations of bupivacaine associated with obstetrical conduction anesthesia. Anesthesiology 34: $81,1971$.

Irestedt, L., Lagercrantz, H., Hjemdahl, P., Hägnevik, K., and Belfrage, P.: Fetal and maternal plasma catecholamine levels at elective cesarean section under general or epidural anesthesia versus vaginal delivery. Amer. J. Obstet. Gynecol. 142: 1004, 1982.

Jacobson, $\mathbb{L}$., and Rooth, G.: Interpretative aspects on the acid-base composition and its variation in fetal scalp blood and maternal blood during labour. J. Obstet. Gynaecol. Brit. Cwlth. 78: 971, 1971.

de Jong, R.H.: Effects of lidocaine on spontaneous cortical and subcortical electrical activity. Arch. Neurol. 28: 277, 1968.

de Jong, R.H.: Local anesthetic seizures. Anesthesiology 30: 5, 1969.

de Jong, R.H., and Heavmer, J.E.: Diazepam and Lidocaine-induced cardiovascular changes. Anesthesiology 39: 633, 1973.

Jongsma, H.W., Van Geyn, H.P., and de Haan, J.: The analysis of heart rate variability in the perinatal period. In Krause, W. (ed.): Computerdiagnostik in der Geburtsmedizin. Friedrich Schiller Universität Jena, 1978, p. 249.

Jorfeldt, L., Löfström, B., Pernow, B., Persson, B., Wahren, J., and Widman, B.: The effect of local anaesthetics on the central circulation and respiration in man and dog. Acta Anaesth. Scand. 12: 153, 1968.

Jouppila, R., and Hollmén, A.: The effect of segmental epidural analgesia on maternal and foetal acid-base balance, lactate, serum potossium and creatine phosphokinase during labour. Acta Anaesth. Scand. 20: 259, 1976. 


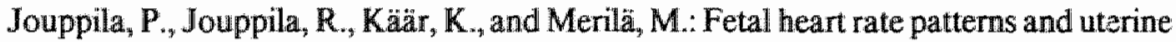
activity after segmental epidural analgesia. Brit. J. Obstet. Gynaecol. 84: 481, 1977.

Jouppila, P., Jouppila, R., Hollmén, A., and Koivula, A.: Lumbar epidural analgesia to improve intervillous blood flow during labor in severe praeclampsia. Obstet. Gynecol. 59: 158,1982 .

Jouppila, R., Jouppila, P., Kuikka, J, and Hollmen, A.: Placental blood flow during Caesarean section under lumbar extradural analgesia. Brit. J. Anaesth. 50: 275, 1978-a.

Jouppila, R., Jouppila, P., Hollmên, A., and Kuikka, J.: Effect of segmental extradural analgesia on placental blood flow during normal labour. Brit. J. Anaesth. 50: 563, 1978-b.

Jouppila, R., Pihlajaniemi, R., Hollmén, A., and Jouppila, P.: Segmental epidural analgesia and post partum sequelae. Ann. Chir. Gynaecol. 67: 85, 1978-c.

Jouppilla, R., Jouppila, P., Kotiniemi, L., Puolakka, J., Puukka, J., and Puukka, R.: Maternal and fetal plasma bupivacaine concentrations in labour with segmental epidural analgesia. Ann. Chir. Gynaecol. 67, 190, 1978-d.

Jouppila, R., Jouppila, P., Hollmén, A., and Koivula, A.: Epidural analgesia and placental blood flow during labour in pregnancies complicated by hypertension. Brit. J. Obstet. Gynaecol. 86: 969, 1979.

Joyce, T., Aquine, N., and Kuchlini, A.: The effects of local anaesthetics on grand human artery strips in vitro. Abstracts of Scientific Papers, American Society of Anesthesiologists. Annual Meeting, 1976, p. 539.

Kennedy, R.L., Erenberg, A., Robillard, J.E., Merkow, A., and Turner, T.: Effects of changes in maternal-fetal $\mathrm{pH}$ on the transplacental equilibrium of bupivacaine. Anesthesiology 51: 50, 1979.

Kubli, F.W.: Influence of labor on fetal acid-base balance. Clin. Obstet. Gynecol. 11: $168,1968$.

Kurver, P.H.J.: Digital processing of the fetal heart rate and the intrauterine pressure. In Krause, W. (ed.): Computer diagnostik in der Geburtsmedizin. Friedrich Schiller Universität Jena, 1968. p; 60 .

Kusaka, M., and Ui, M.: Activation of the cori cycle by epinephrine. Amer. J. Physiol. 232: 145, 1977. 
Lamaze, F.: L'experience francaise de 13accouchement sans douleur. Bull. Circle Claude Bernard. 8: 2, 1954.

Lamaze, F., and Vallay, P.: L'accouchement sans douleur par la methode psychophysique. Premiers resultats partant sur 500 cas. Gaz. Med. Fr. 59: 1445, 1952.

Lavin, J.P., Samuels, S.V., Miodovnik, M., Holroyde, J., Loon, M., and Joyce, T.: The effects of bupivacaine and chloroprocaine as local anesthetics for epidural anesthesia on fetal heart rate monitoring parameters. Amer. J. Obstet. Gynecol. 141:717, 1981.

Lederman, R.P., Mc. Cann, D.S., Work, B., and Huber, M.J.: Endogenous plasma epinephrine and norepinephrine in last-trimester pregnancy and labor. Amer. J. Obstet. Gynecol. 129: 5, 1977.

Lederman, R.P., Lederman, E., Work, B.A., and Mc. Cann, D.S.: The relationship of maternal anxiety, plasma catecholamines, and plasma cortisol to progress in labor. Amer. J. Obstet. Gynecol. 132: 495, 1978.

Levinson, G., Shnider, S.M., De Lorimier, A.A., and Steffenson, J.L.. effects of maternal hyperventilation on uterine blood flow and fetal oxygenation and acid-base status. Anesthesiology 40: 340, 1974.

Löfström, B., Wennberg, A., and Widen, L.: Late disturbances in nerve function after block with local anaesthetic agents. An electroneurographic study. Acta Anaesth. Scand. 10: 111, 1966.

Low, J.A., Pancham, S.R., Worthington, D., and Boston, R.V.: Acid-base lactate and pyruvate characteristics of the normal obstetric patient and fetus during the intrapartum period. Amer. J. Obstet. Gynecol. 120: 862, 1974.

Lowensohn, R.I., Paul, R.H., Fales, S., Yeh, S., and Hon, E.H.: Intrapartum epidural anesthesia an evaluation of effects on uterine activity. Obstet. Gynaecol. 44: 388, 1974.

Lumley, J., Renou, P., Newman, W., and Wood, C.: Hyperventilation in obstetrics. Amer. J. Obstet. Gynecol. 103: 847, 1969.

Lumley, J., and Wood, C.: Effect of changes in maternal oxygen and carbon dioxide tensions on the fetus. Clinical anesthesia 10/2: 121, 1973.

Macraé, D.J., and Bekhit, S.M.: The biochemical effects on mother, fetus and baby of maternal hyperventilation and inhalation of oxygen during labour. Medikon. VII: 5, 1978. 
Magno, R., Berlin, A., Karlsson, K., and Kjellmer, I.: Anesthesia for Cesarean section. IV. Placental transfer and neonatal elimination of bupivacaine following epidural analgesia for elective Cesarean section. Acta Anaesth. Scand. 20: 141, 1976.

Maltau, J.M.: The frequency of fetal bradycardia during selective epidural anaesthesia. Acat Obstet. Gynaecol. Scand. 54: 357, 1975.

Martin, C.B., de Haan, J., Jongsma, H.W., van der Wildt, B., Evers, J.L.H., Dieleman, A., and Arts, T.H.M.: Quantitative investigation of the effect of hypoxemia on FHR variability indices in fetal lambs. In: Abstr. 26th Annual Meeting Soc. Gynecol. Invest. San Diego, CA, 1979, p. 193.

Marx, G.F.: Childbirth in the nineteen-eighties. Regional anesth. 6: 67, 1981.

Matadial, L., and Cibils, L.A.: The effect of epidural anesthesia on uterine activity and blood pressure. Amer. J. Obstet. Gynecol. 125: 846, 1976.

Mather, L.E., Long, G.J., and Thomas, J.: The binding of bupivacaine to maternal and foetal plasma proteins. J. Pharm. Pharmacol. 23: 359, 1971.

Mather, L.E., Tucker, G.T., Murphy, T.M., Stanton-Hicks, M., and Bonica, J.J.: The effects of adding adrenaline to etidocaine and lignocaine in extradural anaesthesia. II: Pharmacokinetics. Brit. J. Anaesth. 48: 989, 1976.

Mc. Caughey, H.S., Corey, E.L., Eastwood, D., and Thornton, W.N.: Effects of synthetic anesthetics on the spontaneous motility of human uterine muscle in vitro. Obstet. Gynecol. 19: 233, 1962.

Mc. Donald, J.S., Bjorkman, L.L., and Reed, E.C.: Epidural analgesia for obstetrics. A maternal fetal and neonatal study. Amer. J. Obstet. Gynecol. 120: 1055, 1974.

Mc. Guinness, G.A., Merkow, A.J., Kennedy, R.L., and Erenberg, A.: Epidural anesthesia with bupivacaine for Cesarean section: neonatal blood levels and neurobehavioral responses. Anesthesiology 49: 270, 1978.

Mendez-Bauer, C., Arroyo, J., Menndez, A., Salmean, J., Manas, J., Lavilla, M., Martinez San Martin, S., Villa Elizaga, I., and Zamarriego Crespo, J.: Effects of different maternal positions during labour. In Rooth, G., and Bratteby, L.E. (eds.): Perinatal Medicine. Stockholm, Almqvist and Wiksell international, 1976, pp. 233-237.

Miller, F.C., Petrie, R.H., Arce, J.J., Paul, R.H., and Hon, H.E.: Hyperventilation during labor. Amer. J. Obstet. Gynecol. 120: 489, 1974. 
Miller, F.C., Yeh, S., Schifrin, B.S., Paul, R.H., and Hon, E.H.: Quantitation of uterine activity in 100 primiparous patients. Amer. J. Obstet. Gynecol. 124: 398, 1976.

Miller, F.C., Quesnel, G., Petrie, R.H., Paul, R.H., and Hon, E.H.: The effects of paracervical block on uterine activity and beat-to-beat wariability of the fetal heart rate. Amer. J. Obstet. Gynecol. 130: 284, 1978.

Mohan, J., and Potter, J.M.: Pupillary constriction and ptosis following caudal epidural analgesia. Anaesthesia 30: 769, 1975.

Moir, C.: The nature of the pain of labour. J. Obstet. Gynaec. Brit. Emp. 46:409, 1939.

Moir, D.D.: Obstetric anaesthesia and analgesia. London, Baillière Tindall, 1976.

Moir, D.D., and Davidson, S.: Postpartum complications of forceps delivery performed under epidural and pudendal nerve block. Brit. J. Anaesth. 44: 1197, 1972.

Moore, D.C., Bridenbaugh, L.D., Bridenbaugh, P.O., and Tucker, G.T.: Bupivacaine hydrochloride: Laboratory and clinical studies. Anesthesiology 32: 78, 1970.

Moore, D.C., Bridenbaugh, L.D., Bridenbaugh, P.O., and Tucker, G.T.: Caudal and epidural blocks with bupivacaine for childbirth. Report of 657 parturients. Obstet. Gynecol. 37: 667, 1971.

Moore, D.C., Mather, L.E., Bridenbaugh, L.D., Thompson, G.E., Balfour, R.I., Lysons, D.F., and Horton, W.G.: Bupivacaine (Marcaine): An evaluation of its tissue and systemic toxicity in humans. Acta Anaesth. Scand. 21: 109, 1977.

Munson, E.S., Tucker, W.K., Ausinsch, B., and Malagodi, M.H.: Etidocaine, bupivacaine and lidocaine seizure threshold in monkeys. Anesthesiology 42: 471, 1975.

Narahashi, T., Frazier, D.T., and Yamada, M.: The site of action and active form of local anesthetics. I. Theory and $\mathrm{pH}$ experiments with tertiary compounds. J. Pharmacol. Exp. Ther. 171: 32, 1970.

Newman, W., Braid, D., and Wood, C.: Fetal acid-base status. I. Relationship between maternal and fetal pCO2. Amer. J. Obstet. Gynecol. 97: 43, 1967-a.

Newman, W., Mitchell, P., and Wood, C.: Fetal acid-base status. II. Relationship between maternal and fetal blood bicarbonate concentrations. Amer. J. Obstet. Gynecol. 97: 52, 1967-b.

Nielsen, J.S., Spoerel, W.E., Keenleyside, H.B., Slater, P.E., and Ciancy, P.R.: Continuous epidural analgesia for labour and delivery. Canad. Anaesth. Soc. J. 9: 143, 1962. 
Noble, A.D., Craft, I.L., Bootes, J.A.H., Edwards, P.A., Thomas, D.J., and Mills, K.L.M.: Continuous lumbar epidural analgesia using bupivacaine: A study of the fetus and newborn child. J. Obstet. Gynaec. Brit. Cwlth. 78: 559, 1971.

Nordquist, P., and Dhunêr, K.G.: Blood and liver function during local anaesthesia with marcaine. Acta Anaesth. Scand. suppl. 23: 414, 1966.

Nyirjesy, I., Hawks, B.L., Hebert, J.E., Hopwood, H.G., and Falls, H.C.: Hazards of the use of paracervical block anesthesia in obstetrics. Amer. J. Obstet. Gynecol. 87: 231, 1963.

O'Gureck, J.E., Roux, J.F., and Neuman, M.R.: A practical classification of fetal heart rate patterns. Obstet. Gynecol. 40: 356, 1972.

Oliva, P.B.: Lactic acidosis. Amer. J. Med. 48: 209, 1970.

Ostheimer, G.W., Palahniuk, R.J., and Shnider, S.M.: Epidural blood patch for postlumbar puncture headache. Anesthesiology 41: 307, 1974.

Page, E.P., Kamm, M.L., and Chappell, C.C.: Usefulness of paracervical block in obstetrics. Amer. J. Obstet. Gynecol. 81: 1094, 1961.

Parer, J.T.: Fetal oxygen uptake and umbilical circulation during maternal hypoxia in the chronically catheterized sheep. In Longo, L.D., and Reneau, D.D. (eds.): Fetal and Newborn cardiovascular physiology. Vol. 2 Fetal and newborn circulation. New York, Garland STPM Press, 1978, pp. 231-247.

Pearson, J.F., and Davies, P.: The effects of continuous lumbar epidural analgesia on the acid-base status of maternal arterial blood during the first stage of labour. J. Obstet. Gynaecol. Brit. Cwlth. 80: 218, 1973-a.

Pearson, J.F., and Davies, P.: The effect of continuous lumbar epidural analgesia on maternal acid-base balance and arterial lactate concentration during the second stage of labour. J. Obstet. Gynaecol. Brit. Cwlth. 80: 225, 1973-b.

Pearson, J.F., and Davies, P.: The effect of continuous lumbar epidural analgesia upon fetal acid-base status during the first stage of labour. J. Obstet. Gynaecol. Brit. Cwilth. 81: 971, 1974-a.

Pearson, J.F., and Davies, P.: The effect of continuous lumbar epidural analgesia upon fetal acid-base status during the second stage of labour. J. Obstet. Gynaecol. Brit. Cwilth. 81: 975, 1974-b.

Philip, J.H., and Brown, W.U.: Total spinal anesthesia late in the course of obstetric bupivacaine epidural block. Anesthesiology 44: 340, 1976. 
Phillips, J.C., Hockberg, C.J., Petrakis, J.K., and Winkle, J.D.: Epidural analgesia and its effects on the 'normal' progress of labor. Amer. J. Obstet. Gyecol. 129:316, 1977.

Poseiro, J.J.: Compression of the aorta or iliac arteries by the contraction of the human uterus during labor. In: Effects of labor on fetus and newborn. In CaldeyroBarcia, R. (ed.): Effect of labor on fetus on fetus and newborn. New York, Pergamon press, 1967.

Raabe, N., and Belfrage, P.: Epidural analgesia in labour. IV. Influence on uterine activity and fetal heart rate. Acta Obstet. Gynecol. Scand. 55: 305, 1976.

Reids, D.H.S. Respiratory changes in labour. Lancet 1: 784, 1966.

Rekonen, A., Luotola, H., Pitkänen, M. Kuikka, J., and Pyörälä, T.: Measurement of intervillous and myometrial blood flow by an intravenous $133 \mathrm{Xe}$ method. Brit. J. Obstet. Gynaecol. 83: 723, 1976.

Reyolds, F.: Metabolism and excretion of bupivacain in man: A comparison with mepivacaine. Brit. J. Anaesth. 43: 33, 1971-a.

Reynolds, F.: A comparison of the potential toxicity of bupivacaine, lignocaine and mepivacaine during epidural blockade for surgery. Brit. J. Anaesth. 43: 567, 1971-b.

Reynolds, F., and Taylor, G.: Maternal and neonatal blood concentration of bupivacaine. Anesthesia 25: 14, 1970.

Reynolds, F., and Taylor, G: Plasma concentrations of bupivacaine during continuous epidural analgesia in labour: The effct of adrenaline. Brit. J. Anaesth. 43: 436, 1971.

Reynolds, F., Hargrove, R.L., and Wyman, J.B. Maternal and foetal plasma concentrations of bupivacaine after epidural block. Brit. J. Anaesth. 45: 1049, 1973.

Ritchie, J.M.: Mechanism of action of local anaesthetic agents and biotoxins. Brit. J. Anaesth. 47: 191, 1975.

Rithcie, J.M. Ritchie, B., and Greengard, P.: The active structure of local anesthetics. J. Pharmocal. Exp. Ther. 150: 152, 1965-a.

Ritchie, J.M. Rithcie, B., and Greengard, P.: The effect of the nerve sheat on the action of local anesthetics. J. Pharmacol. Exp. Ther. 150: 160, 1965-b.

Robertson, D., Johnson, G.A. Robertson, R.M., Nies, A.S., Shand, D.G., and oates, J.A.: Comparative assessement of stimuli that release neuronal and adrenomedullary catecholamines in man. Circulation 59: 637, 1979. 
Rosenfeld, C.R., Barton, M.D., and Meschia, G.: Effects of epinephrine on distribution of blood flow in the pregnant ewe. J. Obstet. Gynecol. 124: 156, 1976.

Rucker, M.P.: The action of adrenaline on the pregnant uterus. South. Med. J. 18:4123, 1925.

Rysanek, W.J., and Cavanagh, D.: Presacral neurectomy and its effect on subsequent pregnancies, Surg. 24: 335, 1958.

Sala, N.L. Schwarcz, R.L., Althabe, O., Fisch, L., and Fuente, O.: Effect of epidural anesthesia upon uterine contractility induced by artificial cervical dilatation in human pregnancy. Amer. J. Obstet. Gynaecol. 106: 26, 1970.

Saling, E.: A new method for examination of the child during labour. Arc. Gynaekol. 197: 108, 1962.

Sangoul, F., Fox, G.S., and Houle, G.L.: Effect of regional analgesia on maternal oxygen comsumption during the first stage of labour. Amer. J. Obstet. Gynecol. 121: $1080,1975$.

Schellenberg, J.C.: Uterine activity during lumbar epidural analgesia with bupivacaine. Amer. J. Obstet. Gynecol. 127: 26, 1977.

Schifrin, B.S.: Fetal heart rate patterns following epidural anaesthesia and oxytocin infusion dyuring labour. J. Obstet. Gynaecol. Brit. Cwlth. 79: 332, 1972.

Scott, D.B.: Evaluation of the toxicity of local anaesthetic agents in man. Brit. J. Anaesth. 47: 56, 1975.

Scott, D.B.: Analgesia in labour. Brit. J. Anaesth. 49: 11, 1977-a.

Scott, D.B.: Analgesia in labour (correspondence). Brit. J. Anaesth. 49: 841, 1977-b.

Scott, D.B., Davie, I.T., and Stephen, G.W.: Cardiovascular effects of intravenous lignocaine during nitrous oxide/halothane anaesthesia. Brit. J. Anaesth. 43: 595, 1971.

Shnider, S.M., and Levinson, G.: Anesthesia for obstetrics. Baltimore, Williams and Wilkins Company, 1979.

Shnider, S.M., Abboud, T.K., Artal, R., Henriksen, E.H., Stefani, S.J., and Levinson, G.: Maternal catecholamines decrease during labor after lumbar epidural anesthesia. Amer. J. Obstet. Gynecol. 147: 13, 1983. 
Sjöstrand, U., and Widman, B.: Distribution of bupivacaine in the rabbit under normal and acidotic conditions. Acta Anaesth. Scand. Suppl. 50, 1973.

Steer, P.J., Carter, M.C., and Beard, R.W.: Normal levels of active contraction area in spontaneous labour. Brit. J. Obstet. Gynaecol. 91: 211, 1984.

Strichartz, G.R.: The inhibition of sodium currents in myelinated nerve by quarternary derivates of lidocaine. J. Gen. Physiol. 62: 37, 1973.

Studd, J.W.W., Crawford, J.S., Duignan, N.M., Rowbotham, C.J.F., and Hughes, A.O.: The effect of lumbar epidural analgesia on the rate of cervical dilatation and the outcome of labour of spontaneous onset. Brit. J. Obstet. Gynaecol. 87: 1015, 1980.

Thalme, B., Belfrage, P., and Raabe, N.: Lumbar epidural analgesia in labour. I. Acid-base balance and clinical condition of mother, fetus and newborn child. Acta Obstet. Gynecol. Scand. 53: 27, 1974-a.

Thalme, B., Raabe, N., and Belfrage, P.: Lumbar epidural analgesia in labour. II. Effects on glucose, lactate, sodium, chloride, total protein, haematocrit and haemoglobin in maternal, fetal and neonatal blood. Aeta Obstet. Gynec. Scand. 53: 113, 1974-b.

Thiery, M., De Clercq, A., Rolly, G., Derom, R., Vroman, S., and Diesbecq, W.: The fetal influence of continuous lumbar epidural analgesia in labor. Acta Anaesth. Belgica. 1: 29, 1974.

Thomas, J., Long, G., Moore, G., and Morgan, D.: Plasma protein binding and placental transfer. Clin. Pharmacology and Therapeutics 19: 426, 1975.

Thomas, J., Climie, C.R., and Mather, L.E.: The maternal plasma levels and placental transfer of bupivacaine following epidural analgesia. Brit. J. Anaesth. 41: 1035, 1969.

Tucker, G.T., and Mather, L.E.: Pharmacology of local anaesthetic agents. Pharmacokinetics of local anaesthetic agents. Brit. J. Anaesth. 47: 213, 1975.

Tucker, G.T., Boyes, R.N., Bridenbaugh, P.O., and Moore, D.C.: Binding of anilidetype local anesthetics in human plasma. 1 . Relationships between binding, physicochemical properties and anesthetic activity. Anesthesiology 33: 287, 1970-a.

Tucker, G.T., Boyes, R.N., Bridenbaugh, P.O., and Moore, D.C.: Binding of anilidetype local anesthetics in human plasma. II. Implications in vivo, with special reference to transplacental distribution. Anesthesiology 33: 304, 1970-b. 
Tyack, A.J., Parsons, R.J., Millar, D.R., and Nicholas, A.D.G.: Uterine activity and plasma bupivacaine levels after caudal epidural analgesia. J. Obstet. Gynaecol. Brit. Cwlth. 80: 896, 1973.

Usubiaga, J.E.: Neurological complications following epidural analgesia. Int. Anaesth. Clin. 13 (2): 19, 50, 1975.

Vasicka, A., and Kretchmer, H.E.: Uterine dynamics. Clin. Obstet. Gynecol. 4: 17, 1961.

Vasicka, A., Hutchinson, H.T., Eng, M., and Allen, C.R.: Spinal and epidural anesthesia, fetal and uterine response to acute hypo- and hypertension. Amer. J. Obstet. Gynecol. 90: 800, 1964.

Velvoski, II.Z., Chougom, E.A., and Plotitcher, V.A.: The psychoprophylactic and psychotherapeutic method in painless childbirth. Pediat. Akush. Ginek. 1: 32, 1950.

Verheesen, P.E., Brombacher, P.J., Cremers, H.M.H.G., and de Boer, R.: Determination of low levels of bupivacaine (marcaine) in plasma during epidural analgesia. $J$. Clin. Chem. Clin. Biochem. 18: 351, 1980.

Vroman, S., Yo Le Sian, A., Thiery, M., de Hemptinne, D., Vanderheyden, K., Van Kets, H., Martens, G., Derom, R., and Rolly, G.: Elective induction of labor conducted under lumbar epidural block. I. Labor induction by amniotomy and intravenous oxytocin. Europ. J. Obstet. Gynecol. Reprod. Biol. 733: 159, 1977.

Wallis, K.L., Shnider, S.M., Hicks, J.S., and Spivey, H.T.: Epidural anesthesia in the normotensive pregnant ewe: Effects on uterine bloodflow and fetal acid-base status. Anesthesiology 44: 481, 1976.

Weaver, J.B., Pearson, J.F., and Rosen, M.: Posture and epidural block in pregnant women at term. Anaesthesia 30: 752, 1975.

Webb, P.J., James, F.M., and Scott Wheeler, A.: Shivering during epidural analgesia in women in labor. Anesthesiology 55: 706, 1981.

Widman, B.: Plasma concentration of local anaesthetic agents in regard to absorption, distribution and elimination, with special reference to bupivacaine. Brit. J. Anaesth. 47: 231, 1975.

Wieczorek, E., and Sobiech, K.A.: Oxytocinase activity in the course of continuous lumbar epidural analgesia. Acta Obstet. Gynecol. Scand. 59: 421, 1980. 
van der Wildt, B.: Heart rate, breathing movements and brain activity in fetal lambs. Thesis, Nijmegen, 1982.

Wilkinson, G.R., and Lund, P.C.: Bupivacaine levels in plasma and cerebrospinal fluid following peridural administration. Anesthesiology 33: 482, 1970.

Wingate, M.B., Wingate, L., Iffy, L., Freundlich, J., and Gottsegen, D.: The effect of epidural analgesia upon fetal and neonatal status. Amer. J. Obstet. Gynecol. 119: 1101, 1974.

Yeh, S., Forsythe, A., and Hon, E.: Quantification of fetal heart beat-to-beat interval differences. Obstet. Gynecol. 41: 355, 1973.

Zador, G., Englesson, S., and Nilsson, B.A.: Low dose intermittent epidural anaesthesia with lidocaine for vaginal delivery. I. Clinical efficacy and lidocaine concentrations in maternal, foetal and umbilical cord blood. Acta Obstet. Gynecol. Scand. (Suppl.) 34: 3, 1974.

Zador, G., and Nilsson, B.A.: Low dose intermittent epidural anaesthesia with lidocaine for vaginal delivery. II. Influence on labour and foetal acid-base status. Acta Obstet. Gynecol. Scand. Suppl. 34: 17, 1974.

Zilianti, M., Salazar, I.R., Aller, J, and Agüero, O.: Fetal heart rate and $\mathrm{pH}$ of fetal capillary blood during epidural analgesia in labor. Obstet. Gynecol. 36: 881, 1970.

Zuspan, F.P., Cibils, L.A., and Pose, S.V.: Myometrial and cardiovascular responses to atterations in plasma epinephrine and norepinephrine. Amer. J. Obstet. Gynecol. 84: $841,1962$. 



\section{Curriculum vitae}

$24-11-47$

1967

1967

1973

1974

1.974

1975

1975

1979-1980

Vanaf 1 julli 1980
Geboren te Appelscha (Fr)

Eindexamen aan de Christelijke HBS te Assen.

Aanvang studie geneeskunde aan de Rijksuniversiteit van Utrecht

Medewerker cytologisch laboratorium Cyt-U-Universitair (Hoofd: Drs. G. Linthorst)

Arts-examen aan de Rijksuniversiteit van Utrecht

Vakantie-assistentschap op de afdeling Verloskunde en Gynaecologie van het De Weverziekenhuis te Heerlen (Hoofd: Dr. L.A. Schellekens)

Opleiding tot militair hulp-anaesthesist op de afdeling Anaesthesiologie van het De Weverziekenhuis te Heerlen (opleider: Dr. J.P.M. Lelkens).

Aanvang opleiding tot gynaecoloog in het De Weverziekenhuis te Heerlen (opleider: Dr. L.A. Schellekens)

Voltooiing opleiding op de afdeling Obstetrie en Gynaecologie van het Sint Annadal Ziekenhuis te Maastricht. (opleider: Prof. dr. J. de Haan)

Werkzaam als gynaecoloog in het Groot Ziekengasthuis te "s-Hertogenbosch, in associatief werband met Dr. G.H.B. Broeders, Dr. R.S. Corbey en Drs. J.G.M. Horbach. 